\title{
SELECTIVE DEHYDRATION OF HIGH PRESSURE NATURAL GAS USING SUPERSONIC NOZZLES
}





\title{
Selective Dehydration of High Pressure Natural Gas Using Supersonic Nozzles
}

\author{
By \\ Anahid Karimi, B. Eng.
}

\author{
A Thesis \\ Submitted to the School of Graduate Studies \\ in Partial Fulfillment of the Requirements \\ for the Degree of \\ Masters of Engineering
}

Memorial University of Newfoundland

(C) Copyright by Anahid Karimi, December 2006 


$\begin{array}{ll}\begin{array}{l}\text { Library and } \\ \text { Archives Canada }\end{array} & \begin{array}{l}\text { Bibliothèque et } \\ \text { Archives Canada }\end{array} \\ \begin{array}{l}\text { Published Heritage } \\ \text { Branch }\end{array} & \begin{array}{l}\text { Direction du } \\ \text { Patrimoine de l'édition }\end{array} \\ \begin{array}{l}\text { 395 Wellington Street } \\ \text { Ottawa ON K1A 0N4 } \\ \text { Canada }\end{array} & \begin{array}{l}\text { 395, rue Wellington } \\ \text { Ottawa ON K1A 0N4 } \\ \text { Canada }\end{array}\end{array}$

Yourfile Votre référence ISBN: 978-0-494-31262-9 Ourfile Notre référence ISBN: 978-0-494-31262-9

NOTICE:

The author has granted a nonexclusive license allowing Library and Archives Canada to reproduce, publish, archive, preserve, conserve, communicate to the public by telecommunication or on the Internet, loan, distribute and sell theses worldwide, for commercial or noncommercial purposes, in microform, paper, electronic and/or any other formats.

The author retains copyright ownership and moral rights in this thesis. Neither the thesis nor substantial extracts from it may be printed or otherwise reproduced without the author's permission.
AVIS:

L'auteur a accordé une licence non exclusive permettant à la Bibliothèque et Archives Canada de reproduire, publier, archiver, sauvegarder, conserver, transmettre au public par télécommunication ou par l'Internet, prêter, distribuer et vendre des thèses partout dans le monde, à des fins commerciales ou autres, sur support microforme, papier, électronique et/ou autres formats.

L'auteur conserve la propriété du droit d'auteur et des droits moraux qui protège cette thèse. $\mathrm{Ni}$ la thèse ni des extraits substantiels de celle-ci ne doivent être imprimés ou autrement reproduits sans son autorisation.
In compliance with the Canadian

Privacy Act some supporting forms may have been removed from this thesis.

While these forms may be included in the document page count, their removal does not represent any loss of content from the thesis.
Conformément à la loi canadienne sur la protection de la vie privée, quelques formulaires secondaires ont été enlevés de cette thèse.

Bien que ces formulaires aient inclus dans la pagination, il n'y aura aucun contenu manquant. 


\section{Abstract}

The dwindling high quality crude oil reserves and increasing demand for natural gas has encouraged energy industries further towards the discovery of remote offshore reservoirs. Consequently, new technologies have to be developed to efficiently produce and transport stranded natural gas to consuming markets. Compactness of production systems is the most challenging design criteria for offshore applications. From the gas quality perspective, water vapour is the most common impurity in natural gas mixtures. At very high gas pressures within the transportation systems hydrate can easily form even at relatively higher temperatures. Therefore, gas dehydration or hydrate inhibition systems for offshore gas production/processing facilities should meet these requirements. It should also be noted that at certain pressure and composition conditions, the presence of heavy hydrocarbons $\left(\mathrm{C}_{2}^{+}\right)$in natural gas increases pipeline flow capacity and improves compression efficiencies. Supersonic separators are proposed in this thesis as a compact high-pressure processing system capable of selectively removing water from highpressure natural gas streams without affecting the hydrocarbon content. A computer simulation linked to a thermodynamic property package is presented to predict the water removal efficiency and to compare the proposed system with conventional techniques. The simulation is first validated with a commercial computational fluid dynamics (CFD) software (Fluent) and then the effect of pressure, temperature, flow rate, friction and backpressure of the system in this method are analysed. Supersonic nozzles are also placed in different locations in a three-stage separation train on an offshore crude oil 
production platform to test the efficiency for the recovery of Natural Gas Liquids (NGLs) from associated gas. The recovery of NGLs can significantly improve the economy of offshore crude oil production. 


\section{ACKNOWLEDGEMENTS}

I sincerely thank my supervisor Dr. Majid Abedinzadegan Abdi for accepting me as a graduate student, for his patience and availability in discussing the cumbersome details of my thesis, for his constant encouragement in my hours of despair, and for supporting to attend and present my work in the 2006 SPE Gas Technology Symposium in Calgary.

I also acknowledge collaborations with Ph.D. student, Mr. Esam Jassim, in assisting to compare my results with those generated by commercial computational fluid dynamics (CFD) software (Fluent) simulations, and with Ph.D. student, Ms. Erika Beronich, in conducting NGL recovery case studies.

The financial support from the National Science and Engineering Research Council of Canada (NSERC) is also gratefully acknowledged.

I wish to thank Dr. Ramachadran Venkatesan, Associate Dean of Graduate Studies and Research, and Ms. Moya Crocker, Secretary to the Associate Dean of Graduate Studies and Research, for their superb administrative support.

Last but not least, I thank my family and friends for their love and support. 


\section{TABLE OF CONTENTS}

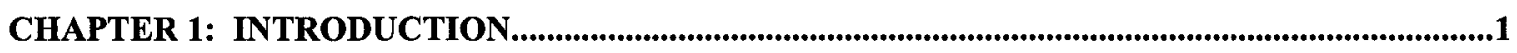

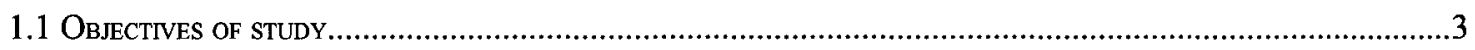

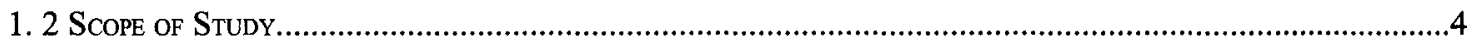

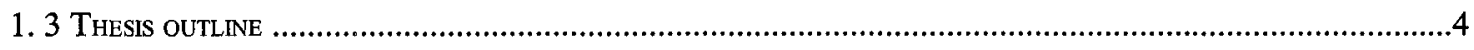

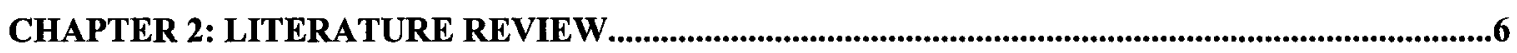

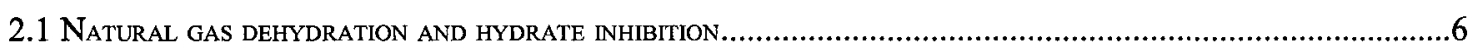

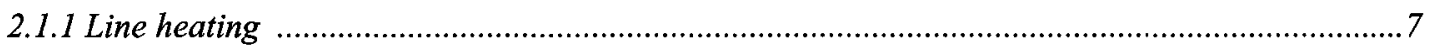

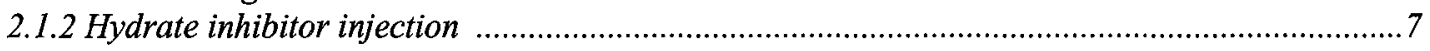

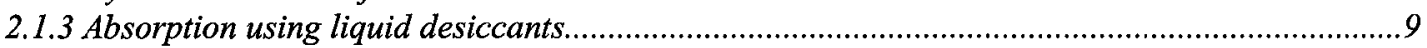

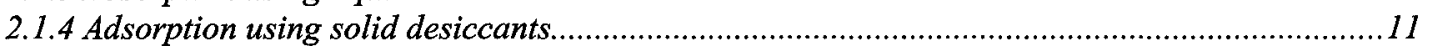

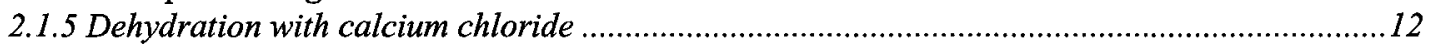

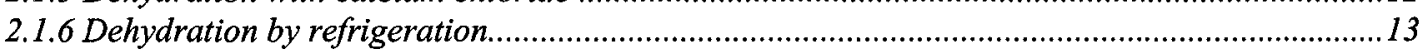

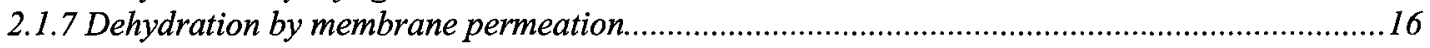

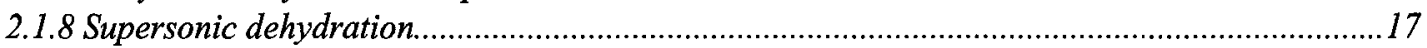

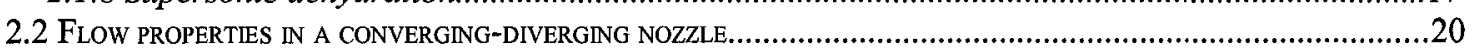

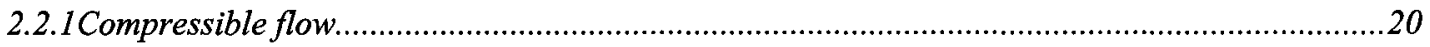

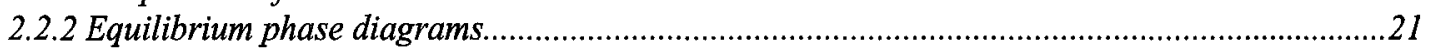

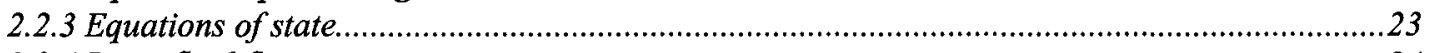

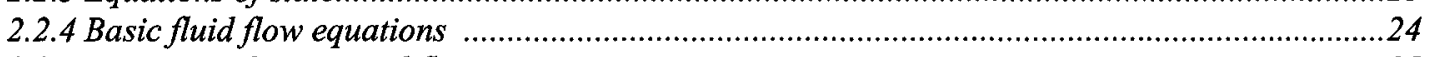

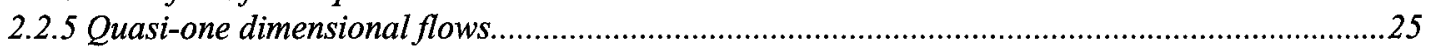

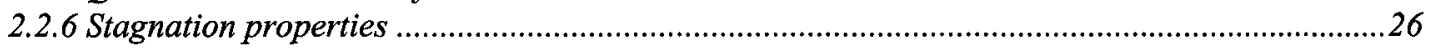

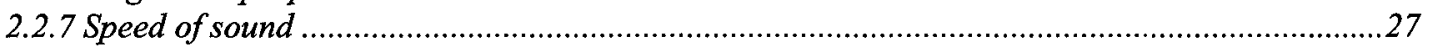

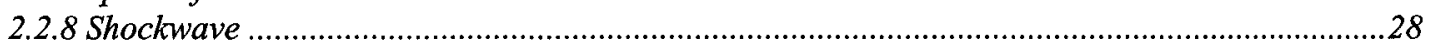

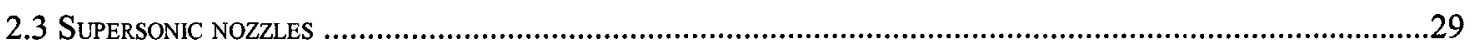

CHAPTER 3: MODELING OF SUPERSONIC NOZZLES.............................................................35

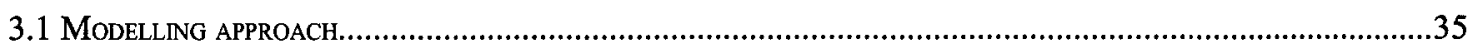

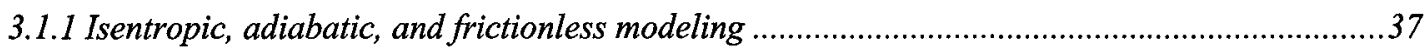

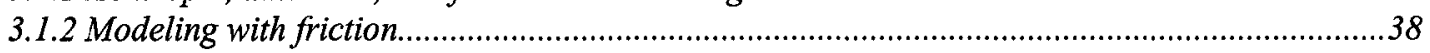

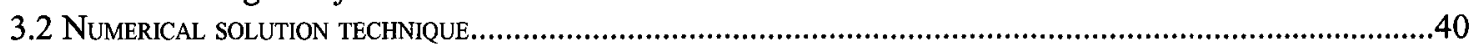

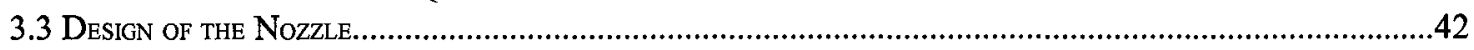

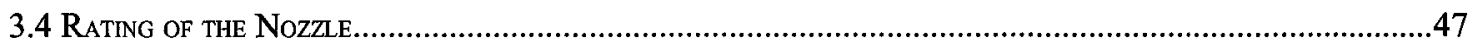

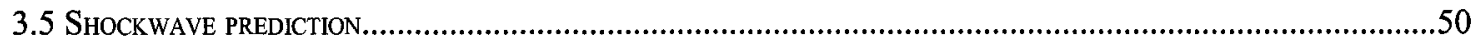

CHAPTER 4: ANALYSIS AND RESULTS.....................................................................................53

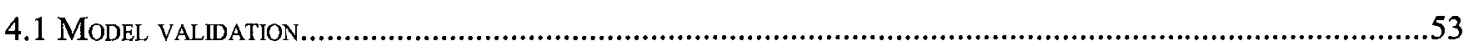

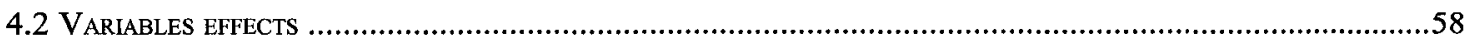

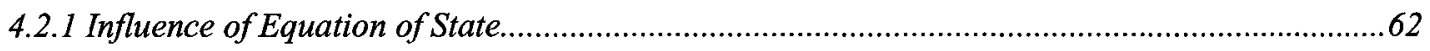

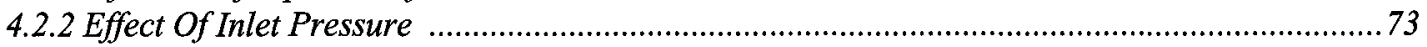

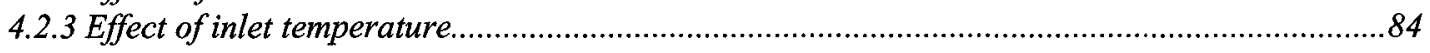

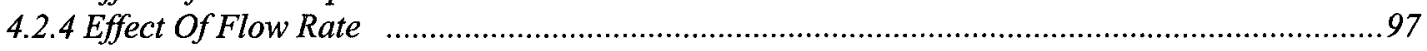

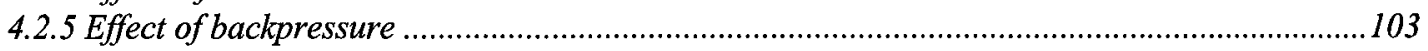




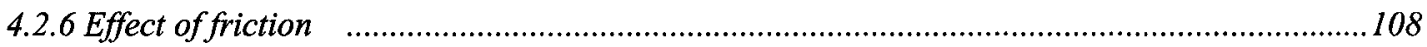

CHAPTER 5: CASE STUDY: NATURAL GAS LIQUIDS (NGLS) RECOVERY ............................114

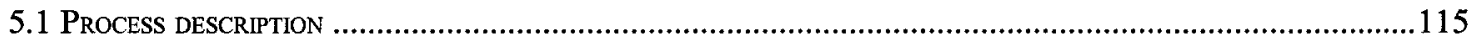

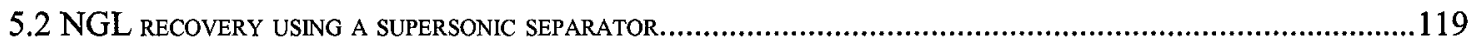

5.2.1 Case 1: Supersonic nozzle at HP separator overhead........................................................121

5.2. 2 Case 2: Supersonic nozzle at MP Separator overhead..............................................................129

5.2.3 Case 3: Supersonic nozzle at LP Separator overhead.................................................................134

5.2.4 Case 4: Supersonic nozzle at HP compressor discharge ..................................................135

5.2.5 case 5: Supersonic separator at MP compressor discharge ….............................................140

5.2.6 Case 6: Supersonic separator at LP compresor discharge .................................................145

5.2 .7 case 7: Nozzles at overheads of HP and MP compressors .................................................147

5.2.8 Case 8: One nozzle after the separated stream from the HP and MP separator are mixed.....151

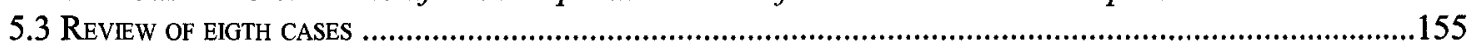

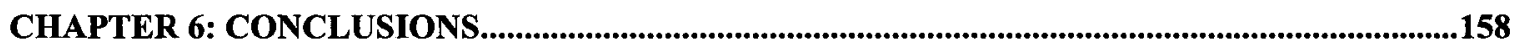

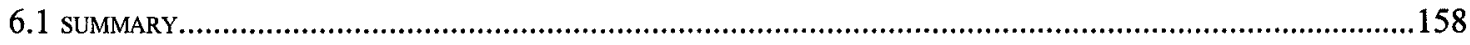

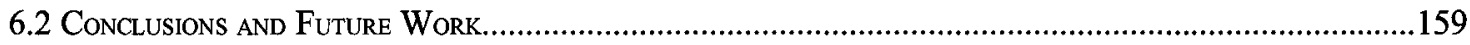

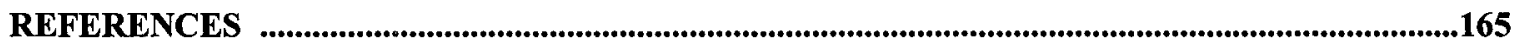

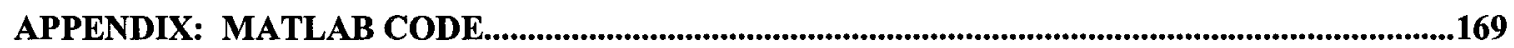

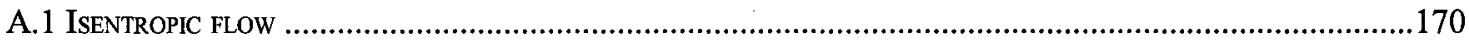

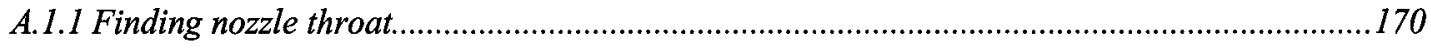

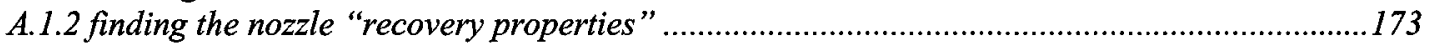

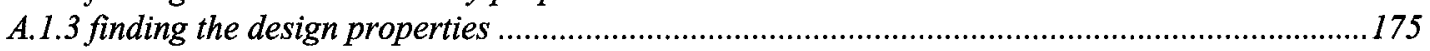

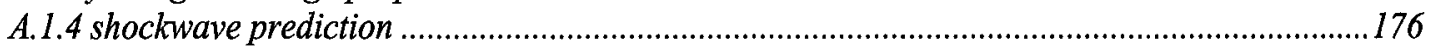

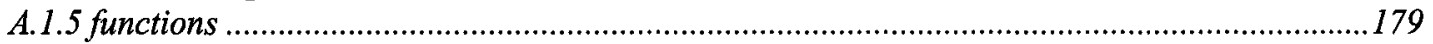

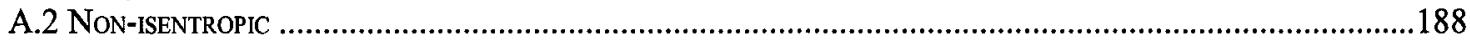

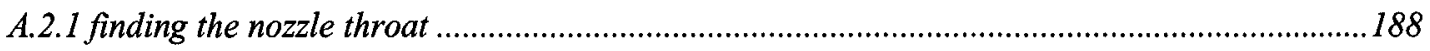

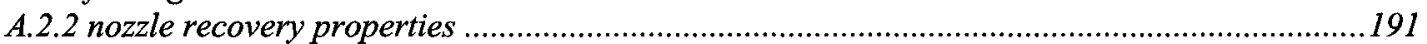

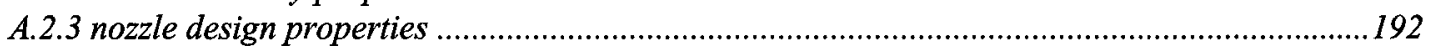

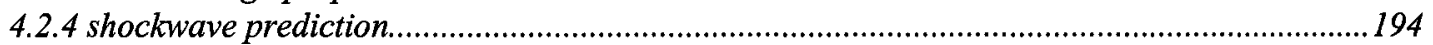

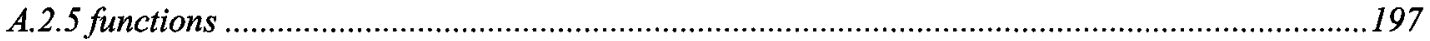




\section{LIST OF FIGURES}

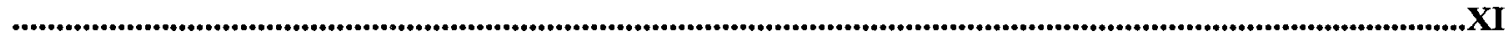

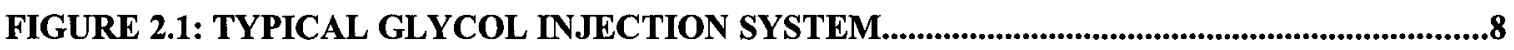

FIGURE2.3: SCHEMATIC OF AN EXAMPLE SOLID ADSORBENT DEHYDRATOR .................12

FIGURE2.4: SCHEMATIC OF A TYPICAL CACL2 DEHYDRATOR............................................13

FIGURE2.5: EXTERNAL REFRIGERATION SYSTEMS......................................................................14

FIGURE2.6: LOW-TEMPERATURE SEPARATIONS WITH GLYCOL INJECTION ...................15

FIGURE2.7: SCHEMATIC DIAGRAM OF A MEMBRANE DEHYDRATION PROCESS .............16

FIGURE2.8: SCHEMATIC DIAGRAM OF A SUPERSONIC DEHYDRATION UNIT ..................18

FIGURE 2.9: PHASE ENVELOPE OF A MULTI-COMPONENT MIXTURE ....................................22

FIGURE 2.10: DIFFERENT PARTS OF A SUPERSONIC NOZZLE ..............................................30

FIGURE 2.11: DIFFERENT POSSIBLE EXIT PRESSURES IN A LAVAL NOZZLE.........................33

FIGURE 2.12: VELOCITY DISTRIBUTION IN A LAVAL NOZZLE....................................................33

FIGURE3.1: SCHEMATIC DIAGRAM OF A SUPERSONIC DEHYDRATION UNIT ...................36

FIGURE 3.2: A FLOW CHART FOR DESIGNING A NOZZLE ....................................................44

FIGURE3. 3: SCHEMATIC DIAGRAM OF THE SUPERSONIC NOZZLE ...................................45

FIGURE 3.5: PROCESS SIMULATION TO SEPARATE THE CONDENSED LIQUID. .................51

FIGURE 4.2: TEMPERATURE DISTRIBUTIONS AND SHOCK LOCATIONS ALONG THE NOZZLE WITH 75.67\% RECOVERY OF PRESSURE INLET IN THE SUPERSONIC-CFD

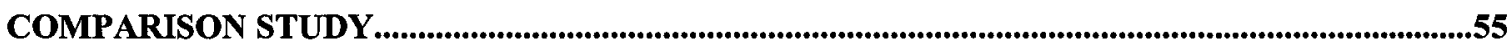

FIGURE 4.3: VELOCITY DISTRIBUTIONS AND SHOCK LOCATIONS ALONG THE NOZZLE WITH 75.67\% RECOVERY OF PRESSURE INLET IN THE SUPERSONIC-CFD COMPARISON

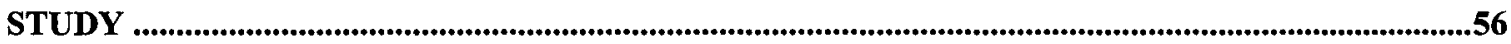

FIGURE 4.4: MACH NUMBER DISTRIBUTIONS AND SHOCK LOCATIONS ALONG THE NOZZLE WITH 75.67\% RECOVERY OF PRESSURE INLET IN THE SUPERSONIC-CFD COMPARISON STUDY .56

FIGURE 4.5: DENSITY DISTRIBUTIONS AND SHOCK LOCATIONS ALONG THE NOZZLE WITH 75.67\% RECOVERY OF PRESSURE INLET IN THE SUPERSONIC-CFD COMPARISON STUDY .57

FIGURE4.6: DRY GAS SATURATING IN HYSYS SIMULATOR. .59

FIGURE 4.7: THE GEOMETRY OF THE SEPARATED DESIGNED NOZZLE FOR IDEAL AND REAL GAS ASSUMPTIONS. .64 
FIGURE 4.8: PRESSURE DISTRIBUTIONS ALONG THE SEPARATELY DESIGNED NOZZLE FOR IDEAL AND REAL GAS ASSUMPTIONS.

FIGURE 4.9: PRESSURE DISTRIBUTION AND SHOCKWAVE LOCATION ALONG THE DESIGNED NOZZLE FOR REAL AND IDEAL GAS ASSUMPTIONS WITH 70\% INLET PRESSURE RECOVERY.

FIGURE 4.10: TEMPERATURE DISTRIBUTION AND SHOCKWAVE LOCATION ALONG THE DESIGNED NOZZLE FOR REAL AND IDEAL GAS ASSUMPTIONS WITH 70\% INLET PRESSURE RECOVERY.

FIGURE 4.11: VELOCITY DISTRIBUTION AND SHOCKWAVE LOCATION ALONG THE DESIGNED NOZZLE FOR REAL AND IDEAL GAS ASSUMPTIONS WITH 70\% INLET PRESSURE RECOVERY.

FIGURE 4.12: THEORETICAL WATER REMOVAL ALONG THE DESIGNED NOZZLE FOR REAL AND IDEAL GAS ASSUMPTIONS WITH 70\% INLET PRESSURE RECOVERY.

FIGURE 4.13: PHASE ENVELOPE AND PRESSURE-TEMPERATURE DISTRIBUTIONS ALONG THE DESIGNED NOZZLE FOR REAL AND IDEAL GAS ASSUMPTIONS WITH 70\% INLET PRESSURE RECOVERY

FIGURE 4.14: PRESSURE DISTRIBUTIONS ALONG THE RATED NOZZLE FOR IDEAL AND REAL GAS ASSUMPTIONS.

FIGURE 4.15: PRESSURE DISTRIBUTIONS AND SHOCKWAVE LOCATION ALONG THE RATED NOZZLE FOR IDEAL AND REAL GAS ASSUMPTIONS WITH 70\% INLET PRESSURE RECOVERY.

FIGURE 4.16: TEMPERATURE DISTRIBUTIONS AND SHOCKWAVE LOCATION ALONG THE RATED NOZZLE FOR IDEAL AND REAL GAS ASSUMPTIONS WITH 70\% INLET PRESSURE RECOVERY

FIGURE 4.17: VELOCITY DISTRIBUTIONS AND SHOCK WAVE LOCATION ALONG THE RATED NOZZLE FOR IDEAL AND REAL GAS ASSUMPTIONS WITH 70\% INLET PRESSURE RECOVERY

FIGURE 4.18: PRESSURE DISTRIBUTIONS ALONG THE DESIGNED NOZZLE FOR PRESSURE-EFFECT STUDIES .76

FIGURE 4.19: PRESSURE DISTRIBUTIONS AND THE SHOCKWAVE LOCATION ALONG THE DESIGNED NOZZLE WITH 70\% PRESSURE RECOVERY FOR PRESSUREEFFECT STUDIES.

FIGURE 4.20: TEMPERATURE DISTRIBUTIONS AND THE SHOCKWAVE LOCATION ALONG THE DESIGNED NOZZLE WITH 70\% PRESSURE RECOVERY FOR PRESSURE-EFFECT STUDIES

FIGURE 4.21: VELOCITY DISTRIBUTIONS AND THE SHOCKWAVE LOCATION ALONG THE DESIGNED NOZZLE WITH 70\% PRESSURE RECOVERY FOR PRESSUREEFFECT STUDIES .78

FIGURE 4.22: PHASE ENVELOPE AND PRESSURE-TEMPERATURE DISTRIBUTIONS FOR DESIGNED NOZZLE IN PRESSURE-EFFECT STUDIES WITH 70\% INLET PRESSURE RECOVERY 
FIGURE 4.24: PRESSURE DISTRIBUTION FOR RATED NOZZLE IN PRESSURE-EFFECT STUDIES WITH 70\% INLET PRESSURE RECOVERY.

FIGURE 4.25: PHASE ENVELOPE ND PRESSURE-TEMPERATURE DISTRIBUTIONS FOR PRESSURE- EFFECT STUDIES WITH 70\% INLET PRESSURE RECOVERY.

FIGURE 4.26: TEMPERATURE DISTRIBUTIONS AND THE SHOCK WAVE LOCATION IN THE RATED NOZZLE IN PRESSURE-EFFECT STUDIES WITH 70\% INLET PRESSURE RECOVERY

FIGURE 4.27: VELOCITY DISTRIBUTIONS AND THE SHOCK WAVE LOCATION IN THE RATED NOZZLE IN PRESSURE-EFFECT STUDIES WITH 70\% INLET PRESSURE RECOVERY

FIGURE 4.28: DESIGNED NOZZLE GEOMETRY FOR TEMPERATURE-EFFECT STUDIES. .86 FIGURE 4.29: PRESSURE DISTRIBUTIONS ALONG THE DESIGNED NOZZLE FOR TEMPERATURE-EFFECT STUDIES

FIGURE 4.30: PRESSURE DISTRIBUTIONS AND SHOCKWAVE LOCATION ALONG THE DESIGNED NOZZLE FOR TEMPERATURE -EFFECT STUDIES WITH 70\% RECOVERY OF INLET PRESSURE

FIGURE 4.31: TEMPERATURE DISTRIBUTIONS AND SHOCKWAVE LOCATION ALONG THE DESIGNED NOZZLE FOR TEMPERATURE-EFFECT STUDIES WITH 70\% RECOVERY OF THE INLET PRESSURE

FIGURE 4.32: VELOCITY DISTRIBUTIONS AND SHOCKWAVE LOCATION ALONG THE DESIGNED NOZZLE FOR TEMPERATURE-EFFECT STUDIES WITH 70\% RECOVERY OF INLET PRESSURE

FIGURE 4.33: PHASE ENVELOPE AND PRESSURE- TEMPERATURE DISTRIBUTIONS ALONG THE DESIGNED NOZZLE AND TEMPERATURE-EFFECT STUDIES WITH 70\% INLET PRESSURE RECOVERY.

FIGURE 4.34: THEORETICAL WATER REMOVAL ALONG THE DESIGNED NOZZLE AND TEMPERATURE-EFFECT STUDIES WITH 70\% INLET PRESSURE RECOVERY.

FIGURE 4.35: PRESSURE DISTRIBUTION ALONG THE RATED NOZZLE IN THE TEMPERATURE-EFFECT-STUDIES

FIGURE 4.36: PRESSURE DISTRIBUTION AND THE SHOCKWAVE LOCATION ALONG A RATED NOZZLE IN TEMPERATURE-EFFECT-STUDIES WITH 70\% RECOVERY OF INLET PRESSURE

FIGURE 4.38: PHASE ENVELOPE AND PRESSURE- TEMPERATURE DISTRIBUTIONS ALONG A RATED NOZZLE IN THE TEMPERATURE-EFFECT STUDIES WITH 70\% INLET PRESSURE RECOVERY

FIGURE 4.39: TEMPERATURE DISTRIBUTION AND THE SHOCKWAVE LOCATION ALONG A RATED NOZZLE IN THE TEMPERATURE-EFFECT-STUDIES WITH 70\% INLET PRESSURE RECOVERY

FIGURE 4.40: VELOCITY DISTRIBUTIONS AND THE SHOCKWAVE LOCATIONS ALONG A RATED NOZZLE IN THE TEMPERATURE-EFFECT-STUDIES WITH 70\% OF INLET PRESSURE RECOVERY. . .96 
FIGURE 4.41: THEORETICAL WATER REMOVAL ALONG THE RATED NOZZLE IN THE TEMPERATURE-EFFECT-STUDIES WITH 70\% INLET PRESSURE RECOVERY.....................97

FIGURE 4.42: PRESSURE DISTRIBUTION ALONG THE RATED NOZZLE IN THE FLOW

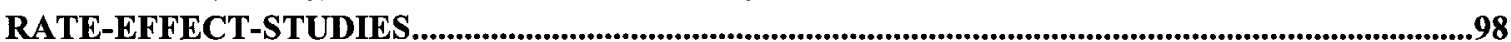

FIGURE 4.43: DESIGNED NOZZLES GEOMETRY IN FLOW RATE-EFFECT-STUDIES............99 FIGURE4.44: PRESSURE DISTRIBUTIONS AND THE SHOCKWAVE LOCATIONS ALONG THE DESIGNED NOZZLE IN FLOW RATE-EFFECT STUDIES WITH 70\%INLET PRESSURE RECOVERY

FIGURE4.45: TEMPERATURE DISTRIBUTIONS AND THE SHOCKWAVE LOCATIONS ALONG THE DESIGNED NOZZLE IN FLOW RATE-EFFECT STUDIES WITH 70\%INLET PRESSURE RECOVERY

FIGURE4.46: VELOCITY DISTRIBUTIONS AND THE SHOCKWAVE LOCATIONS ALONG THE DESIGNED NOZZLE IN FLOW RATE-EFFECT STUDIES WITH 70\%INLET PRESSURE RECOVERY

FIGURE 4.47: MACH NUMBER DISTRIBUTION ALONG THE NOZZLE WITH DIFFERENT FLOW RATES.

FIGURE 4.48: PRESSURE DISTRIBUTION ALONG THE NOZZLE WITH DIFFERENT FLOW RATES.

FIGURE 4.49: PRESSURE DISTRIBUTION ALONG THE NOZZLE FOR DIFFERENT BACK PRESSURES

FIGURE 4.50: PHASE ENVELOPE AND PRESSURE-TEMPERATURE DISTRIBUTIONS WITH 48.5\% INLET PRESSURE RECOVERY

FIGURE 4.51: PHASE ENVELOPE AND PRESSURE-TEMPERATURE DISTRIBUTIONS WITH $60.95 \%$ INLET PRESSURE RECOVERY 106

FIGURE 4.52: PHASE ENVELOPE AND PRESSURE-TEMPERATURE DISTRIBUTIONS WITH 73.38\% INLET PRESSURE RECOVERY.

FIGURE 4.53: PHASE ENVELOPE AND PRESSURE-TEMPERATURE DISTRIBUTIONS WITH 79.95\% INLET PRESSURE RECOVERY.

FIGURE 4.54: PRESSURE DISTRIBUTION AND THE SHOCKWAVE LOCATION ALONG THE DESIGNED NOZZLE FOR THE FRICTION-EFFECT STUDY WITH 70\% INLET PRESSURE RECOVERY

FIGURE 4.55: TEMPERATURE DISTRIBUTION AND THE SHOCKWAVE LOCATION ALONG THE DESIGNED NOZZLE FOR THE FRICTION-EFFECT STUDY WITH 70\% INLET PRESSURE RECOVERY

FIGURE 4.56: VELOCITY DISTRIBUTION AND THE SHOCKWAVE LOCATION ALONG THE DESIGNED NOZZLE FOR THE FRICTION-EFFECT STUDY WITH 70\% INLET PRESSURE RECOVERY.

FIGURE 4.57: PRESSURE DISTRIBUTIONS AND THE SHOCKWAVE LOCATIONS ALONG A RATED NOZZLE WITH 70\% INLET PRESSURE RECOVERY FOR THE FRICTION-EFFECT STUDY. 
FIGURE 4.58: TEMPERATURE DISTRIBUTION AND THE SHOCKWAVE LOCATIONS ALONG A RATED NOZZLE WITH 70\% INLET PRESSURE RECOVERY FOR THE FRICTION-EFFECT STUDY

FIGURE 4.59: VELOCITY DISTRIBUTION AND THE SHOCKWAVE LOCATIONS ALONG A RATED NOZZLE WITH 70\% INLET PRESSURE RECOVERY FOR THE FRICTION-EFFECT STUDY

FIGURE 5.1: THREE-STAGE CRUDE OIL SEPARATION .115

FIGURE 5.2: HYSYS SIMULATION OF CONDENSATE SEPARATION IN THE NOZZLE BEFORE THE SHOCKWAVE. .120

FIGURE 5.3: CASE 1.A: SUPERSONIC NOZZLE AT HP SEPARATOR OVERHEAD; SEPARATED CONDENSATES ROUTED TO MP SEPARATOR

FIGURE 5.4: CASE 1.B: SUPERSONIC NOZZLE AT HP SEPARATOR OVERHEAD; SEPARATED CONDENSATES ROUTED TO LP SEPARATOR

FIGURE 5.5: CASE 1.C- SUPERSONIC NOZZLE AT HP SEPARATOR OVERHEAD; SEPARATED CONDENSATES ROUTED TO LP OIL OUT

FIGURE 5.6: PRESSURE DISTRIBUTION ALONG THE NOZZLE LOCATED AT HP SEPARATOR OVERHEAD.

FIGURE 5.7: PHASE ENVELOPES FOR THE STREAM "LP OLL OUT" FOR "BASE PROCESS", CASES 1.B AND 1.C WITH 70\% INLET PRESSURE RECOVERY IN THE NOZZLE

FIGURE 5.8: PHASE ENVELOPES FOR STREAM "LP OIL OUT" FOR "BASE PROCESS", CASES 1.A, 1.B AND 1.C WITH 80\% INLET PRESSURE RECOVERY IN THE NOZZLE.........129 FIGURE 5.9: CASE 2.A: SUPERSONIC NOZZLE AT MP SEPARATOR OVERHEAD; SEPARATED CONDENSATES ROUTED TO LP SEPARATOR .130

FIGURE 5.10: CASE 2.B: SUPERSONIC NOZZLE AT MP SEPARATOR OVERHEAD; SEPARATED CONDENSATES ROUTED TO LP OIL OUT .130

FIGURE 5.11: PRESSURE DISTRIBUTION ALONG THE NOZZLE LOCATED AT MP SEPARATOR OVERHEAD WITH 80\% INLET PRESSURE RECOVERY .132

FIGURE 5.12: PHASE ENVELOPES FOR STREAM "LP OIL OUT" FOR "BASE PROCESS" AND CASE 2

WITH $80 \%$ INLET PRESSURE RECOVERY. .132

FIGURE 5.13: CASE 3: SUPERSONIC NOZZLE AT LP SEPARATOR OVERHEAD; SEPARATED CONDENSATES ROUTED TO LP OIL OUT .134

FIGURE 5.14: CASE 4.A: SUPERSONIC SEPARATOR AT HP COMPRESSOR DISCHARGE; SEPARATED CONDENSATES ROUTED TO MP SEPARATOR .136

FIGURE 5.15: CASE 4.B: SUPERSONIC SEPARATOR AT HP COMPRESSOR DISCHARGE; SEPARATED CONDENSATES ROUTED TO LP SEPARATOR. .136 
FIGURE 5.16: CASE 4.C: SUPERSONIC SEPARATOR AT HP COMPRESSOR DISCHARGE; SEPARATED CONDENSATES ROUTED TO LP OIL OUT..............................................................137

FIGURE 5.17: PRESSURE DISTRIBUTION ALONG THE NOZZLE WITH 70\% PRESSURE

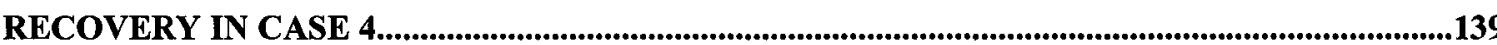

FIGURE 5.18: PHASE ENVELOPES FOR STREAM "LP OIL OUT" FOR "BASE PROCESS" AND CASE 4 WITH 70\% PRESSURE RECOVERY .140

FIGURE 5.19: CASE 5.A: SUPERSONIC SEPARATOR AT MP COMPRESSOR DISCHARGE; SEPARATED CONDENSATES ROUTED TO LP SEPARATOR.

FIGURE 5.20: CASE 5.B: SUPERSONIC SEPARATOR AT MP COMPRESSOR DISCHARGE; SEPARATED CONDENSATES ROUTED TO LP OIL OUT.

FIGURE 5.21: PRESSURE DISTRIBUTION ALONG THE NOZZLE WITH 70\% PRESSURE RECOVERY IN CASE 5 .

FIGURE 5.22: PHASE ENVELOPES FOR THE STREAM "LP OIL OUT" FOR "BASE PROCESS” AND CASE 5 WITH 70\% PRESSURE RECOVERY

FIGURE 5.23: CASE 6: SUPERSONIC SEPARATOR AT LP COMPRESSOR DISCHARGE; SEPARATED CONDENSATES ROUTED TO LP OLL OUT.

FIGURE 5.24: PRESSURE DISTRIBUTION ALONG THE NOZZLE WITH 70\% PRESSURE RECOVERY IN CASE 6

FIGURE 5.25: CASE 7.A: TWO SUPERSONIC NOZZLES AT DISCHARGES OF HP AND MP COMPRESSORS; SEPARATED LIQUIDS TO MP AND LP SEPARATORS

FIGURE 5.26: CASE 7.B: TWO SUPERSONIC NOZZLES AT DISCHARGES OF HP AND MP COMPRESSORS; SEPARATED LIQUIDS TO LP SEPARATOR

FIGURE 5.27: PRESSURE DISTRIBUTION ALONG MP NOZZLE WITH 70\% PRESSURE RECOVERY IN CASE 7 WITH 70\% INLET PRESSURE RECOVERY. 149

FIGURE 5.28: PHASE ENVELOPES FOR THE STREAM "LP OIL OUT" FOR "BASE PROCESS" AND CASE 7 WITH 70\% PRESSURE RECOVERY

FIGURE 5.29: CASE 8; SUPERSONIC NOZZLE AFTER THE MIXED STREAM FROM HP AND MP SEPARATORS

FIGURE 5.30: PRESSURE DISTRIBUTION ALONG THE NOZZLE WITH 70\% PRESSURE RECOVERY IN CASE 8.

FIGURE 5.31: PHASE ENVELOPES FOR THE STREAM "LP OIL OUT" FOR "BASE PROCESS" AND CASE 8 WITH 70\% PRESSURE RECOVERY 


\section{LIST OF TABLES}

TABLE 4.1: NOZZLE GEOMETRY FOR VALIDATION WITH FLUENT ........................53

TABLE 4.2: NOZZLE INLET FLOW CONDITIONS FOR VALIDATION........................54 TABLE 4.4: DRY GAS COMPOSITION FOR VARIABLE-EFFECTS STUDIES...........................58

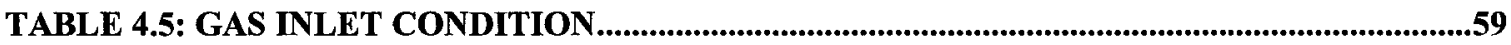

TABLE 4.6: "TEST STREAM" GAS COMPOSITION............................................................60

TABLE 4.7: FIXED PARAMETERS USED IN THE STUDY OF VARIABLE EFFECTS

TABLE 4.8: NOZZLE SPECIFICATIONS FOR "TEST STREAM"...................................................62

TABLE 4.9: DESIGNED NOZZLE SPECIFICATIONS FOR AN IDEAL GAS................................63 STUDIES

TABLE 4.10: INLET STREAMS CONDITIONS FOR INLET-PRESSURE-EFFECT

TABLE 4.11: STREAMS GAS COMPOSITION (MOLE FRACTIONS) FOR INLET-PRESSUREEFFECT STUDIES

TABLE 4.12: INLET CONDITION OF THE STREAMS IN THE PRESSURE EFFECT STUDIES

TABLE 4.13: INLET CONDITIONS FOR STREAMS WITH DIFFERENT PRESSURES.........75

TABLE 4.14: ADJUSTED FLOW RATES AND EXIT PRESSURE RANGE FOR PRESSUREEFFECT STUDIES.

TABLE 4.15: SHOCKWAVE LOCATION: COMPARISON FOR PRESSURE-EFFECT STUDIES

TABLE 4.16: INLET CONDITION OF THE STREAMS FOR INLET-TEMPERATUREEFFECT STUDIES

TABLE 4.18: NOZZLE GEOMETRY IN TEMPERATURE-EFFECT STUDIES....................86

TABLE 4.19: REMAINED WATER CONTENT IN THE NOZZLE STREAM AFTER THE SHOCKWAVE FOR THE DESIGNED NOZZLE IN TEMPERATURE-EFFECT STUDY WITH 70\% INLET RECOVERY.

TABLE 4.20: THE ADJUSTED FLOW RATE TO RATE THE NOZZLE IN TEMPERATURE EFFECT-STUDIES.

TABLE 4.21: REMAINED WATER CONTENT IN THE NOZZLE STREAM AFTER THE SHOCKWAVE FOR THE DESIGNED NOZZLE IN TEMPERATURE-EFFECT STUDY WITH 70\% INLET RECOVERY.

TABLE 4.23: DESIGNED NOZZLE GEOMETRY IN FLOW RATE-EFFECT STUDIES

TABLE 4.24: WATER CONTENT ALONG THE NOZZLE 
TABLE 5.1: INLET AND OUTLET CONDITIONS FOR EACH SEPARATOR IN "BASE PROCESS"

TABLE 5.2: MOLE FRACTIONS AND MOLAR FLOW RATES OF WELLHEAD STREAM AND

"LP OUT OIL" STREAM IN "BASE PROCESS".

TABLE 5.3: CRUDE OIL PRODUCTION OF "BASE PROCESS"..................................................118

TABLE 5.4: NOZZLE GEOMETRY FOR CASE ONE.

TABLE 5.5: MOLE FRACTIONS AND MOLAR FLOW RATES FOR'LP OIL OUT" STREAM FOR CASES 1.B AND 1.C

TABLE 5.7: CRUDE OIL PRODUCTION OF THE CASES 1.B, 1.C FOR 70\% INLET PRESSURE RECOVERY.

TABLE 5.7: MOLE FRACTIONS AND MOLAR FLOW RATES FOR"LP OIL OUT" STREAM FOR THREE PROCESSES IN CASE ONE FOR 80\% PRESSURE RECOVERY.

TABLE 5.8: CRUDE OIL PRODUCTION OF THE THREE PROCESSES IN CASE ONE FOR 80\% INLET PRESSURE RECOVERY.

TABLE 5.9: NOZZLE GEOMETRY FOR CASE TWO.

TABLE 5.10: MOLE FRACTIONS AND MOLAR FLOW RATES OF"LP OIL OUT" STREAM IN

CASE 2 WITH $80 \%$ INLET PRESSURE RECOVERY

TABLE 5.11: CRUDE OIL PRODUCTION OF THE THREE PROCESSES IN CASE 2 FOR 80\% INLET PRESSURE RECOVERY.

TABLE 5.12: MOLE FRACTIONS AND MOLAR FLOW RATES FOR STREAM"LP OIL OUT"

IN CASE 4 WITH 70\% INLET PRESSURE RECOVERY

TABLE 5.13: CRUDE OIL PRODUCTION OF THE THREE PROCESSES IN CASE 4 FOR 70\%

INLET PRESSURE RECOVERY.

TABLE 5.14: NOZZLE GEOMETRY FOR CASE 5

TABLE 5.15:MOLE FRACTIONS AND MOLAR FLOW RATES FOR STREAM "LP OIL OUT" FOR TWO PROCESSES IN CASE 5.

TABLE 5.16: CRUDE OIL PRODUCTION OF THE THREE PROCESSES IN CASE 5 FOR 70\%

INLET PRESSURE RECOVERY.

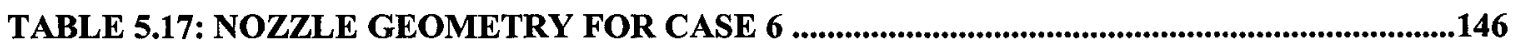

TABLE 5.18: "MP NOZZLE" GEOMETRY FOR CASE 7.A ...........................................................149

TABLE 5.19: MOLE FRACTIONS AND MOLAR FLOW RATES OF” LP OIL OUT" FOR CASE 7.

TABLE 5.20: CRUDE OIL PRODUCTION OF THE THREE PROCESSES IN CASE 7 FOR 70\% INLET PRESSURE RECOVERY.

TABLE 5.21: PROPERTIES OF NOZZLE INLET STREAM IN CASE 8.............152

TABLE 5.22: NOZZLE GEOMETRY FOR CASE 8 
TABLE 5.23: MOLE FRACTIONS AND MOLAR FLOW RATES OF THE" LP OIL OUT" STREAM IN CASE EIGHT.

TABLE 5.24 CRUDE OIL PRODUCTION OF THE THREE PROCESSES IN CASE 8 FOR 70\%

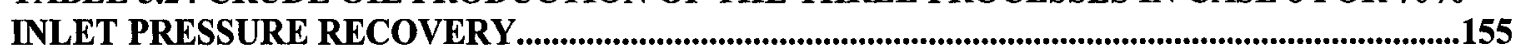

TABLE 5.25: FINAL COMPOSITIONS IN THE EXIT STREAMS (LP OIL OUT) FOR CASES

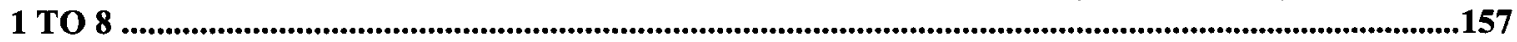




\section{NomenClature}

UNITs:

bbls/d: barrels/day

$\mathrm{STDm}^{3} / \mathrm{d}$ : standard cubic meters per day

$\mathrm{mol} / \mathrm{s}$ : mol per seconds

$\mathrm{mg} / \mathrm{std}^{3}:$ miligrams per standard cubic meter

$\mathrm{Kmol}$ gas $/ 10^{6} \mathrm{std} . \mathrm{m}^{3}$ : mole per standard cubic meter

\section{LETTERS:}

$a, b$ : equations of state constants characterizing the molecular properties

$c$ : speed of sound $(\mathrm{m} / \mathrm{s})$

$d L \_c$ : Converging part incremental length

$d L \_d$ : diverging part incremental length

$e$ : system energy

$f$ : friction coefficient

$h$ : mass enthalpy, $\mathrm{KJ} / \mathrm{Kg}$

$h_{o}$ : stagnation enthalpy , $\mathrm{KJ} / \mathrm{Kg}$

$k$ : specific heats ratio $\left(C_{p} / C_{v}\right)$

$n$ : amount of substance in mole

$u$ : constant of cubic equation of state

$w$ : constant of cubic equation of state

$A$ : cross section area, $\mathrm{m}^{2}$

$A_{\text {ex }}$ : exit cross section area

Cs: Control surface

$C v$ : Control volume

$D$ : Diameter (m)

$D_{\text {in }}$ : inlet diameter

$D_{t h}$ : throat diameter

$D_{\text {ex: }}$ exit diameter

$C_{p}$ : Specific heat capacity at constant pressure

$C_{v}$ : Specific heat capacity at constant volume

$G, F$ : Newton-Raphson functions

$F_{B}$ : body forces

$F_{B x}:$ X-component of body forces

$F_{f}$ friction factor

$F_{\text {s: }}$ surface forces

I: trust

$L \_c$ : length of the converging part 
$L \_$: length of the diverging part

$\bar{M}$ : mach number

$M_{w}$ : molecular weight

$P$ : pressure, $\mathrm{MPa}$

$P_{o}$ : stagnation pressure

$R$ : ideal gas constant

$R_{x}$ : pressure force

$R e_{D}$ : Reynolds number

$S$ : mass entropy, $\mathrm{KJ} / \mathrm{Kg} \mathrm{C}$

$T$ : Temperature

$T_{o}$ : stagnation temperature

$V:$ velocity $\mathrm{m} / \mathrm{s}$

$Z$ : compressibility

$\dot{m}$ : mass flow, $\mathrm{Kg} / \mathrm{h}$

$\delta Q$ : mount of heat transferred to the system

$\dot{Q}$ : heat transfer rate

$\dot{W}_{s}$ : shaft work

$\dot{W}$

$W_{\text {shear }}$ : work done by shear stresses

$\dot{W}_{\text {other }}$ other work

\section{GreEK:}

$\alpha$ : onvergence half angle

$\beta$ : ivergence half angle

$\varepsilon$ : surface roughness

$\rho$ : gas density $\left(\mathrm{kg} / \mathrm{m}^{3}\right)$

$\rho_{o}$ : stagnation density

$v$ : molar volume

$\bar{\xi}_{c}$ : incremental properties

$\Phi$ : frictional loss term

$\tau$ : shear stress 


\section{CHAPTER 1: INTRODUCTION}

The demand for natural gas has motivated the oil and gas industry to discover natural gas reservoirs even in remote and hard to reach locations. Natural gas is more abundant than estimated even just ten years ago. The global need for less-carbon and potentially no-carbon content fuels (such as hydrogen) is motivated by environmental concerns. Natural gas is, at present, the only hydrocarbon energy source that will lead to major reductions in green house gases and other pollutants. Natural gas, produced from the reservoir is not a single-component mixture, but a mixture of hydrocarbons which may include heavier than methane hydrocarbons constituents $\left(\mathrm{C}_{2}^{+}\right)$or natural gas liquids (NGLs), reservoir water and various impurities such as inert gases, carbon dioxide, and hydrogen sulphide. Natural gas needs to be processed before being used in the supply network. The impurities such as nitrogen, carbon dioxide, hydrogen sulphide and heavy hydrocarbons can be removed in a central plant (Berger and Anderson 1980). However, some other impurities such as sand and free water should be removed near the wellhead.

Produced natural gas is in the dense phase. During natural gas processing it is likely that the water and the hydrocarbon components condense and form a liquid phase. This phase behaviour can be explained using the equilibrium phase diagrams known also as phase envelope of the stream. The condensation of water and hydrocarbons in natural gas decreases its heating value and causes operational problems such as corrosion, excessive pressure drop, hydrate formation and consequently slugging flow and reduction 
in gas transmission efficiency. The possibility of obstruction due to the formation of hydrate within the flow lines is one of the most serious problems in the gas industry. The point at which gas hydrate forms and therefore becomes a source of trouble depends on the pressure, temperature, and gas composition. Within the transportation system and at very high pressure of the gas, hydrate can form even at relatively high temperatures (close or above $20^{\circ} \mathrm{C}$ ). Therefore, it is important to assure that hydrate does not form as the gas is transported from the wellhead to a processing facility. Line heating, injection of hydrate inhibitors, and dehydration are commonly practiced to meet this requirement (Hengwei et al., 2005).

In processes such as transmission of gas in high pressure pipelines and the gas storage in high pressure containers for land or marine transportation of gas in compressed form, in certain specific pressure and temperature conditions, the presence of heavier hydrocarbons in natural gas is favourable (Mohitpour et al., 2003). The mass flow capacity in pipelines is related to the gas gravity (directly proportional to molecular weight, $M$ ) and reversely proportional to the square root of the compressibility factor $(Z)$. Light gases (with higher percentage of methane) have higher flow capacities because of the low gas gravity and the compressibility factor of close to unity. As the heavier hydrocarbons $\left(\mathrm{C}_{2}^{+}\right)$are introduced in the gas stream, the gas gravity increases and the compressibility factor decreases. The overall effect of heavy hydrocarbons addition will be determined by reduction in gas compressibility, which not only depends on the gas composition but also on pressure and temperature (Mohitpour et al., 2003). Mohitpour et 
al. reviewed the standard volume flow and the mass flow capacities at $1.66^{\circ} \mathrm{C}\left(35^{\circ} \mathrm{F}\right)$ and for pressures between 5.5-14.75 $\mathrm{MPa}(800-2,140$ psia) for a mixture of methane and ethane. The results showed increases in the mass flow capacity with the increase of ethane content in the mixture which resulted in an increase in the amount of energy that could be transported with the mixture. The heating value of the mixture increased at the same rate. Therefore, higher hydrocarbon content of the gas improves the compressibility and transportability of the gas. Water however is a risk factor contributing to the plugging of the pipe and corrosion and therefore should be removed or dealt with in a proper way.

\subsection{OBJeCtives OF STUDY}

The purpose of this thesis is to propose an alternative dehydration process. The proposed system should be capable of working at high-pressure conditions and be able to remove water selectively without affecting the hydrocarbon content of the gas. After evaluating different alternatives, a new approach in using supersonic dehydration systems is proposed to selectively remove water from the gas in supercritical conditions. This study provides a good understanding of the supersonic dehydration especially when water is removed selectively form high-pressure natural gas streams. In addition, the performance of such systems is also studied in the recovery of heavier hydrocarbons. For the NGL recovery studies, the supersonic separators are introduced within a typical crude surface separation facility on an offshore platform to determine the efficiency of the unit 
for such applications.

\section{2 SCOPE OF STUdY}

Based on literature reviews, two companies have commercially implemented supersonic separators for gas treatment: Twister BV (Brouwer et al., 2004) and Translang TechnologiesLtd. (Alfyorov et al., 2005). Supersonic separators are used for different applications such as water and hydrocarbon dew pointing, natural gas liquids (NGL/LPG)

extraction, heating value reduction, fuel gas treatment, $\mathrm{CO}_{2}$ extraction, ethane recovery and Liquefied Natural Gas (LNG) applications (Brouwer et al., 2004 and Alfyorov et al., 2005).

Limited data and information is presented on the performance of supersonic separators in the previously mentioned applications. In this research a complete overview of water dew pointing applications using the supersonic separators are given.

\section{3 ThESIS OUTLINE}

The thesis is divided into seven chapters. Chapter 1 provides an introduction to the supersonic separators and their applications. In Chapter 2, several alternative processes to eliminate liquid phase from natural gas such as refrigeration, liquid desiccant dehydration, solid desiccant dehydration, and membrane separators are reviewed. The necessary background on the supersonic separators is also given Chapter 2. In Chapter 3, further introduction to the supersonic dehydration is given and the methodology to 
simulate the system is discussed. In Chapter 4 , the prediction of the behaviour of the supersonic dehydration unit based on the proposed model is presented. The nozzle is assumed to work in an isentropic (frictionless, reversible, and constant entropy) condition. A condition where friction exists is also presented. In Chapter 5, supersonic separators are introduced within a typical crude surface production system on an offshore platform to determine the efficiency of the unit to recover NGLs. Chapter 6 summarizes the thesis and the conclusions reached are presented. In addition, recommendations for future work are provided. 


\section{Chapter 2: Literature Review}

In this chapter, various dehydration processes are reviewed and the introduction on a supersonic nozzle as the main part of the supersonic dehydration system is given.

\subsection{NATURAL GAS DEHYDRATION AND HYDRATE INHIBITION}

Natural gas dehydration is an important process for several reasons including the following:

1. Free water in natural gas can cause operational problems such as corrosion and excessive pressure drop due to the two-phase flow

2. Water decreases the heating value of the gas

3. Water can form hydrate and consequently plug the pipeline

Among all, hydrate formation is one of the most serious problems in natural gas industry and has been identified as a major hazard to the safe operation of natural gas transmission pipelines.

Gas hydrates are non-stoichiometric compounds that form when the host material, like water traps the guest molecules such as methane. The temperature and pressure of hydrate formation can be predicted on the gas composition basis. Hydrate crystals might not form even when hydrate formation is thermodynamically possible as the crystal growth process is random but to be safe, hydrate prevention is needed. There are several methods to prevent hydrate formation in natural gas pipelines: 


\subsubsection{LINE HEATING}

Line heating may keep the minimum line temperature above the hydrate formation point. The initial investment needed for this method is not very high as fuel is available to operate the heater. Line heaters are simple and do not need much maintenance however they do not remove the water vapour which causes hydrate formation. Line heating therefore is needed at any point where the risk of hydrate formation exists. This method is not very suitable for long distance pipeline transmission systems (Berger and Anderson, 1980).

\subsubsection{HYDRATE INHIBITOR INJECTION}

An alternative method to control hydrate formation is to use kinetic inhibitors, anti-agglomerates and thermodynamic hydrate inhibitors such as methanol, glycols (mainly ethylene and di-ethylene glycols). Injecting the inhibitors prevents hydrate formation by lowering the temperature at which hydrate might form at a given pressure. For an effective injection, inhibitor should be introduced at every point in the process where the wet gas is cooled down to its hydrate temperature. The injected inhibitor should preferably be recovered, regenerated, and re-injected in the process. The physical limitations and economics at certain conditions are factors to choose one inhibitor over the other (GPSA Data book 1998, and Covington et al., 1999). Anti-agglomerates prevent small hydrate particles from growing into larger sizes and kinetic inhibitors slow crystal formation. Kinetic inhibitors have some advantages as their required concentration is as low as $0.5-2.0$ wt. $\%$ in the aqueous phase and they are non-volatile 
but they are banned to be used in some areas due to environmental reasons and that too much inhibitor may even increase the hydrate formation rate (Iluhi, 2005 and Kidnay, Parrish, 2006). The principal thermodynamic inhibitors are methanol and ethylene glycols. Their required dosage is predictable but it can be as high as $50 \mathrm{wt} . \%$ of the aqueous phase. Ethylene glycol is usually preferred over di-ethylene glycol and triethylene glycol due to its lower solubility and viscosity. The rate of harmful emissions (mainly aromatic hydrocarbons) from the glycol regenerators to the environment is the most common concern for glycol injection units. Methanol is usually not regenerated in the process so the disadvantage of damaging the environment might be omitted but it will be a costly process (Covington et al., 1999). Figure 2.1 shows a simple sketch of a glycol injection unit.

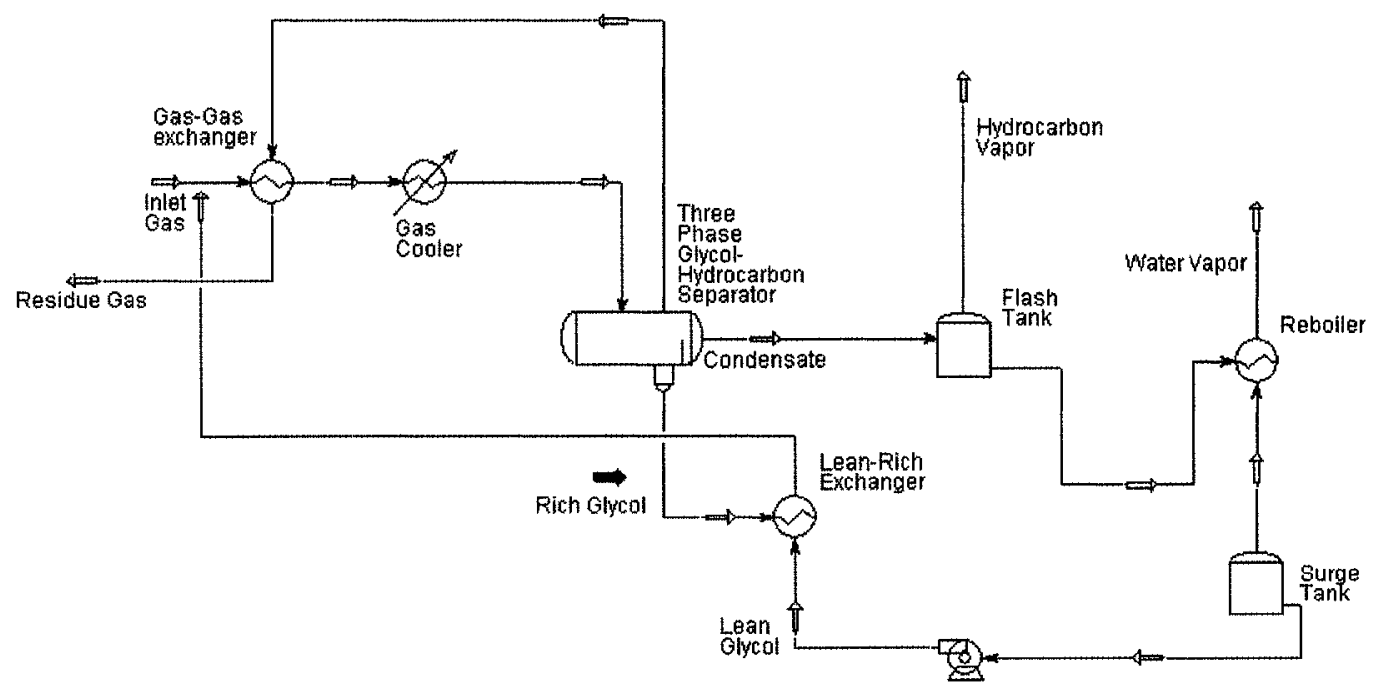

Figure 2.1: Typical glycol injection system

Hydrate formation can also be prevented by eliminating water using gas 
dehydration processes. Dehydration may be performed with or without removal of other liquid phases and the condensable components of natural gas before delivery or consumption (GPSA Data book, 1998).

\subsubsection{ABSORPTION USING LIQUID DESICCANTS}

Glycols are very good absorbers for water because the hydroxyl groups in glycols form similar associations with water molecules. Among different glycols such as diethylene glycol (DEG), tri-ethylene glycol (TEG) and tetra-ethylene glycol (TREG) which are used as liquid desiccants, Tri-ethylene glycol is the most common liquid desiccant for natural gas (GPSA Data book, 1998).

The intimate contact between a wet gas and glycol can be made in bubble cap or valve tray absorbers or other gas-liquid contact devices. The gas gives the water vapour to glycol as it passes through the absorber. Water-rich glycol leaves the bottom of the tower and is pumped through a regeneration system to boil off the absorbed water. It is then circulated back to the absorber to complete a closed loop process cycle (Ballard, 1979). Liquid desiccant systems are simple to operate and maintain and it is possible to automate them for unmanned operations (GPSA Data book, 1998). This technology needs a large facility and due to the need for glycol, there is a possibility for some operational problems and the way to prevent such problems should be recognized. Some of these problems and the way to avoid them are as follows (Ballard, 1979):

- Oxidation: air should be kept out of the system

- Thermal Decomposition: excessive heat should be avoided 
- $\mathrm{pH}$ control: $\mathrm{pH}$ needs to be watched carefully by using glycol to lower the $\mathrm{pH}$ and increase the acidity and corrosion.

- Salt contamination: should be removed by an efficient scrubber before the glycol unit

- Liquid hydrocarbons: should be separated with the gas-glycol separator or activated carbon beds

- Sludge: solid particles suspended in glycol can be separated by good filtration

- Foaming: be prevented by effective gas cleaning ahead of the unit and filtration Other glycol based gas dehydration technologies were developed to increase the glycol purity after regeneration and decrease the emission gas to the environment (GPSA, Data book, 1998). A process flow diagram for a typical glycol dehydration unit is shown in Figure 2.2.

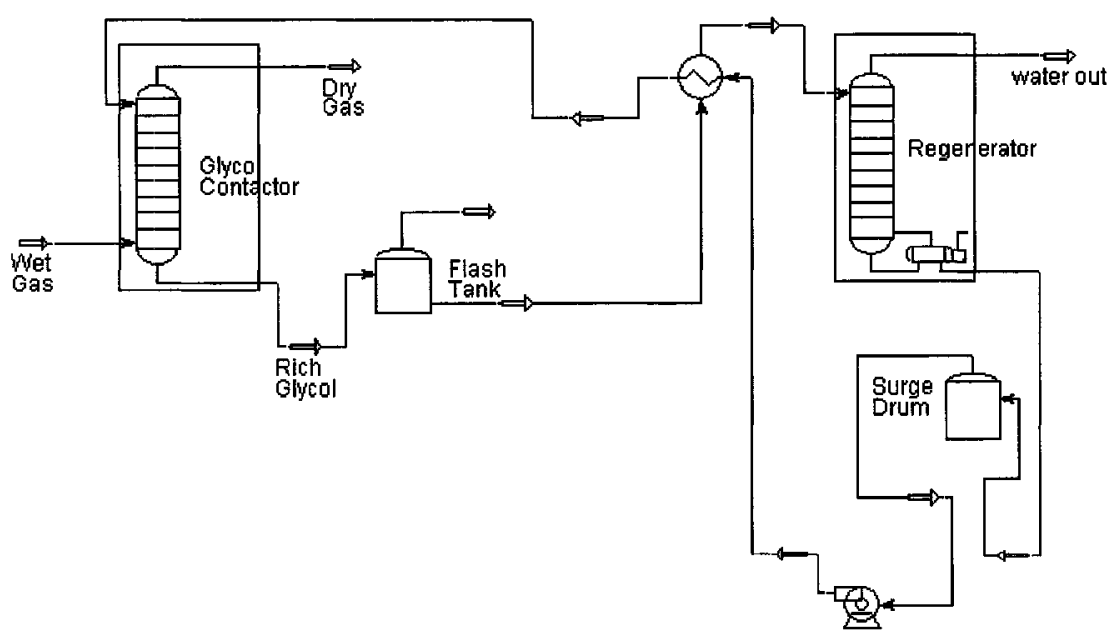

FiFigure2.2: Schematic diagram of a typical glycol dehydration system 


\subsubsection{AdSORPTION USING SOLID DESICCANTS}

Solid desiccant dehydration is also known as dry-bed dehydration. It uses a solid reagent to remove water. Adsorbents also known as desiccants are high capacity material for water removal including alumina, silica gels, and molecular sieves. Molecular sieves produce the lowest water dew point and have the highest capacity for water removal but the heat required to regenerate them is more than alumina or silica gels. Molecular sieves are also more expensive compared to other desiccants. The solid desiccant dehydration system is consisted of two or more towers and the associated regeneration equipment. Before introducing the gas into a cylindrical bed containing the desiccant, the wet gas enters an inlet separator to remove contaminants and free water and hydrocarbon by gravity. Desiccants have limited capacity for water, become saturated soon, and therefore should be regenerated to restore its adsorptive capacity. The regeneration is usually accomplished by heating. Hot gas vaporizes the water from the adsorbent. Dry bed dehydration is a semi continuous process for which at least two parallel vessels filled with the adsorbent are required. In this arrangement, one vessel is adsorbing while other is regenerating (GPSA Data book, 1998, Ballard, 1979, and Manning and Thompson, 1991). Figure 2.3 outlines a schematic of this process. 


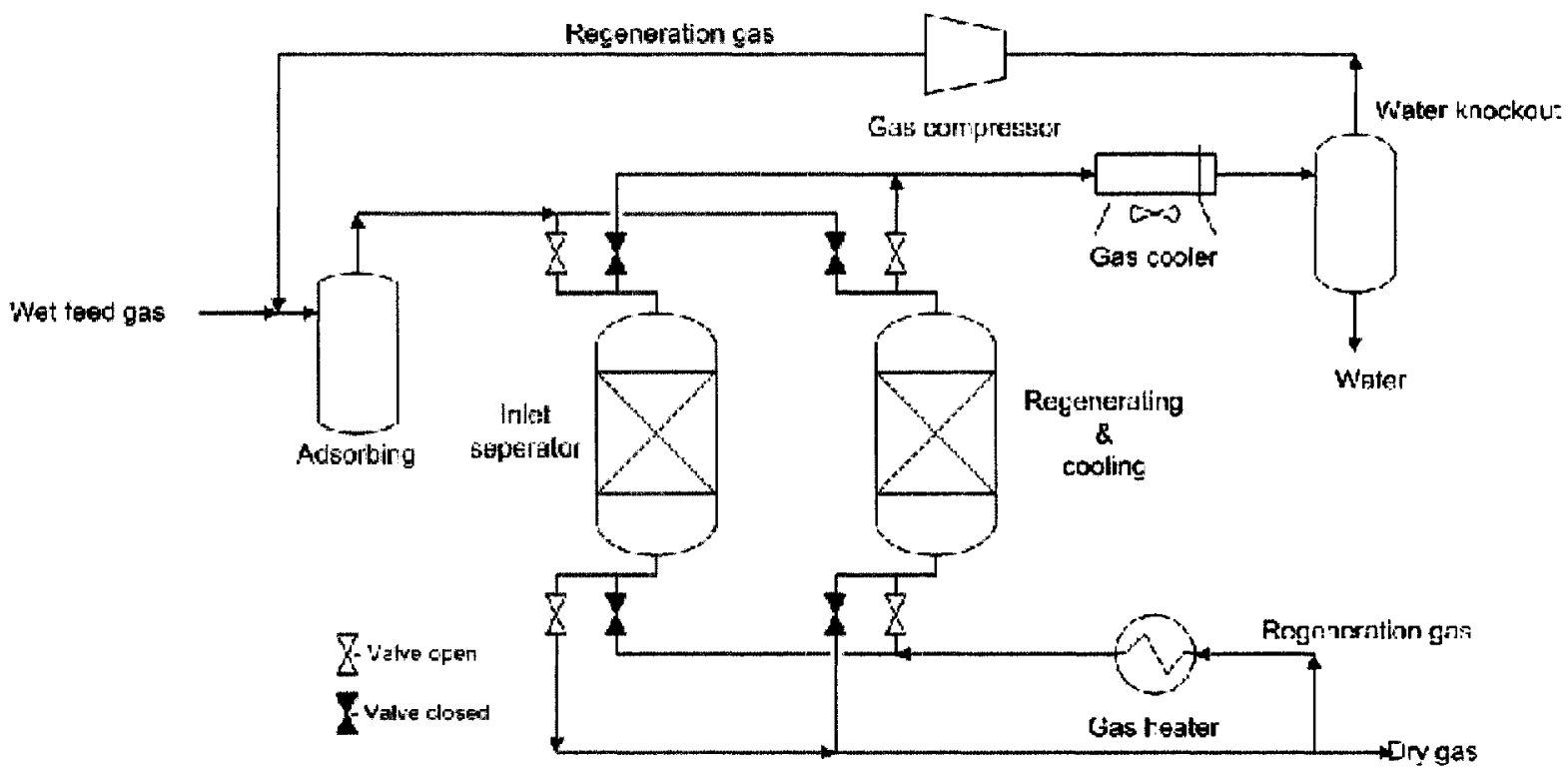

Figure2.3: Schematic of an example solid adsorbent dehydrator

\subsubsection{DehydRATION WITH CALCIUM ChLORIDE}

Solid anhydrous calcium chloride $\left(\mathrm{CaCl}_{2}\right)$ which forms various $\mathrm{CaCl}_{2}$ hydrates when combined with water can be used as desiccant to dehydrate natural gas. As water absorption continues, brine solution will be formed. In this unit calcium chloride pellets are placed in a fixed bed. To increase the unit capacity three to four trays can be installed below the fixed bed to pre-contact the gas with the brine solution and remove a portion of water before the gas contacts the solid $\mathrm{CaCl}_{2}$. The Unit might show poor performance under some conditions if $\mathrm{CaCl}_{2}$ pellets bond together and form a solid bridge in the tower (GPSA Data book, 1998). Figure2.4 outlines a typical $\mathrm{CaCl}_{2}$ dehydrator. 


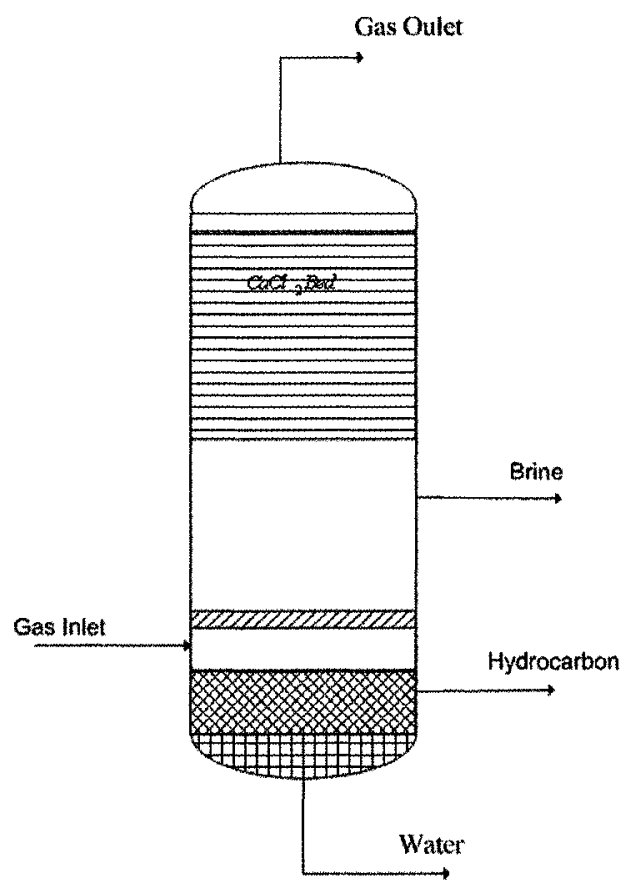

Figure2.4: Schematic of a typical $\mathrm{CaCl} 2$ dehydrator

\subsubsection{DEHYDRATION BY REFRIGERATION}

Natural gas consists of many different components. Heavier-than-methane hydrocarbon constituents of natural gas that can liquefy in the field or processing plants are called natural gas liquids (NGL). Refrigeration through external vapour recompression is the simplest and most common process for dew point control of NGLs and water. In external or mechanical refrigeration systems the cooling is supplied by a vapour recompression cycles that typically use propane as the refrigerant or the working fluid. The refrigerant (often $\mathrm{C}_{3}$ in natural gas industries) boils off and leaves the chillers as a saturated vapour (GPSA Data book, 1998 and Kidnay and Parrish, 2006). This 
process is shown in Figure 2.5 (GPSA Data book 1998, Arnold and Stewart 1999, Manning and Thompson, 1991).

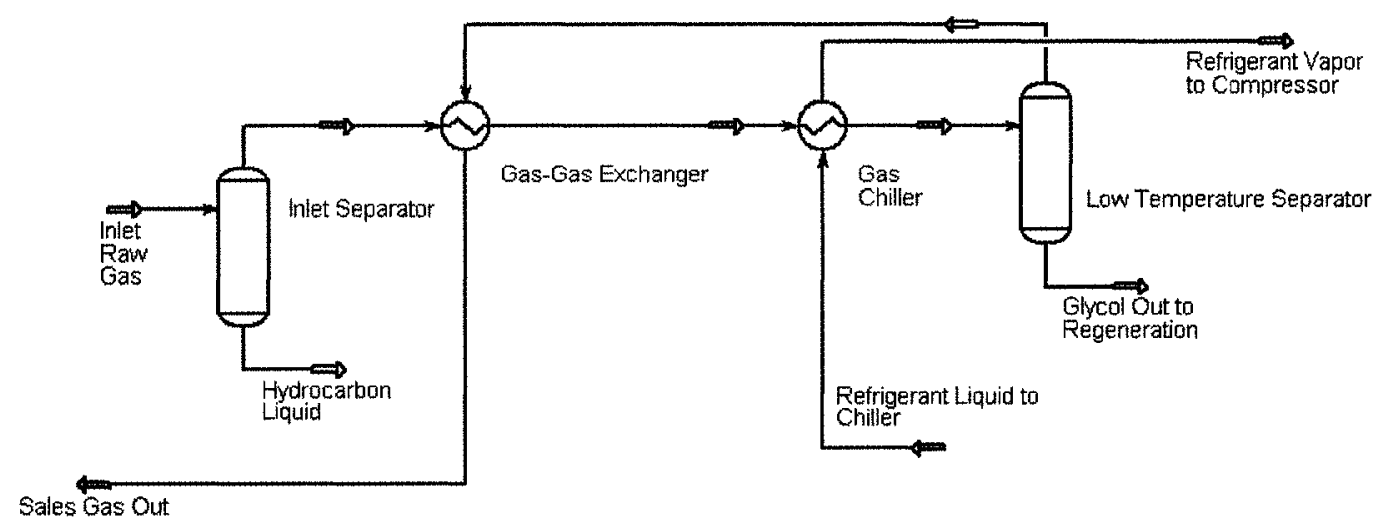

Figure2.5: External refrigeration systems

If the inlet pressure is high enough, there will not be a need for external cooling and the expansion refrigeration that is known as low temperature extraction (LTX) or low temperature separation (LTS) will be used. This process applies the Joule-Thompson (JT) effect to reduce the gas temperature upon expansion in order to condense water and hydrocarbon and recover condensate with or without hydrate inhibition. The JouleThompson (J-T) in this process induces "self-refrigeration" as apposed to "external refrigeration" (Manning and Thompson, 1991). To run LTS without using hydrate inhibitors, the temperature should be sufficient to prevent hydrate formation upstream of the valve where joule-Thompson expansion occurs. The expansion is essentially a 
constant enthalpy process. The inlet gas passes through the gas-gas exchanger, then to an expansion or choke valve. Non-ideal behaviour of the inlet gas causes the temperature to fall with the pressure reduction (GPSA Data book, 1998, Manning and Thompson, 1991).This technique requires a large pressure drop so it is used when the main objective is to recover condensate. Figure2.6 shows an LTS that uses glycol injection and J-T expansion for cooling.

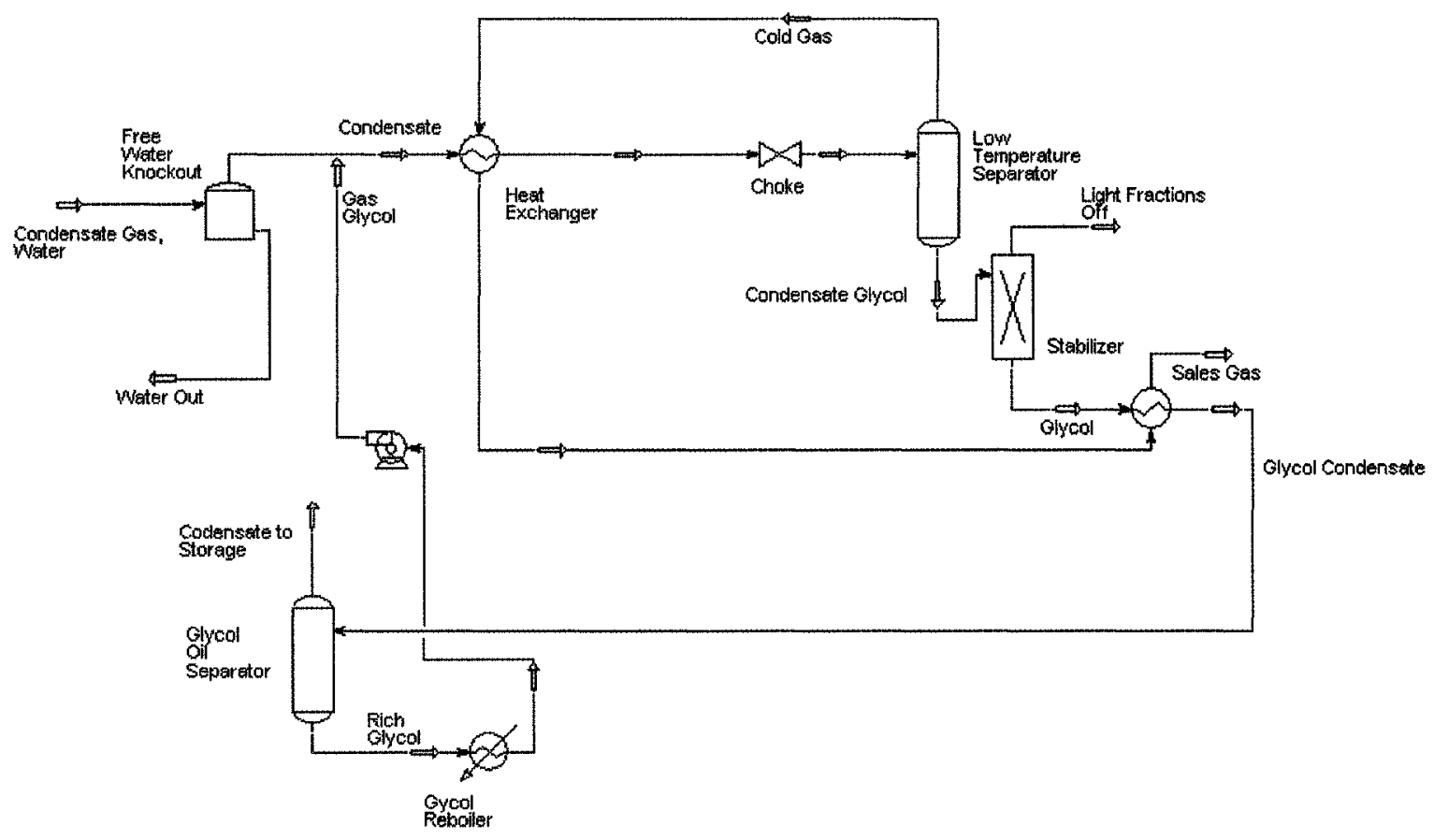

Figure2.6: Low-temperature separations with glycol injection 


\subsubsection{DEHYDRATION BY MEMBRANE PERMEATION}

Membranes have been successfully used to remove acid gases from natural gas. They are also being promoted by suppliers of membrane technology for water removal (Arnold and Stewart, 1999). They are relatively expensive (especially for large gas flow rates) and can be easily fouled by gas contaminants. They also need high pressure for efficient operation. However, they have a low-pressure drop through the process and do not need any chemical reagents. The installation and change of the membrane cartridge are relatively easy and the maintenance cost is low. The membranes' capability to remove water vapour is not selective and part of the gas is always wasted through copermeation. Figure 2.7 shows the membrane dehydration process (Stookey et al. 1984).

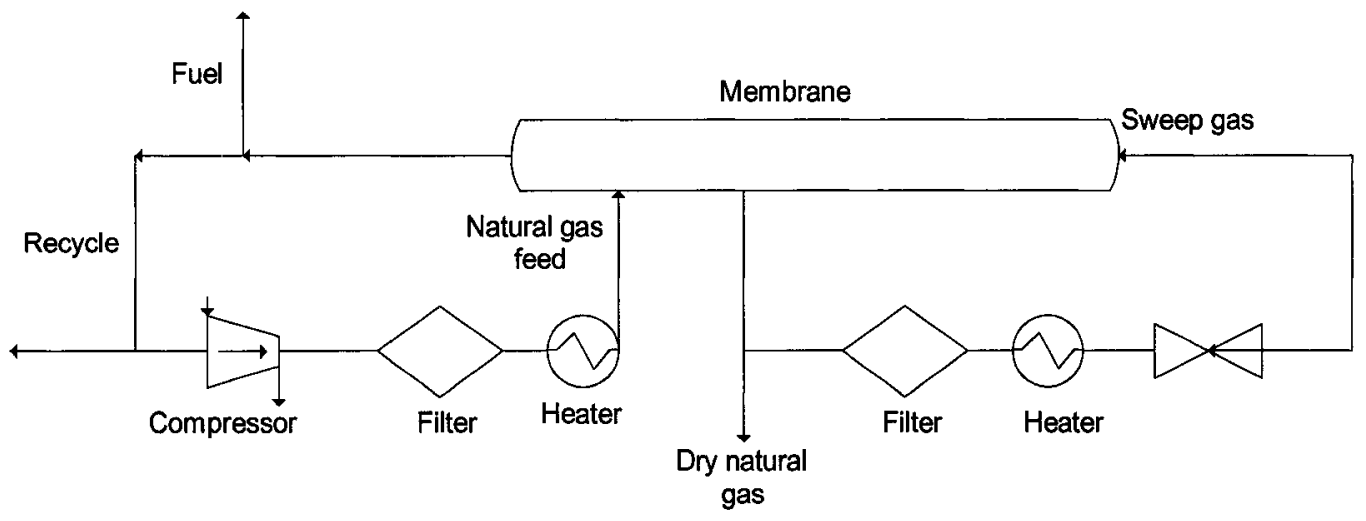

Figure2.7: Schematic diagram of a membrane dehydration process 


\subsubsection{SUPERSONIC DEHYDRATION}

Most of the previously mentioned methods have good dehydration performance but they have some disadvantages including the need for relatively large facilities, a considerable investment and complex mechanical work and the possibility of having a negative impact on the environment. Supersonic dehydration unit were introduced to overcome some of the disadvantages of the alternative processes for dehydration. Full scale supersonic separator units have been tested in five different gas plants with different gas compositions and operating conditions since 1998 (Brouwer et al., 2004). The first commercial gas conditioning technology using the supersonic separator in the offshore applications was started up in December 2003 (Brouwer et al., 2004). 3-S separator is another unit based on the same technology with different structure (Alfyorov et al., 2005). The idea of 3-S separators was proposed by a group of Russian specialists (Alfyorov et al., 2005). This group joined Translang Technologies Ltd., Calgary. 3-S separators performances have been studied and tested since 1996. An experimental test plant was constructed in Russia. Later another pilot plant for greater natural gas flow rate was built in Calgary. None of these facilities was capable of very high pressures. The first industrial 3-S separator was started operating in Western Siberia (Alfyorov et al., 2005). These cyclonic gas/liquid separators, which combine expansion and recompression in a compact, tubular device, have very similar thermodynamic performance to that of turbo-expanders. A similar temperature drop as in turbo expanders, within which pressure transforms to shaft power can be achieved in both units by transforming 
pressure to kinetic energy (Brouwer et al., 2004 and Schinkelshoek et al., 2006). The Twister supersonic separator and 3-S separators both include a supersonic nozzle to expand the saturated feed gas to supersonic velocities and therefore lower temperature and pressure which results in water and hydrocarbon condensation. Separation of the liquid droplets can be achieved by centrifugal forces using two different methods: a) using a wing or blade at the end of the nozzle and in the supersonic region, b) using a flow swirling device ahead of the nozzle. The former was used by the Twister's design at this stage and the latter was used in 3-S separators. In both cases after liquids are separated from the gas, dry gas in the exit becomes subsonic and some of the pressure can be recovered. Another unit with the same technology was tested experimentally with wet air as a working fluid and $1 \mathrm{MPa}$ working pressure (Hengwei et al., 2005). The pressure recovery of this system was less than $75 \%$.

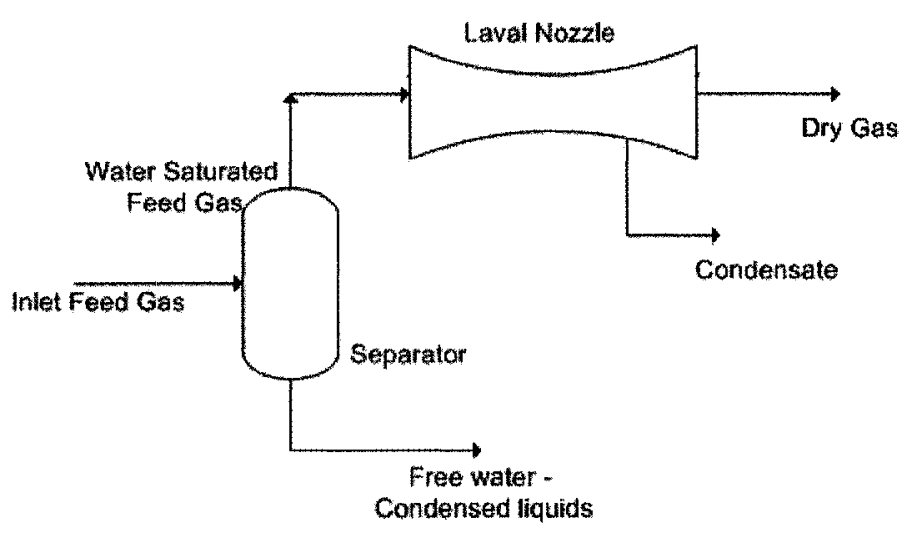

Figure2.8: Schematic diagram of a supersonic dehydration unit 
The main part of the supersonic dehydration unit is a supersonic (converging diverging) nozzle (see Figure 2.8). The supersonic nozzle is simple in design and does not include any moving parts. In the supersonic nozzle both condensation (or solidification of hydrate) and separation occur at supersonic velocities, which leaves hydrate no time to deposit on the wall surfaces due to the short residence time and the high velocity of the fluid. The simplicity of this device makes it suitable for unmanned operation (Brouwer et al., 2004 and Schinkelshoek, 2006) for underwater or remote gas production applications. As a result, the gas in this system can be dehydrated in a smaller, lighter, cheaper, more environmentally friendly, and less complex facility.

In the supersonic dehydration unit, the gas temperature is lowered based on gas expansion principles without the need of any refrigerant. The compactness of this design is a major advantage over traditional means of dehydration particularly for offshore applications. The gas velocity in this device is very high which prevents fouling or deposition of solids and ice. Refrigeration is self-induced therefore no heat is transferred through the walls and unlike external refrigeration systems, no inhibitor injection and inhibitor recovery system are necessary. Intensive water dew points down to -50 to -60 ${ }^{\circ} \mathrm{C}$ can be achieved without any external cooling or use of solid adsorption techniques. The major drawback of this system is the pressure loss due to the expansion in the nozzle. New designs are under development to overcome the loss of energy as the gas passes through the high speed nozzles. Most of the traditional means of dehydration remove water and hydrocarbon simultaneously and they are not selective to any one element 
alone. At certain conditions of pressure and temperature, presence of heavy hydrocarbons $\left(\mathrm{C}_{2}^{+}\right)$increases the gas gravity and reduces the compressibility factor, which results in an increase in the pipeline mass flow capacity (Mohitpour et al., 2003). Furthermore, the compactness and reliability of the process equipment are very important especially for offshore applications where the foot print area is at a premium. Therefore, for special applications development of a compact system that is capable of selectively removing water from high pressure natural gas streams without affecting the hydrocarbon content will be needed. To remove water selectively natural gas should be kept in a single phase and hydrocarbon condensation should be avoided.

\subsection{FLOW PROPERTIES IN A CONVERGING-DIVERGING NOZZLE}

In order to analyze the behaviour of fluid in supersonic nozzles a sound understanding of the basics of thermodynamics, phase equilibrium and dynamics of compressible fluid flow is required. These principles are briefly reviewed in the following sections.

\subsubsection{COMPRESSIBLE FLOW}

Natural gas is a highly compressible fluid. In compressible fluids the density changes as the fluid pass though flow passages. Two different kinds of processes can cause density to change. In a dynamic process the fluid density can change in association 
with the fluid acceleration, whereas in a thermodynamic process in which density changes due to thele addition of heat from an external source. Sometimes density changes are because of combination of both processes (Greitzer et al., 2004).

\subsubsection{EQUILIBRIUM PHASE DIAGRAMS}

Phase diagrams also called phase envelopes, are used to examine the phase or phases that may exist at any given conditions of pressure and temperature. The diagrams show the locus of points between the two equilibrating phases on a P-T plot (see Figure 2.9). Several terms are used to define different points on the phase envelope. Cricondenbar and cricondentherm are the respective maximum pressure and temperature at which liquid and vapour can coexist in equilibrium. If the pressure is kept above the cricondenbar (above the phase envelope), a single dense phase exists. Bubble point line is the locus at which vaporization begins and dew point line is the locus at which condensation begins. These two lines meet each other at the critical point. The system changes from all liquid to all vapour and vice-versa in the critical point. $P_{c}$ and $T_{c}$ on the following phase diagram show the critical pressure and temperature respectively. 


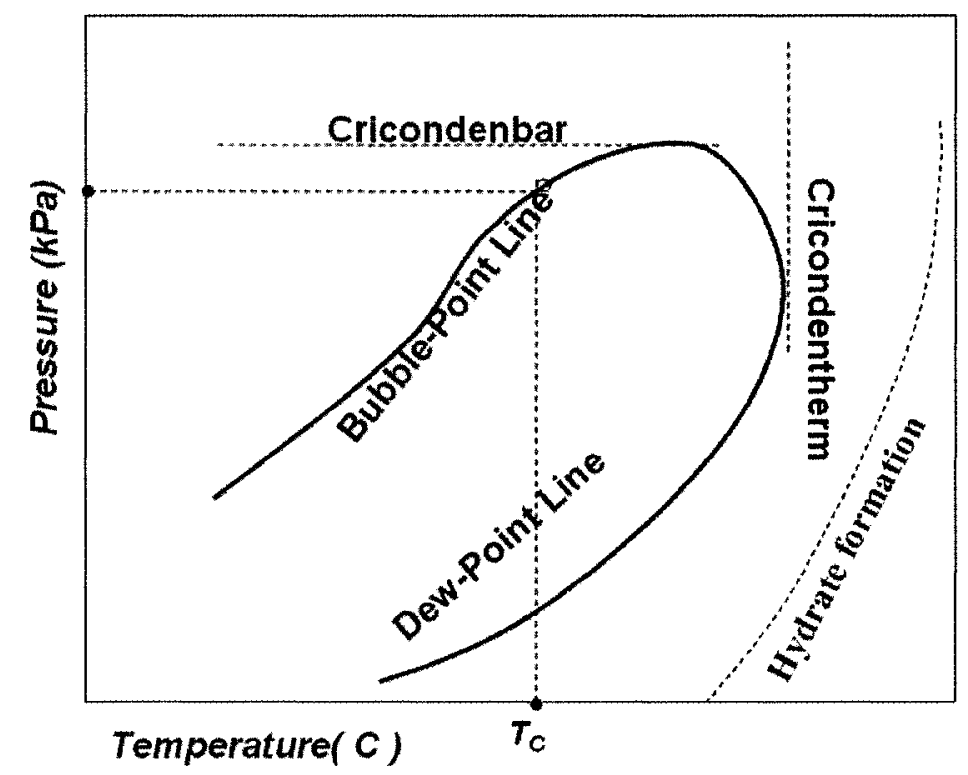

Figure 2.9: Phase envelope of a multi-component mixture

For a multi-component mixture, the gap between the dew point and bubble point lines can vary with composition. The gap becomes wider as heavier hydrocarbons are added to the mixture. As a result, the points indicating cricondenbar and cricondentherm can move upward or downward depending on the gas composition.

The fluid at a temperature and pressure conditions above its critical values is called supercritical as its expansion or compression at constant temperature does not result in any phase change.

Non-hydrocarbon impurities such as water, carbon dioxide, hydrogen sulphide and nitrogen also affect the shape of the phase envelope. Presence of carbon dioxide and hydrogen sulphide lower the cricondenbar but nitrogen increases cricondenbar. On the other hand, as water has a low vapour pressure it does not have a significant effect on the 
shape of hydrocarbon phase envelope except in high temperature and low pressure regions (Campbell, 1992).

\subsubsection{Equations of STATE}

By using basic thermodynamic relations and the equations of state (EOS), the gas properties such as density, enthalpy, and entropy can be predicted. Equations of state describe the interconnection between the measurable thermodynamic properties of a fluid system. Many gases follow the ideal gas law very closely at high temperatures and low pressures usually up to $400 \mathrm{kPa}$ (Campbell, 1992). The ideal gas equation becomes increasingly inaccurate at higher pressures and lower temperatures and fails to predict condensation from gas to liquid. Ideal gas law describes a gas whose molecules do not interact with each other and it is simply defined with the following formula:

$$
p v=n R T
$$

Many different equations have been developed to describe non ideal, real gas behaviour. Real gas laws predict the true behaviour of a gas by considering the terms to describe attractions between molecules. The van der Waals (VW) equation which was the first cubic equation to predict the real gas properties was developed in 1873 (Molleson and Stasenko, 2005). The van der Waals equation does predict the formation of liquid phase but its agreement with experimental data is limited for conditions where liquid forms. The Redlich-Kwong (RK) equation, a two-parameter equation, was 
introduced in 1949 as an improvement to van der Waals equation. Although this equation is superior over the previous equations of state, it cannot be used to predict the vapour-liquid equilibrium properties. Later a third parameter was added to the cubic equations of state and an accurate prediction was taken using Soave-Redlich-Kwong (SRK) and Peng Robinson (PR) equations in year 1972 and 1976. SRK and PR are the most commonly used equations of state in natural gas processing industries. The cubic equations have the following general form (Jacobsen et al., 1997):

$$
p=\frac{R T}{v-b}-\frac{a}{v^{2}+u b v+w b^{2}}
$$

Where $b, u$, and $w$ are constants and $a$ is a function of temperature and has dimensions of $P v^{2}$. The quantities $v$ and $R$ may be expressed on either mass or molar basis.

\subsubsection{BASIC FLUID FLOW EQUATIONS}

The basics equations of fluid flow can be derived from the principles of mass, energy and momentum conservation as well as laws of thermodynamics (Fox and McDonald, 1985). A fixed control volume can be used to develop the general governing equations between two points for the flow stream:

Continuity equation:

$$
\frac{\partial}{\partial t} \int_{c v} \rho d V+\int_{c s} \rho \vec{\rho} \cdot \overrightarrow{d A}=0
$$


Momentum equation:

$$
F_{s}+F_{B}=\frac{\partial}{\partial t} \int_{c v} V \rho d V+\int_{c s} V \rho \overrightarrow{\rho V} \cdot \overrightarrow{d A}
$$

First law of thermodynamics:

$$
\dot{Q}-\dot{W}_{s}-\dot{W}_{\text {shear }}-\dot{W}_{\text {other }}=\frac{\partial}{\partial t} \int_{c v} e \rho d V+\int_{c s}(e+p v) \rho \vec{V} \cdot d \vec{A}
$$

Second law of thermodynamics:

$$
\int_{c s}^{1} \frac{1}{T} \frac{\dot{Q}}{A} d A \leq \frac{\partial}{\partial t} \int_{c v} s \rho d V+\int_{c s} s \rho \vec{V} \cdot \overrightarrow{d A}
$$

Certain assumptions will be made to simplify the governing equations for each condition.

\subsubsection{QUASI-ONE DIMENSIONAL FLOWS}

In most of the high-speed gas flows within a duct as the cross sectional area varies along the duct, pressure, temperature, density and velocity changes downstream of the duct. But the flow direction will remain approximately the same. This is called quasi one-dimensional flow. This type of analysis is a useful estimate to study the response of the compressible flow to alternations in area, addition of mass, momentum, and energy. The quasi one-dimensional assumption can be applied to a duct or channels where the length along the flow direction is much larger than the width. Nozzles are one of the common examples of this geometry. 


\subsubsection{STAGNATION PROPERTIES}

Stagnation state is a theoretical state in which the flow is brought to complete rest in an isentropic process. To specify the compressible flow stagnation properties the isentropic processes is considered. Stagnation properties are the reference properties of the fluid if it is decelerated to zero velocity. For ideal gas the equations for the stagnation properties have been specified and exist in literature (Fox and McDonald, 1985). The following equations show the calculations for stagnation pressure, temperature, and density respectively:

$$
\begin{aligned}
& \frac{P_{0}}{P}=\left[1+\frac{k-1}{2} M^{2}\right]^{k / k-1} \\
& \frac{T_{0}}{T}=1+\frac{k-1}{2} M^{2} \\
& \frac{\rho_{0}}{\rho}=\left[1+\frac{k-1}{2} M^{2}\right]^{1 / k-1}
\end{aligned}
$$

For real gas stagnation properties can be found by solving the basic equations along with a suitable equation of state for compressible, steady state, one dimensional isentropic flow where heating loss and system works and gravity forces are negligible. The basic equations will be simplified as follows (Fox and McDonald, 1985): Continuity equation:

$$
\rho_{1} V_{1} A_{1}=\rho_{2} V_{2} A_{2}=\rho V A=\dot{m}=\mathrm{cons} \tan t
$$


Momentum equation:

$$
R_{x}+p_{1} A_{1}-p_{2} A_{2}=\dot{m} V_{2}-\dot{m} V_{1}
$$

Where $R_{x}$ is the surface force acting on the control volume.

First law of thermodynamics:

$$
h_{0}=h_{1}+\frac{V_{1}^{2}}{2}=h_{2}+\frac{V_{2}^{2}}{2}
$$

$h_{0}$ is the stagnation enthalpy which is constant throughout an adiabatic flow field.

Second law of thermodynamics for an isentropic (constant entropy) flow can be written as follows (Fox and McDonald, 1985):

$$
S_{2}=S_{1}=S
$$

\subsubsection{SPEED OF SOUND}

The terms subsonic and supersonic refer to the conditions where the fluid velocities are less and greater than the speed of sound - an important characteristic for compressible flow systems. By solving the continuity and momentum equations for steady state and uniform flow conditions and assuming that the process is reversible and adiabatic, as there is very little time for heat transfer in sound wave propagation, the 
speed of sound can be calculated using the following equation:

$$
c=\sqrt{\left(\frac{\partial P}{\partial \rho}\right)_{\mathrm{s}}}
$$

To calculate the speed of sound for ideal gas a simplified equation based on the ideal gas law is available (Fox and McDonald, 1985). Mach number is defined as the ratio of the local fluid speed to the speed of sound.

\subsubsection{SHOCKWAVE}

Shockwave is an irreversible discontinuity that happens if the flow can not achieve the exit properties with the same conditions at upstream of the shock. During this process, large change in pressure, temperature, and other properties including entropy can occur in a small distance and the supersonic flow becomes subsonic. The thickness of a shock is about $0.2 \mu m$ (Fox and Mc Donald, 1985). As the shock thickness is small, the cross section areas at the upstream and downstream of the shock are equal and the energy and heat loss is negligible. For each upstream condition of a shock, there is a single unique downstream state. The basic equations can be simplified as shown below to calculate the properties on both sides of the normal shockwave: 
Continuity equation:

The cross sectional area upstream and downstream of the shock is equal as the shock is very thin therefore:

$$
\rho_{1} V_{1}=\rho_{2} V_{2}=\frac{\dot{m}}{A}
$$

Momentum equation:

$$
p_{1} A_{1}-p_{2} A_{2}=\dot{m} V_{2}-\dot{m} V_{1}
$$

First law of thermodynamics:

$$
h_{0}=h_{1}+\frac{V_{1}^{2}}{2}=h_{2}+\frac{V_{2}^{2}}{2}
$$

$h_{0}$ is the stagnation enthalpy which is constant throughout an adiabatic flow field.

Second law of thermodynamics:

Through the shockwave, the flow is irreversible as the discontinuous property change happens, as a result the entropy across the shock increases:

$$
S_{2}>S_{1}
$$

Shock strength can be determined by the pressure increase across the shock (Greitzer et al., 2004).

\subsection{SupERSONIC NOZZLES}

The supersonic nozzle, which is the main part of the proposed dehydration unit, is 
a tube, which is pinched in the middle. The nozzle is composed of three sections: the converging section (subsonic zone), throat (critical zone), and diverging section (supersonic zone) ( see figure 2.10) .

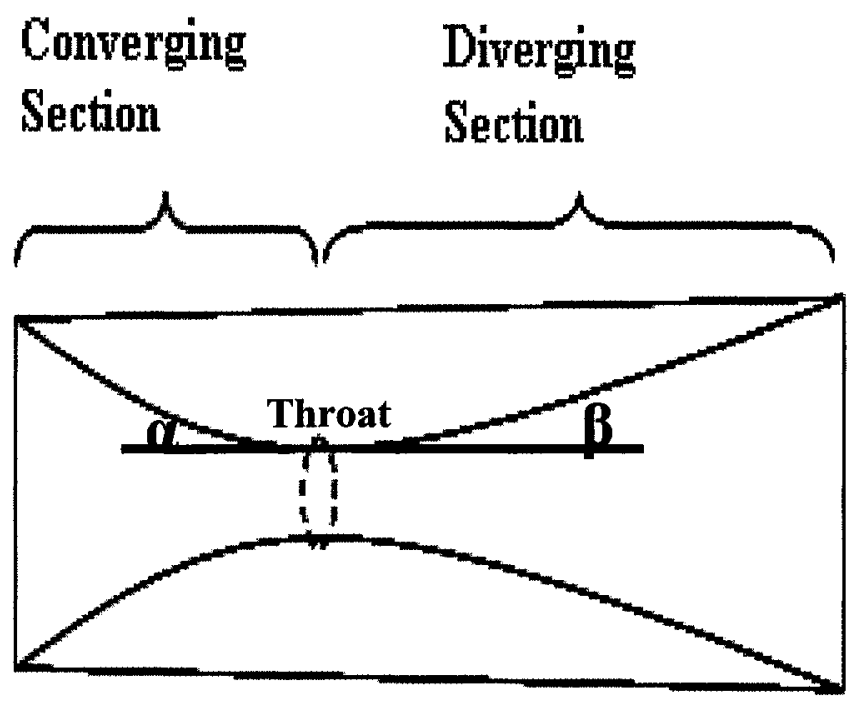

Figure 2.10: Different parts of a supersonic nozzle

Due to the constant flow rate, flow acceleration happens in the pipe carrying the flow as it narrows. Therefore, the function of the converging part is to accelerate the gas as well as keeping the flow uniform and parallel. In practical conditions, in order to get the sonic speed at the throat where the cross sectional area is minimum, usually the inlet diameter is kept larger than $\sqrt{5}$ of the throat diameter and the converging length is equal to or greater than the throat diameter (Man et al., 1997). Once the inlet thermodynamic conditions and the variation of the cross section area of the nozzle as a function of distance are defined, the outlet conditions will also be uniquely defined (Moraitis and 
Akritidis, 1997). Figure 2.11 shows the different possibilities for the exit pressure of the nozzle and Figure 2.12 ouline the velocity distribution in the supersonic nozzle. If the mass flow rate is not sufficient to provide the desired pressure drop, the flow will be subsonic all the way through nozzle (see figure 2.11 and 2.12 line A). It accelerates in the nozzle and gets the minimum pressure and the maximum velocity in the minimum cross section of the nozzle, and decelerates in the diverging part of the nozzle. In this condition, the minimum area is not considered as the throat. The flow rate should increase until the flow velocity reaches the sonic velocity where the Mach number is close to unity in the minimum cross section of the nozzle. This smallest cross section is called the throat of the nozzle where the flow is called choked flow. The flow rate, in which choked flow happens, is the maximum possible flow for the specific nozzle geometry and the inlet condition (Fox and Mc Donald, 1985). If the choked flow never happens inside the nozzle because of insufficient mass flow rate, the flow will never accelerate to supersonic velocity. However, the sonic flow in the throat might become subsonic or supersonic as the cross sectional area increases in the diverging part of the nozzle. This depends on the ratio between the inlet stagnation pressure and the backpressure (ambient pressure at the exit of the nozzle). At a certain ratio between inlet and back pressure the exit flow is subsonic and most of the pressure will be recovered before any further compression happens (see line B, Figure 2.11 and 2.12). These exit properties will be called "Nozzle recovery properties" from now on in this thesis. If the flow is supersonic in the diverging part of the nozzle and no pressure recovery happens, 
the outlet nozzle condition is called the "design condition" and the exit flow remains supersonic (line D, Figure 2.11 and 2.12 ). The properties in the design condition are called "Nozzle design properties "in this thesis. The nozzle subsonic pressure and the design pressure will be achieved if the backpressure is equal to the exit pressure of the nozzle. Line $\mathrm{C}$ indicates a case where a normal shockwave happens inside the diverging part of the nozzle. The normal shock happens if the backpressure falls between the nozzle's subsonic and design pressure. This nozzle is called over-expanded because the pressure at some point is less than backpressure. In an over expanded nozzle, a shockwave happens either inside or outside of the diverging part of the nozzle which results in pressure recovery. If the shock wave happens inside the diverging part of the nozzle, the back pressure and the exit pressure are equal. But in the conditions where the shock wave happens outside the diverging part but still between the subsonic and design pressure, the exit pressure is lower than the back pressure. Shockwave location is related to the inlet to back pressure ratio.

The nozzle with the backpressure less than the design pressure is called underexpanded as some of the expansion will occur outside of the nozzle. 


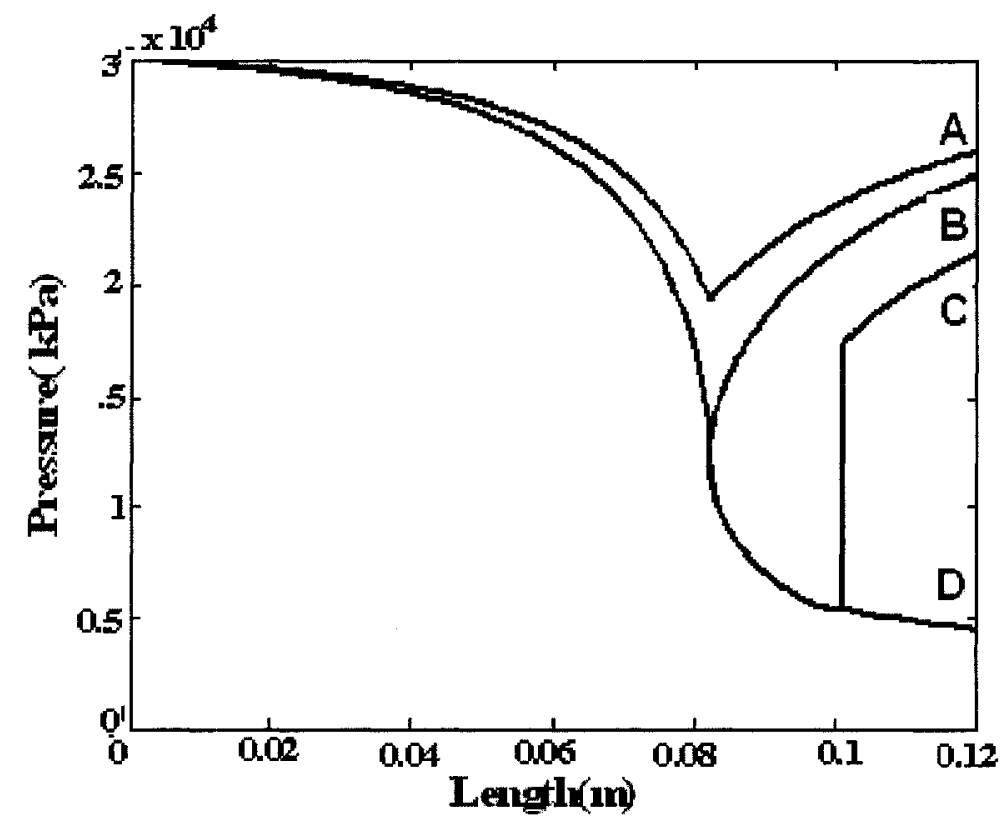

Figure 2.11: Different possible exit pressures in a Laval nozzle

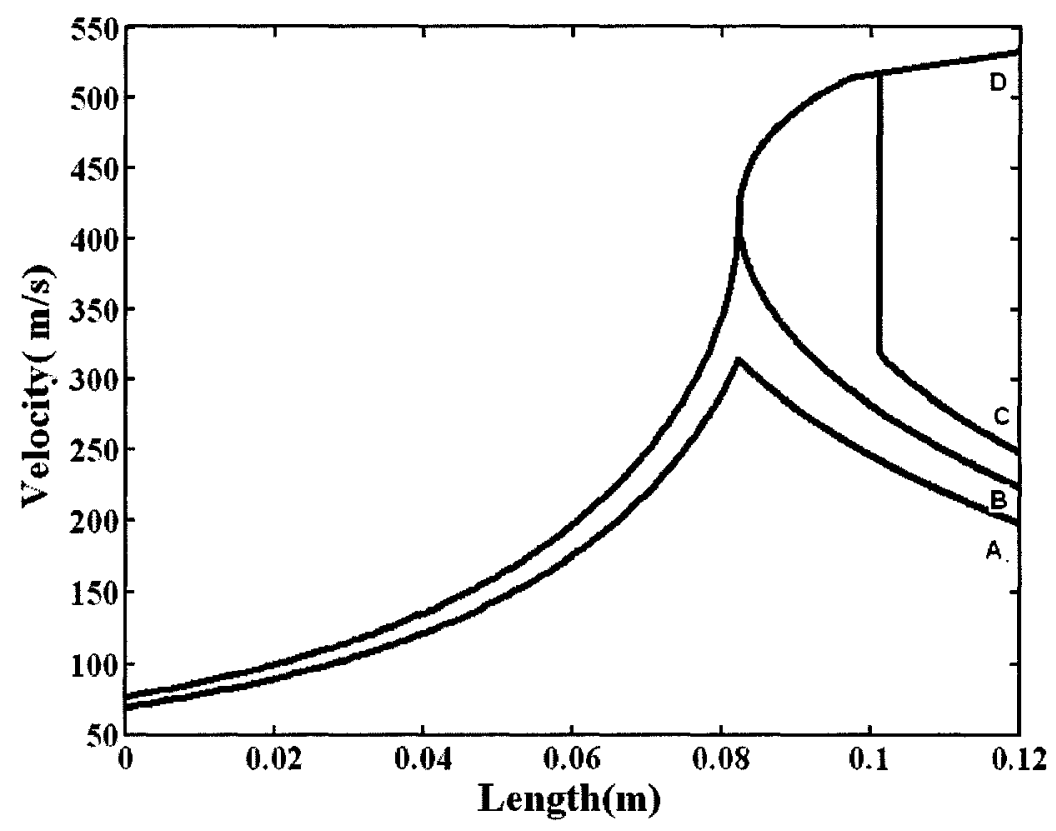

Figure 2.12: Velocity distribution in a Laval nozzle 
Nozzle exit cross section area depends on not only the total length of the nozzle but also the throat location inside the nozzle. Throat location depends on the flow properties and needs to be determined as the first step to design a nozzle. 


\section{Chapter 3: Modeling of Supersonic Nozzles}

\subsection{Modelling APPROACH}

This thesis focuses on modelling and designing the proposed supersonic dehydration system. The main part of the system is a converging-diverging nozzle, also known as the Laval nozzle. In the modelling approach two different software packages are linked: MATLAB, a numerical computing environment and programming language and HYSYS, a process modeling and simulation software. Connecting these two software packages leads to a powerful simulation tool to study new processes (Beronich et al., 2005) and helped this study to analyze various process alternatives.

As the stream pressure and temperature is reduced by gas expansion within the nozzle, the water vapour starts to condense to the aqueous phase. The condensed liquids (including possibly natural gas liquids in case the pressure is below the cricondenbar) should be removed from the gas stream before the nozzle diverges downstream of the shockwave (see Figure 3.1). Some gas leaves the nozzle together with the liquids, which should be separated and returned to the main gas leaving the nozzle at the exit. The nozzle should be designed such that the gas leaving at the exit contains the desired level of water and/or heavier hydrocarbons.

It is not the purpose of this work to focus on the ways by which these liquids could be separated within the nozzle; however, there are various techniques the liquid drop out could be separated (Alfyorov et al., 2005). 


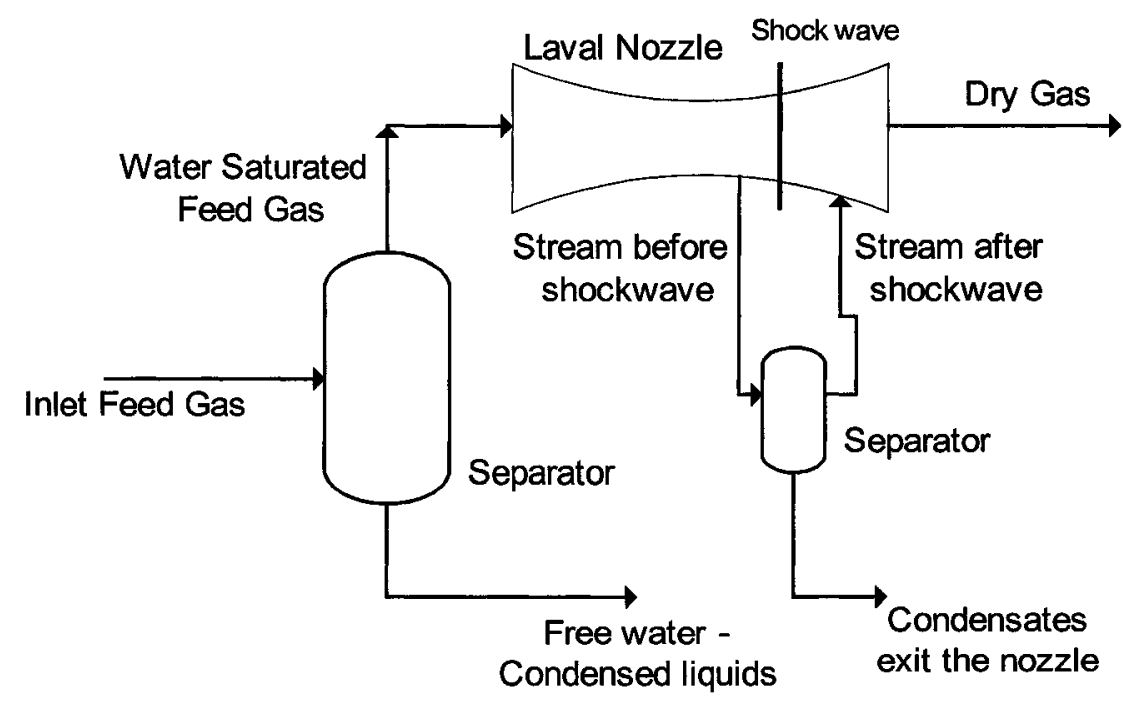

Figure3.1: Schematic diagram of a supersonic dehydration unit

The first step to solve a nozzle is predicting the behaviour of the stream which flows through the nozzle. Therefore, a MATLAB program was developed to solve the governing equations of the system such as the continuity and momentum equations as well as the first and second laws of thermodynamics. Besides, an equation of state is needed to calculate the thermodynamic properties of the gas stream such as density, viscosity, enthalpy, and entropy. The HYSYS process simulator was used to predict gas properties using commonly used thermodynamic models and fluid properties estimation techniques. The link between MATLAB and HYSYS gives simulation model the capability of working with different EOSs. Input parameters to HYSYS are gas composition, inlet temperature, pressure and the flow rate. Free water is almost always present at well head conditions and it is assumed that the produced gas is saturated before 
entering the process (Kidnay and Parrish, 2006). The simulation was started with a dry gas composition. A mixer was introduced in the simulation to saturate the feed gas with water. Natural gas can hold different amounts of water at different conditions of pressure and temperature. Natural gas saturation capacity increases as temperature increases and pressure decreases. As the dry stream becomes saturated, there will be a change in composition, inlet temperature, and flow rate of the gas stream. Condensation of water causes a reduction in water dew point and a reduction in water content of the gas.

The flow through the nozzle is assumed to be supercritical, steady state, one dimensional and compressible with no heat exchange. Two different cases for this process were considered:

\subsubsection{ISENTROPIC, ADIABATIC, AND FRICTIONLESS MODELING}

The simplified conservation equations in the isentropic flow are as follows:

$$
\begin{aligned}
& \rho_{1} V_{1} A_{1}=\rho_{2} V_{2} A_{2}=\rho V A=\dot{m}=\mathrm{constant} \\
& h_{0}=h_{1}+\frac{V_{1}^{2}}{2}=h_{2}+\frac{V_{2}^{2}}{2} \\
& S_{2}=S_{1}=S
\end{aligned}
$$

By solving these equations, momentum equation will be satisfied automatically.

$$
R_{x}+p_{1} A_{1}-p_{2} A_{2}=\dot{m} V_{2}-\dot{m} V_{1}
$$


Where $R_{x}$ is called the thrust and can be defined as $\left(\frac{P_{1}+P_{2}}{2}\right)\left(A_{1}-A_{2}\right)$.

A suitable equation of state is needed to predict the necessary properties. For the real gas assumption, the Peng-Robinson model was used here as the equation of state.

The ideal gas assumption was also made and the pertinent equations were included in the simulation program so that a comparison between real and ideal gas behaviour could be made. The only difference between the equations for real and ideal gas is the equation of state. Ideal gas law is used as the equation of state in ideal gas assumption. In this case, there will be no need to solve equations numerically as the simplified equations are already available in the literature (Fox and Mc Donald, 1985). In ideal gas flow, stagnation properties can be found by substituting the inlet properties in these analytically derived equations. Stagnation properties will be constant throughout the steady state flow and properties at each section can be found with respect to these properties.

\subsubsection{MODELING WITH FRICTION}

In this case the flow is not isentropic and friction terms will be added to the equations (Ozalp, 2005). In frictional flow the mean incremental properties can be calculated using the following equation:

$$
\bar{\xi}_{c}=\frac{\xi_{c, 1}+\xi_{c, 2}}{2}
$$


The Reynolds number for each segment can be calculated using Equation 3.6:

$$
\left(\operatorname{Re}_{D}\right)_{c}=\frac{\bar{U}_{c} \bar{D}_{c}}{\bar{v}_{c}}
$$

It is known that the friction coefficient $(f)$ is a function of the Reynolds number $\left(\mathrm{Re}_{D}\right)$ and the surface roughness $(\varepsilon)$ and can be defined by the Colebrook (Ozalp, 2005) formula:

$$
\frac{1}{\sqrt{\bar{f}_{c}}}=-3.6 \log \left[\frac{6.9}{\left(\operatorname{Re}_{D}\right)_{c}}+\left(\frac{\varepsilon / \bar{D}_{c}}{3.7}\right)^{1.11}\right]
$$

Having the friction coefficient in each segment, shear stress (Equation 3.8) and the friction factor (Equation 3.9) will be found as follows:

$$
\begin{aligned}
& \bar{\tau}_{c}=\bar{f}_{c} \bar{\rho}_{c} \frac{\left(\bar{U}_{c}\right)^{2}}{2} \\
& \left(\bar{F}_{f}\right)_{c}=\bar{\tau}_{c} \pi \bar{D}_{c} \Delta x_{c}
\end{aligned}
$$

The frictional loss term can then be defined as:

$$
\bar{\Phi}_{c}=\frac{\left(\bar{F}_{f}\right)_{c} U_{c}}{\dot{m}}
$$

And the thrust is: 


$$
\bar{I}_{c}=\left(\frac{P_{1}+P_{2}}{2}\right)\left(A_{1}-A_{2}\right)
$$

Therefore, the following equations together with an equation of state need to be solved simultaneously to predict the system.

$$
\begin{aligned}
& \rho_{1} V_{1} A_{1}=\rho_{2} V_{2} A_{2}=\rho V A=\dot{m}=\text { constant } \\
& h_{1}+\frac{V_{1}^{2}}{2}=h_{2}+\frac{V_{2}^{2}}{2}+\bar{\Phi}_{c} \\
& p_{1} A_{1}-p_{2} A_{2}=\dot{m} V_{2}-\dot{m} V_{1}+\left(\bar{F}_{f}\right)_{c}+\bar{I}_{c}
\end{aligned}
$$

Which will satisfy the entropy equation where:

$$
S_{2}>S_{1}
$$

\subsection{NUMERICAL SOLUTION TECHNIQUE}

Solving all the equations analytically, is a time consuming process if not practically impossible, therefore, a numerical technique was chosen to design the nozzle. The Newton- Raphson (NR) method was used in this study. By using this method the nonlinear equations can be solved simultaneously to predict the nozzle unknown variables. In design and analysis of the supersonic nozzle, the goal is almost always predicting two variables, pressure and temperature. These variables can be computed by the Newtonian iteration. A two variable NR method can be developed by preparing the following matrix (Hollis, 1996). 


$$
\overrightarrow{G^{n+1}}=\overrightarrow{G^{n}}-\left|\frac{\partial E}{\partial G}\right|^{-1} \vec{F}
$$

Where $G$ shows the variables to be determined, $F$ includes the equations that should be satisfied and $n$ is the iteration level. All the derivatives in this simulation were computed numerically. The Newton-Raphson method was used in this simulation to solve the relevant equations for three different conditions. Equation 3.17 is the actual matrix used for each condition. Temperature and pressure are the variables to be determined and the general form of the Newton-Raphson method in this simulation is as described in Equation 3.16.

$$
\left[\begin{array}{l}
T \\
P
\end{array}\right]^{n+1}=\left[\begin{array}{l}
T \\
P
\end{array}\right]^{n}-\left[\begin{array}{ll}
\frac{\partial F_{1}}{\partial T} & \frac{\partial F_{1}}{\partial P} \\
\frac{\partial F_{2}}{\partial T} & \frac{\partial F_{2}}{\partial P}
\end{array}\right]^{-1}\left[\begin{array}{l}
F_{1} \\
F_{2}
\end{array}\right]
$$

If the flow is assumed to be isentropic, energy and entropy equations should be satisfied so $F_{1}$ and $F_{2}$ are as follows:

$$
\begin{aligned}
& F_{1}=h_{i-1}+\frac{v_{i-1}^{2}}{2}-\left(h_{i}+\frac{v_{i}^{2}}{2}\right)=0 \\
& F_{2}=S_{i-1}-S_{i}=0
\end{aligned}
$$

In a non-isentropic flow when friction is present $F_{1}$ and $F_{2}$ are described as Equations 3.20 and 3.21 , as entropy is not constant and the energy and momentum equations will be satisfied: 


$$
\begin{gathered}
F_{1}=h_{i-1}+\frac{v_{i-1}^{2}}{2}-\left(h_{i}+\frac{v_{i}^{2}}{2}+\bar{\Phi}_{c}\right)=0 \\
F_{2}=P_{i-1} A_{i-1}+\dot{m} v_{i-1}-\left(P_{i} A_{i}+\dot{m} v_{i}+\left(\overline{F_{f}}\right)_{c}+\overline{I_{c}}\right)=0
\end{gathered}
$$

To predict the properties downstream of the shock $F_{1}$ and $F_{2}$ are defined as equations 3.22 and 3.23 :

$$
\begin{aligned}
& F_{1}=h_{i-1}+\frac{v_{i-1}^{2}}{2}-\left(h_{i}+\frac{v_{i}^{2}}{2}\right)=0 \\
& F_{2}=P_{i-1} A_{i-1}+\dot{m} v_{i-1}-\left(P_{i} A_{i}+\dot{m} v_{i}\right)=0
\end{aligned}
$$

Where $i$ denotes the properties in the section that properties are to be defined and ${ }_{i-1}$ indicates the properties in the previous section.

In this method, an initial guess for pressure and temperature is made at each segment of known cross section area. The mixture density at the estimated pressure and temperature is then found using the EOS. As the flow rate is known, flow velocity can be predicted using the continuity equation. The actual properties are found by solving NR matrix.

\subsection{Design of the Nozzle}

In order to design a Laval nozzle, the following data should be predetermined:

- Nozzle inlet diameter

- Half convergent and divergence angle 
- Inlet temperature of the dry gas stream

- Inlet pressure of the dry gas stream

- Inlet flow rate of the dry gas stream

- Nozzle total length

Nozzle is designed if its geometry, throat diameter, and the converging and diverging lengths, is known. The flowchart in Figure 3.2 describes the nozzle design procedure. 


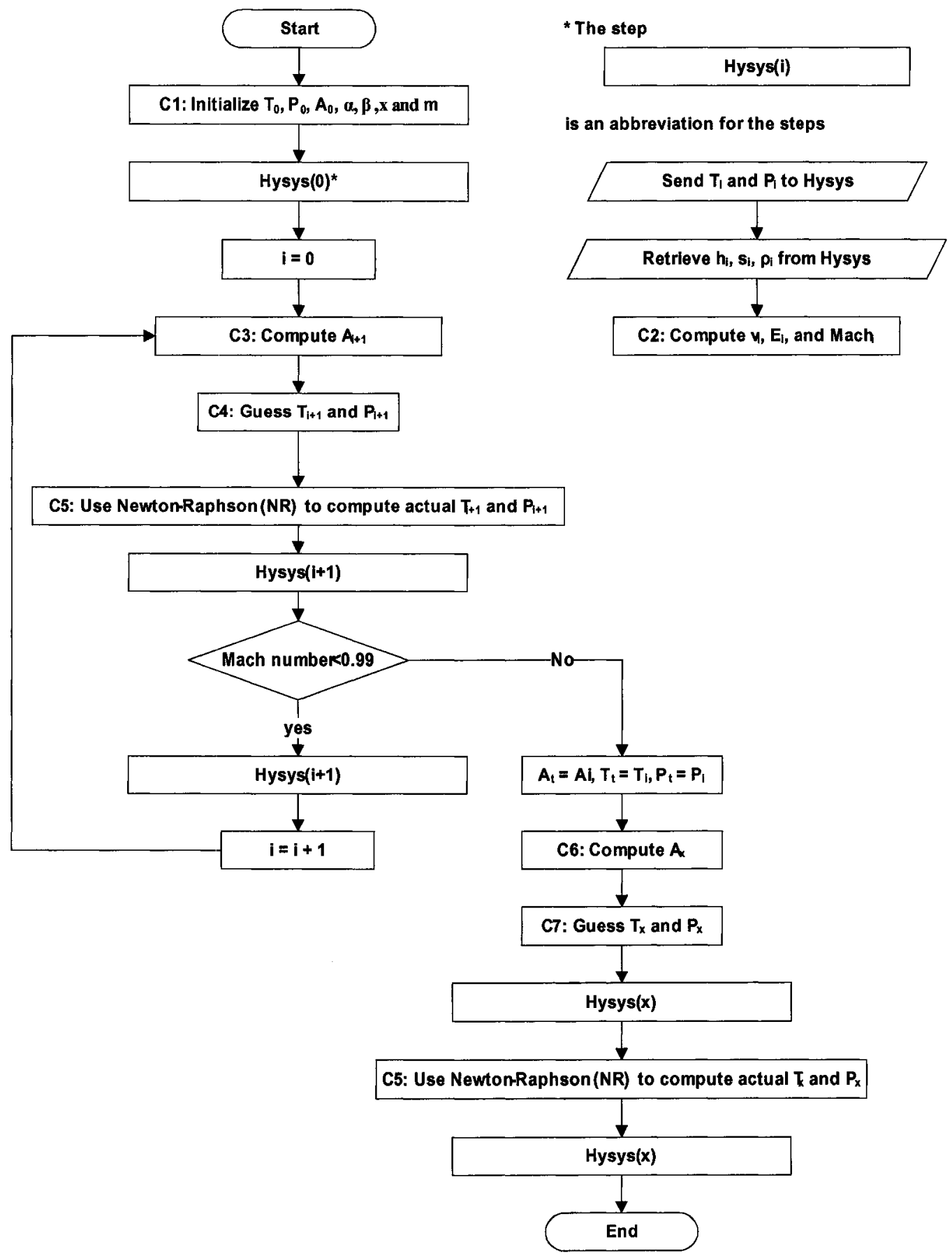

Figure 3.2: A flow chart for designing a nozzle 
In this flowchart, Step $\mathrm{C} 1$ indicates that the program requires the user for the input of inlet flow conditions and the fixed parameters in the nozzle geometry. These parameters are inlet temperature, pressure, flow rate, inlet cross section area and the half convergence and divergence angles, and the length increments. The flow inlet conditions are given to the HYSYS simulator and by retrieving the density, enthalpy and entropy form HYSYS and using the continuity equation, flow velocity can be found as indicated in Step C2. Also in this step the speed of sound and Mach number are computed, and the set of the necessary equations to use in Newton-Raphson method will be formed. These set of equations are Equations 3.18 and 3.19 for the isentropic flow and Equations 3.20 and 3.21 for considering the presence of friction. To form and solve the friction equation kinematics' viscosity is retrieved from HYSYS, too. In Step C3, $A_{i+1}$ is found having $A_{i}$ as the previous cross section area ( $i$ is the incremental index). In this study, it is assumed that the nozzle cross section area changes linearly with length. Figure 3.3 shows the schematic diagram of a typical Laval nozzle where $\alpha$ and $\beta$ are the convergence and divergence half angles respectively.

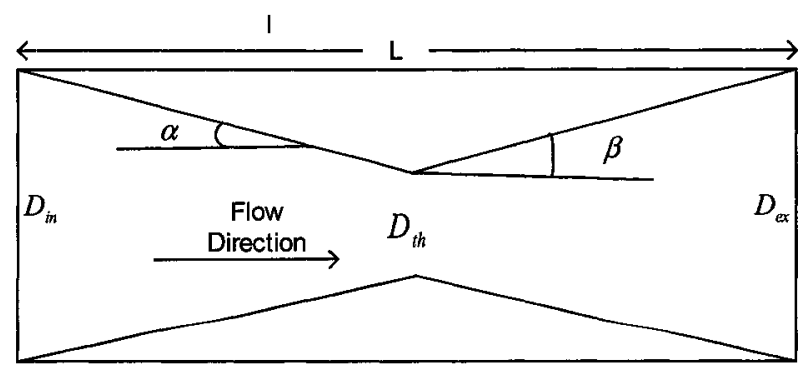

Figure3. 3: Schematic diagram of the supersonic nozzle 
The nozzle is divided to smaller increments of length " $x$ " and the flow properties at each incremental cross section area along the nozzle are calculated. In the assumed nozzle, the diameter at each increment will change with the following trend (Equation 3.18) in the converging part considering $D_{i n}$ as $D_{l}$ at the beginning.

$$
A_{i+1}=\pi\left(D_{i}-2 x \tan \alpha\right)^{2} / 4
$$

Step C4 asks the user for an initial guess for pressure and temperature to be used in the Newton-Raphson (NR) method. This initial guess is arbitrary; however, there might be an initial guess with which Newton-Raphson cannot converge. Using Newton-Raphson to calculate the actual pressure and temperature is done in Step C5. This process continues until the Mach number is greater than 0.99 , which is really close to unity. This last cross section area will be the throat of the nozzle. As the total length and the throat of the nozzle are known, the converging $\left(L_{-} c\right)$ and diverging $\left(L_{-} d\right)$ lengths can be calculated. As shown in Step C6, the nozzle exit cross section area $\left(A_{x}\right)$ will be found using Equation 3.19 and the throat diameter $\left(D_{t h}\right)$ and the half divergence angle of the nozzle.

$$
A_{e x}=\pi\left(D_{t h}+2 *\left(L_{-} d\right) \tan \beta\right)^{2} / 4
$$

Knowing the exit cross section area, pressure and temperature and other flow properties can be known at the nozzle exit. 


\subsection{RATiNG OF THE NozZLE}

In some situations the nozzle geometry is completely defined and the aim is to find the maximum possible flow rate and/or pressure and temperature distributions along the nozzle. If there is not enough flow rate in the system the overall pressure drop will be low, but at the same time the flow is not expanded to the sonic velocity and it will be subsonic everywhere in the nozzle. The flow in the system can be increased until the maximum flow rate can be found considering the sonic velocity and choked flow exist in the nozzle throat. Figure 3.4 illustrates the flow chart of rating a nozzle. As the first step (C1) to rate the nozzle, the user is asked for the initial inlet conditions such as pressure, temperature, the flow rate, and the complete nozzle geometry including the inlet, throat and outlet cross section areas. The necessary equations for the Newton-Raphson method will be formed in Step C2 by retrieving the enthalpy, entropy, density, and kinematics viscosity and by finding the velocity. In Step C3 an initial guess for pressure and temperature in the throat is made. The Newton-Raphson method is used to predict the actual pressure and temperature at the throat. If this method converges and the actual properties are found in the throat, Mach number at the throat will be computed and if the flow is choked (Mach number $>0.99$ ), the same procedure will be repeated (Steps C5 and C6) to find the exit pressure and temperature. If Mach number at the throat is less than 0.99 , the flow rate should be adjusted and the flow capacity is higher. In case the Newton-Raphson method does not converge to find the pressure and temperature in Step $\mathrm{C} 4$, the flow rate is more than the maximum possible flow rate and it is needed to be 
reduced. By dividing the converging and diverging length to smaller increments (defined as $d L_{-} c$ and $\left.d L \_d\right)$, pressure and temperature distribution along the nozzle can be found. To find the properties distribution in the nozzle, a parameter for a diverging length increment $\left(d L \_d\right)$ is defined and the cross section areas are computed using Equation 3.20 .

$$
A_{i+1}=\pi\left(D_{i}+2 *\left(d L_{-} d\right) \tan \beta\right)^{2} / 4
$$




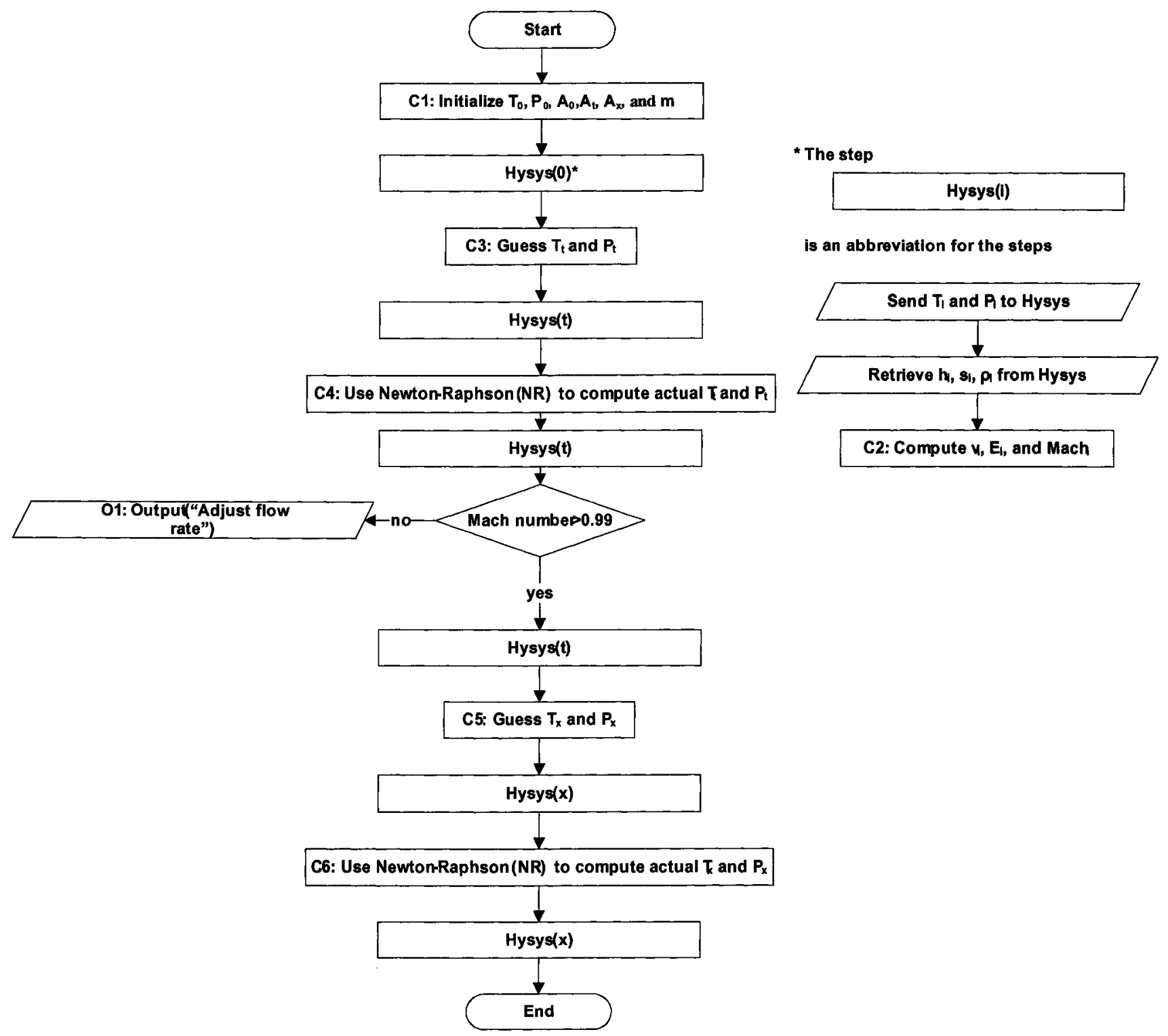

Figure 3.4: Flow chart for rating a nozzle 


\subsection{SHOCKWAVE PREDICTION}

After the nozzle is either designed or rated, it is time to find the properties such as pressure and temperature properties and predict the shockwave location (if happening). The flow expands as the nozzle converges and the flow pressure and temperature will be predicted using the Newton-Raphson method. The other properties such as density, velocity, and Mach number will be computed using the pressure and temperature. By reducing the pressure and temperature, the water in the flow starts condensing and the remaining water in the vapour phase is retrieved from the HYSYS. After the throat, depending on the backpressure of the nozzle, the pressure might recover without any further expansion or it might expand further down and become supersonic. Therefore, more liquid will be separated in the liquid phase. If the flow is supersonic in the diverging part of the nozzle, depending on the backpressure a shockwave may occur. The shockwave might happen inside or outside of the diverging part of the nozzle.

In this process a few shock locations were assumed at different lengths form the nozzle throat, in the diverging part of the nozzle. Since the pressure and temperature along the nozzle before the shock is predicted at each cross section area, the upstream properties of the shockwave are known. The condensed liquids should be separated before the shock. This process was simulated in HYSYS by using a separator (3.5). A vapour stream from the top of the separator enters the diverging part of the nozzle after the shock. A set of flow properties upstream of the shock are found. The flow properties 
in the rest of the nozzle are found with respect to the shock's downstream properties. Finally the exit properties, including the pressure recovery percentage are predicted as the exit nozzle cross section area is already known.

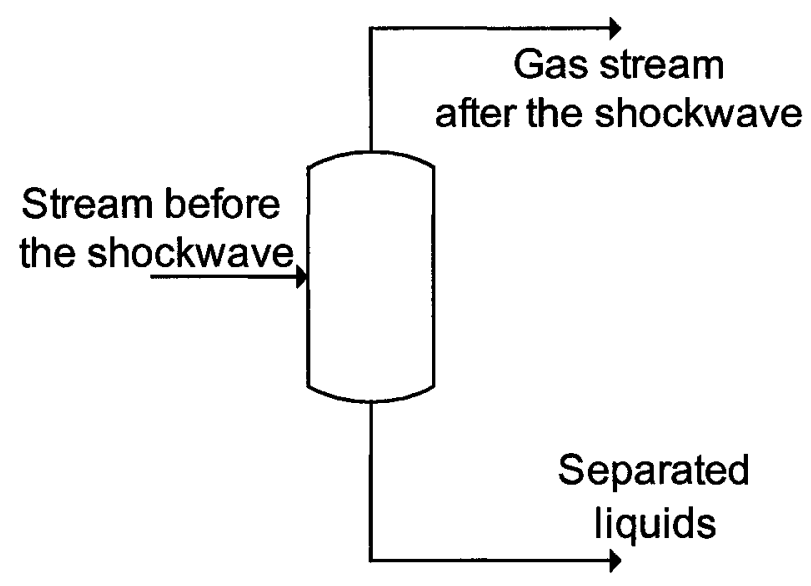

Figure 3.5: Process simulation to separate the condensed liquid.

If the selective water removal is required the pressure and temperature before the shock need to be kept above the cricondenbar and cricondentherm (Karimi and Abedinzadegan Abdi, 2006). There are several possibilities to keep the pressure and temperature such that the fluid remains in a single phase. The stream can be compressed to pressures well above critical pressure so the fluid remains in supercritical conditions all the way through the nozzle. The combination of high pressure with high temperature is another method of keeping the stream in a single phase. In a number of conditions of pressure and temperature (especially high pressures), the pressure recovery percentage 
can be chosen in order to predict the shockwave before hydrocarbon condensation happens while near to complete water removal is achieved. In lower pressure conditions, selective water removal can still be achieved but a higher pressure-recovery will result in less expansion in the stream and a reduction in the water removal efficiency. 


\section{Chapter 4: Analysis and Results}

\subsection{Model validation}

The proposed model to simulate the flow behaviour in the supersonic nozzles was validated by the computational fluid dynamics (CFD) modeling using commercial CFD software (Fluent). Unlike HYSYS, Fluent is limited to a few EOS and can only use a pure gas as the working fluid rather than a gas mixture. Therefore, in the CFD modelling, pure methane was considered as the working fluid and the modified Benedict Webb Rubin (MBWR) used as the equation of state. In this equation of state, pressure is an explicit function of temperature and density as shown in Equation 4.1:

$$
P=\rho R T+Y(\rho, T)
$$

Where function $Y$ includes 32 terms and 33 adjustable constants.

The nozzle geometry and other nozzle's parameters are shown in Table 4.1. The nozzle has a rectangular cross section area and the inlet and outlet cross section areas are 0.04 and $0.03\left(\mathrm{~m}^{2}\right)$, respectively.

Table 4.1: Nozzle geometry for validation with Fluent

\begin{tabular}{|l|l|}
\hline Nozzle inlet diameter $(\mathbf{m})$ & 0.0400 \\
\hline Nozzle throat diameter $(\mathbf{m})$ & 0.0163 \\
\hline Nozzle outlet diameter $(\mathbf{m})$ & 0.0300 \\
\hline Nozzle converging length $(\mathbf{m})$ & 0.0527 \\
\hline Nozzle diverging length $(\mathbf{m})$ & 0.1473 \\
\hline Nozzle total length $(\mathbf{m})$ & 0.2000 \\
\hline
\end{tabular}

To predict the flow behaviour in the supersonic nozzle with the proposed model 
in this thesis, pressure, temperature and the flow rate should be known as the inlet conditions. However, in CFD simulation, the inlet pressure and temperature are sufficient to predict the flow behaviour in the nozzle and the flow rate will be computed based on the inlet conditions. Fluent uses a rather complex k-e turbulent model and solves the governing partial differential equations using finite volume approach to predict the flow field behaviour. The proposed model in this thesis uses the simplified onedimensional conservation laws and other related thermodynamic relations discussed before in Chapter 3 to predict the variation of various parameters along the nozzle. Table 4.2 lists the inlet pressure and temperature. For the model used in this work, the inlet flow rate is predefined at $67,330 \mathrm{kmole} / \mathrm{h}(300 \mathrm{~kg} / \mathrm{s})$ and the predicted flow rate with CFD modelling is the same.

Table 4.2: Nozzle inlet flow conditions for validation

\begin{tabular}{|l|c|}
\hline Inlet temperature $\left({ }^{\circ} \mathrm{C}\right)$ & 18.5 \\
\hline Inlet pressure $(\mathbf{k P a})$ & 9,250 \\
\hline
\end{tabular}

The flow behaviour in the absence and presence of friction is predicted in both models. The results of this comparison with $75.67 \%$ inlet pressure recovery (backpressure of $7 \mathrm{MPa}$ ) are shown in Figures 4.1 to 4.5 . 


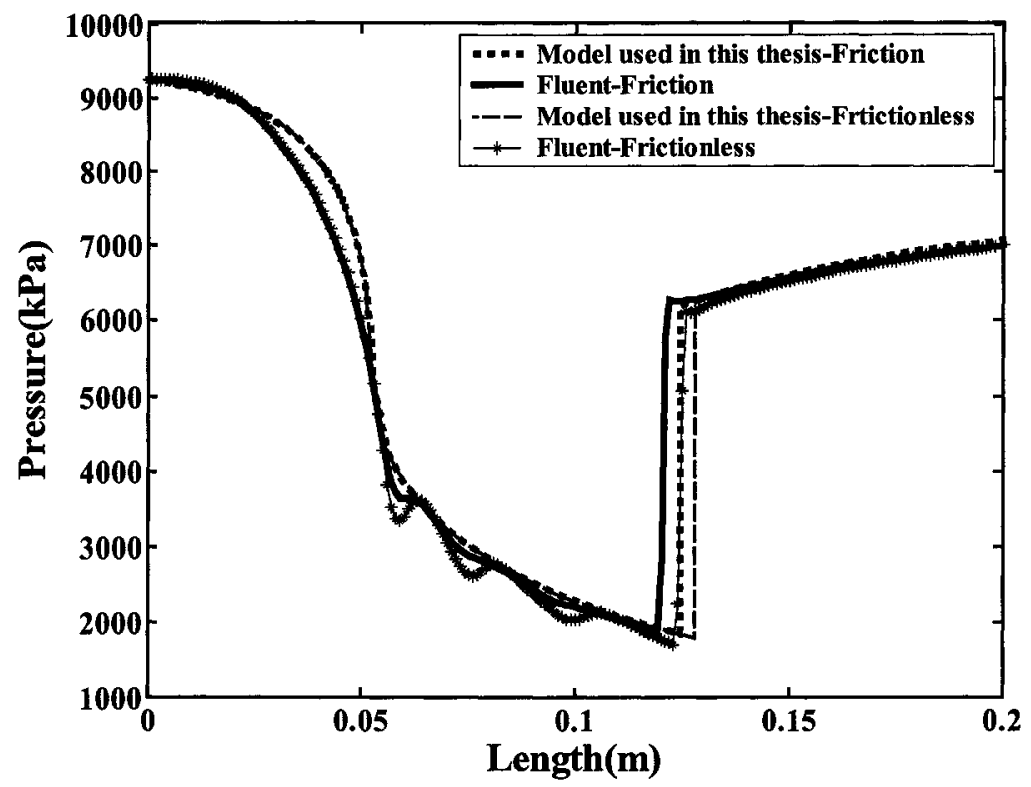

Figure 4.1: Pressure distributions and shockwave locations along the nozzle with $75.67 \%$ recovery of inlet pressure in the supersonic-CFD comparison study

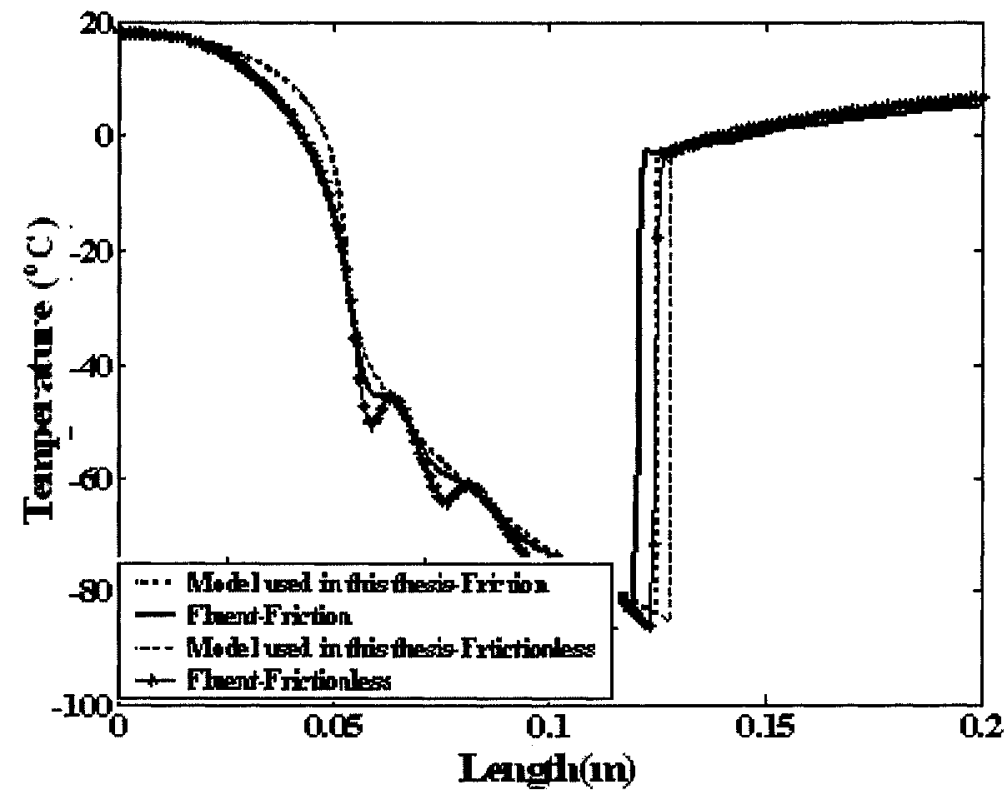

Figure 4.2: Temperature distributions and shock locations along the nozzle with $75.67 \%$ recovery of pressure inlet in the supersonic-CFD comparison study 


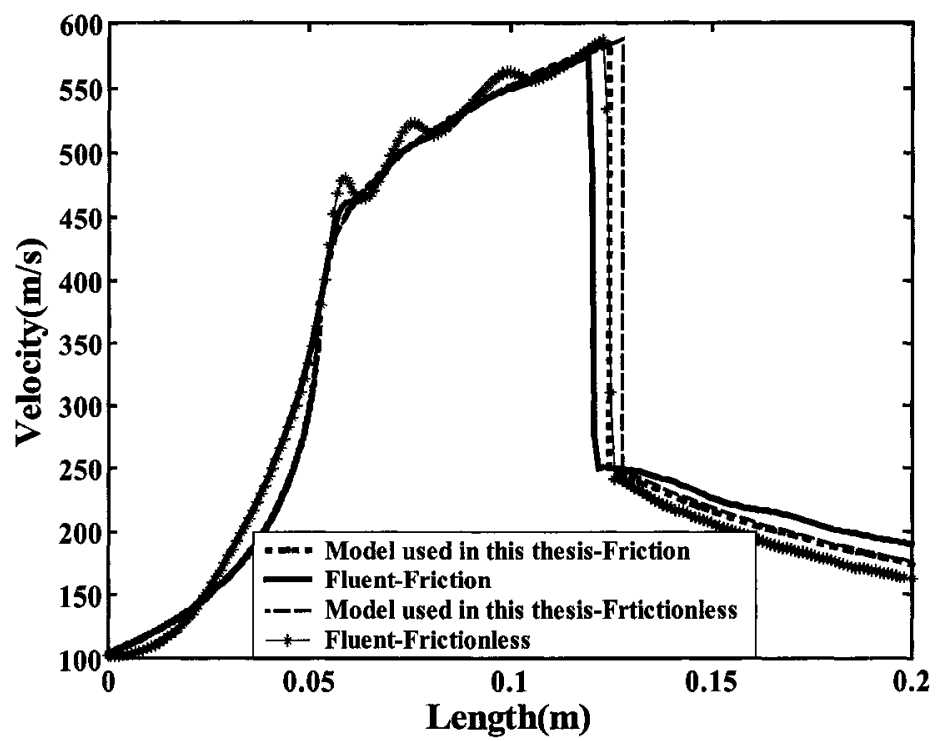

Figure 4.3: Velocity distributions and shock locations along the nozzle with $75.67 \%$ recovery of pressure inlet in the supersonic-CFD comparison study

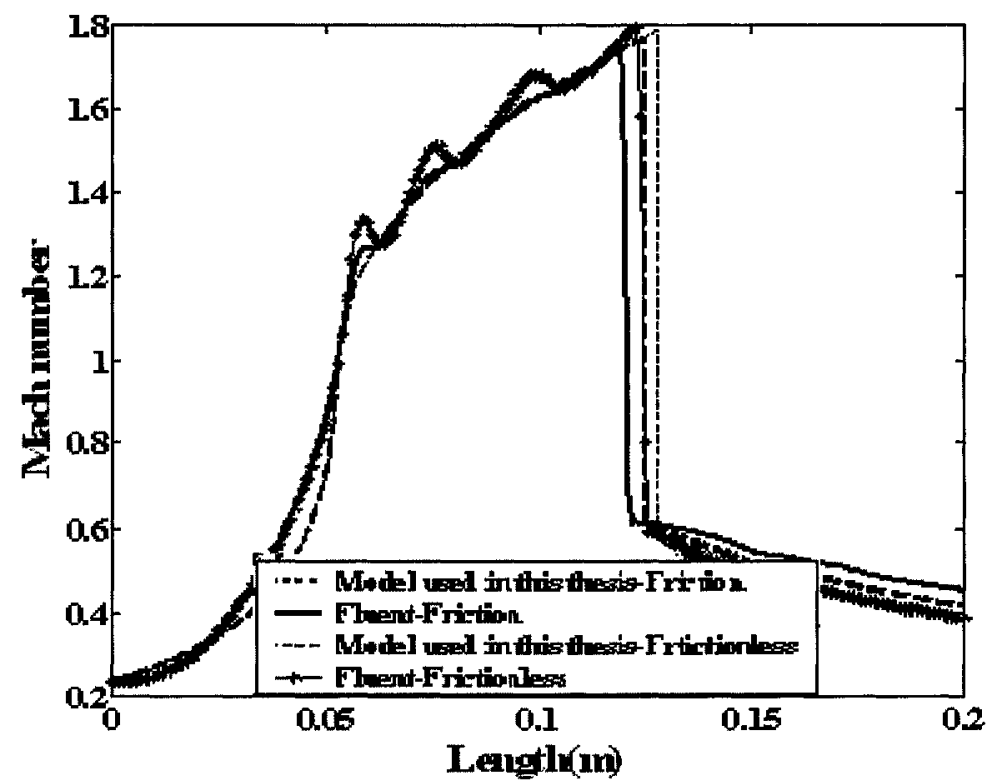

Figure 4.4: Mach number distributions and shock locations along the nozzle with $75.67 \%$ recovery of pressure inlet in the supersonic-CFD comparison study 


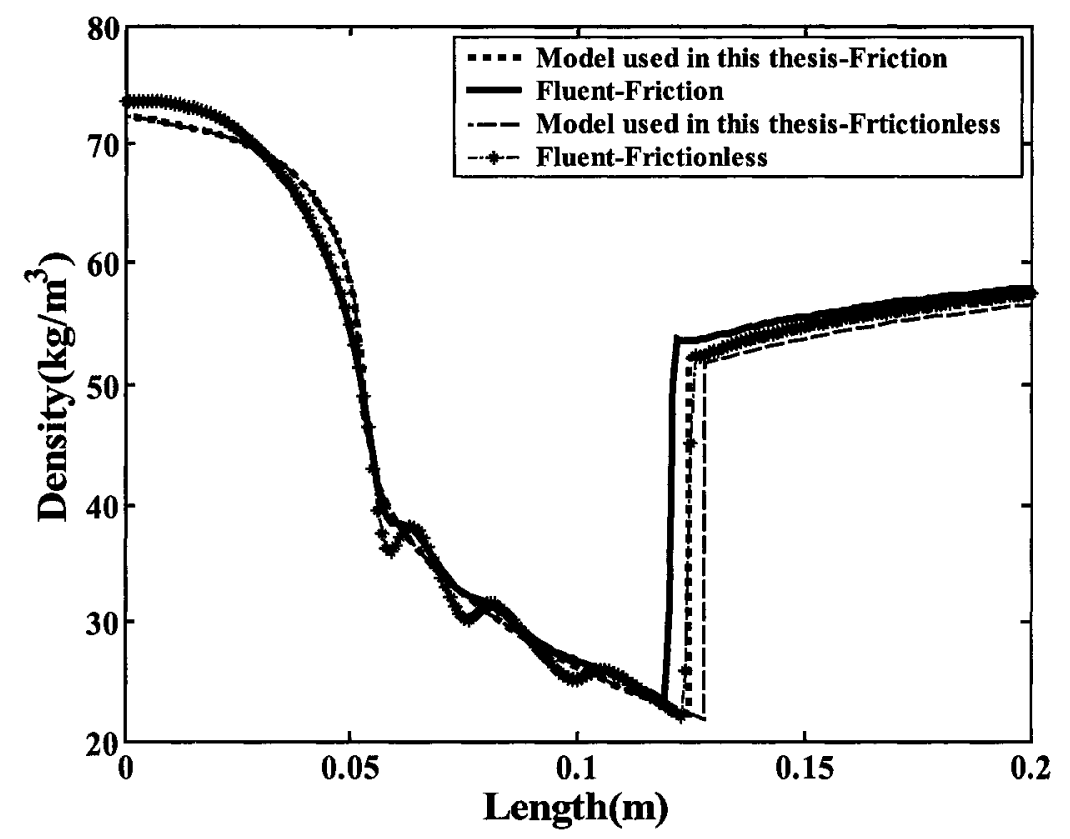

Figure 4.5: Density distributions and shock locations along the nozzle with $75.67 \%$ recovery of pressure inlet in the supersonic-CFD comparison study

Both simulations showed that the flow behaviour along the nozzle is not significantly affected by the presence of friction. The friction however changes the location of shockwave when it happens inside the nozzle. The shockwave location in the frictionless flow is ahead of the frictional flow and towards the nozzle exit. Table 4.3 shows the shock locations in both simulations, in the cases where friction is present, and in the frictionless case as a percentage of the total length.

Table 4.3: Shock location predicted with the two simulators ( $\%$ of total length)

\begin{tabular}{|l|c|c|c|}
\hline & Frictionless & Friction & \% Deviation \\
\hline CFD modeling & 61.5 & 59.5 & 3.25 \\
\hline Model used in this thesis & 64 & 62.25 & 2.73 \\
\hline
\end{tabular}


The flow behaviour predicted by the proposed method for supersonic separator agrees extremely well with the behaviour predicted by a complex computational modelling software (Fluent), giving rise to the accuracy of computational modelling and analyses preformed in this thesis. We could not claim that the result would also agree well with the actual nozzle performance until experimental tests are conducted. Such tests are beyond the scope of the current research work.

\subsection{VARIABLES EFFECTS}

A dry gas (a stream that does not contain water) with the composition shown in Table 4.4 is used in the simulation. It was assumed that the flow field is compressible, steady state, and one-dimensional.

Table 4.4: Dry gas composition for variable-effects studies

\begin{tabular}{|c|c|}
\hline Gas Components & Mole fractions \\
\hline Methane & 0.95 \\
\hline Ethane & 0.04 \\
\hline Propane & 0.01 \\
\hline
\end{tabular}

The natural gas water content depends on the stream conditions and the equation of state used. The dry gas stream was saturated with water in the HYSYS simulator to represent produced gas conditions. The gas is saturated in the HYSYS simulation using the appropriate equation of state assuming that natural gas is a real gas. In this simulation, the Peng-Robinson equation was used as the thermodynamic model to saturate the stream with water. In this process, a dry gas stream is mixed with free water 
in a mixer, until the stream is saturated with water. Saturated gas is separated from free water in a separator as the vapour outlet and is used as the working fluid for the supersonic nozzle. The saturation results from HYSYS were compared with the data from the McKetta charts (GPSA Databook,1998) and the descripency between the two methods were less than \pm 3 .

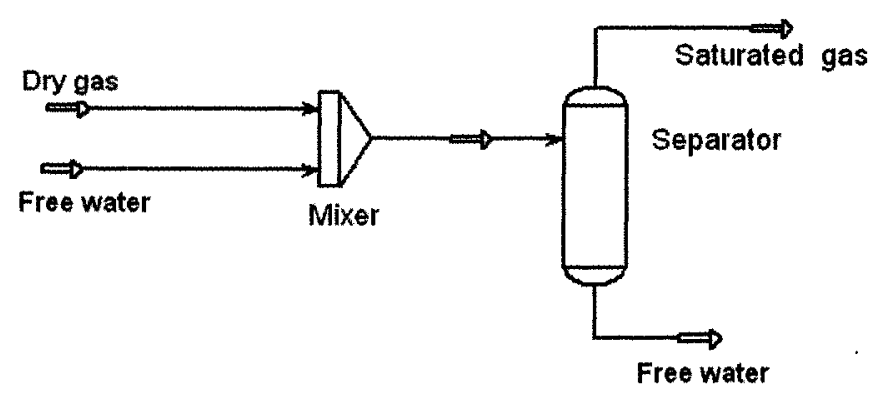

Figure4.6: Dry gas saturating in HYSYS simulator

In this study a dry stream with the inlet condition shown in Table 4.5 is defined as the base stream for all the simulations. This dry stream, after saturation, is called "Test Stream" in this thesis. Gas saturation will slightly change the stream temperature and flow rate. The inlet condition of the dry gas stream and the "Test Stream" are shown in Table 4.5. After the gas is saturated with water, the gas composition is changed. Table 4.6 shows the "Test Stream" composition.

Table 4.5: Gas inlet condition

\begin{tabular}{|l|c|c|}
\hline \multicolumn{1}{|c|}{ Stream Parameters } & Dry gas & Saturated gas \\
\hline Temperature $\left({ }^{\circ} \mathrm{C}\right)$ & 20.00 & 19.85 \\
\hline Pressure $(\mathrm{MPa})$ & 30 & 30 \\
\hline Molar flow Rate $(\mathrm{kmol} / \mathrm{h})$ & 5,000 & $5,001.14$ \\
\hline
\end{tabular}


Table 4.6: "Test Stream" gas composition

\begin{tabular}{|c|c|}
\hline Gas Components & Mole fractions \\
\hline Methane & 0.94970 \\
\hline Ethane & 0.39990 \\
\hline Propane & 0.09997 \\
\hline Water & 0.00023 \\
\hline
\end{tabular}

"Test Stream" behaviour in the supersonic nozzle such as properties distribution along the nozzle, shockwave location, and water removal efficiency are studied as functions of different variables such as the nozzle length, equation of state, pressure, temperature and flow rate and backpressure in the nozzle.

To design a supersonic nozzle in this condition, the nozzle inlet diameter, and the convergence and divergence half angles are fixed as shown in Table 4.7. These parameters are chosen arbitrarily.

Table 4.7: Fixed parameters used in the study of variable effects

\begin{tabular}{|l|c|}
\hline Nozzle inlet diameter $(\mathbf{m})$ & 0.04 \\
\hline Convergence half angle & $6.85^{\circ}$ \\
\hline Divergence half angle & $3.00^{\circ}$ \\
\hline
\end{tabular}

In this design, the total length of the nozzle is also fixed. The nozzle length is chosen arbitrarily but within a range found using the following procedure. For each flow inlet condition and the nozzle geometry, there is a unique cross section area in which the 
flow is choked (sonic velocity is reached). Therefore, the converging part in each nozzle is constant but the diverging part varies with the variation in the nozzle total length. The lower bound for the nozzle length is therefore where the nozzle turns to a mere converging nozzle and the total length is the distance from the nozzle inlet to the throat. The upper bound of the length is the longest length for which, at any flow rate smaller than the design flow rate, the exit pressure should not exceed the inlet pressure.

For the "Test Stream", the nozzle throat was designed and the converging part of the nozzle is found to be $0.082 \mathrm{~m}$. A stream with the pressure and temperature equal to "Test Stream" but with the molar flow rate lower than the design flow rate of 5,000 $k m o l e / h$ was introduced to nozzles with different lengths starting with the converging nozzle length. This molar flow rate is intentionally chosen very small to produce the lowest possible pressure drop in the longest possible nozzle where the exit pressure will be really close to inlet pressure. To simulate this situation, the nozzle length is increased gradually and the subsonic nozzle pressure is found for each condition. This process is continued until the longest nozzle length is found. The longest possible nozzle is when a tiny increase in the length will result in a subsonic nozzle pressure greater than the inlet pressure. The longest possible nozzle for the "Test Stream" is found to be $0.27 \mathrm{~m}$. Therefore, the chosen nozzle length should be between 0.082 and $0.27 \mathrm{~m}$. A short nozzle causes the high-pressure drop and long nozzle will result in a bigger nozzle. For this simulation, a nozzle of $0.12 \mathrm{~m}$ long is chosen.

A nozzle can be designed using the fixed parameters in the nozzle geometry and a 
gas stream with known inlet pressure, temperature, and flow rate as a working fluid. Table 4.8 indicates the designed nozzle specifications considering the fixed length of 0.12 $m$ for the nozzle.

Table 4.8: Nozzle specifications for "Test Stream"

\begin{tabular}{|l|l|}
\hline Nozzle throat diameter(m) & 0.021 \\
\hline Nozzle convergence length (m) & 0.082 \\
\hline Nozzle divergence length(m) & 0.038 \\
\hline Nozzle outlet diameter(m) & 0.024 \\
\hline
\end{tabular}

As the system of governing equations is solved, properties distribution along the nozzle will be known. For each designed nozzle, unique "recovery properties" and "design properties" exist. Different shockwave locations can be predicted by choosing different backpressures. Higher backpressure results in a higher pressure recovery. However, backpressure can not be higher than the nozzle "recovery pressure". Higher pressure recovery causes the shockwave to happen earlier in the nozzle. It can therefore be chosen such that the stream conditions can be kept in the dense gas phase in the phase envelope and consequently a selective water removal can be achieved.

\subsubsection{Influence of Equation of State}

The "Test Stream" behaviour as a real gas, which follows the peng-Robinson equation of state, was compared with the results of simulation assuming that the stream is an ideal gas. In order to predict the property distributions along the nozzle for the ideal gas case, the stream properties such as molecular weight and $k\left(C_{p} / C_{v}\right)$ for the ideal gas should be known. These properties can be extracted from standard physical properties 
handbooks such as GPSA Data book or from the HYSYS physical properties library.

To compare the behaviour under real and ideal gas assumptions, two approaches were used:

\subsubsection{DESIGNING A NEW NOZZLE USING IDEAL GAS}

As the first approach, a nozzle was designed using ideal gas law for the same stream conditions. Assuming a fixed nozzle length, the nozzle throat location was found considering the choked flow at the nozzle throat. Knowing the nozzle converging and diverging lengths, the outlet diameter will also be known (See Table 4.9).

Table 4.9: Designed nozzle specifications for an ideal gas

\begin{tabular}{|l|l|}
\hline Nozzle throat diameter(m) & 0.024 \\
\hline Nozzle converging length (m) & 0.067 \\
\hline Nozzle diverging length(m) & 0.054 \\
\hline Nozzle outlet diameter(m) & 0.030 \\
\hline
\end{tabular}

Figure 4.7 shows the geometry of the designed nozzle for the real gas and ideal gas assumptions. The nozzles geometry indicates that for the same inlet flow rate, the nozzle throat under ideal gas conditions is $18.34 \%$ larger than real gas which results in a $22 \%$ bigger outlet diameter. The length at which the ideal gas becomes choked is $18.8 \%$ shorter than the length for the real gas. 


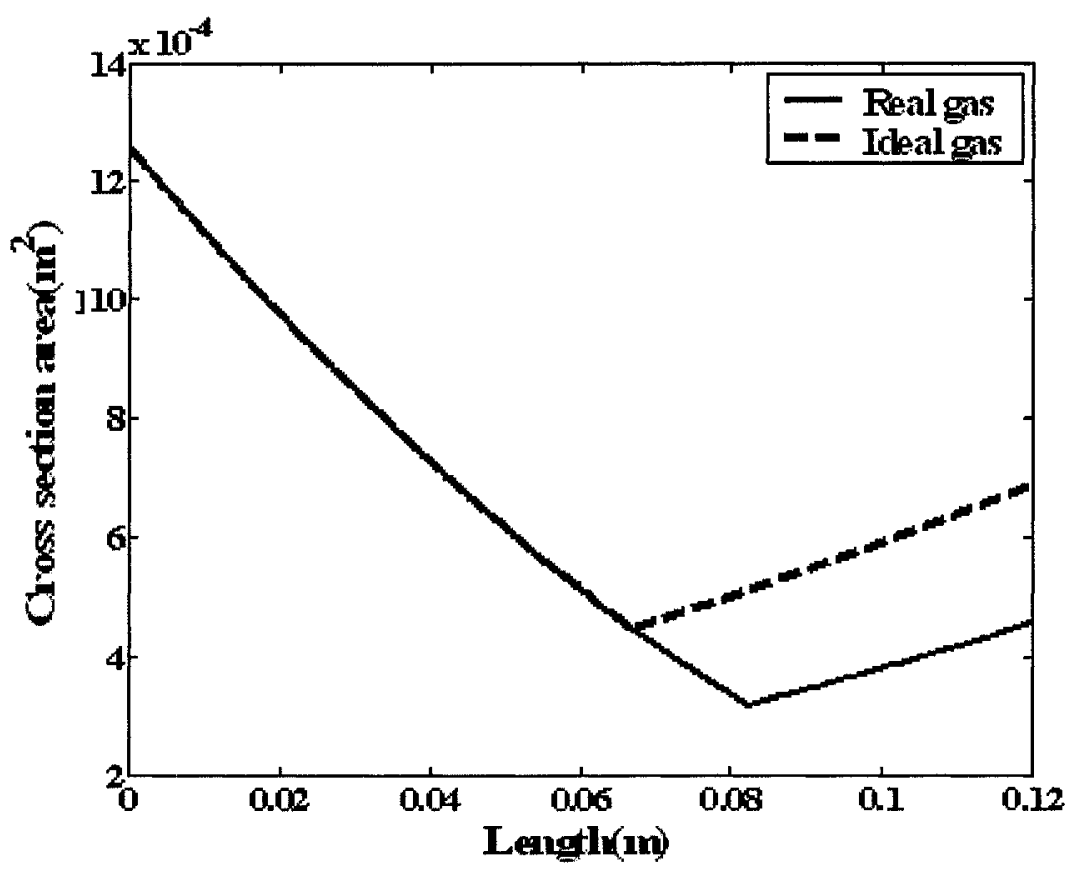

Figure 4.7: The geometry of the separated designed nozzle for ideal and real gas assumptions

In Figure 4.8, the nozzle subsonic pressures and nozzle design pressures for the two nozzles are presented and compared. The results show that ideal gas needs a longer nozzle to achieve the same pressure reduction as real gas. For the nozzle with the specified length in this example, the design pressure is $36.73 \%$ and the subsonic pressure is $11.6 \%$ lower for the real gas. As a result, the highest possible inlet pressure recovery is $92.3 \%$ in an ideal gas situation and $82.7 \%$ for real gas. 


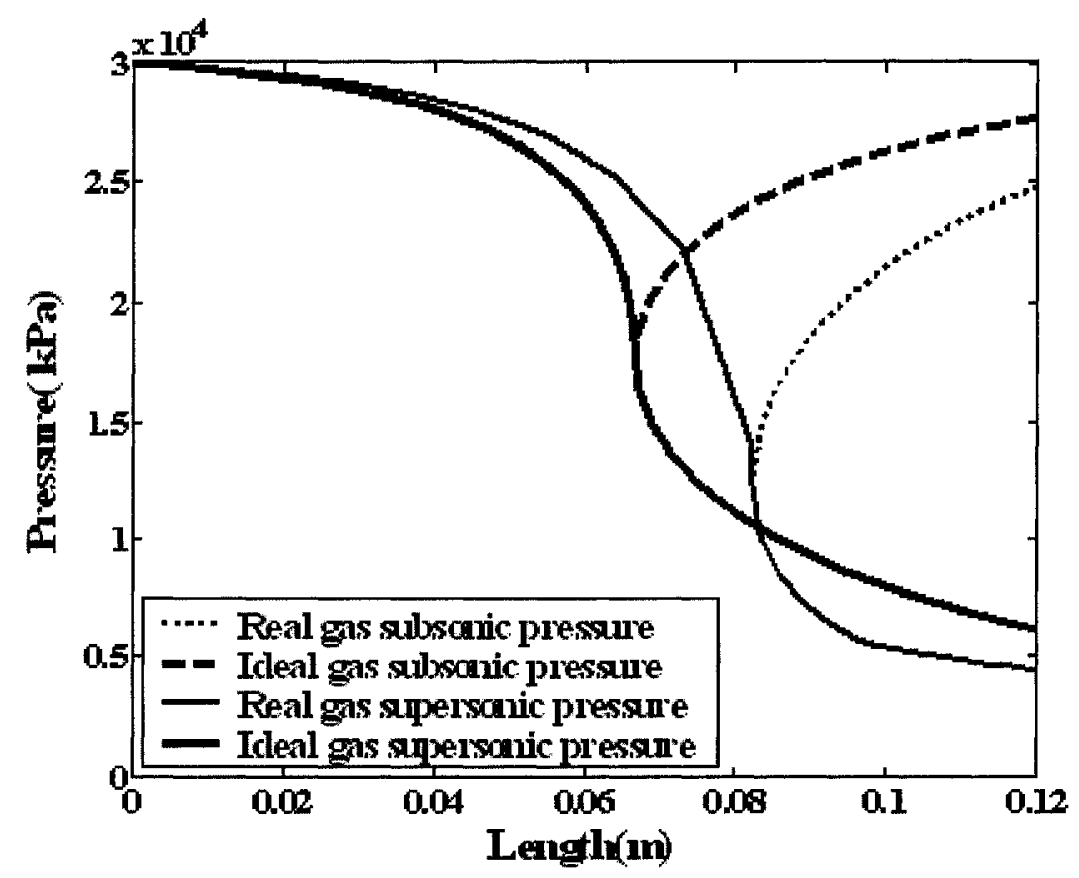

Figure 4.8: Pressure distributions along the separately designed nozzle for ideal and real gas assumptions

To be able to predict the shockwave location in the nozzle to partially recover the inlet pressure, backpressure should be chosen between the nozzle "recovery pressure" and "design pressure". Figure 4.9 presents the pressure distribution along the nozzle when a normal shockwave occurs to recover $70 \%$ of the inlet pressure (exit pressure of $21 \mathrm{MPa}$ ). The shockwave in the real gas nozzle happens at $85 \%$ of the nozzle length and in ideal gas, it shifts $12 \%$ toward the nozzle exit. In the real gas case, the pressure reduction before the shockwave is $82.42 \%$ of the inlet pressure and it reduces to $78.22 \%$ of the inlet pressure for the ideal gas case. 


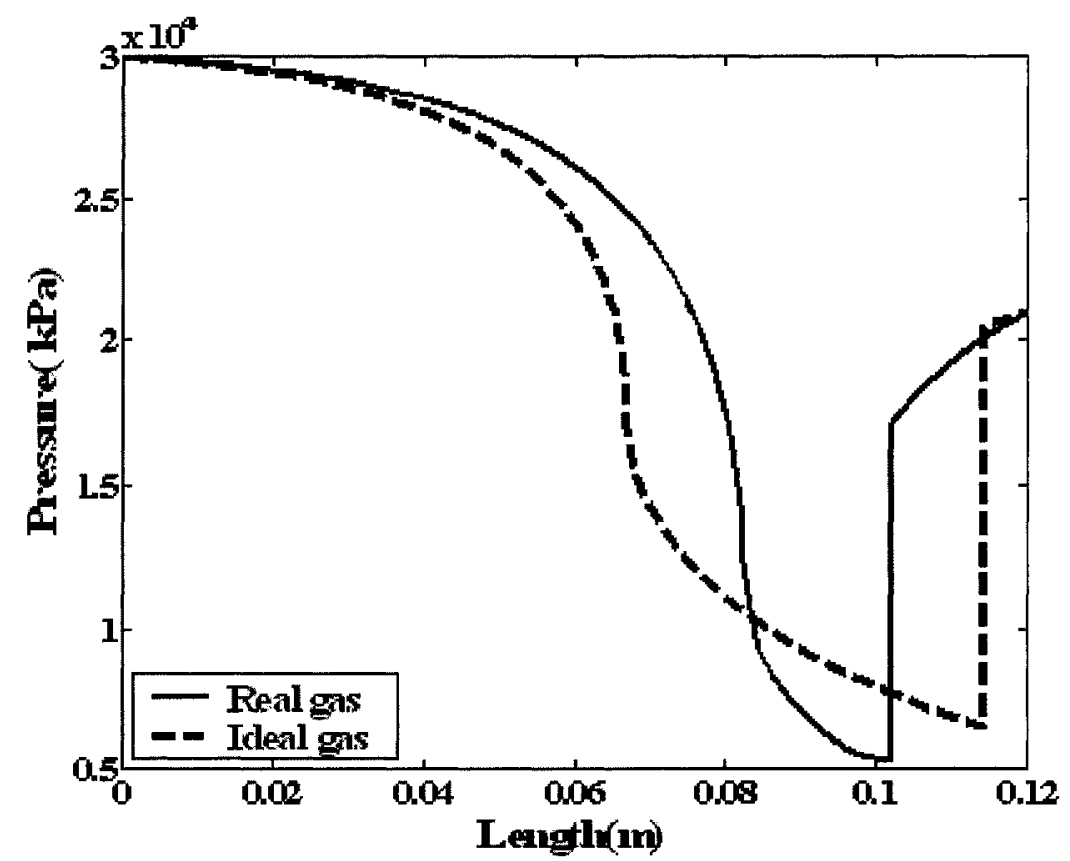

Figure 4.9: Pressure distribution and shockwave location along the designed nozzle for real and ideal gas assumptions with $70 \%$ inlet pressure recovery

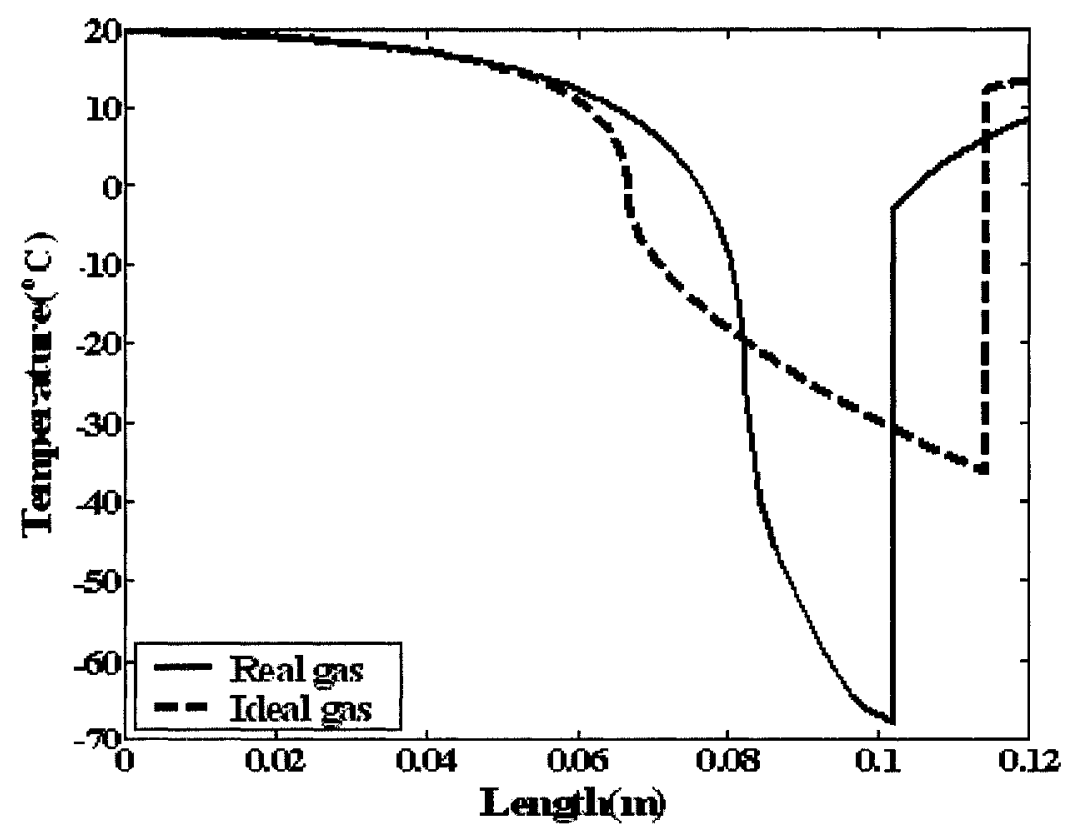

Figure 4.10: Temperature distribution and shockwave location along the designed nozzle for real and ideal gas assumptions with $70 \%$ inlet pressure recovery 
Figures 4.10 and 4.11 show the temperature and velocity distributions in the designed nozzles under ideal and real gas conditions.

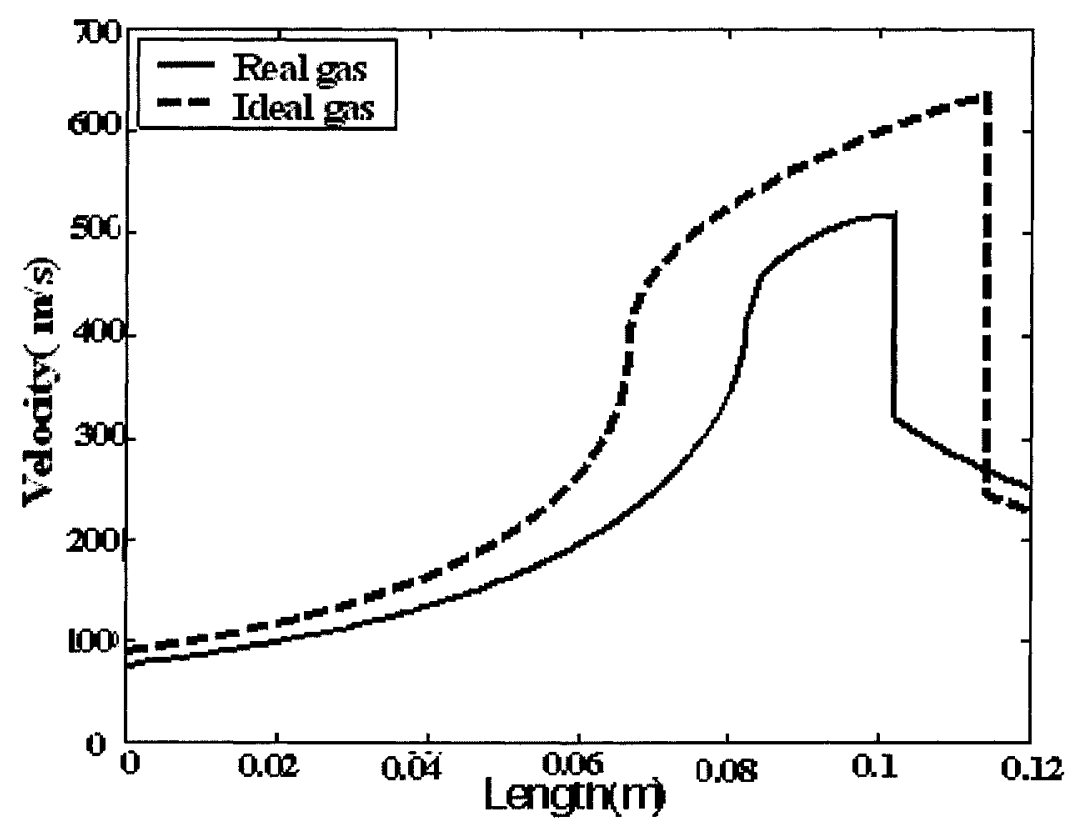

Figure 4.11: Velocity distribution and shockwave location along the designed nozzle for real and ideal gas assumptions with $70 \%$ inlet pressure recovery

The ideal gas assumption underestimates the water capacity of natural gas. Figure 4.12 shows water removal performance of the nozzle for a case where a $70 \%$ of the inlet pressure recovery is considered as the design criteria. Both real and ideal gas can predict close to complete water removal, i.e., $99 \%$ for real gas and $95 \%$ for ideal gas (See Figure 4.12). As the pressure and temperature are lower in the ideal gas case, the only liquid phase will be the aqueous phase as the flow conditions stay within the gas phase region of the phase envelope. For the real gas case, just before the shockwave the 
pressure and temperature fall into the two-phase region of the phase envelope and therefore a liquid hydrocarbon phase is formed. In Figure 4.13 , the pressure, temperature distribution along the nozzle as well as the phase diagram related to PengRobinson as the equation of state is shown. .

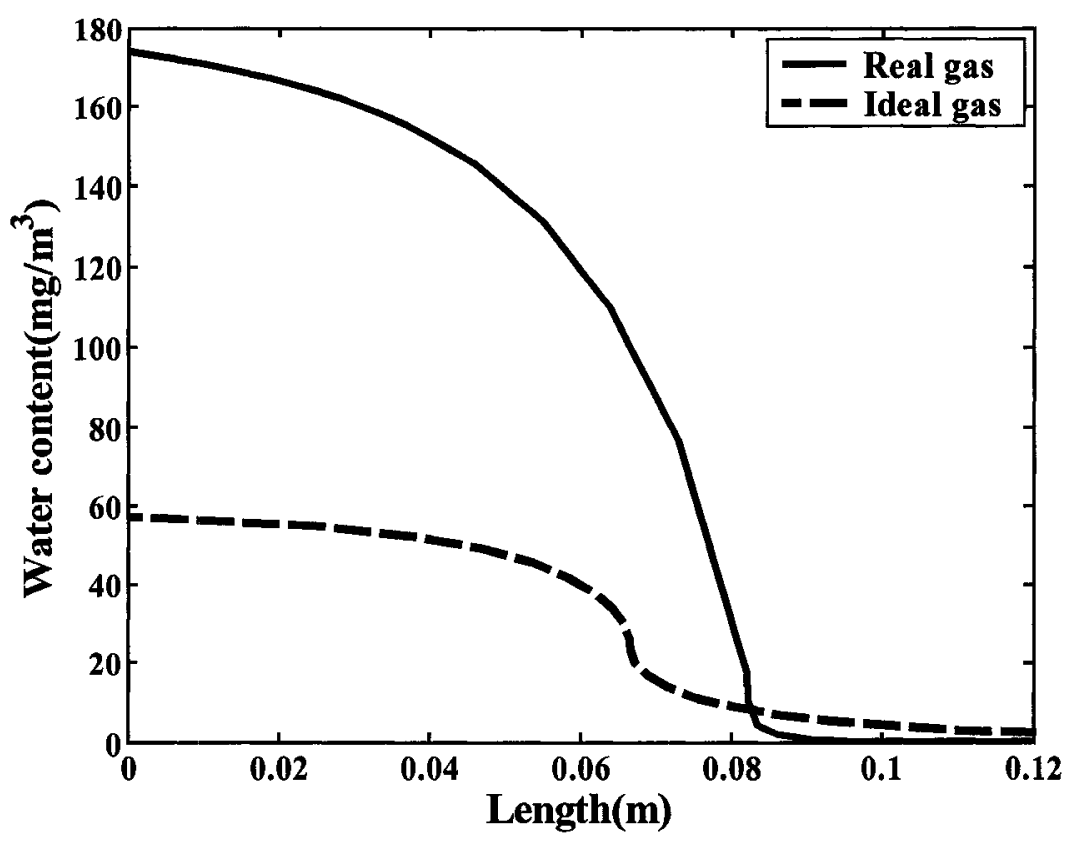

Figure 4.12: Theoretical water removal along the designed nozzle for real and ideal gas assumptions with $70 \%$ inlet pressure recovery 


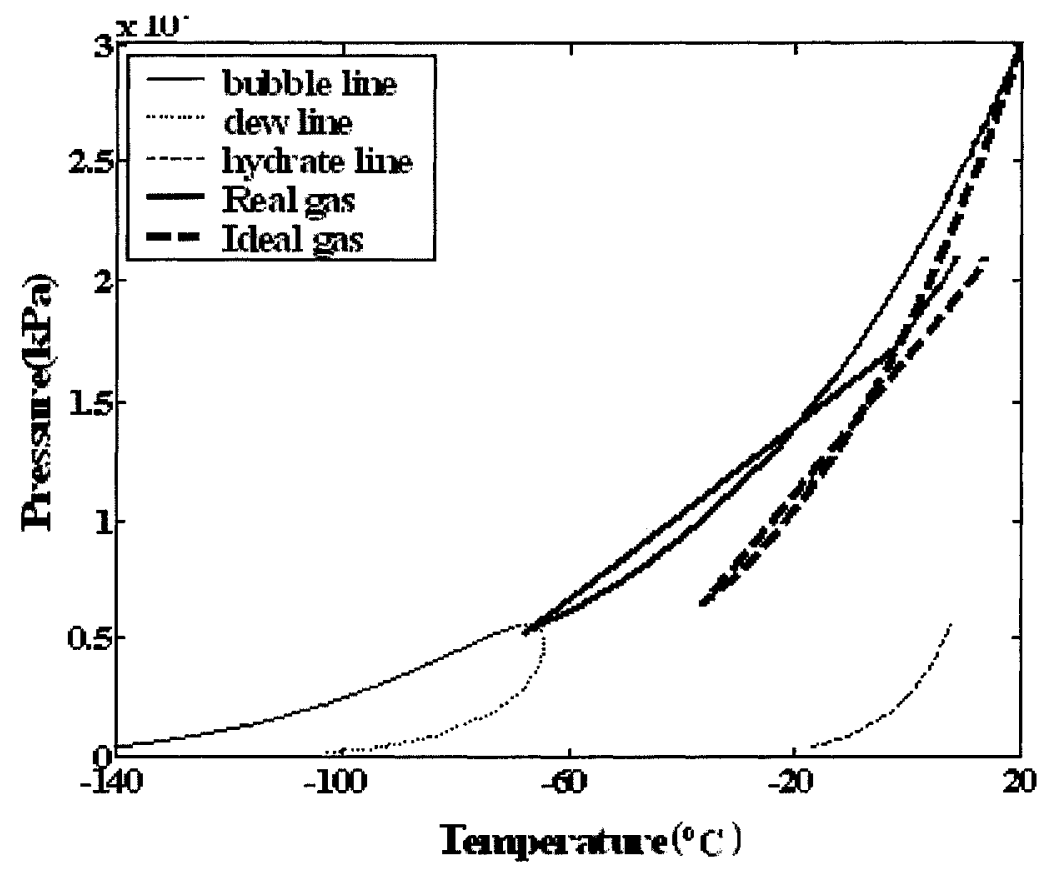

Figure 4.13: Phase envelope and Pressure-Temperature distributions along the designed nozzle for real and ideal gas assumptions with $70 \%$ inlet pressure recovery

\subsubsection{RATING NozZLES USING IDEAL GAS ASSUMPTION}

Since the goal here is to use the same nozzle for both real and ideal gas cases, the nozzle needs to be rated under the two real and ideal gas conditions. Therefore, both real and ideal gas nozzles should have the same geometry. The nozzle flow capacity under ideal gas conditions is less than that of the real gas as the flow rate needs to be reduced to 3,524.7 from 5,001.14 kmole/h in order to get the Mach number close to unity at the throat. All the comparisons were made under constant nozzle specifications and inlet flow properties; the flow rate however could not be fixed. Figure 4.14 presents the comparison between the"recovery pressure" and the "design pressure" in each nozzle. 
The ideal gas "design pressure" is $50 \%$ and its"recovery pressure" is $8 \%$ higher than the real gas. Therefore, the inlet pressure can be recovered up to $8 \%$ more in the ideal gas case. The maximum pressure recoveries for real and ideal gas situations are 82.7 and $89.3 \%$ of the inlet pressure, respectively.

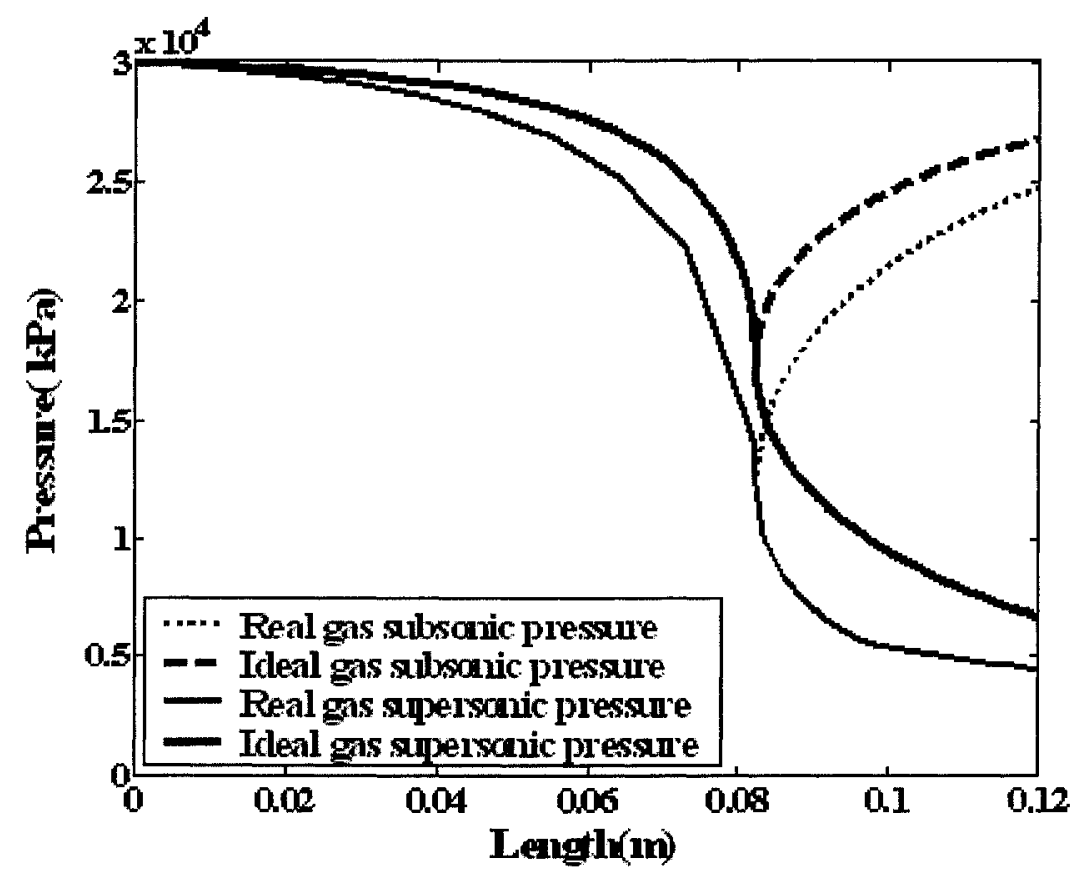

Figure 4.14: Pressure distributions along the rated nozzle for ideal and real gas assumptions

If the backpressure is fixed at $70 \%$ recovery of the inlet pressure ( $21 \mathrm{MPa}$ at the nozzle exit), the shockwave location in the ideal and real gas cases will be different. Shockwave location for ideal gas will be at $97.33 \%$ of the total nozzle length while shock occurs at $82.83 \%$ of the total length in the real gas conditions. In the real gas case, the 
pressure reduction before the shockwave is $82.42 \%$ of the inlet pressure and it drops to $76.6 \%$ for the ideal gas.

Figures $4.15,4.16$, and 4.17 present the pressure, temperature and velocity distributions along the nozzle for the same inlet pressure recovery $(70 \%)$ condition.

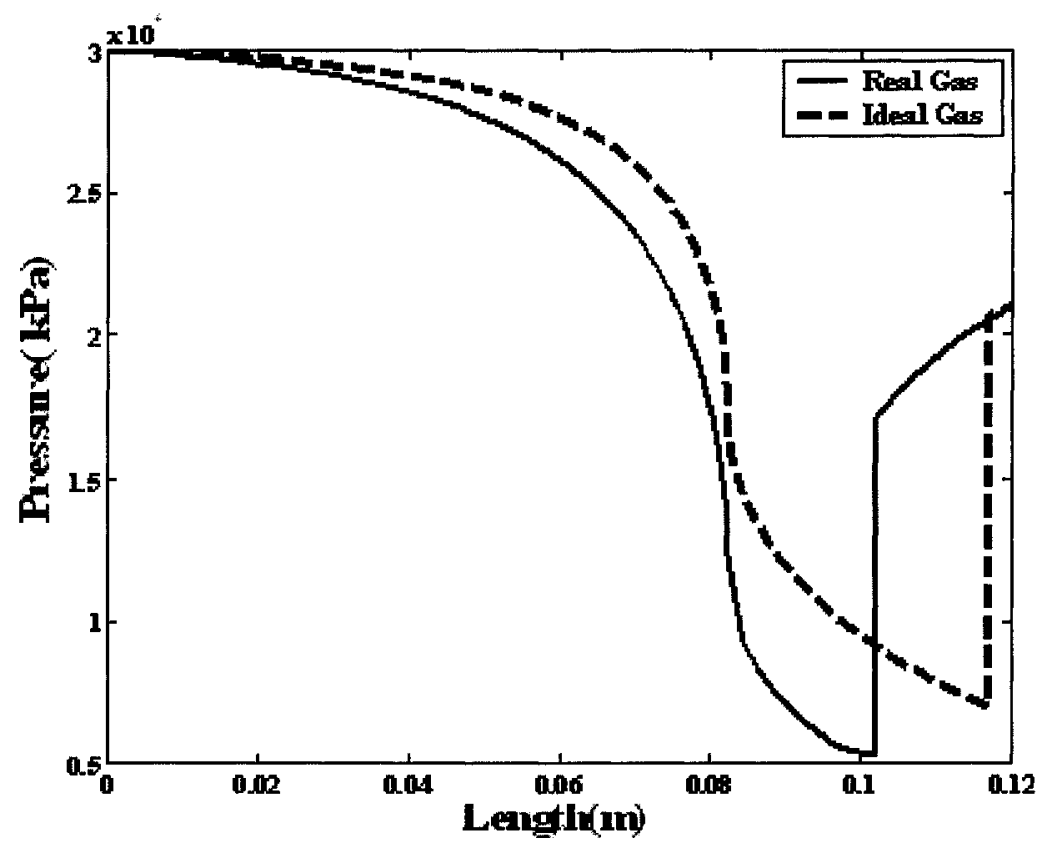

Figure 4.15: Pressure distributions and shockwave location along the rated nozzle for ideal and real gas assumptions with $70 \%$ inlet pressure recovery 


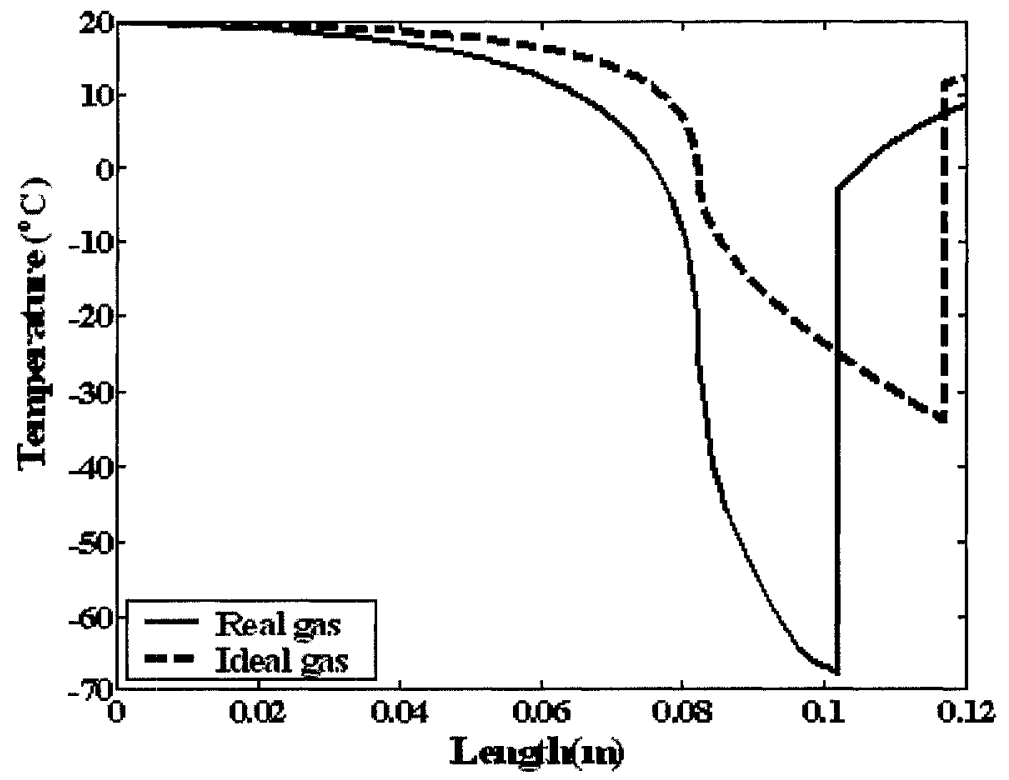

Figure 4.16: Temperature distributions and shockwave location along the rated nozzle for ideal and real gas assumptions with $70 \%$ inlet pressure recovery

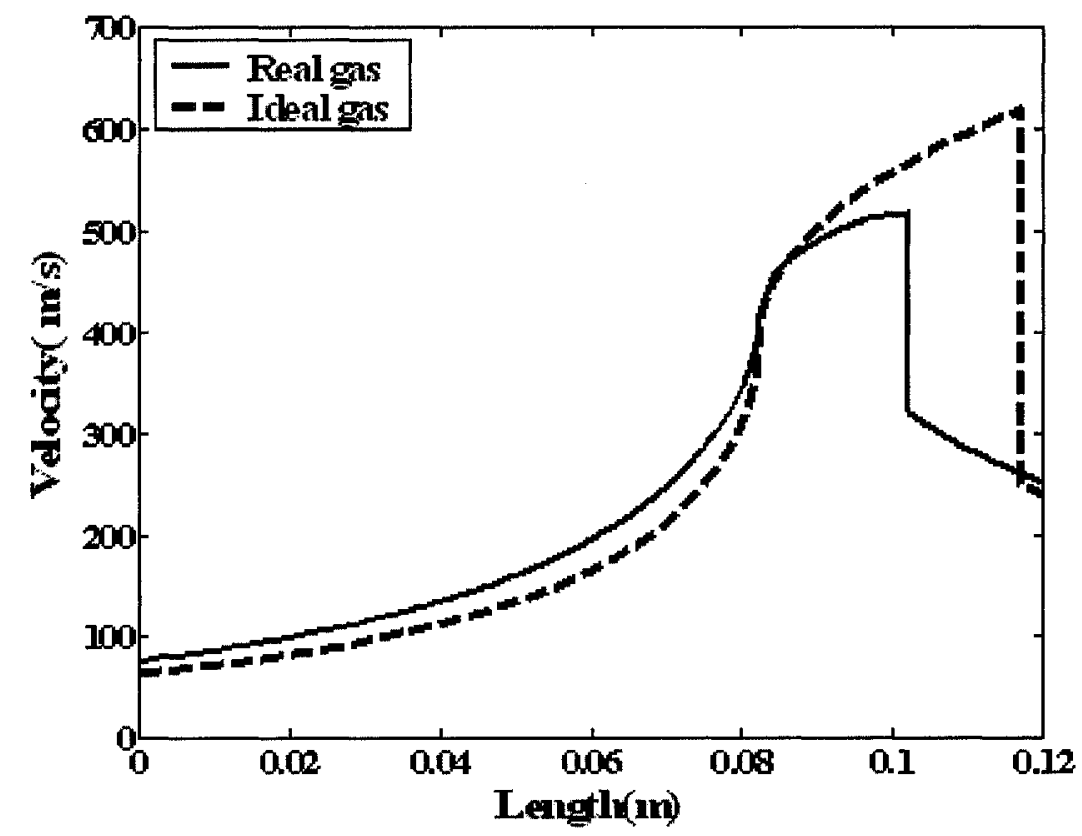

Figure 4.17: Velocity distributions and shock wave location along the rated nozzle for ideal and real gas assumptions with $70 \%$ inlet pressure recovery

The above discussions and analyses show the importance of choosing a suitable 
equation of state. In a supersonic nozzle the ideal gas assumption, results in significant deviations in calculating the gas properties along the nozzle as well as predicting the nozzle performance when compared to the results obtained when the real gas assumption is made.

\subsubsection{Effect Of Inlet Pressure}

Four dry gas streams (streams with no water content) with equal temperatures and different pressures are introduced to the nozzle and saturated with water. As mentioned before water saturation slightly changes the temperature and the flow rate. The stream capacity to hold water will decrease by the increase in inlet pressure as shown in Table 4.10. The stream composition after saturation is shown in Table 4.11.

Table 4.10: Inlet streams conditions for inlet-pressure-effect studies

\begin{tabular}{|c|c|c|c|c|}
\hline Stream Name & $\mathbf{1}$ & $\begin{array}{c}\text { Test } \\
\text { stream }\end{array}$ & $\mathbf{2}$ & $\mathbf{3}$ \\
\hline Temperature $\left({ }^{\circ} \mathrm{C}\right)$ & 19.72 & 19.85 & 19.86 & 19.87 \\
\hline Pressure $(\mathrm{MPa})$ & 10 & 30 & 50 & 70 \\
\hline Molar flow Rate $(\mathrm{kmol} / \mathrm{h})$ & $5,001.7$ & $5,001.1$ & 5,0010 & $5,000.9$ \\
\hline Water content $\left(\mathrm{mg} / \mathrm{m}^{3}\right)$ & 264.5 & 174.1 & 150.3 & 109.7 \\
\hline
\end{tabular}

Table 4.11: Streams gas composition (mole fractions) for inlet-pressure-effect studies

\begin{tabular}{|c|c|c|c|c|} 
Methane & 0.950 & 0.950 & 0.950 & 0.950 \\
\hline Ethane & 0.040 & 0.400 & 0.040 & 0.040 \\
\hline Propane & 0.010 & 0.100 & 0.010 & 0.010 \\
\hline Water & 0.000 & 0.000 & 0.000 & 0.000 \\
\hline
\end{tabular}


These streams were introduced to the nozzle designed using the "Test Stream" condition. For the streams with pressures above that of the "Test Stream" (Streams 3 and 4), the Mach numbers at the throat are lower than unity ( 0.333 and 0.231 , respectively) which means the flow rate is not enough to reach supersonic conditions for the specified nozzle geometry. The Newton-Raphson component of the program diverges and fails to compute the Mach number at the throat for Stream 1. Therefore, either the flow rate should be adjusted in order to choke the flow at the throat or a suitable nozzle for each stream condition should be designed.

\subsubsection{DESIGNING NOZZLE FOR EACH GAS STREAME IN PRESSSURE-EFFECT STUDIES}

The purpose of this study is to design a nozzle for each of the streams such that the flow becomes choked at the nozzle throat. The flow rate used for all different inlet conditions remains constant in this study. For each stream, the nozzle throat diameter should first be found. The throat distance from the inlet is the converging length of the nozzle and the lower bound for the nozzle total length. The upper bound for the nozzle length is predicted using the previously mentioned procedure (see Section 4.2). As shown in Table 4.12, the converging length of the nozzle increases with the inlet pressure while the throat diameter decreases. The nozzle designed for Stream 1 is a lot shorter than the nozzle for the other streams. A comparison was made between the pressure distributions in the nozzle designed for "Test Stream", and Streams 2 and 3 as the nozzle length for Stream 1 is different. Figure 4.18 shows the pressure distributions along the 
nozzles designed using these three streams ("Test Stream", Streams 2 and 3) as the working fluids. For this comparison, nozzle total length is considered to be $0.12 \mathrm{~m}$. Figure 4.18 also shows the pressure distributions along the nozzle with the total length of $0.06 m$ for Stream1. The nozzle "recovery pressure" and "design pressure" are obtained in each case. These two pressures define the range of the nozzle exit pressure as a percentage of the inlet pressure. These ranges are shown in Table 4.13.

Table 4.12: Inlet condition of the streams in the pressure effect studies

\begin{tabular}{|l|c|c|c|c|}
\hline \multicolumn{1}{|c|}{ Stream Name } & $\mathbf{1}$ & $\begin{array}{c}\text { Test } \\
\text { Stream }\end{array}$ & $\mathbf{2}$ & $\mathbf{3}$ \\
\hline Nozzle throat diameter(m) & 0.035 & 0.020 & 0.016 & 0.014 \\
\hline Nozzle convergence length (m) & 0.020 & 0.081 & 0.099 & 0.108 \\
\hline Length upper bound (m) & 0.066 & 0.270 & 0.327 & 0.355 \\
\hline
\end{tabular}

As shown in Table 4.13, for the same flow rate, a very shorter nozzle is designed for Stream 1 where the pressure is low. As the pressure increases, the nozzle's recovery pressure decreases which means that a longer nozzle should be designed to recover the same amount of pressure for streams with lower pressures. For Stream 3 and in a nozzle of $0.12 \mathrm{~m}$ long, the $70 \%$ inlet pressure recovery never happens; therefore a longer nozzle should be designed.

Table 4.13: Inlet conditions for streams with different pressures

\begin{tabular}{|c|c|c|c|c|}
\hline Stream Name & $\mathbf{1}$ & Test Stream & $\mathbf{2}$ & $\mathbf{3}$ \\
\hline Nozzle length $(m)$ & 0.06 & 0.12 & 0.12 & 0.12 \\
\hline $\begin{array}{c}\text { Exit pressure range } \\
\text { (\% of inlet } \\
\text { pressure) }\end{array}$ & $29.61-98.10$ & $14.84-82.72$ & $10.25-77.99$ & $7.45-62.8$ \\
\hline
\end{tabular}




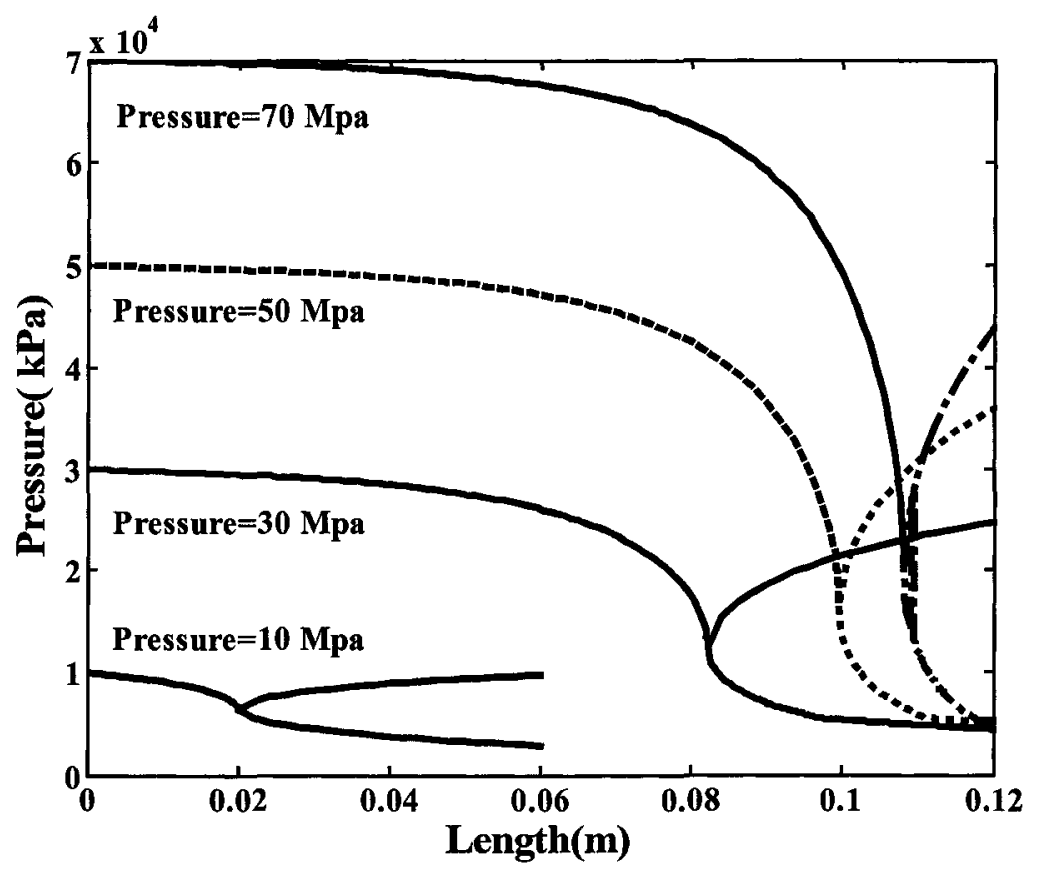

Figure 4.18: Pressure distributions along the designed nozzle for pressureeffect studies

A nozzle of $0.12 \mathrm{~m}$, capable of recovering $70 \%$ of the inlet pressure could be designed for the "Test Stream" and Stream 2. Figures 4.19 to 4.21 show the pressure, temperature, and velocity distributions as well as shockwave locations along a nozzle with a length of $0.12 \mathrm{~m}$ with $70 \%$ inlet pressure recovery for the "Test Stream" and Stream 2 . 


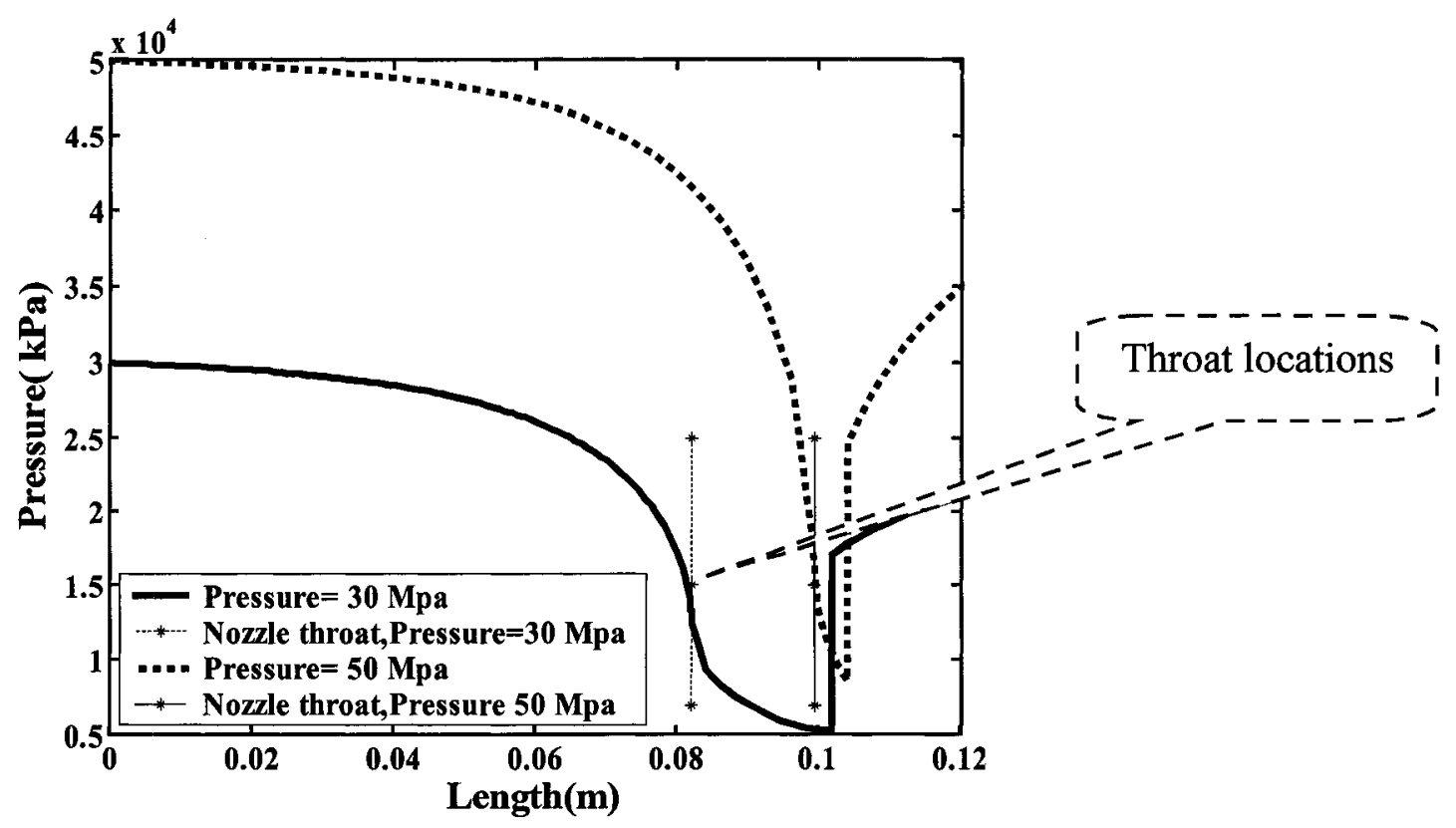

Figure 4.19: Pressure distributions and the shockwave location along the designed nozzle with $70 \%$ pressure recovery for pressure-effect studies

The increase in the inlet pressure causes the choked flow to happen later in the nozzle and therefore the throat for "Test Stream " is at $68.5 \%$ of the total length and increases to $82.85 \%$ and $90 \%$ of the total length as the inlet pressure increases from 30 to $70 \mathrm{MPa}$. As mentioned $70 \%$ of the inlet pressure can not be recovered in the nozzle designed for Stream 3 but the shockwave happens inside the diverging part of the nozzle of $0.12 \mathrm{~m}$ long for the "Test Stream " and Stream 2 at 85.85 and $86.69 \%$ of the total nozzle length. 


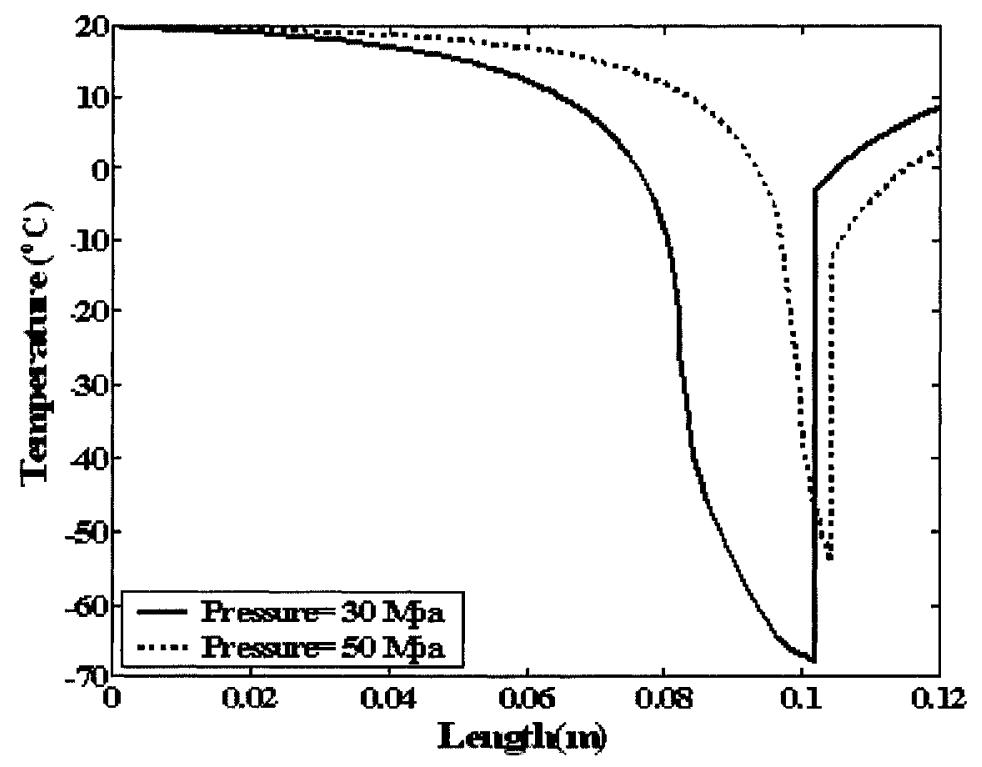

Figure 4.20: Temperature distributions and the shockwave location along the designed nozzle with $70 \%$ pressure recovery for pressure-effect studies

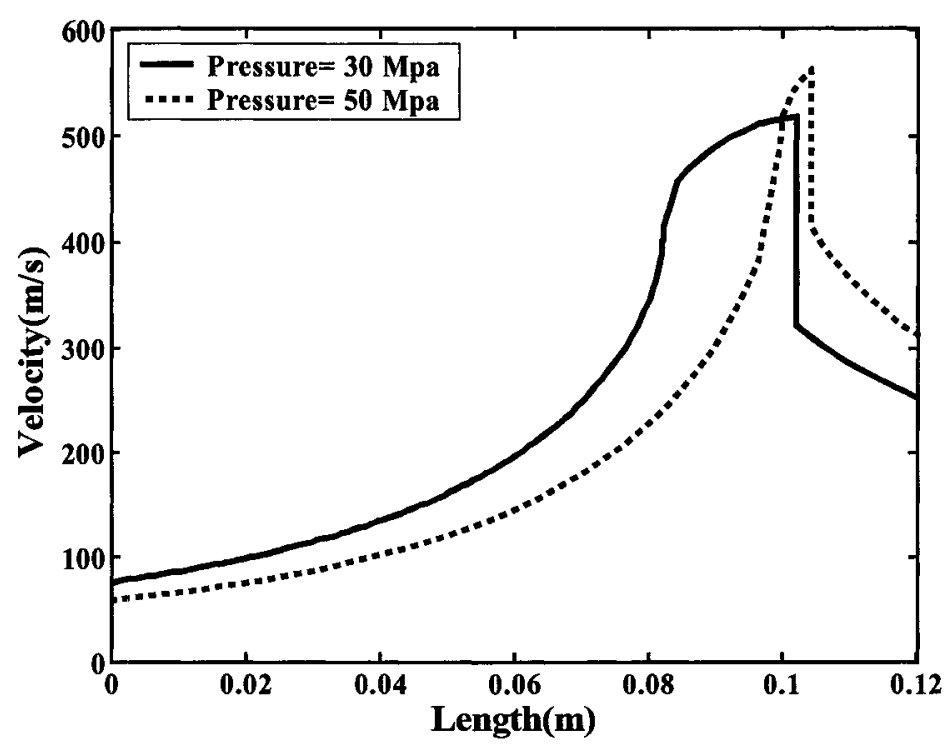

Figure 4.21: Velocity distributions and the shockwave location along the designed nozzle with $70 \%$ pressure recovery for pressure-effect studies 
Figure 4.22 presents the phase envelope and the pressure-temperature distributions along the designed nozzle with $70 \%$ recovery of the inlet pressure. It can be seen that in Stream 2 (with an inlet pressure of $50 \mathrm{MPa}$ ), the selective water removal can be achieved as the pressure and temperature are kept above the phase envelope and in the single dense phase.

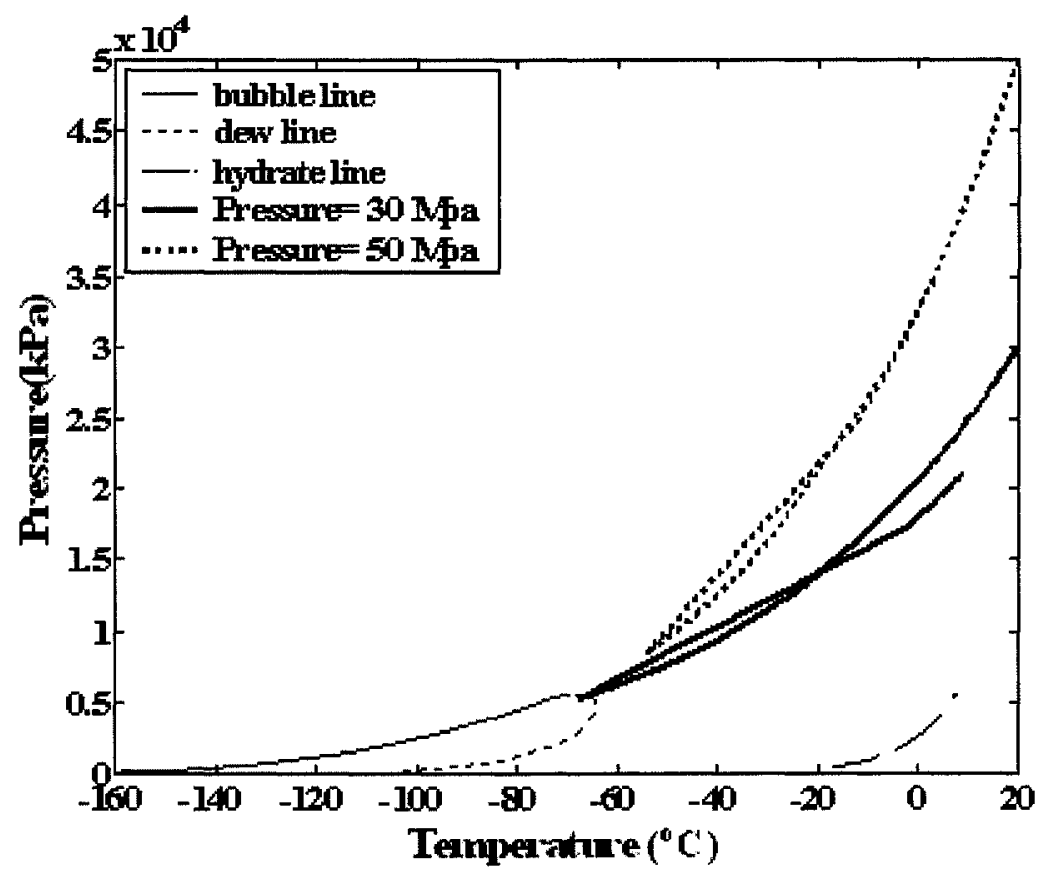

Figure 4.22: Phase envelope and Pressure-Temperature distributions for designed nozzle in pressure-effect studies with $70 \%$ inlet pressure recovery

\subsubsection{RATING NOZZLES FOR EACH GAS STREAM IN PRESSURE- EFFECT STUDIES}

Since the gas flow rates are either not enough or more than enough to achieve the sonic conditions at the throat, the inlet flow rates were adjusted for each stream condition. The flow capacity of the nozzle increases with pressure. Depending on the backpressure 
of the nozzle, the exit pressure will fall in a range whose lower and upper bounds are given by a percentage of the inlet pressure as shown in Table 4.14. These results are shown in Figure 4.23.

Table 4.14: Adjusted flow rates and exit pressure range for pressure-effect studies

\begin{tabular}{|l|c|c|c|c|}
\hline \multicolumn{1}{|c|}{ Stream Name } & $\mathbf{1}$ & Test Stream & $\mathbf{2}$ & $\mathbf{3}$ \\
\hline $\begin{array}{l}\text { Molar flow Rate } \\
\text { (kmole/h) }\end{array}$ & 1,421 & 5.000 & 8,016 & 10,544 \\
\hline $\begin{array}{l}\text { Exit pressure range } \\
\text { (\%of inlet pressure) }\end{array}$ & $\begin{array}{c}20.25- \\
87.88\end{array}$ & $14.83-82.71$ & $9.42-$ & $6.56-78.14$ \\
\hline
\end{tabular}

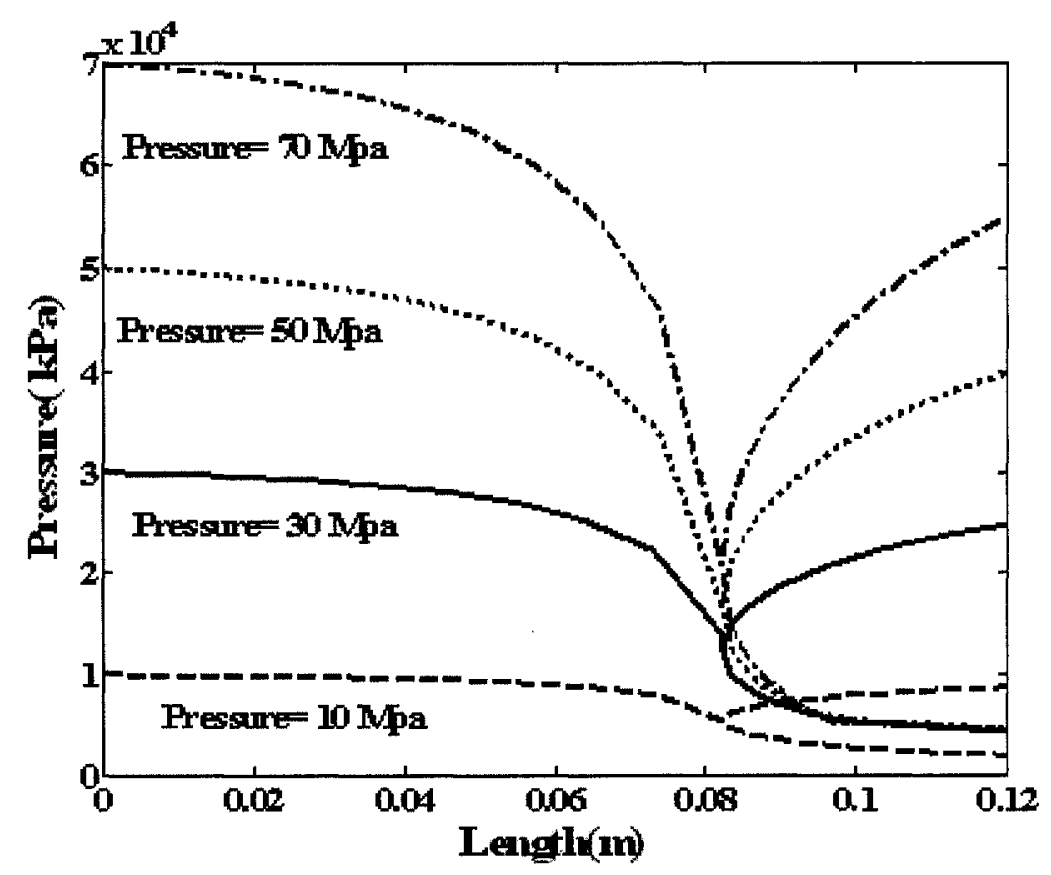

Figure 4.23: Pressure distributions along the rated nozzle for pressureeffect studies

As pressure increases from 10 to $70 \mathrm{MPa}$, the maximum pressure recovery of the nozzle will be reduced for nearly $10 \%$. A shockwave occurs in the nozzle in all conditions of pressure and temperature, when $70 \%$ recovery of the inlet pressure is 
desired. As Figure 4.24 shows, the decrease in inlet pressure will shift the shockwave location towards the nozzle exit.

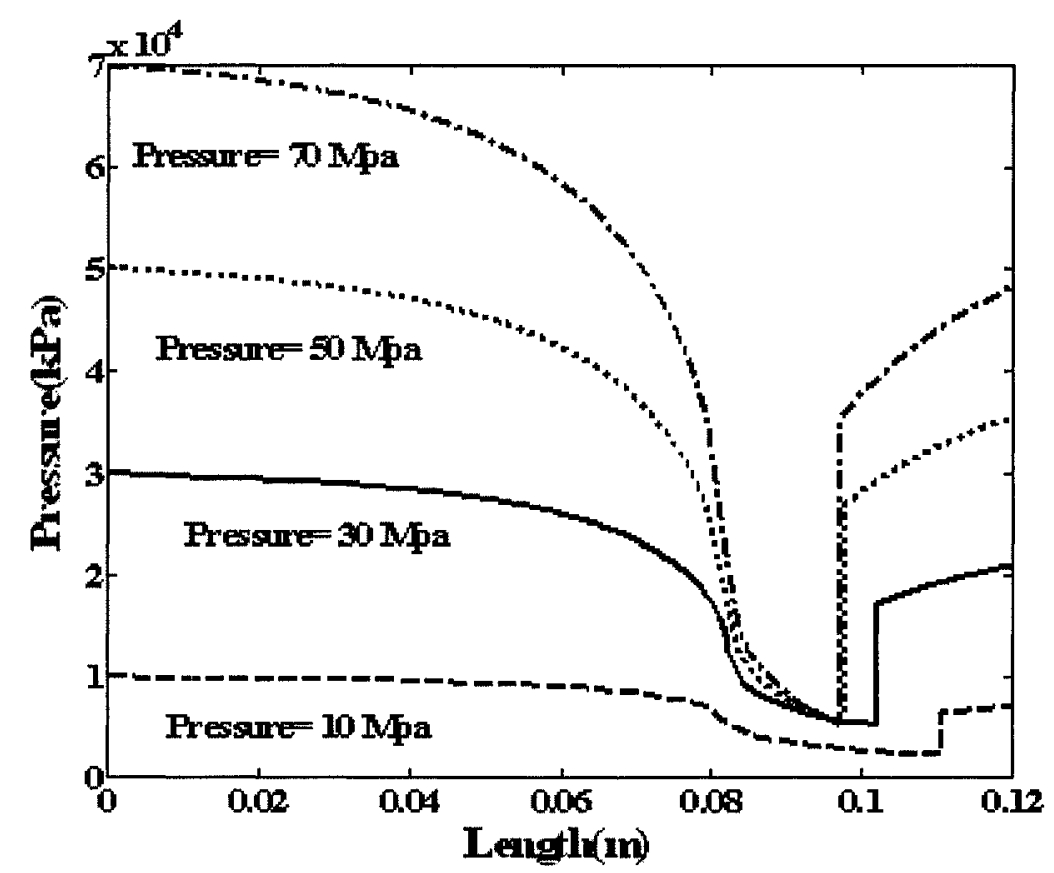

Figure 4.24: Pressure distribution for rated nozzle in pressure-effect studies with $70 \%$ inlet pressure recovery

Table 4.15 indicates that as the inlet pressure increases, the pressure along the nozzle will decrease further before the shockwave occurs. Since the location of shockwave is closer to the nozzle exit in lower inlet pressures, it can be concluded that pressure reduction will be steeper in higher pressures. As pressure decreases from 70 to $10 \mathrm{MPa}$, shockwave will shift $12.29 \%$ towards the nozzle exit. Supersonic nozzles can therefore become shorter as inlet pressure increases and shockwave happens earlier in the nozzle. 
Table 4.15: Shockwave location: comparison for pressure-effect studies

\begin{tabular}{|c|c|c|c|c|}
\hline Stream Name & $\mathbf{1}$ & $\begin{array}{c}\text { Test } \\
\text { Stream }\end{array}$ & $\mathbf{2}$ & $\mathbf{3}$ \\
\hline Pressure reduction (\% of inlet pressure) & 76.79 & 82.43 & 88.92 & 92.36 \\
\hline Shockwave location (\% of total length) & 92.25 & 85.03 & 81.41 & 80.92 \\
\hline
\end{tabular}

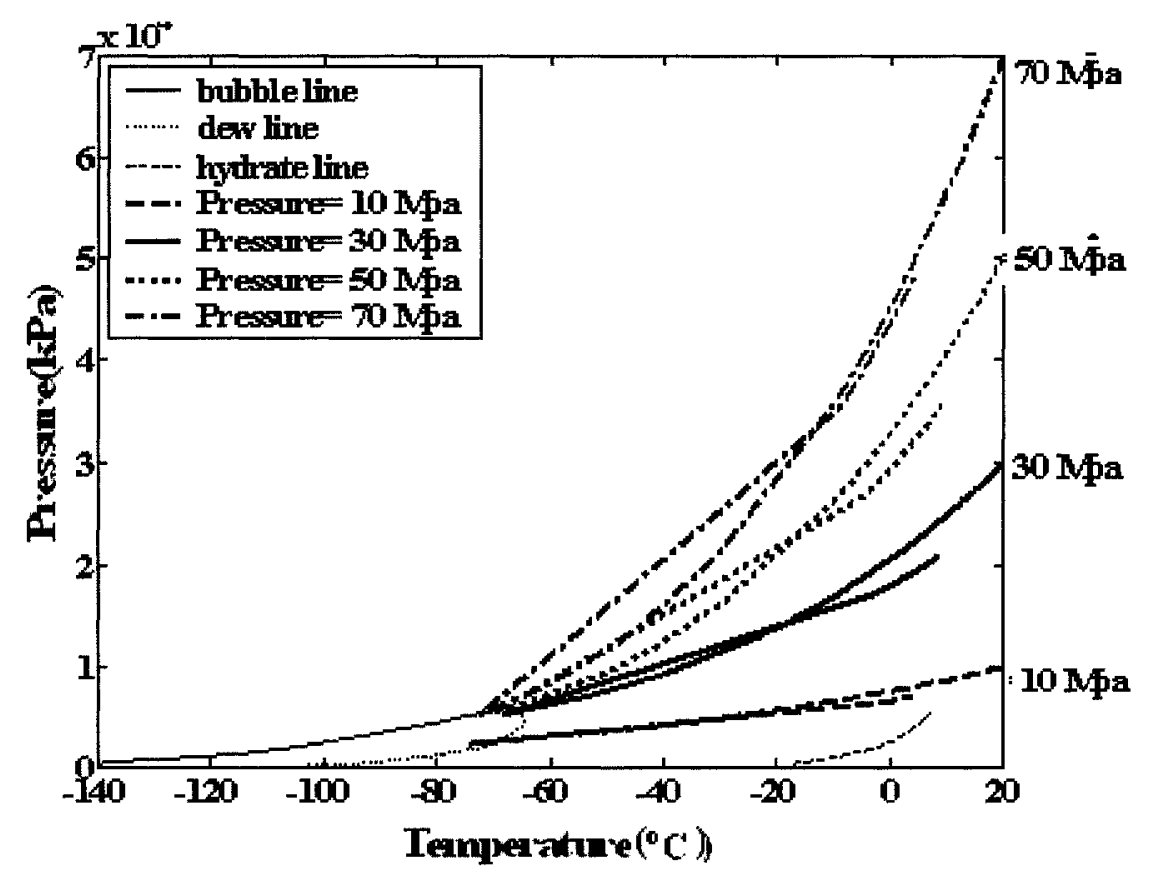

Figure 4.25: Phase envelope nd Pressure-Temperature distributions for pressureeffect studies with $70 \%$ inlet pressure recovery

Plotting the temperature variation with pressure for a nozzle in which $70 \%$ of the inlet pressure recovery is desired, illustrates in the four gas conditions, the lines remain in the dense phase region all the time and therefore, two liquid phases (water and hydrocarbon) will be present. However, as the inlet pressure increases the temperaturepressure variation is more likely to stay in the dense supercritical phase of the phase 
envelope (see Figure 4.25). Figures 4.26 and 4.27 indicate the temperature and velocity distribution along the nozzle when $70 \%$ recovery of the inlet pressure is the design criteria.

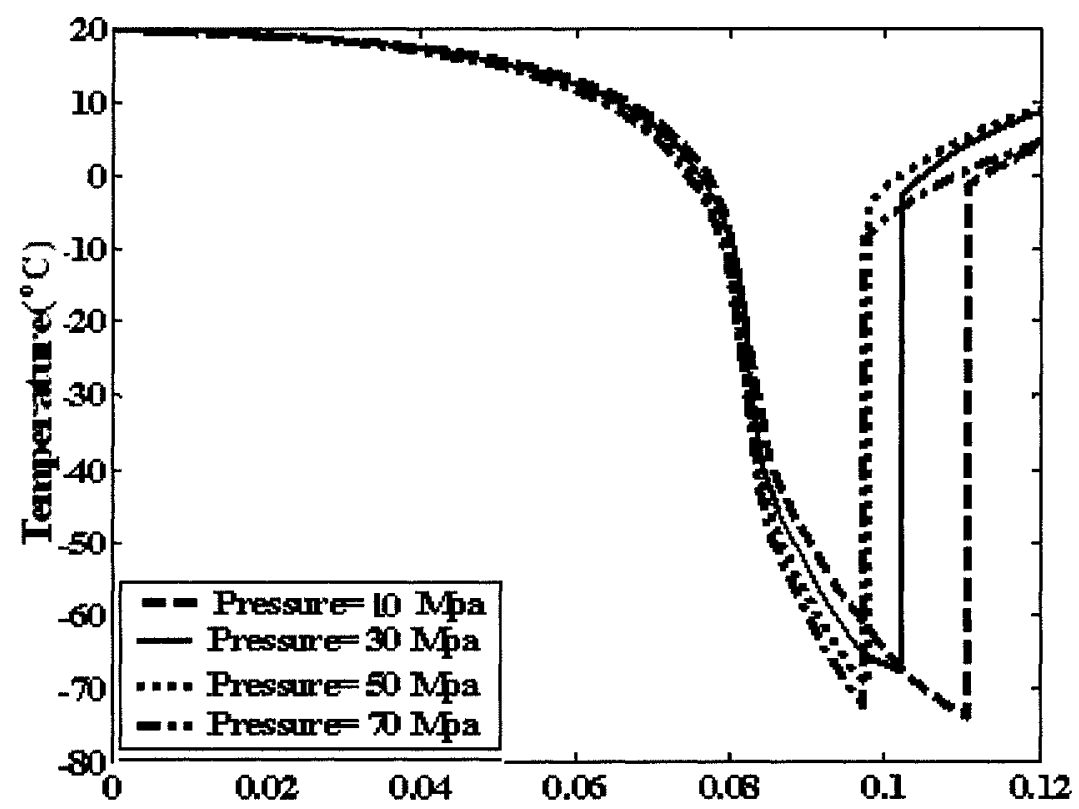

Figure 4.26: Temperature distributions and the shock wave location in the rated nozzle in pressure-effect studies with $70 \%$ inlet pressure recovery 


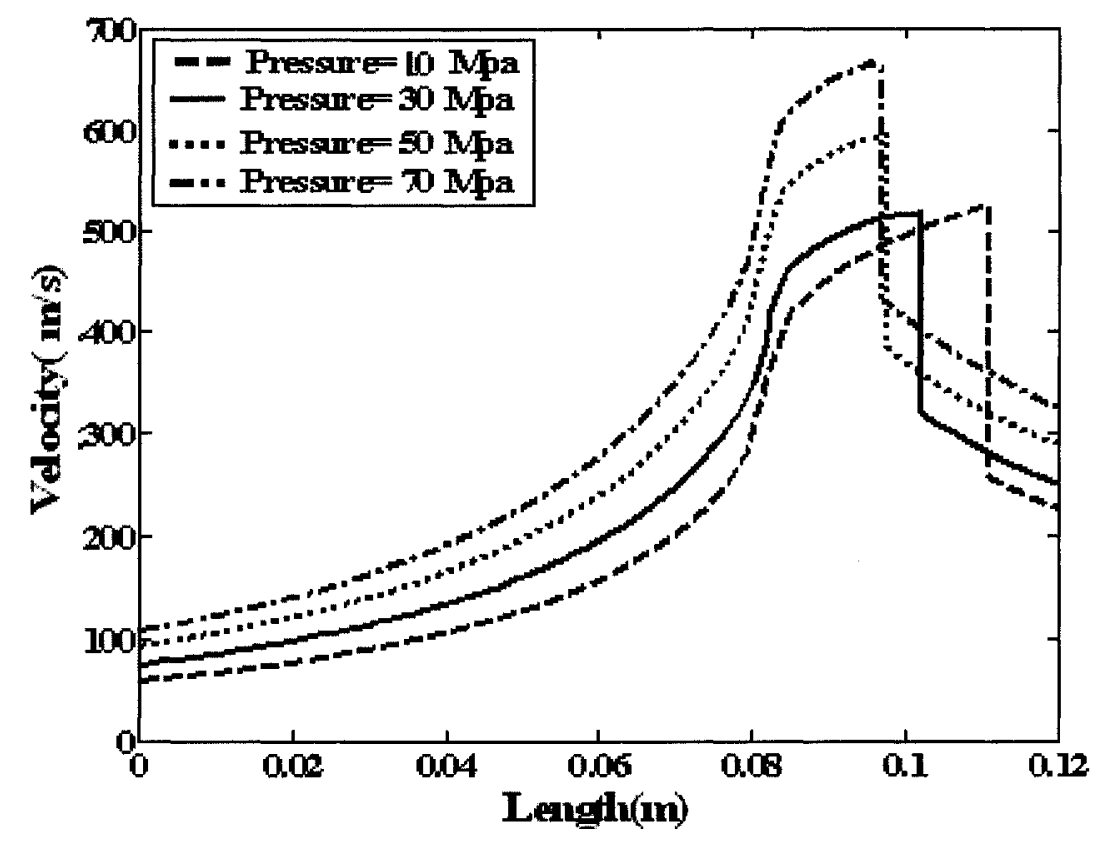

Figure 4.27: Velocity distributions and the shock wave location in the rated nozzle in pressure-effect studies with $70 \%$ inlet pressure recovery

\subsubsection{EFFECT OF INLET TEMPERATURE}

Four dry streams (streams with no water content) with equal pressures and different temperatures are introduced and saturated with water. As mentioned before water saturation slightly changes the temperature and the flow rate as shown in Table 4.16. It can be seen that the streams water content increases with the increase in temperature (see Tables 4.16 and 4.17). 
Table 4.16: Inlet condition of the streams for inlet-temperature-effect studies

\begin{tabular}{|l|c|c|c|c|}
\hline \multicolumn{1}{|c|}{ Stream name } & $\mathbf{1}$ & $\begin{array}{c}\text { Test } \\
\text { Stream }\end{array}$ & $\mathbf{2}$ & $\mathbf{3}$ \\
\hline Temperature $\left({ }^{\circ} \mathrm{C}\right)$ & 0.95 & 19.85 & 39.60 & 59.05 \\
\hline Pressure $(\mathrm{MPa})$ & 30 & 30 & 30 & 30 \\
\hline Molar flow Rate $(\mathrm{kmol} / \mathrm{h})$ & $5,000.4$ & $5,001.1$ & $5,003.0$ & $5,007.1$ \\
\hline Water content $\left(\mathrm{mg} / \mathrm{m}^{3}\right)$ & 60.187 & 174.072 & 465.095 & $1,085.250$ \\
\hline
\end{tabular}

Table 4.17: Streams gas composition (mole fractions) for inlet-temperature-effect studies

\begin{tabular}{|c|c|c|c|c|}
\hline Methane & $9.4997 \mathrm{E}-01$ & $9.4970 \mathrm{E}-01$ & $9.4942 \mathrm{E}-01$ & $9.986 \mathrm{E}-01$ \\
\hline Ethane & $4.000 \mathrm{E}-02$ & $3.9990 \mathrm{E}-01$ & $3.997 \mathrm{e}-02$ & $3.994 \mathrm{E}-02$ \\
\hline Propane & $9.999 \mathrm{E}-03$ & $9.9970 \mathrm{E}-02$ & $9.993 \mathrm{e}-03$ & $9.986-03$ \\
\hline Water & $7011 \mathrm{E}-05$ & $2.3000 \mathrm{E}-04$ & $6.1042 \mathrm{e}-04$ & $1.424 \mathrm{E}-05$ \\
\hline
\end{tabular}

These streams were introduced to the nozzle designed using the "Test Stream" as the working fluid. For the streams with the temperature lower than the "Test Stream" (Stream 1), the Mach number at the throat will be lower than unity $(0.61414)$ which means the flow rate is not enough for this stream conditions and nozzle geometry. The Newton-Raphson component of the program (see section 3.4) does not converge to find the Mach number at the throat for Streams 2 and 3. Therefore, either the flow rate should be adjusted in order to choke the flow at the throat or a suitable nozzle for each stream condition should be designed.

\subsubsection{DESIGNING A NEW NOZZLE FOR EACH GAS STREAM IN TEMPERSTURE-EFFECT SUDIES}

In order to have the choked flow at the nozzle throat in different inlet conditions and constant flow rates, a specific nozzle should be designed for each case. Designing a nozzle for each condition of inlet pressure and temperature with a constant inlet flow rate, 
indicates that the length of the convergence part of the nozzle increases with inlet temperature Table 4.18 shows the throat diameter and the nozzle convergence length. Figure 4.28 presents the designed nozzle geometry for each condition.

Table 4.18: Nozzle geometry in temperature-effect studies

\begin{tabular}{|l|c|c|c|c|}
\hline \multicolumn{1}{|c|}{ Stream name } & $\mathbf{1}$ & $\begin{array}{c}\text { Test } \\
\text { stream }\end{array}$ & $\mathbf{2}$ & $\mathbf{3}$ \\
\hline Nozzle throat diameter(m) & 0.0192 & 0.0203 & 0.0212 & 0.0221 \\
\hline Nozzle convergence length $(\mathrm{m})$ & 0.0864 & 0.0813 & 0.0782 & 0.0746 \\
\hline
\end{tabular}

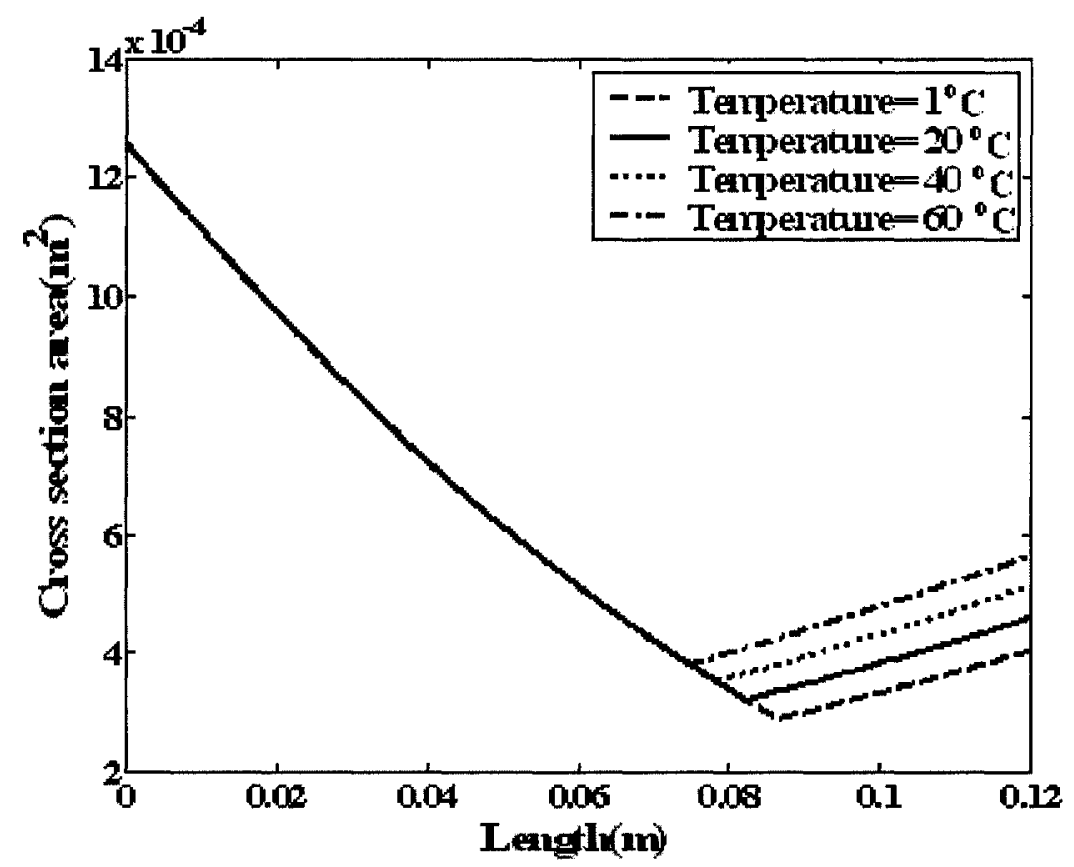

Figure 4.28: Designed nozzle geometry for temperature-effect studies

Figure 4.29 shows the nozzle "recovery pressure" and the "design pressure" in each nozzle. In all four cases the "design pressure" is about $15 \%$ of the inlet pressure. The highest possible pressure recovery in the nozzle, "recovery pressure", increases with 
the increase in temperature and falls between 79.26 and $87.13 \%$ of the inlet pressure for the nozzle with the defined length.

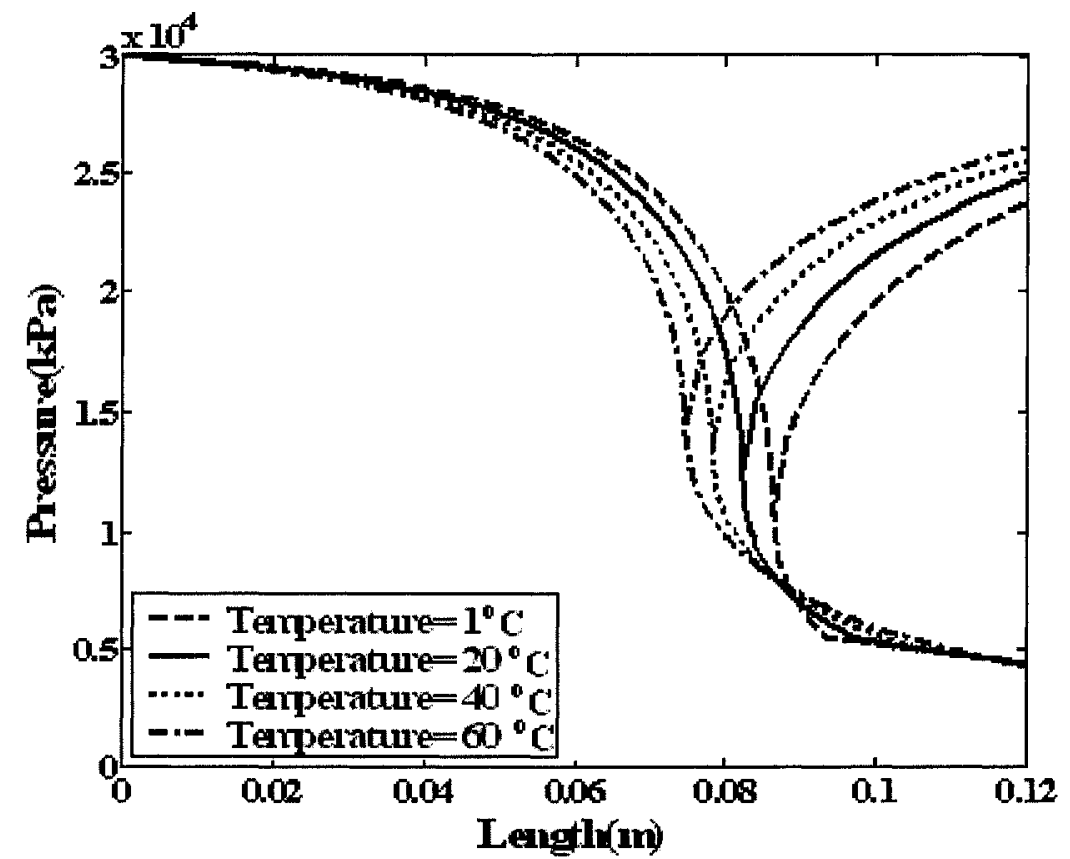

Figure 4.29: Pressure distributions along the designed nozzle for temperature-effect studies 


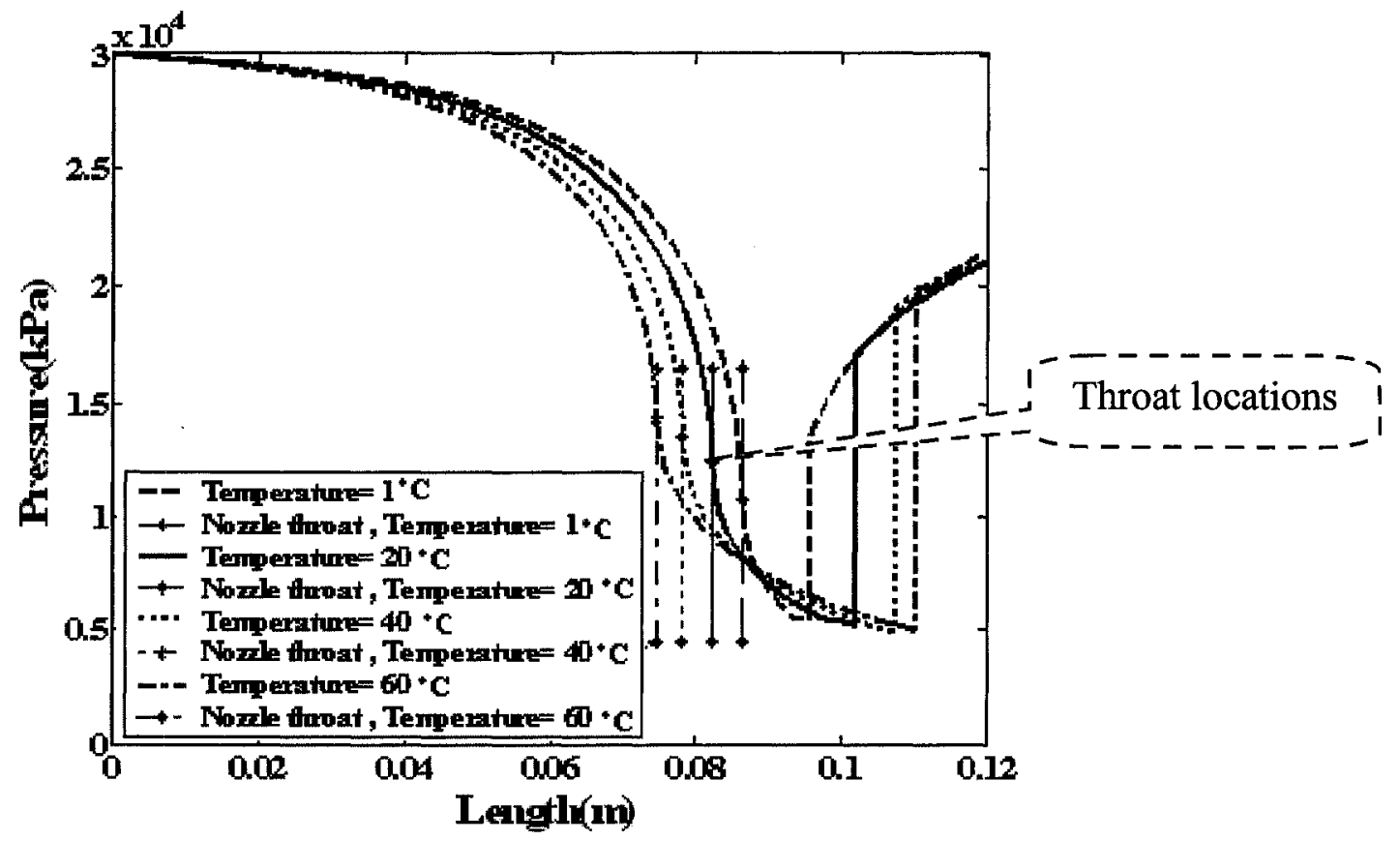

Figure 4.30: Pressure distributions and shockwave location along the designed nozzle for temperature -effect studies with $70 \%$ recovery of inlet pressure

Figure 4.30 shows the pressure distributions in the nozzle if the $70 \%$ recovery of the inlet pressure $(21 \mathrm{MPa})$ is chosen as the design criteria. The throat in each nozzle is marked in this figure. While the inlet pressure and the flow rate are constant, with an increase in inlet temperature, the length of the converging part of the nozzle decreases and the flow is choked earlier in the nozzle. At the same time, the shockwave location shifts towards the nozzle exit. Therefore, the distance between the nozzle throat and the shockwave increases. As the inlet temperature decreases from 60 to $1^{\circ} \mathrm{C}$, the throat cross section area decreases $24.14 \%$ and the nozzle exit cross section decreases $29.00 ? \%$.

In the nozzle with Stream 1 as the working fluid, the distance between the nozzle 
throat and the shockwave location is $9.47 \%$ of the nozzle length and this distance becomes longer, up to $32.19 \%$ of the nozzle length as the temperature increases to $60{ }^{\circ} \mathrm{C}$.

With the increase in inlet temperature from 1 to $60^{\circ} \mathrm{C}$, the throat location shifts form $72.00 \%$ of the total length to $62.16 \%$ of the total length so the flow can become choked, up to $10 \%$ of the total length earlier. At the same situation, shockwave location varies from $79.58 \%$ of the total length to $91.66 \%$ of the total length.

Figures 4.31 and 4.32 present the temperature and velocity distributions along the nozzle with $70 \%$ recovery of the inlet pressure.

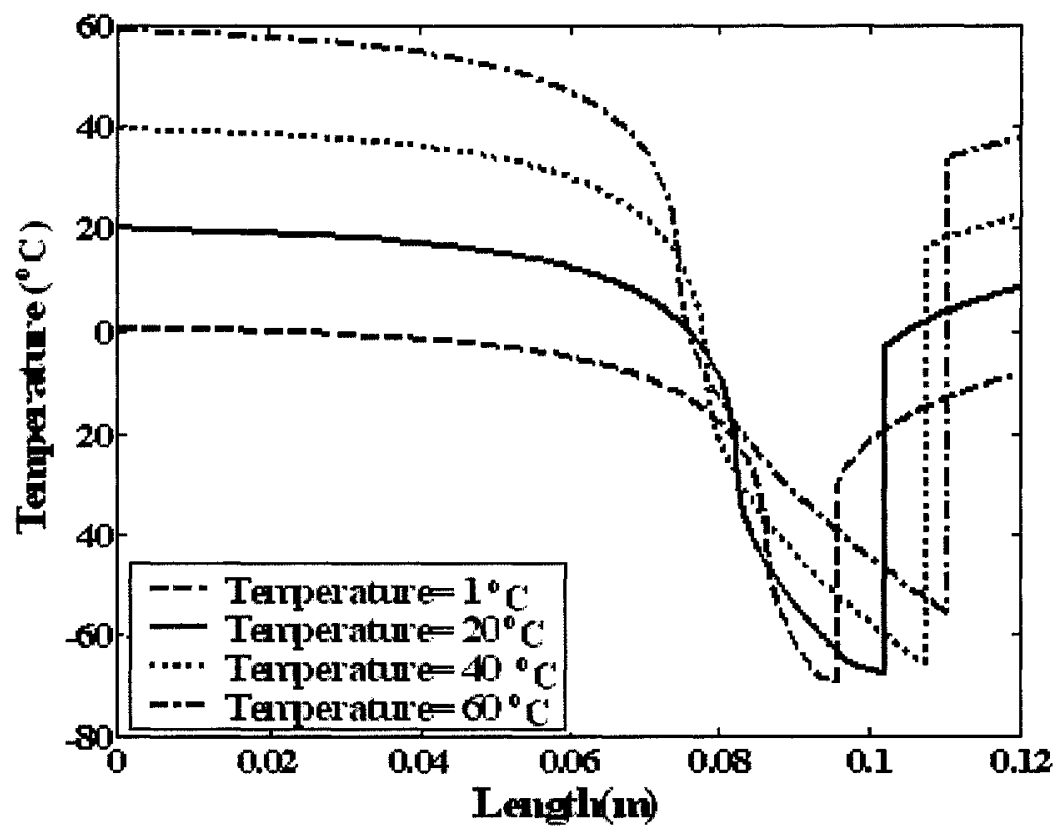

Figure 4.31: Temperature distributions and shockwave location along the designed nozzle for temperature-effect studies with $70 \%$ recovery of the inlet pressure 


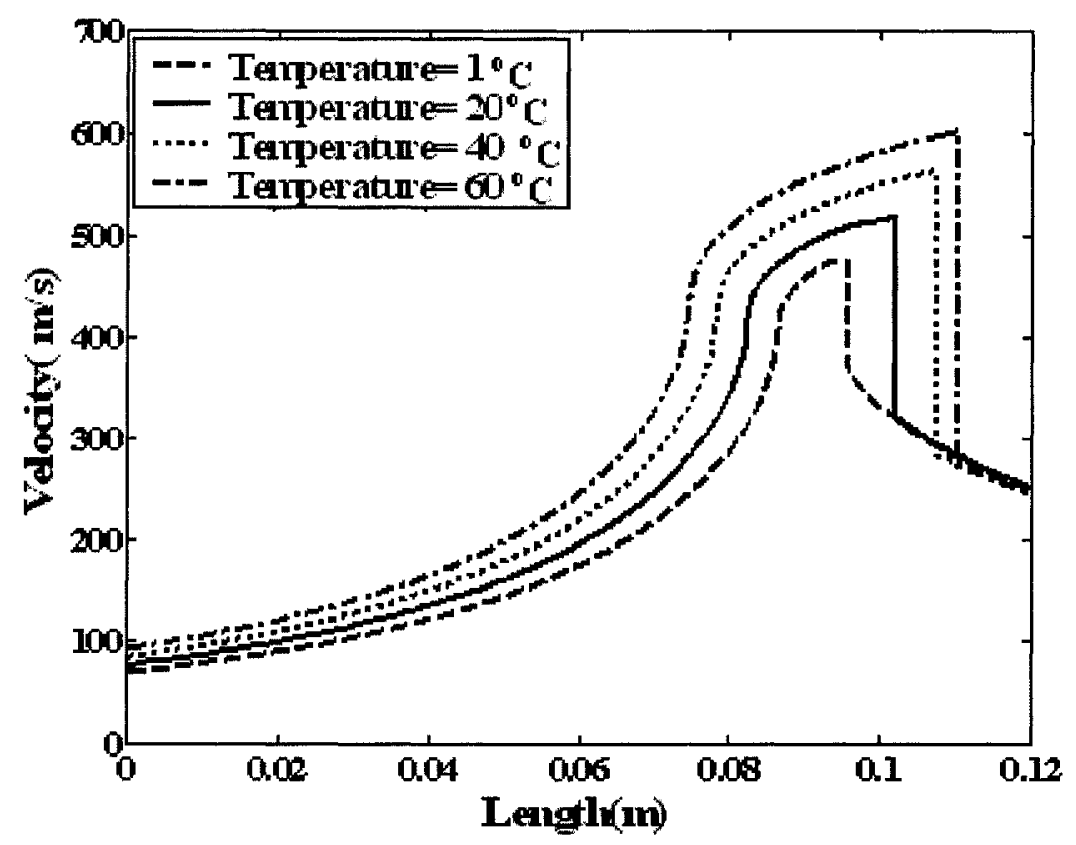

Figure 4.32: Velocity distributions and shockwave location along the designed nozzle for temperature-effect studies with $70 \%$ recovery of inlet pressure

As can be seen in Figure 4.33, smaller pressure expansions happen with temperature when the design criterion is set for $70 \%$ recovery of inlet pressure. At the temperature of $60^{\circ} \mathrm{C}$, the flow condition will be in the single phase region of the phase envelope and therefore, water phase is the only liquid phase and water can be removed selectively, without affecting the hydrocarbon content of the gas stream. 


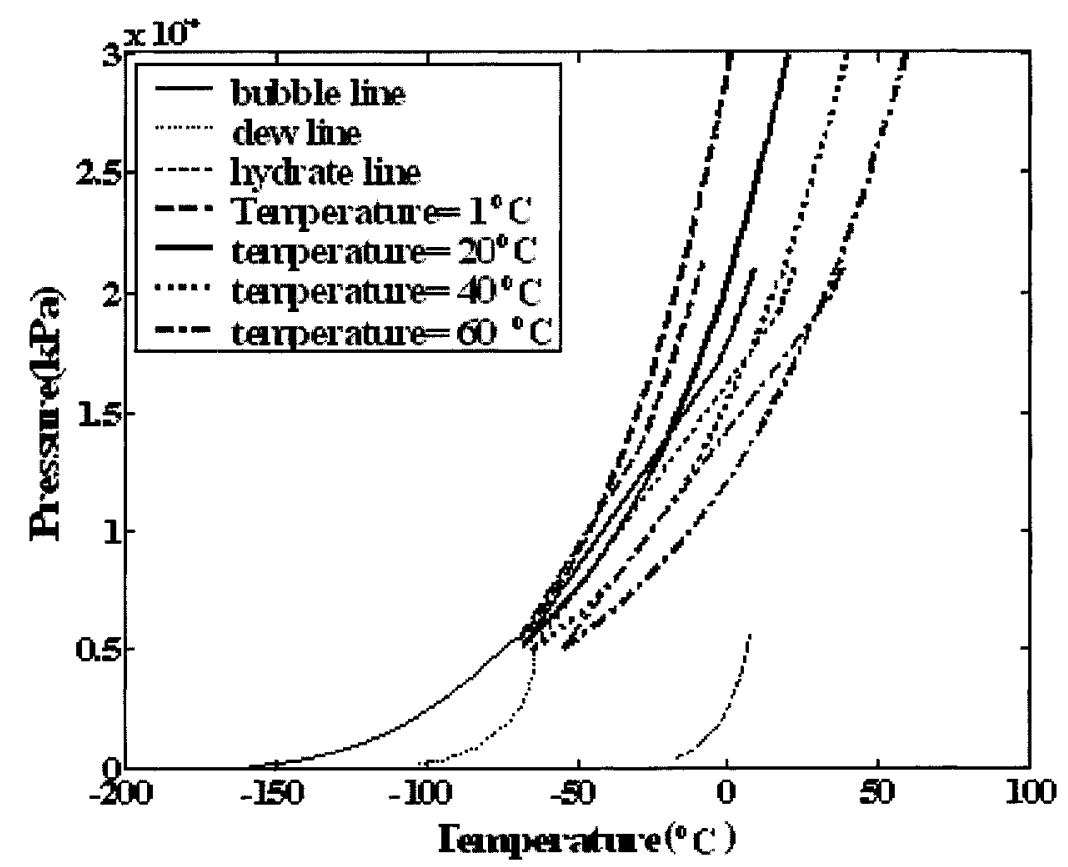

Figure 4.33: Phase envelope and Pressure- Temperature distributions along the designed nozzle and temperature-effect studies with $70 \%$ inlet pressure recovery

Table 4.19 presents the initial water content in the stream and the remained water content in the nozzle stream after separating the condensed liquid before the shockwave in a nozzle which is designed to recover $70 \%$ of the inlet pressure. In reality condensed liquids cannot be completely separated from the main stream in the nozzle, therefore the results shown here are theoretical assuming that $100 \%$ of the condensed liquid is separated. Figure 4.34 shows the gas water content along the nozzle. The water content increases with inlet temperature (see Figure 4.34). Theoretically, a close to complete water removal can be achieved in the supersonic nozzle in all the inlet conditions. 
Table 4.19: Remained water content in the nozzle stream after the shockwave for the designed nozzle in temperature-effect study with $70 \%$ inlet recovery

\begin{tabular}{|c|c|c|}
\hline $\begin{array}{c}\text { Inlet } \\
\text { temperature } \\
\left({ }^{\circ} \mathbf{C}\right)\end{array}$ & $\begin{array}{c}\text { Initial water content } \\
(\mathbf{m g} / \mathbf{m 3})\end{array}$ & Remainder water content $(\mathbf{m g} / \mathbf{m} 3)$ \\
\hline 1 & 59.39 & 0.23 \\
\hline 20 & 174.07 & 0.18 \\
\hline 40 & 464.22 & 0.24 \\
\hline 60 & 1084.30 & 0.84 \\
\hline
\end{tabular}

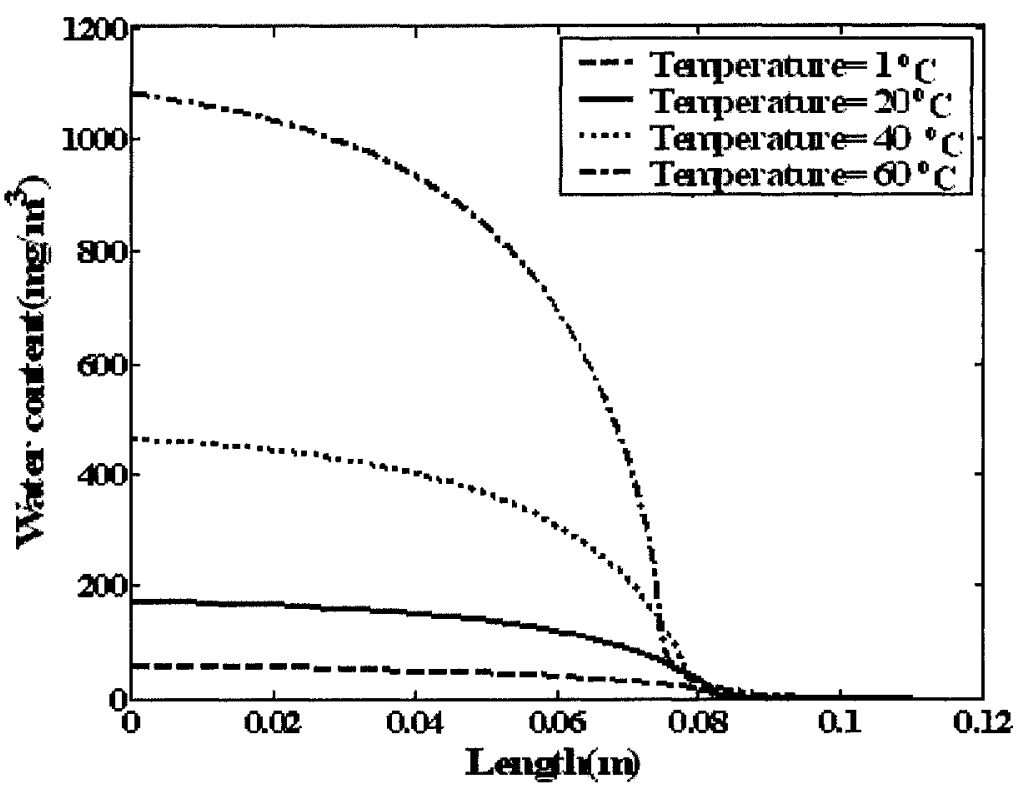

Figure 4.34: Theoretical water removal along the designed nozzle and temperature-effect studies with $70 \%$ inlet pressure recovery.

\subsubsection{RATING NOZZLES FOR EACH GAS STREAM IN TEMPERATURE-EFFECT STUDIES}

If the aim is using one nozzle for different inlet temperatures, the flow rate should be adjusted such that the sonic velocity is reached at the throat and the flow is choked. The designed nozzle using the "Test Stream" is used for this simulation. Table 4.20 shows the adjusted flow rates in each condition inlet temperature. The flow capacity 
decreases with the increase in the inlet temperature.

Table 4.20: the adjusted flow rate to rate the nozzle in temperature -effect-studies

\begin{tabular}{|c|c|c|c|c|}
\hline Stream name & $\mathbf{1}$ & Test stream & $\mathbf{2}$ & $\mathbf{3}$ \\
\hline Molar flow Rate (kmole/h) & 5,565 & 5,000 & 4,538 & 4,179 \\
\hline $\begin{array}{c}\text { Exit pressure range } \\
\text { (\% of inlet pressure) }\end{array}$ & $14.51,-, 80.76$ & $14.84,-, 82.71$ & $14.94,-, 84.14$ & $15.23,-, 85.24$ \\
\hline
\end{tabular}

Depending on the nozzle backpressure, the exit pressure will fall in a range whose lower and upper bounds are given as a percentage of the inlet pressure in Table 4.20. In nozzles with constant lengths, as the inlet temperature increases, the maximum possible recovery of inlet pressure will increase while the lowest exit pressure will stay almost unchanged. These results are shown in Figure 4.35.

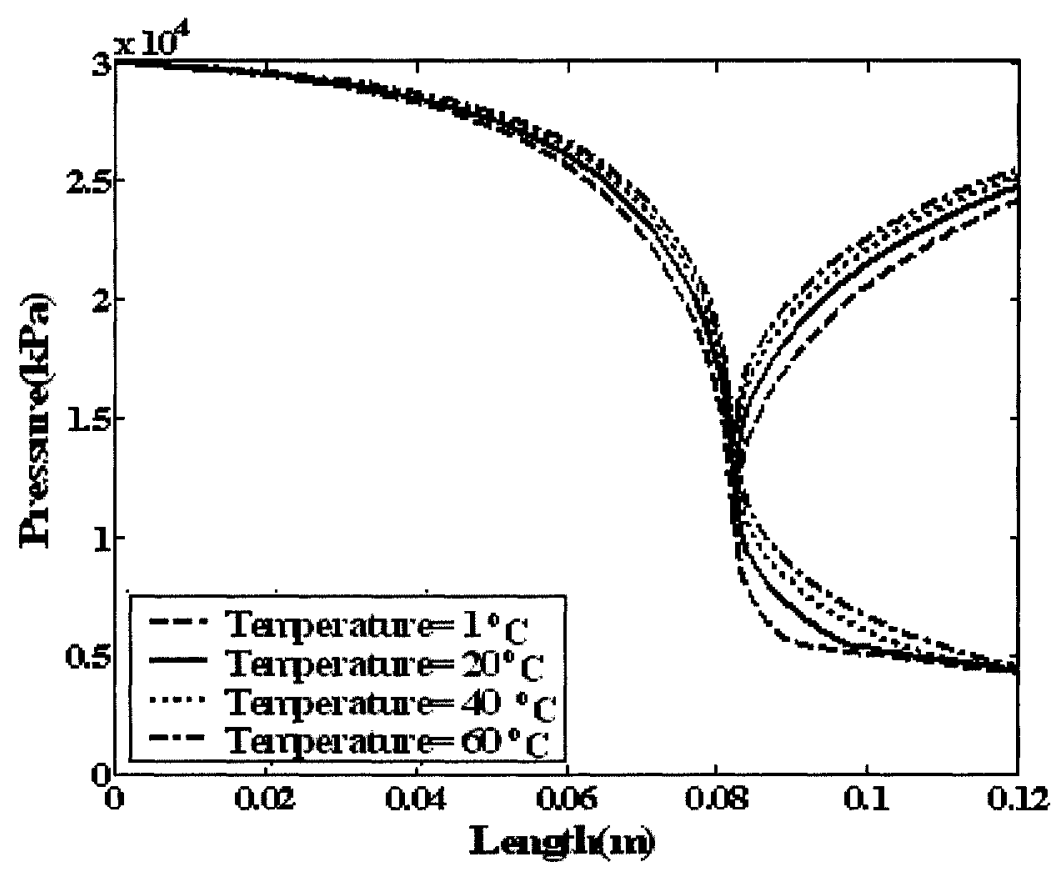

Figure 4.35: Pressure distribution along the rated nozzle in the temperature-effect-studies 
If the $70 \%$ recovery of the inlet pressure is used as the design criteria, the shockwave location varies depending on the inlet conditions (see Figure 4.36). Increasing the inlet temperature from 1 to $60^{\circ} \mathrm{C}$, shifts the shockwave location $12.82 \%$ towards the nozzle exit. The inlet pressure decreases between 82 to $83 \%$ before the shockwave happens.

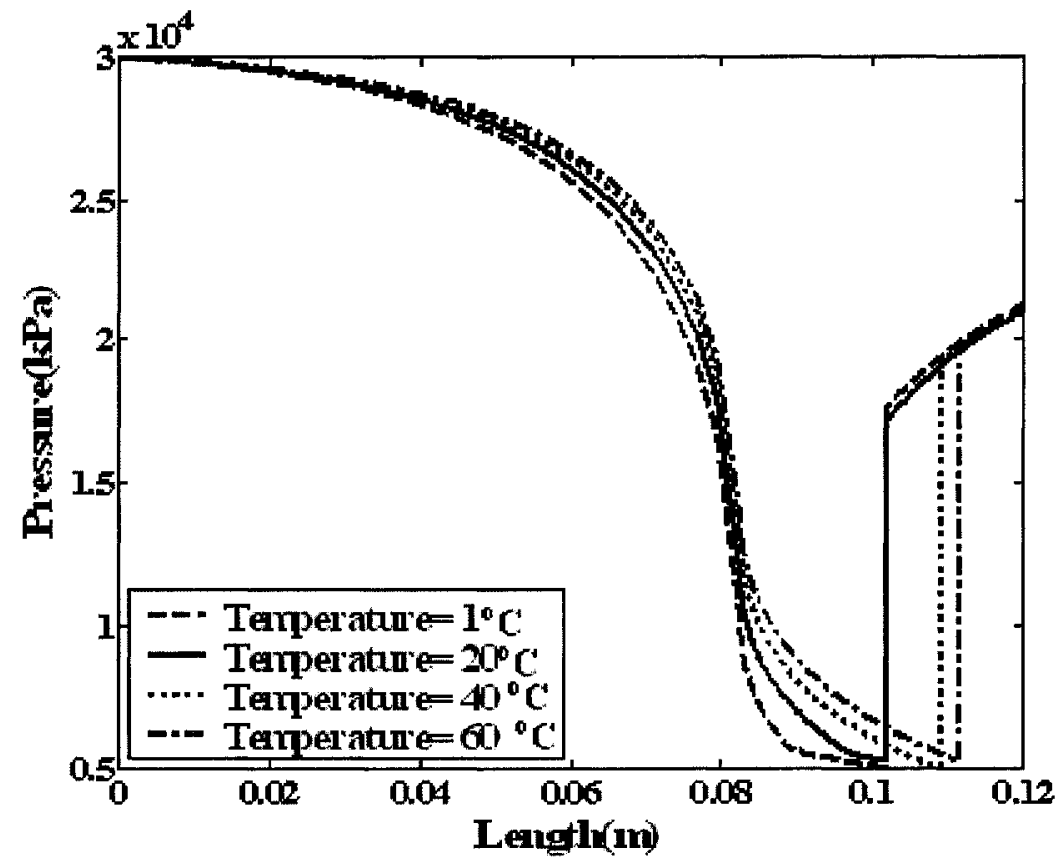

Figure 4.36: Pressure distribution and the shockwave location along a rated nozzle in temperature-effect-studies with $70 \%$ recovery of inlet pressure

Figure 4.38 illustrates that with $70 \%$ recovery of inlet pressure, as the inlet temperature increases the amount of the liquid phase decreases and finally it can be seen that with the inlet conditions for Stream 3, the flow remains in a single phase. Figures 4.39 and 4.40 show the temperature and velocity distributions along the rated nozzle in the temperature effect studies and when $70 \%$ of the inlet pressure recovery is obtained. 
Figure 4.36 illustrates that close to complete water removal occurs in the nozzle before the shockwave happens (see Table 4.21).

Table 4.21: Remained water content in the nozzle stream after the shockwave for the designed nozzle in temperature-effect study with $70 \%$ inlet recovery

\begin{tabular}{|c|c|c|}
\hline $\begin{array}{c}\text { Inlet } \\
\text { temperature } \\
\left({ }^{\circ} \mathbf{C}\right)\end{array}$ & Initial water content $(\mathbf{m g} / \mathbf{m 3})$ & $\begin{array}{c}\text { Remainder water content } \\
(\mathbf{m g} / \mathbf{m} 3)\end{array}$ \\
\hline 1 & 59.39 & 0.15 \\
\hline 20 & 174.07 & 0.18 \\
\hline 40 & 464.22 & 0.24 \\
\hline 60 & $1,084.30$ & 0.77 \\
\hline
\end{tabular}

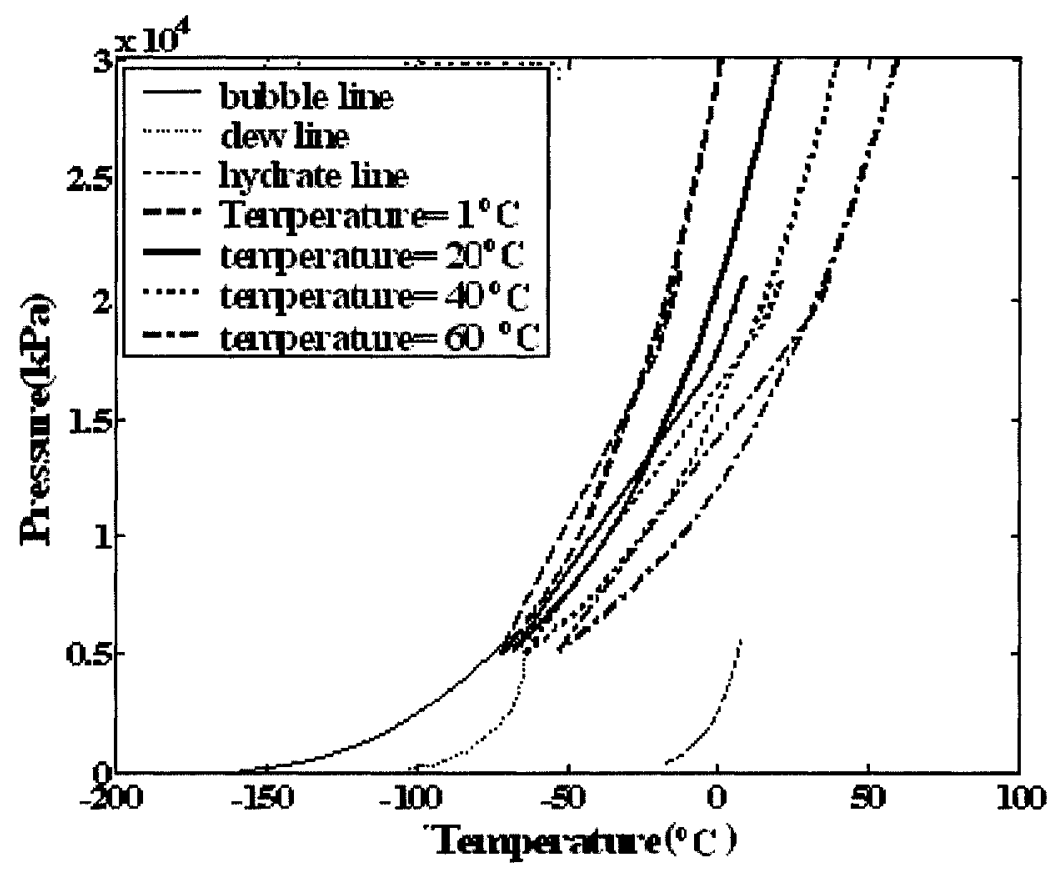

Figure 4.38: Phase envelope and Pressure- Temperature distributions along a rated nozzle in the temperature-effect studies with $70 \%$ inlet pressure recovery 


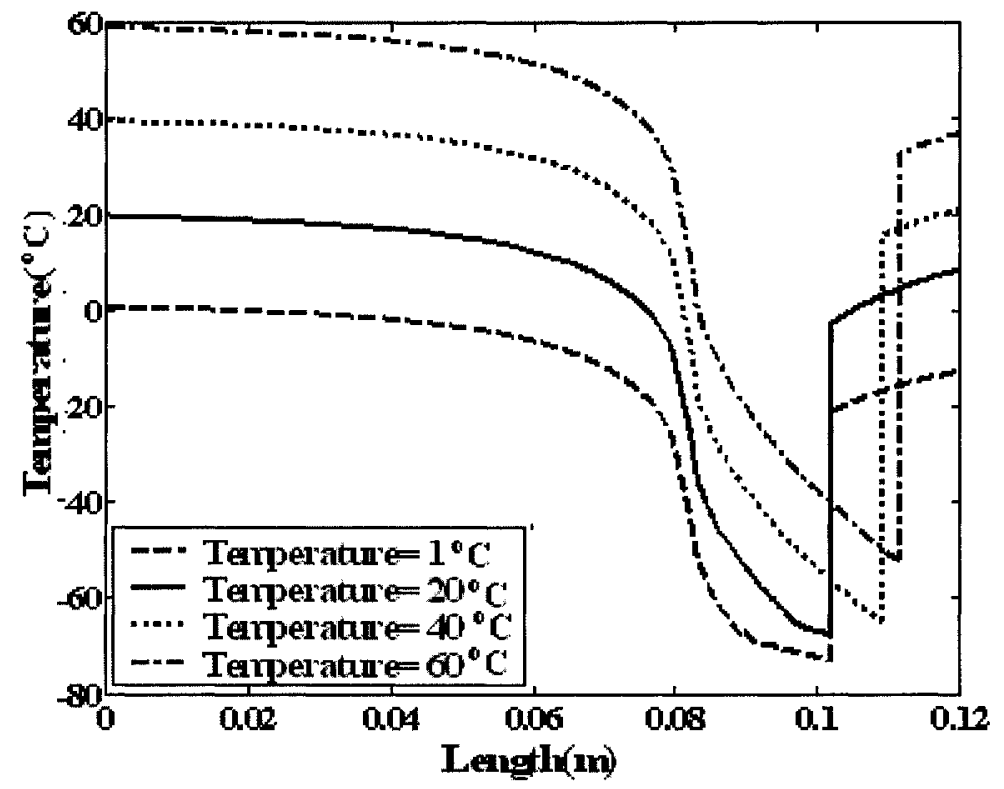

Figure 4.39: Temperature distribution and the shockwave location along a rated nozzle in the temperature-effect-studies with $70 \%$ inlet pressure recovery

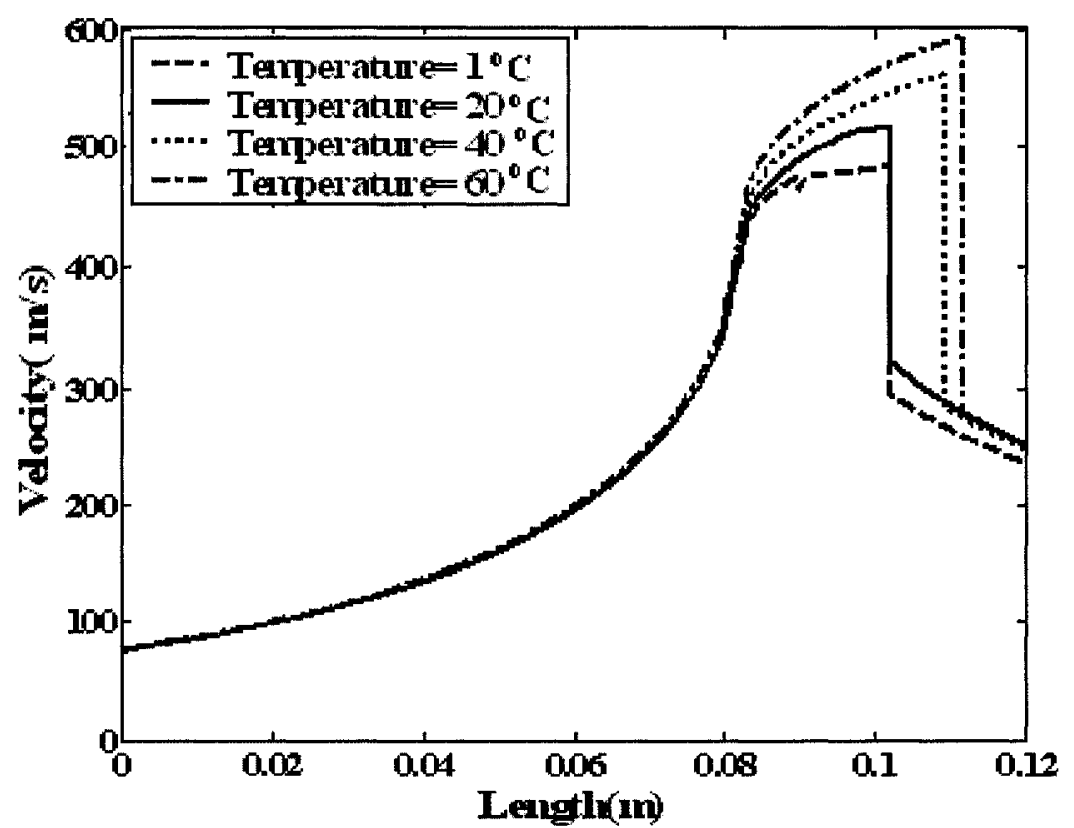

Figure 4.40: Velocity distributions and the shockwave locations along a rated nozzle in the temperature-effect-studies with $70 \%$ of inlet pressure recovery 


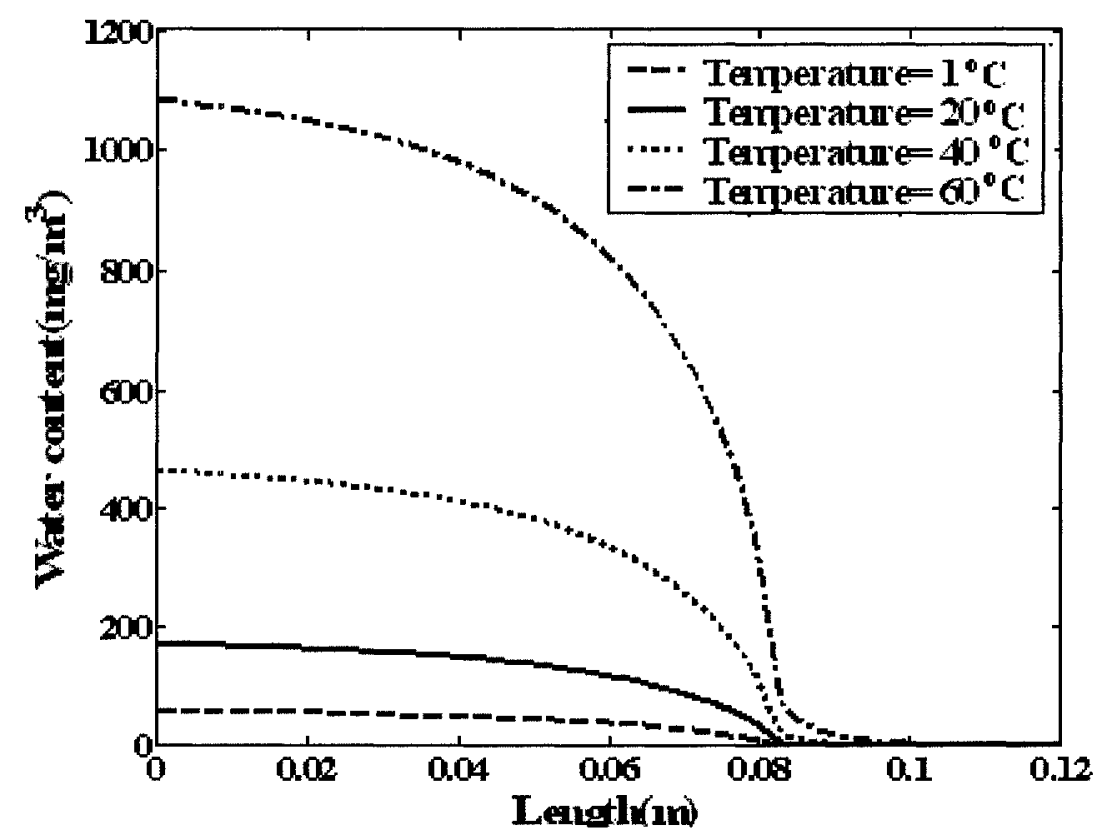

Figure 4.41: Theoretical water removal along the rated nozzle in the temperature-effectstudies with $70 \%$ inlet pressure recovery

\subsubsection{EfFect Of Flow Rate}

\subsubsection{DESIGNING A NOZZLE FOR DIFFERENT FLOW RATES IN FLOW RATE-EFFECT STUDIES}

A few streams with the pressure, temperature, and composition the same as that of "Test Stream" but with different flow rates are considered as the working fluid and a nozzle was designed for each case. Table 4.22 shows the inlet flow rate and the range of the exit pressures as a percentage of the inlet pressure. A wider range of pressure recovery can be achieved in the nozzle with the increase in inlet flow rate. Therefore, the "recovery pressure" increases with inlet flow rate. In the nozzle with a length of $0.12 \mathrm{~m}$, the highest possible pressure recovery is 64.80 and $93.03 \% \%$ of the inlet pressure for 
Stream 1 and 4, respectively. Figure 4.42 presents the result shown in Table 4.22.

Table 4.22: The pressure recovery range in the flow rate-effect-studies

\begin{tabular}{|l|c|c|c|c|c|}
\hline \multicolumn{1}{|c|}{ Stream name } & $\mathbf{1}$ & $\mathbf{2}$ & Test stream & $\mathbf{3}$ & $\mathbf{4}$ \\
\hline $\begin{array}{l}\text { Molar flow Rate } \\
\text { (kmole/h) }\end{array}$ & 2,000 & 4,000 & 5,000 & 6,000 & 10,000 \\
\hline $\begin{array}{l}\text { Exit pressure range } \\
\text { (\% of inlet pressure) }\end{array}$ & $20.4-64.8$ & $15.6-79.8$ & $14.8-82.7$ & $14.4-85.0$ & $13.5-93.0$ \\
\hline
\end{tabular}

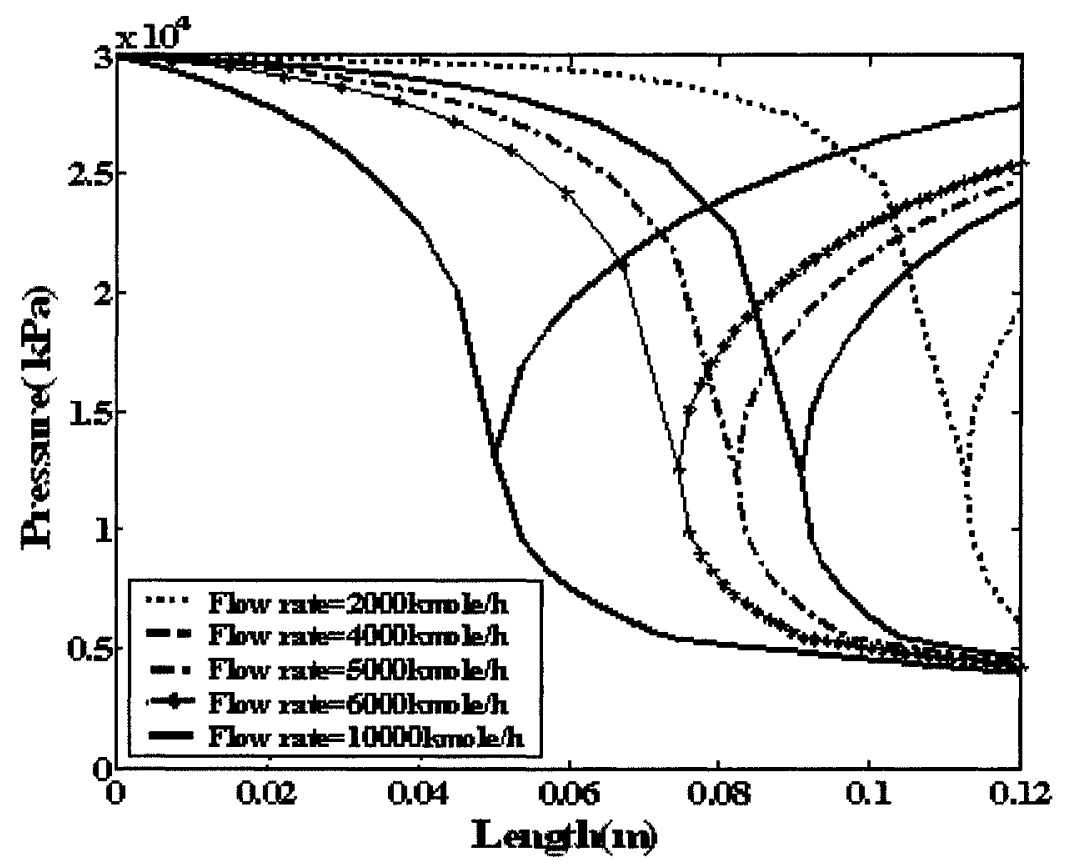

Figure 4.42: Pressure distribution along the rated nozzle in the flow rate-effect-studies

Figure 4.43 shows the different nozzle geometries. As it can be seen the flow becomes choked earlier along the nozzle as the flow rate increases. Therefore, the converging length of the nozzle is shorter and the throat diameter is bigger. These results are shown in Table 4.23. 


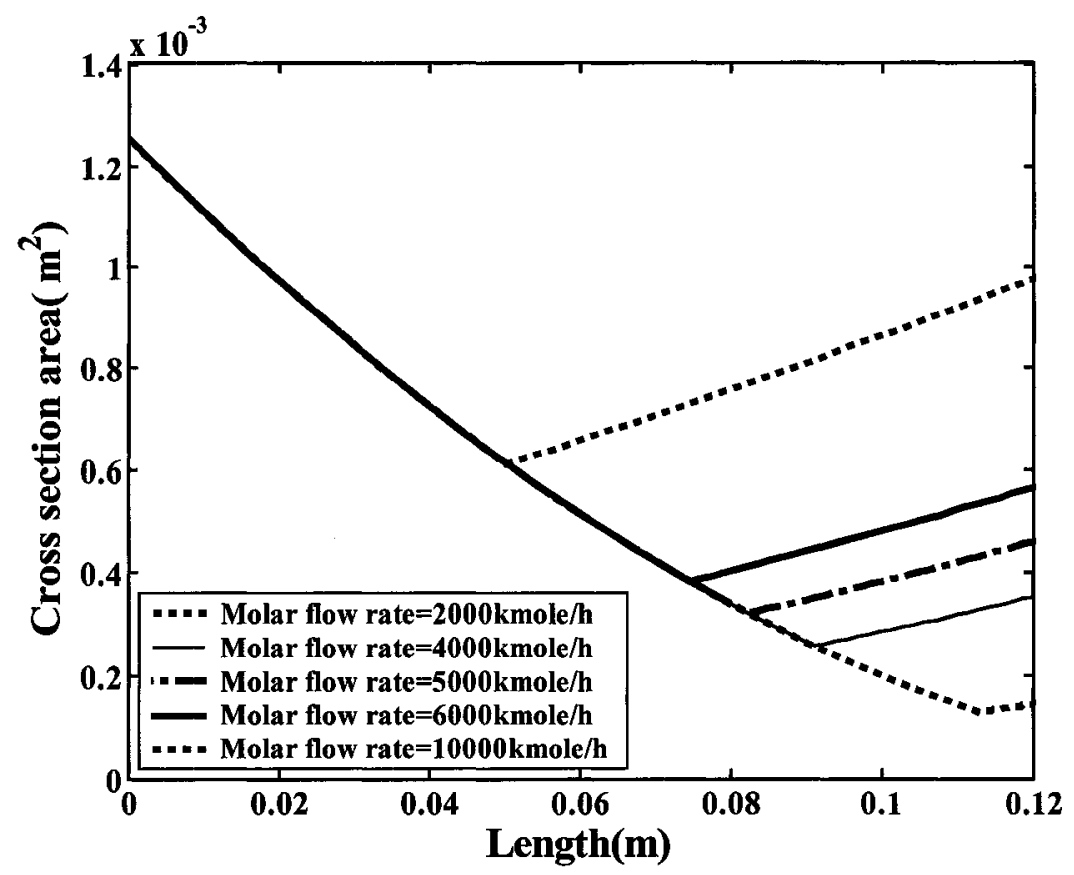

Figure 4.43: Designed nozzles geometry in flow rate-effect-studies

Table 4.23: Designed nozzle geometry in flow rate-effect studies

\begin{tabular}{|l|c|c|c|c|c|}
\hline \multicolumn{1}{|c|}{ Stream name } & $\mathbf{1}$ & $\mathbf{2}$ & $\begin{array}{c}\text { Test } \\
\text { stream }\end{array}$ & $\mathbf{3}$ & $\mathbf{4}$ \\
\hline Throat diameter(m) & 0.0129 & 0.0182 & 0.0203 & 0.0221 & 0.0279 \\
\hline Nozzle converging length $(\mathrm{m})$ & 0.1128 & 0.0908 & 0.0821 & 0.0744 & 0.0502 \\
\hline
\end{tabular}

With the design criteria of $70 \%$ recovery of the inlet pressure, no nozzle with the length of $0.12 \mathrm{~m}$ can be designed for Stream 1 as $64.80 \%$ of the inlet pressure recovery is the highest possible recovery in such a nozzle. The pressure, temperature and velocity distributions and the shockwave locations along a designed nozzle with $70 \%$ inlet 
pressure recovery are shown in Figure 4.44, 4.45 and 4.46. Shockwave happens at $77.07 \%$ of the total nozzle length when the molar flow rate is $10,000 \mathrm{kmole} / \mathrm{h}$. The shockwave location shifts toward the nozzle exit as the molar flow rate of the nozzle decreases. When the molar flow rate is $4,000 \mathrm{kmole} / \mathrm{h}$, shockwave happens at $88.33 \%$ of the total length.

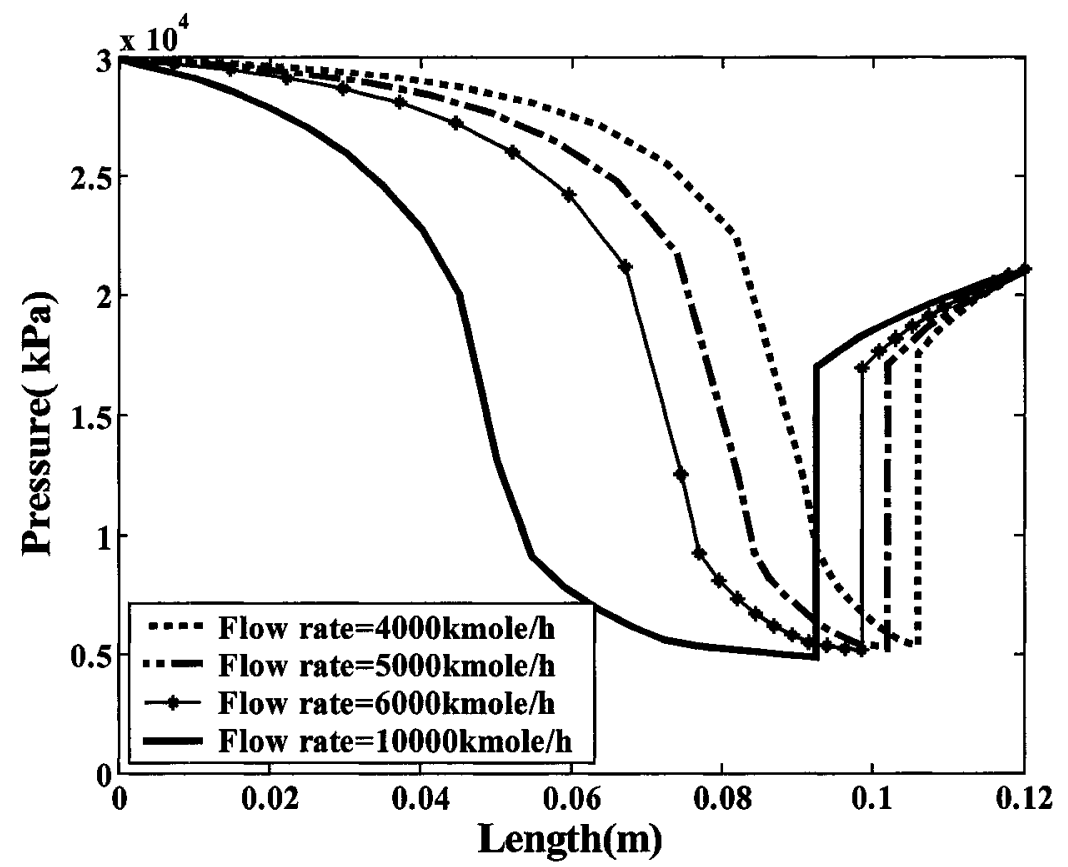

Figure4.44: Pressure distributions and the shockwave locations along the designed nozzle in flow rate-effect studies with $70 \%$ inlet pressure recovery 


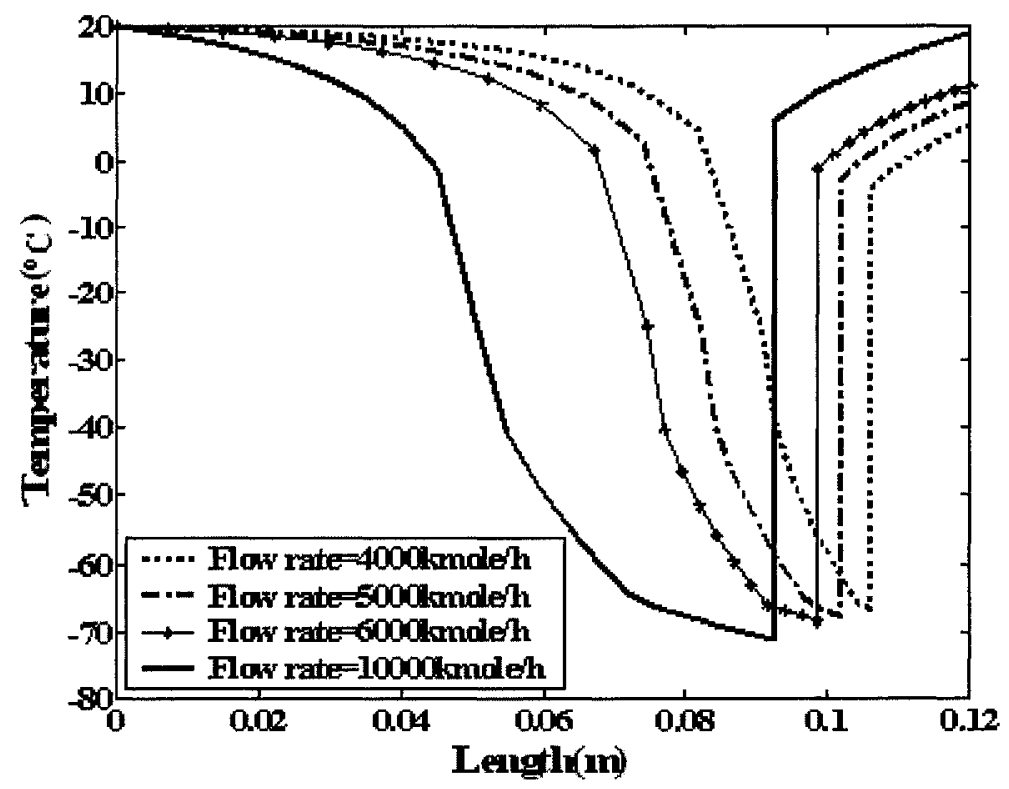

Figure4.45: Temperature distributions and the shockwave locations along the designed nozzle in flow rate-effect studies with $70 \%$ inlet pressure recovery

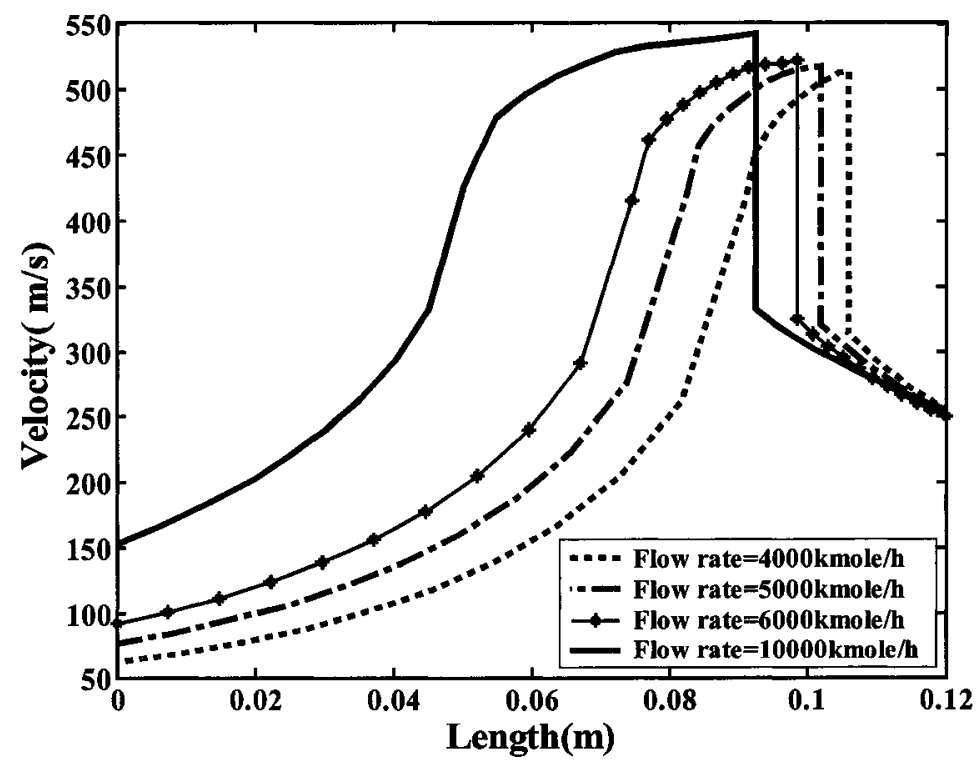

Figure4.46: Velocity distributions and the shockwave locations along the designed nozzle in flow rate-effect studies with $70 \%$ inlet pressure recovery 
For any each stream conditions and the specified nozzle geometry, there is a flow rate (design flow rate) in which the critical conditions are presents at the throat and the flow is choked. If the flow rate is lower than the specified flow rate, the Mach number will be less than unity in the throat of the nozzle and the flow will never be choked. Figures 4.47 and 4.48 show the Mach number and the pressure distributions of the streams with pressures and temperatures equal to that of the "Test Stream" at different flow rates. For the flow rate equal to 5,000 kmole/ $\mathrm{h}$ for which the nozzle was designed, the Mach number at the throat reaches unity but for the lower flow rates the stream is always remain subsonic (see Figure 4.47).

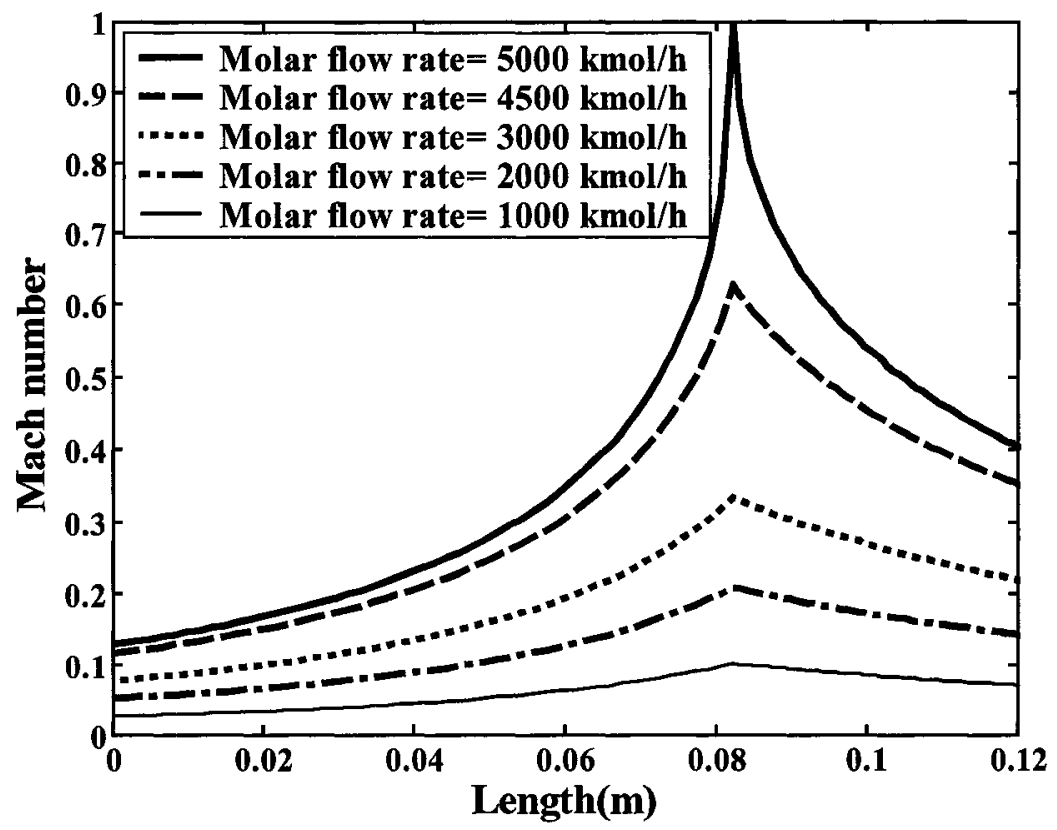

Figure 4.47: Mach number distribution along the nozzle with different flow rates

As shown in Figure 4.48, the pressure drop on both sides of the nozzle increases 
as the flow rate increases to the design flow rate. This pressure drop is the lowest possible pressure drop along the specified nozzle, while the flow is choked.

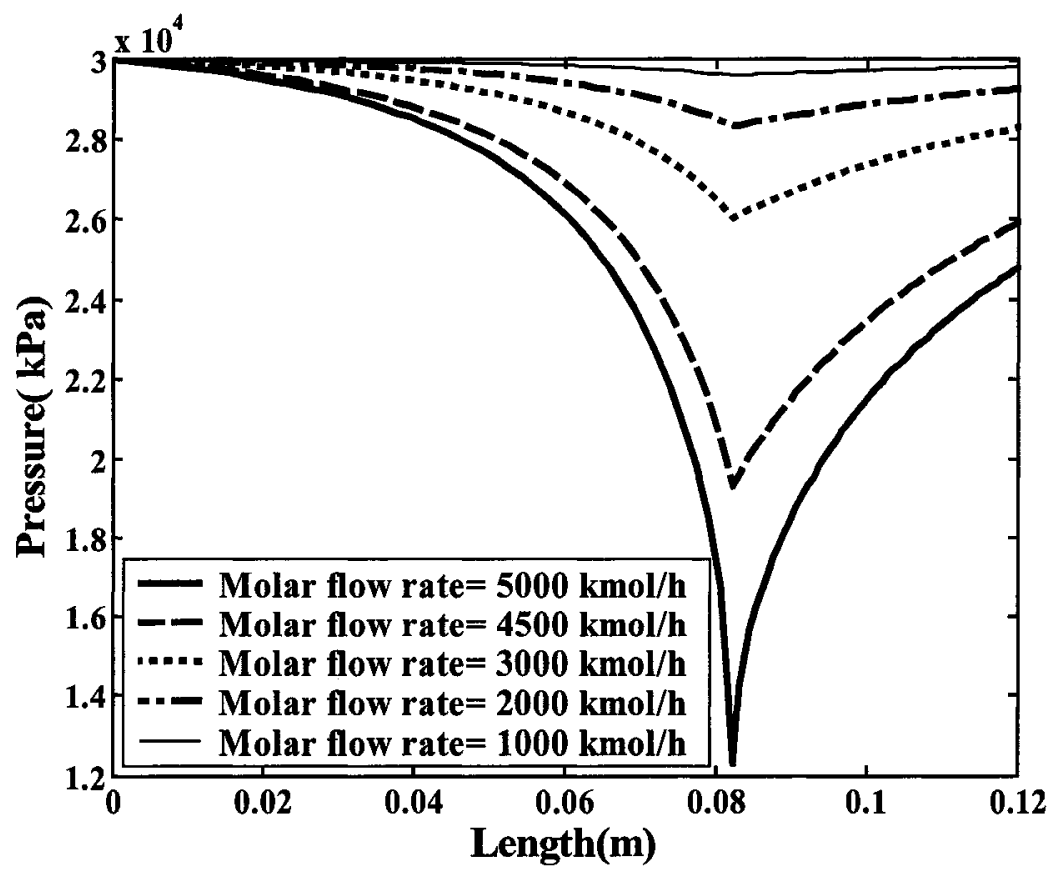

Figure 4.48: Pressure distribution along the nozzle with different flow rates

\subsubsection{EFFECT OF BACKPRESSURE}

The behaviour of the working fluid in the nozzle depends on the back pressure (pressure at the nozzle exit) of the nozzle. For a nozzle of $0.12 \mathrm{~m}$ long and the "Test Stream" as a working fluid, the backpressure should not exceed $82.71 \%$ of the inlet pressure in order to choke the flow at the throat. This exit pressure is equal to the nozzle "recovery pressure". The" design pressure" in this condition is $14.84 \%$ of the inlet pressure. If the backpressure is between the nozzle "recovery pressure" and "design pressure", a shockwave happens either inside or outside of the diverging part of the 
nozzle. With the decrease in the backpressure, the shockwave location shifts towards the nozzle exit until when the backpressure is equal to $48.5 \%$ of the inlet pressure where the shockwave happens at the nozzle exit. The shockwave happens outside the nozzle if the backpressure decreases further down and falls between 48.50 to $14.84 \%$ of the inlet pressure.

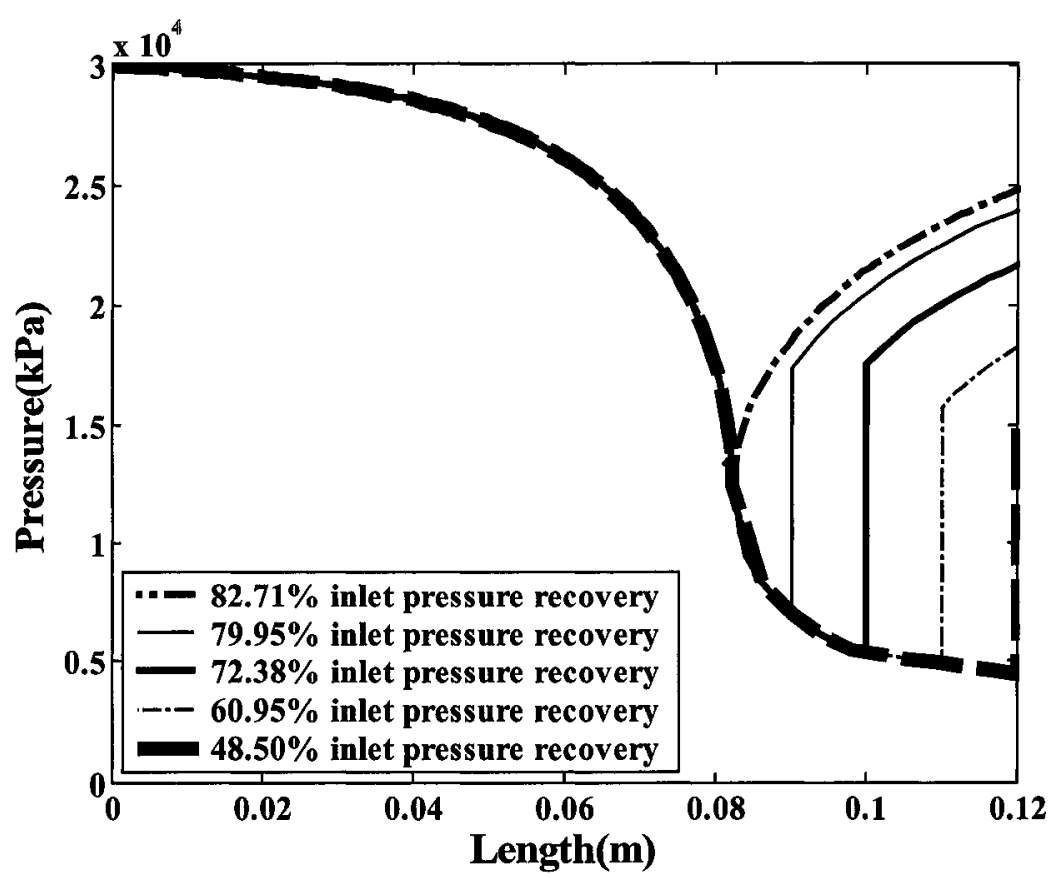

Figure 4.49: Pressure distribution along the nozzle for different back pressures

Figures 4.50 to 4.53 show the temperature-pressure variations and the location of the lowest temperature with respect to the two-phase region. It is clear that by lowering the pressure recovery (higher pressure drops along the nozzle), the gas will expand more and pressure and temperature will be lower before the shockwave happens. The pressure drop can be reduced by increasing the backpressure which results in higher pressure and 
temperature before the shockwave. If the selective water removal is desired, pressure and temperature before the shock should be prevented from falling into the two-phase region. As indicated in Figures 4.50 to 4.53 , higher backpressures cause the shockwave to happen earlier and less liquid hydrocarbons will form. Increasing the backpressure might reduce the water removal efficiency. Table 4.24 lists the amount of water remained in the gas at different shockwave locations along the nozzle. As it can be seen $94 \%$ of the water is removed in the converging part of the nozzle. In this condition, although about only $80 \%$ of the inlet pressure is recovered, close to complete water removal is achieved. A selective water removal is obtained in this case (see Figure 4.53 ) and $94 \%$ of the total amount of water in the stream will be condensed in the converging part of the nozzle. The rest of the water will start condensing in the diverging part.

Table 4.24: Water content along the nozzle

\begin{tabular}{|l|c|c|c|c|c|}
\hline Shockwave location (m) & 0.082 & 0.090 & 0.100 & 0.110 & 0.120 \\
\hline $\begin{array}{l}\text { Pressure recovery } \\
\text { (\% of inlet pressure) }\end{array}$ & 82.71 & 79.95 & 72.38 & 60.95 & 48.5 \\
\hline $\begin{array}{l}\text { Water remainder in vapour phase } \\
\text { (\% of initial water content) }\left(\mathbf{m g} / \mathbf{m}^{3}\right)\end{array}$ & 6.00 & 0.50 & 0.11 & 0.06 & 0.04 \\
\hline
\end{tabular}




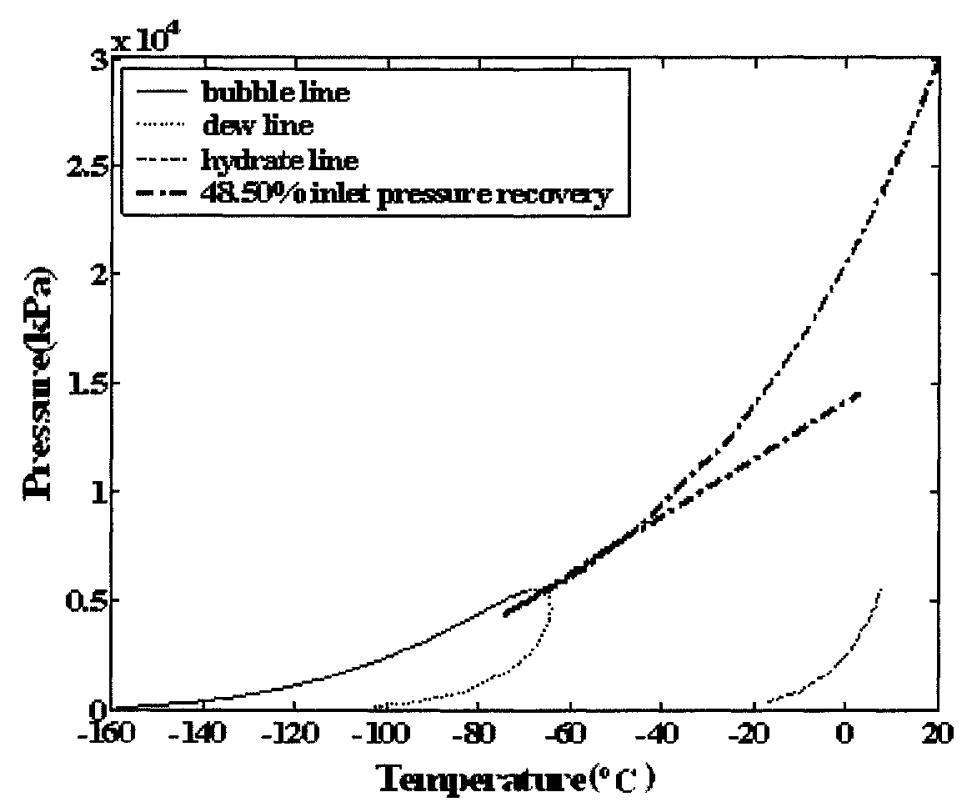

Figure 4.50: Phase envelope and Pressure-Temperature distributions with $48.5 \%$ inlet pressure recovery

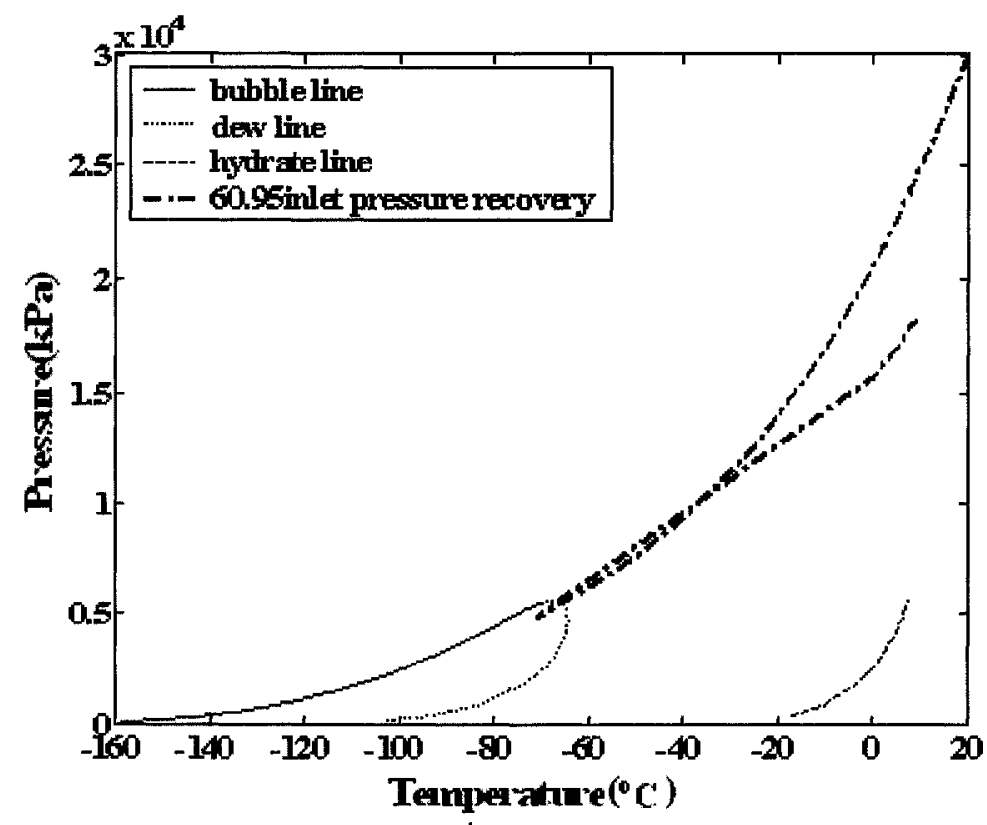

Figure 4.51: Phase envelope and Pressure-Temperature distributions with $60.95 \%$ inlet pressure recovery 


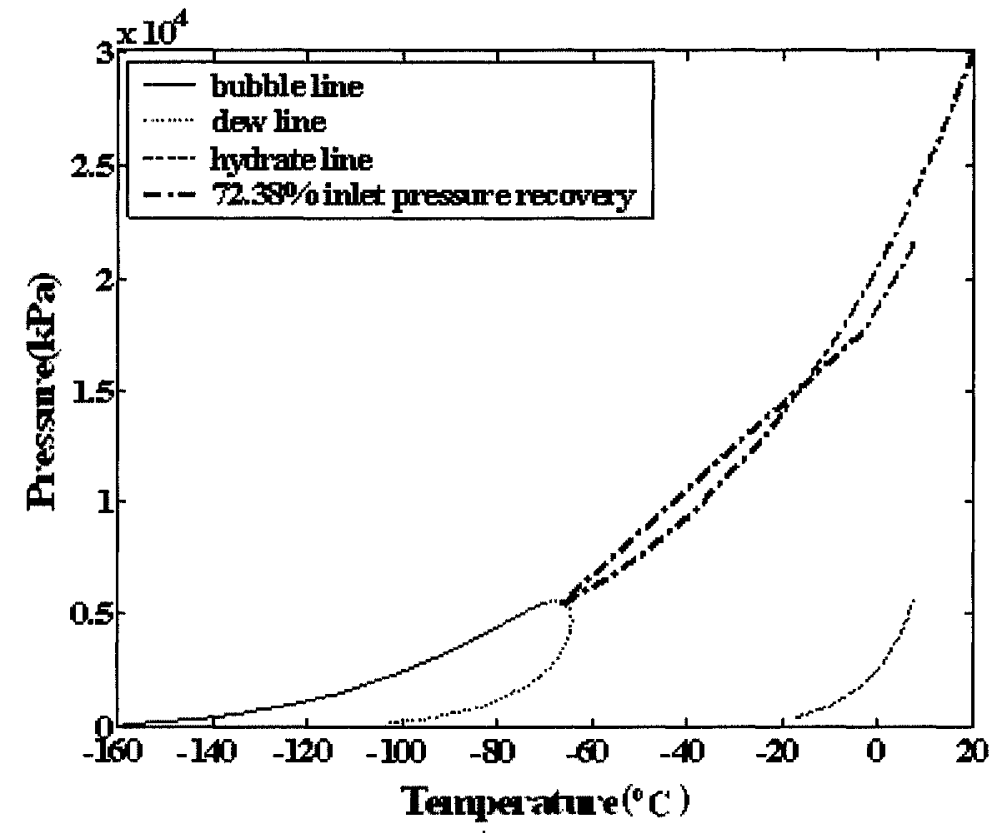

Figure 4.52: Phase envelope and Pressure-Temperature distributions with $73.38 \%$ inlet pressure recovery

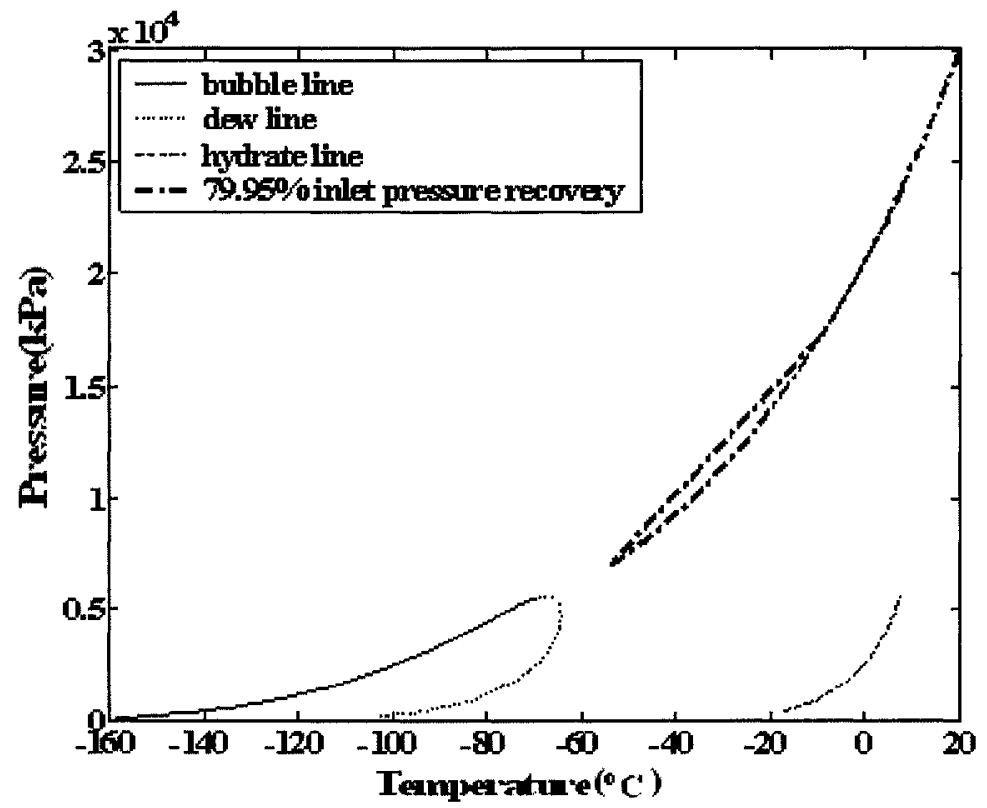

Figure 4.53: Phase envelope and Pressure-Temperature distributions with $79.95 \%$ inlet pressure recovery 


\subsubsection{EFFECT OF FRICTION}

All the analyses up to this point were performed considering no friction in the nozzle; the effect of friction in the nozzle will be considered in this part of the thesis. As a result of friction, the flow will not remain isentropic and the entropy of the flow will therefore be increasing along the nozzle. The nozzle is assumed to be made of mild steel with an absolute roughness of $4.572 \times 10^{-5} \mathrm{~m}$. The analyses are performed by designing a nozzle in which a non-isentropic flow exists or alternatively by rating the nozzle which is designed in isentropic condition, considering the non-isentropic flow as a working fluid.

\subsubsection{DESIGNING A NEW NOZZLE USING NON-ISENTROPIC FLOW IN FRCITION- EFFET STUDIES}

A nozzle is designed assuming that friction is present in the nozzle and the "Test Stream" is flowing through the nozzle. The throat diameter used in this simulation is $0.11 \%$ larger than that of the frictionless case and the converging length is $0.05 \%$ shorter than that of the case with frictionless flow. These two geometrical values affect the pressure at the throat, the "recovery pressure", and the "design pressure" in less than $0.5 \%$. Most probably the discrepancies are because of the errors in the developed program such as the errors such as a result of the tolerance defined in calculating the results, round off error and truncating errors, present in the computations. Therefore, the "recovery pressure" and the "design pressure" of the nozzle are the same for both frictionless and frictional flow (see Figure 4.54) but the shockwave location in the diverging part of the nozzle will be different. The differences between the shockwave 
locations with the design criteria of $70 \%$ inlet pressure recovery, is shown in Figure 4.54. In the frictionless flow, shockwave occurs at $85 \%$ of the total nozzle length and for the frictional flow it shifts $8.83 \%$ towards the nozzle exit and occurs at $93.83 \%$ of the total length. Figures 4.55 and 4.56 show the temperature and velocity distributions along the designed nozzle for the friction-effect studies.

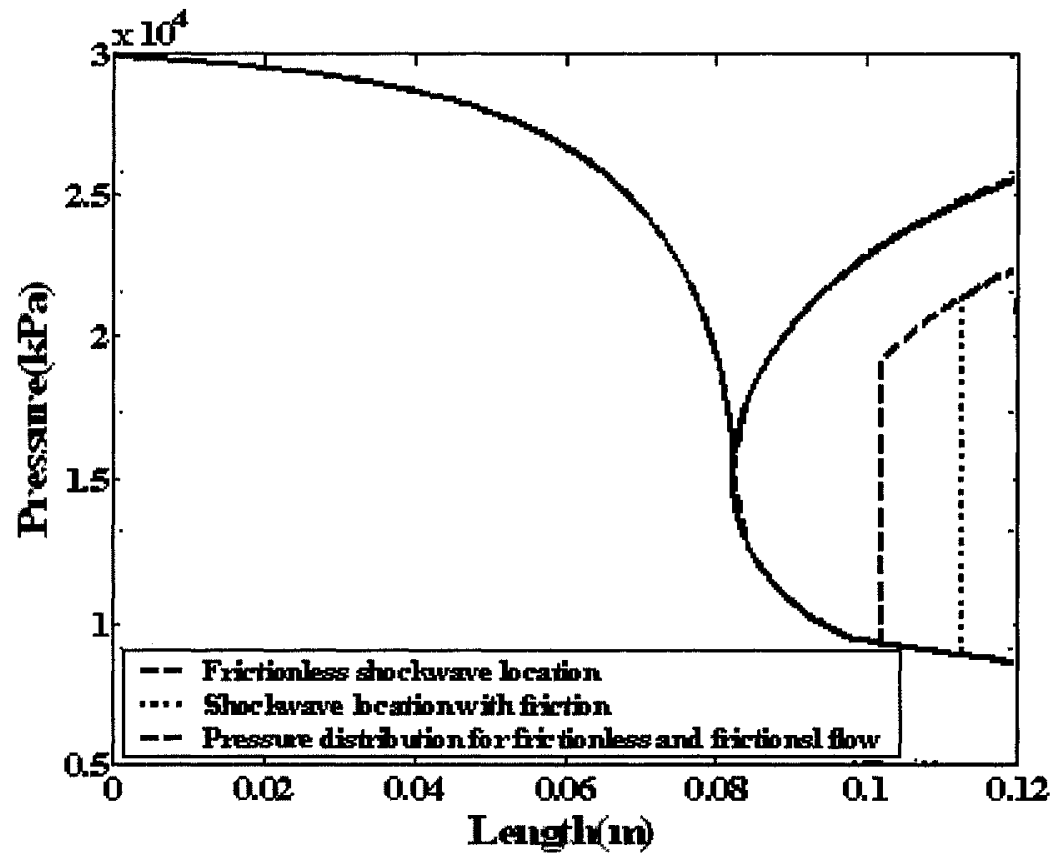

Figure 4.54: Pressure distribution and the shockwave location along the designed nozzle for the friction-effect study with $70 \%$ inlet pressure recovery 


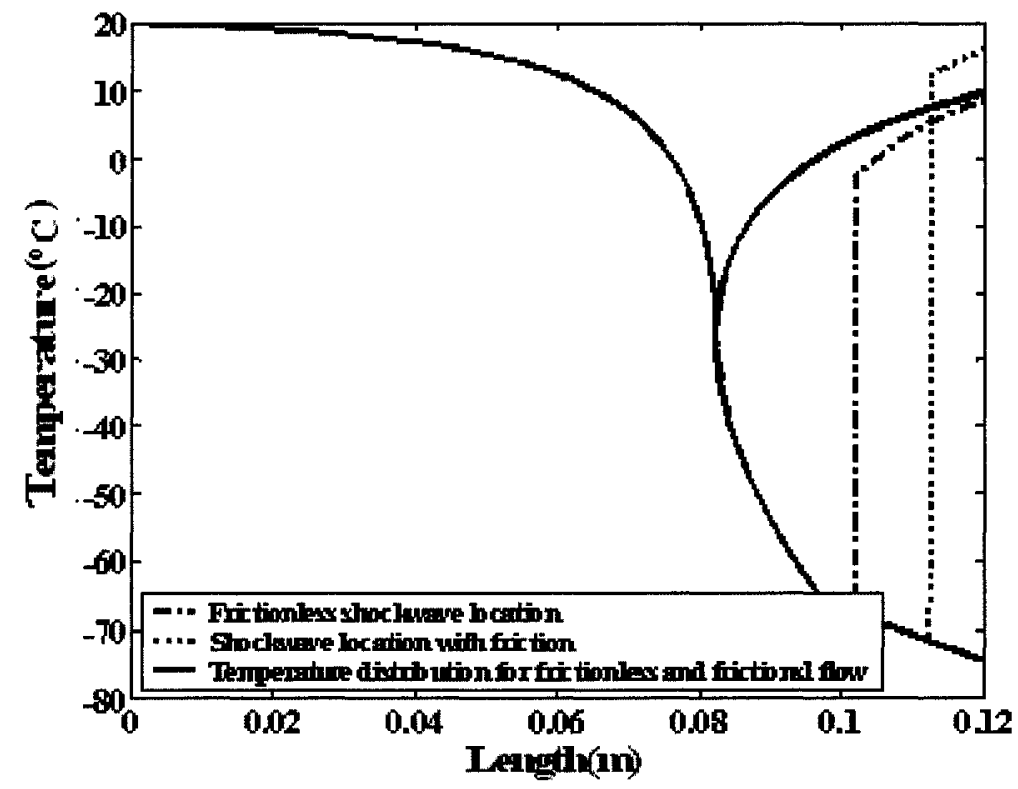

Figure 4.55: Temperature distribution and the shockwave location along the designed nozzle for the friction-effect study with $70 \%$ inlet pressure recovery

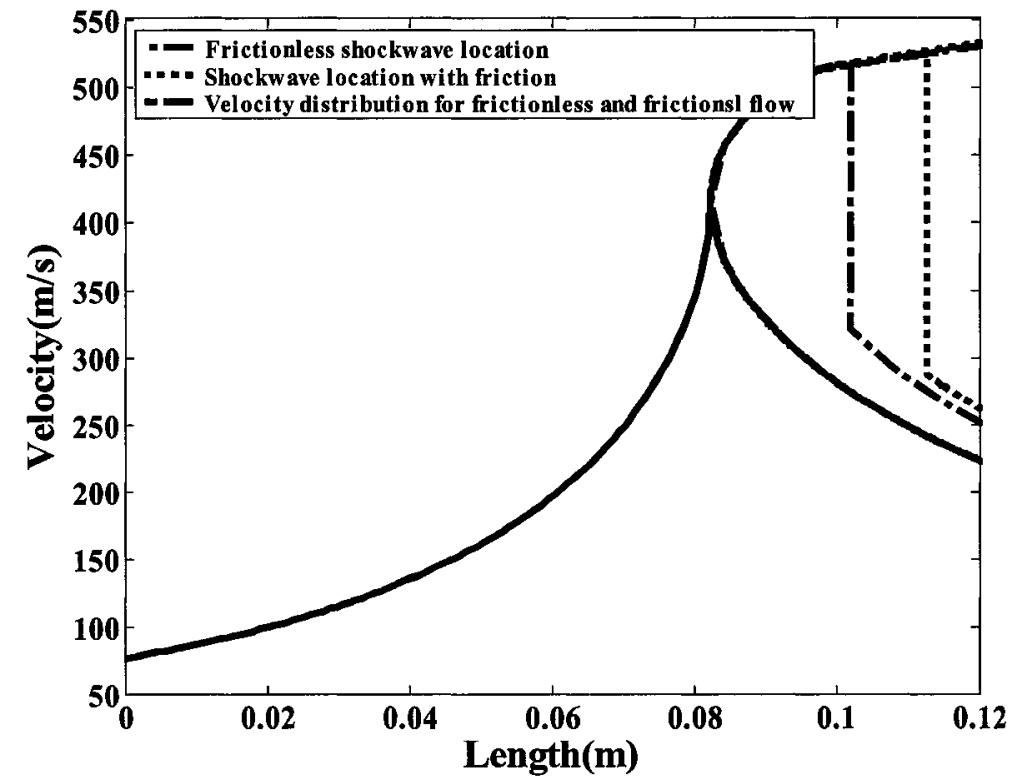

Figure 4.56: Velocity distribution and the shockwave location along the designed nozzle for the friction-effect study with $70 \%$ inlet pressure recovery 


\subsubsection{RATING THE DESIGHNED NOZZLE WITH THE NON-ISENTROPIC FLOW IN FROCTION EFFECT STUDIES}

In order to rate the nozzle for the non-isentropic flow, we considered a nozzle previously designed for test stream assuming isentropic flow. For the same flow rate as in the friction less flow, the nozzle will not choke at the throat and the throat Mach number will be 0.879 . Therefore, the flow rate needs to be increased. The desired flow rate in this case is $5,003 \mathrm{kmole} / \mathrm{h}$ instead of 5,000 kmole/ $\mathrm{h}$. the new flow rate is just $0.06 \%$ larger than the isentropic flow and also the differences between the pressure at the throat, nozzle" recovery pressure" and "design pressure" for the two cases are less than $0.5 \%$, respectively. It can be assumed that the nozzle geometry and the flow rate are the same in an isentropic flow as well as the case when friction is present in the nozzle. The friction however affects the shockwave location in the diverging part of the nozzle. As the friction is introduced to the nozzle the shockwave location shifts towards the nozzle exit. When rating the nozzle, the shockwave is $9.48 \%$ of the total length ahead of the shockwave location in the isentropic flow and occurs at $94.5 \%$ of the total length.

Figures $4.57,4.58$, and 4.59 show the comparisons between the isentropic and non-isentropic flows. 


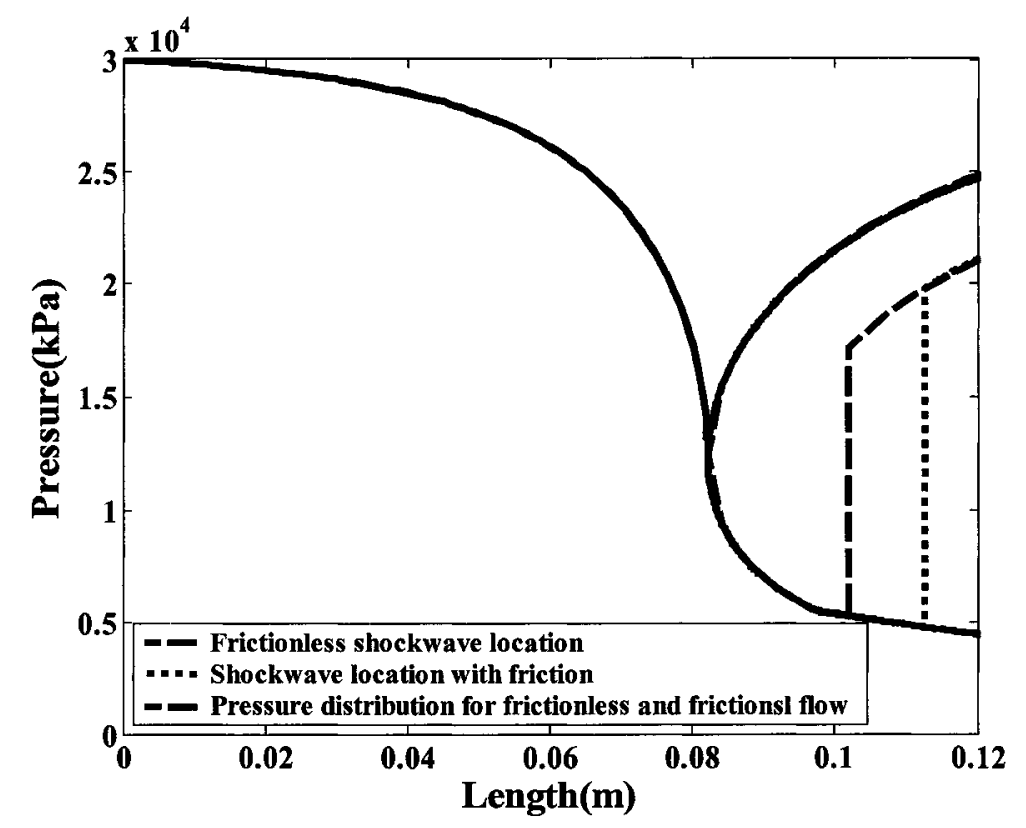

Figure 4.57: Pressure distributions and the shockwave locations along a rated nozzle with $70 \%$ inlet pressure recovery for the friction-effect study.

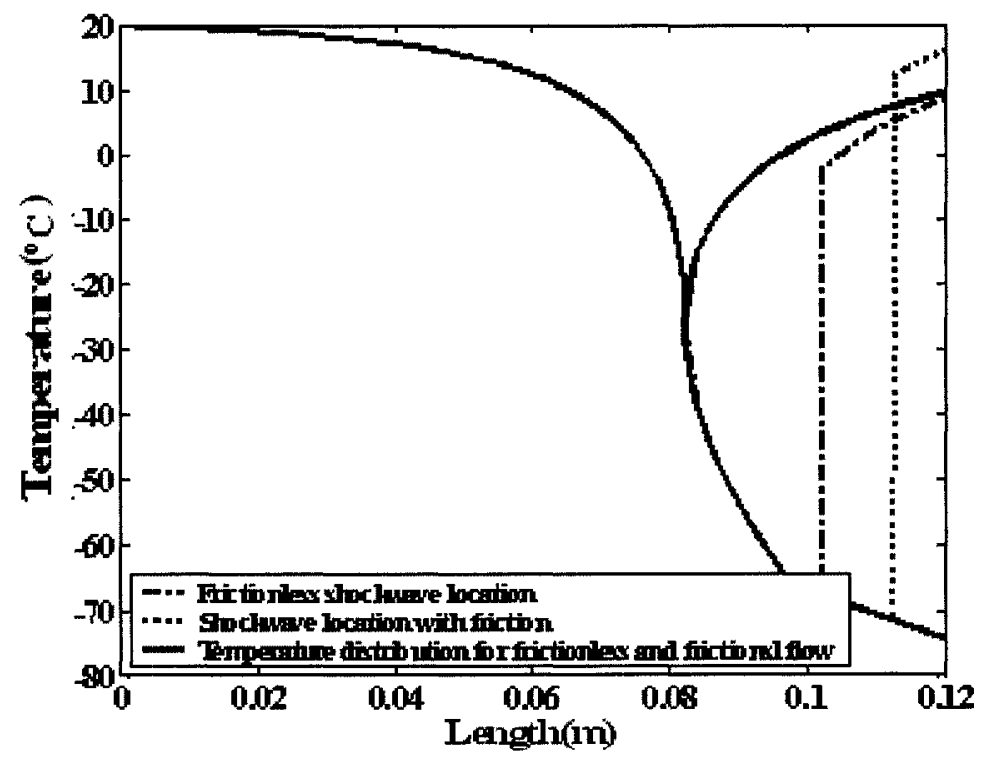

Figure 4.58: Temperature distribution and the shockwave locations along a rated nozzle with $70 \%$ inlet pressure recovery for the friction-effect study 


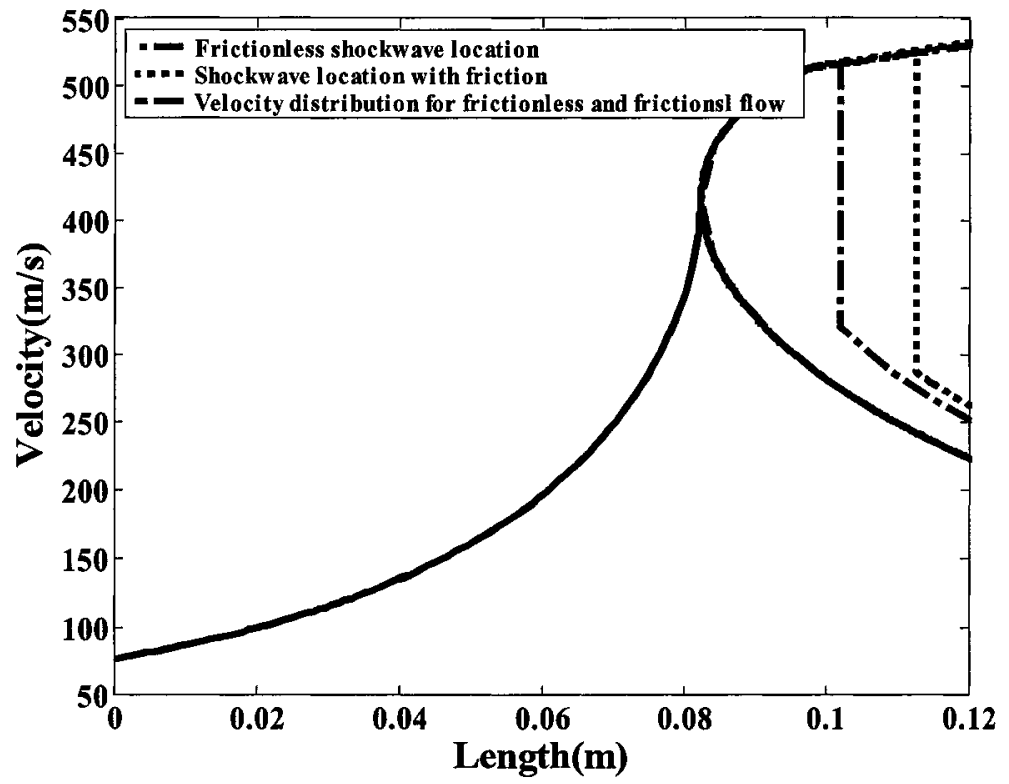

Figure 4.59: Velocity distribution and the shockwave locations along a rated nozzle with $70 \%$ inlet pressure recovery for the friction-effect study 


\section{Chapter 5: Case study: Natural Gas Liquids (NGLs) RECOVERY}

The recovery of natural gas constituents heavier than methane is a common process in natural gas treatment for dew point control and enhanced hydrocarbon recovery purposes. Large quantities of the produced gas used to be flared during the production of crude oil. The flaring of associated gas is gradually being abandoned and there are very strict regulations to minimize this wasteful practice, however there are still offshore facilities where a significant amount of gas has to be flared due to the lack of infrastructure to transport the gas to the market. Recovering NGL from the produced gas can significantly decrease the toxicity as well as reduce the wastage of valuable hydrocarbons of the flared gases. Supersonic separators are also used for the efficient recovery of NGLs, as natural gas condensate can be formed as a result of the expansion occurring in the nozzle. Therefore, by placing a supersonic separator within a typical crude surface production system on an offshore platform, the efficiency of the production unit can be improved. The position of the separator within the separator train will impact the recovery of the NGLs. The purpose of this chapter is to study the performance of supersonic nozzles for the recovery of NGLs. For this study a supersonic separators is placed in different positions and the crude oil production performance in each case is compared with the original production system without the NGL recovery. Membranes were studied for the NGL recovery in offshore facilities (Beronich, 2006). The 
information used in Beronich's work is chosen here to study the efficiency of supersonic separators in the recovery of NGLs.

\subsection{PROCESS DESCRIPTION}

The location chosen to perform this study is the Hibernia platform located offshore of the province of Newfoundland and Labrador. A typical separation train on an offshore platform consists of series of separators at different pressures. Figure 5.1 outlines a typical diagram of this process. The pressure and temperature of the wellhead stream before entering the process are based on industry data (Beronich et al., 2006).
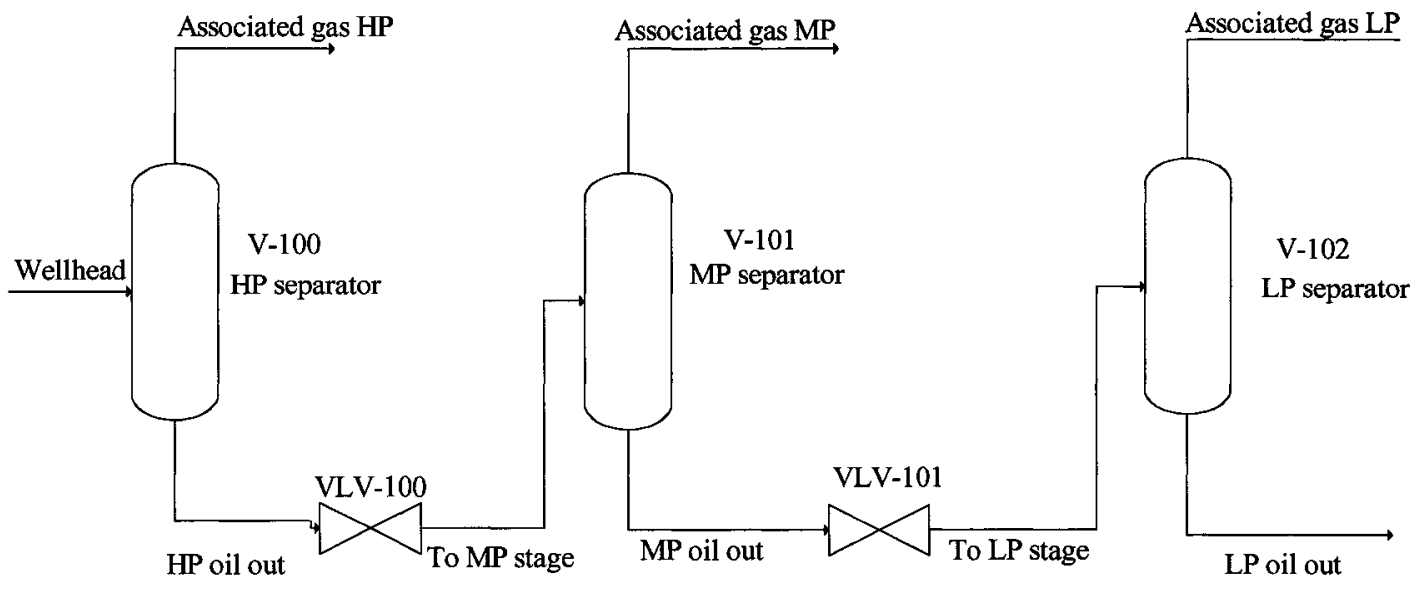

Figure 5.1: Three-stage crude oil separation

The reservoir fluid passes through a three stage separation process, where each stage works at different pressure, to optimize the crude oil production. The three separators operate at $6,998,1,724$ and $413.7 \mathrm{kPa}$, respectively. Each separator flashes the 
lighter gases through the top of the column and concentrates the heavier hydrocarbons in the bottom. In the first stage, the wellhead stream enters a high-pressure separator (V100). At each stage the pressure of the liquids leaving the separator is reduced to meet the operation criteria and sent to the next separator. The compression ratio at each stage should not be more than four as the compression ratio affect the temperature of the stream. If the compression ratio excesses four, the temperature could be high and special material should be used. Table 5.1 summarizes the inlet and outlet conditions for each separator. In this Table the total molar flow rate of each stream and its percentage of the "wellhead" stream are also shown. This process is called the "Base Process".

The composition and the molar flow of the "Wellhead" stream in this location and the outlet stream from the train ("LP Out oil") which reflects the amount of the produced crude oil, are shown in Table 5.2(more information can be found in Beronich, 2006). Also the amount of the recovered hydrocarbons in the process is indicated. The described process before locating any nozzles in the train is called "Base Process". The hydrocarbons heavier than ethane can be defined as $\mathrm{C}_{3}{ }^{+}$. Therefore, the compositions can be categorized as methane, ethane, $\mathrm{C}_{3}{ }^{+}, \mathrm{CO}_{2}$ and $\mathrm{N}_{2}$.

The value called the Reid Vapour Pressure (RVP) is presented for this stream .where crude oil is concentrated ("LP oil out").The ideal value for RVP is 12 psia, it is safe to store crude oil at atmospheric conditions, for values close to this ideal value. When a high pressure stream is mixed with a low pressure stream, a lot of lower components are added to the stream that might increase the RVP. If the value of RVP 
exceeds the ideal value, the crude may flash vapours in storage or transportation, increasing explosion and over-pressure risks. The RVP value obtained in the crude oil product is not necessary high considering that this oil goes to other facilities for further processing. The gas is going to be flashed to break emulsions at near ambient pressure which reduces the RVP value. Table 5.3 shows the crude oil production and RVP in the "Base Process".

Table 5.1: Inlet and Outlet conditions for each separator in "Base Process"

\begin{tabular}{|c|c|c|c|c|c|}
\hline & Streams & $\begin{array}{c}\text { Temperatu } \\
\text { re } \\
\left({ }^{\circ} \mathrm{C}\right)\end{array}$ & $\begin{array}{c}\text { Pressure } \\
\text { (kPa) }\end{array}$ & $\begin{array}{c}\text { Molar Flow } \\
\text { kgmole/h }\end{array}$ & $\begin{array}{c}\text { Molar } \\
\text { Flow } \\
\text { (\% of } \\
\text { wellhead } \\
\text { stream) }\end{array}$ \\
\hline \multirow{3}{*}{$\begin{array}{c}\text { HP } \\
\text { Separator }\end{array}$} & "Wellhead" Stream & 42.3 & $6,998.0$ & $19,975.30$ & $100.00 \%$ \\
\hline & "Associated Gas HP" & 42.3 & $6,998.0$ & $11,218.87$ & $56.16 \%$ \\
\hline & "HP Out Oil" & 42.3 & $6,998.0$ & $8,756.43$ & $43.84 \%$ \\
\hline \multirow{3}{*}{$\begin{array}{c}\text { MP } \\
\text { Separator }\end{array}$} & "To MP stage" & 40.7 & $1,724.0$ & $8,756.43$ & $43.84 \%$ \\
\hline & "Associated Gas MP & 40.7 & $1,724.0$ & $1,670.81$ & $8.36 \%$ \\
\hline & "MP Out Oil" & 40.7 & $1,724.0$ & $7,085.63$ & $35.47 \%$ \\
\hline \multirow{3}{*}{$\begin{array}{c}\text { LP } \\
\text { Separator }\end{array}$} & "To LP stage" & 38.9 & 413.7 & $7,085.63$ & $35.47 \%$ \\
\hline & "Associated Gas LP" & 38.9 & 413.7 & 584.31 & $2.93 \%$ \\
\hline & "LP Out Oil" & 38.9 & 413.7 & $6,501.32$ & $32.55 \%$ \\
\hline
\end{tabular}


Table 5.2: Mole fractions and molar flow rates of wellhead stream and " $L P$ out oil" stream in "Base Process"

\begin{tabular}{|c|c|c|c|c|c|}
\hline & \multicolumn{2}{|c|}{ Wellhead } & \multicolumn{3}{c|}{ LP oil out } \\
\cline { 2 - 6 } & $\begin{array}{c}\text { Mole } \\
\text { Fraction }\end{array}$ & $\begin{array}{c}\text { Molar Flow } \\
\text { (kgmole/h) }\end{array}$ & $\begin{array}{c}\text { Mole } \\
\text { Fraction }\end{array}$ & $\begin{array}{c}\text { Molar Flow } \\
\text { ((kgmole/h) }\end{array}$ & $\begin{array}{c}\text { Recovery } \\
\text { (\% of wellhead ) }\end{array}$ \\
\hline Total & 1.000 & $1,9975.260$ & 1.000 & $6,501.373$ & 32.547 \\
\hline Methane & 0.568 & $1,1347.100$ & 0.007 & 45.366 & 0.400 \\
\hline Ethane & 0.064 & $1,273.280$ & 0.020 & 126.800 & 9.959 \\
\hline Propane & 0.052 & $1,039.680$ & 0.059 & 384.900 & 37.021 \\
\hline i-Butane & 0.006 & 122.570 & 0.011 & 73.360 & 59.852 \\
\hline n-Butane & 0.015 & 294.160 & 0.031 & 200.400 & 68.126 \\
\hline i-Pentane & 0.003 & 53.350 & 0.007 & 44.001 & 82.477 \\
\hline n-Pentane & 0.003 & 57.680 & 0.008 & 49.625 & 86.035 \\
\hline Hexane & 0.001 & 21.630 & 0.003 & 20.358 & 94.121 \\
\hline $\mathrm{C} 7+$ & 0.278 & $5,555.290$ & 0.854 & $5,554.940$ & 99.994 \\
\hline $\mathrm{C} 2 ~ P l u s$ P3 Plus & 0.422 & $8,417.660$ & 0.993 & $6,454.385$ & 76.677 \\
\hline $\mathrm{N}_{2}$ & 0.358 & $7,144.380$ & 0.973 & $6,327.585$ & 88.567 \\
\hline $\mathrm{CO}_{2}$ & 0.009 & 171.590 & 0.000 & 0.041 & 0.024 \\
\hline
\end{tabular}

Table 5.3: Crude oil production of "Base Process"

\begin{tabular}{|c|c|c|c|c|c|}
\hline & \multirow{2}{*}{$\begin{array}{c}\text { Molar } \\
\text { Flow } \\
\text { (kgmole/h) }\end{array}$} & \multirow{2}{*}{$\begin{array}{c}\text { Recovery } \\
(\%)\end{array}$} & \multirow{2}{*}{$\begin{array}{l}\text { RVP } \\
\text { (psia) }\end{array}$} & \multicolumn{2}{|c|}{ Volume Flow } \\
\hline & & & & $\left(\mathrm{m}^{3} / \mathrm{h}\right)$ & (bbl/day) \\
\hline Total & $6,501.37$ & 32.547 & 19.773 & $1,382.64$ & $208,716.2$ \\
\hline Methane & 45.366 & 0.4 & - & 2.431 & 366.963 \\
\hline $\begin{array}{c}\text { Ethane } \\
\text { Plus } \\
\end{array}$ & $6,454.39$ & 76.677 & - & $1,380.12$ & $208,336.3$ \\
\hline $\begin{array}{l}\text { Propane } \\
\text { Plus }\end{array}$ & $6,327.59$ & 88.567 & - & $1,369.4$ & $206,718.1$ \\
\hline
\end{tabular}




\subsection{NGL RECOVERY USING A SUPERSONIC SEPARATOR}

A supersonic separator was placed at different locations within the crude production train to predict the NGL recovery. Depending on the nozzle's location, the inlet conditions such as pressure, temperature, and the flow rate can be different; and therefore a different nozzle should be designed to meet the requirement for each inlet conditions (see Section 3.3). The flow is assumed to be isentropic, steady state, one dimensional and compressible. To design this nozzle the convergence half angle and the divergence half angle of the nozzle are fixed at $6.85^{\circ}$ and $3^{\circ}$, respectively. The nozzle inlet diameter is fixed arbitrarily such that the inlet Mach number stays around 0.3-0.4. The maximum and minimum nozzle length can be found by applying the method discussed in Section 4.2 and the total nozzle length is chosen arbitrarily in between the minimum and maximum length.. If shockwave happens in the nozzle, the formed condensates are separated from the main stream before the shockwave. As discussed before in Section 2.1.8, they are a number of ways to separate the condensates from the main stream in the nozzle. The process was simulated in HYSYS simulator as demonstrated in the process flow diagram shown in Figure 5.2. The main stream in the nozzle, which can be in two- or three-phase flow, enters a separator. Vapour and liquid phases are separated and the liquid phase enters a splitter. A complete removal of the liquid is not possible in the nozzle, therefore it is assumed that $75 \%$ of the liquid phase will exit from bottom of the splitter and the rest remains in the main stream leaving the 
nozzle with the rest of the gas. The top stream from the separator and splitter are mixed and used as the nozzle main stream after the shockwave. The liquid condensates are separated from the main stream in the nozzle. The pressure of the separated liquids should be equal to the operating pressure of the next stage; therefore, the nozzle pressure before the shockwave should stay higher than the operating pressure of the next stage. The following cases very studied to evaluate the increase in crude production using the supersonic nozzle to recover NGLs from associated gases.

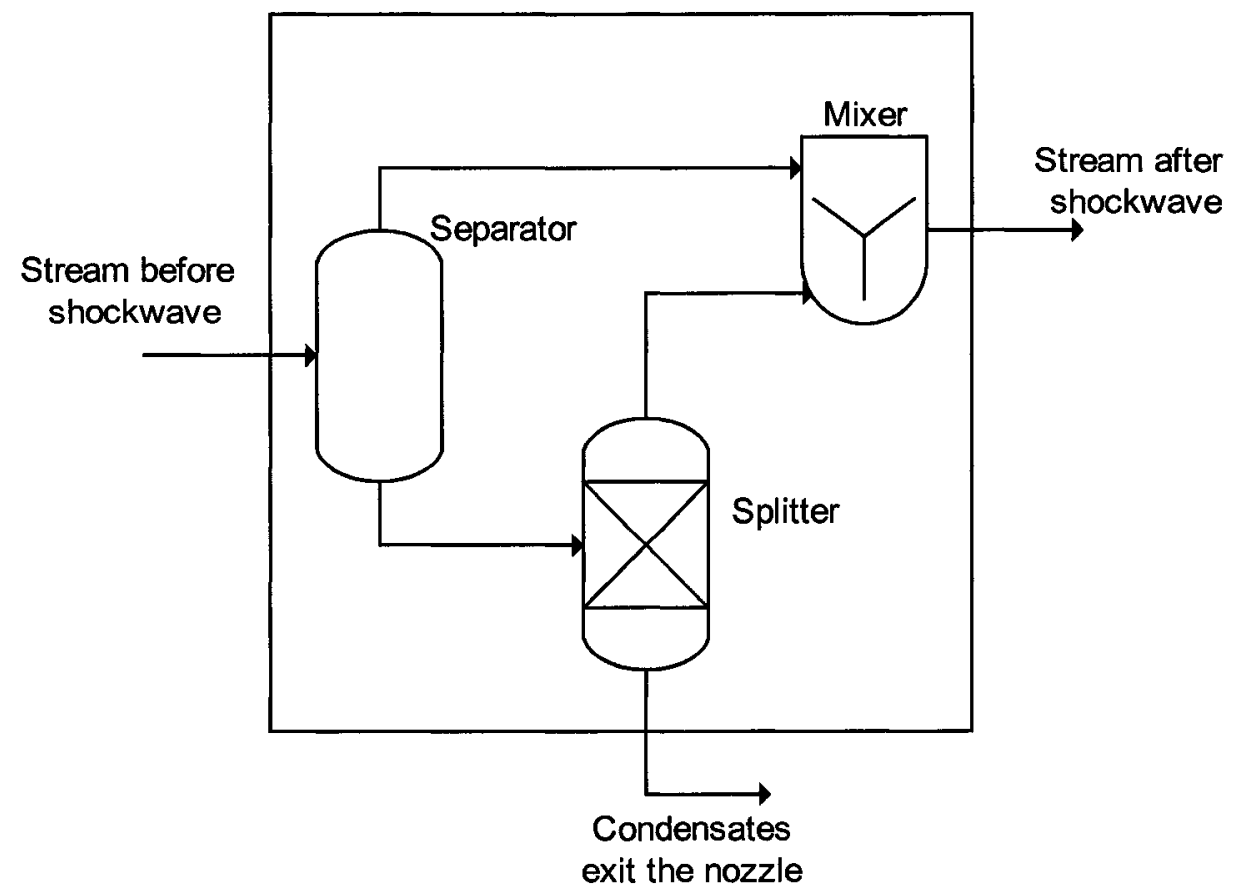

Figure 5.2: HYSYS simulation of condensate separation in the nozzle before the shockwave 


\subsubsection{CASE 1: SuPERSonic NOZZle AT HP SEPARATOR OVERHEAD}

In Case 1, the supersonic nozzle is located at the overhead of the HP separator. The inlet stream of the nozzle has the same pressure, temperature, and flow rate as "Associated Gas HP "Stream (see Table 5.1). In Case 1.A the stream of separated liquids is mixed with the liquids from the HP separator and enters the MP separator and in Case 1.B it is mixed with the liquids from the MP separator and enters the LP separator and in Case 1.C it is mixed with the stream coming out of the train (" $L P$ oil out"). Figure 5.3, 5.4 , and 5.5 show the schematics of these processes.

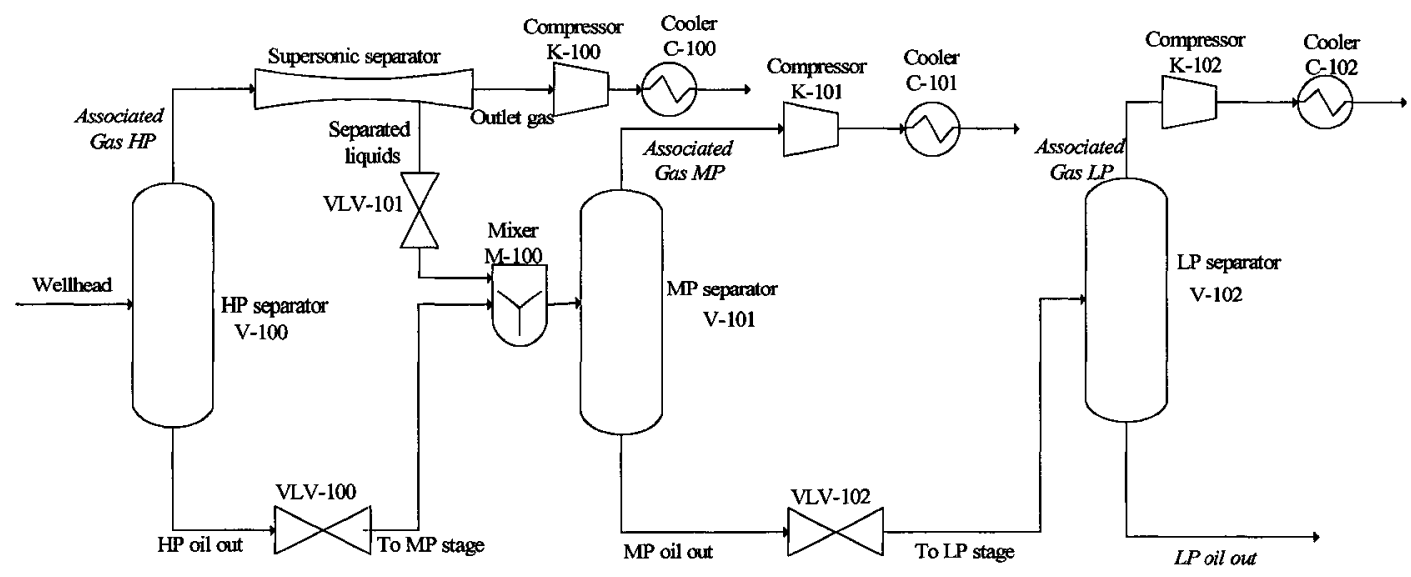

Figure 5.3: Case 1.A: Supersonic nozzle at HP Separator overhead; separated condensates routed to MP Separator 


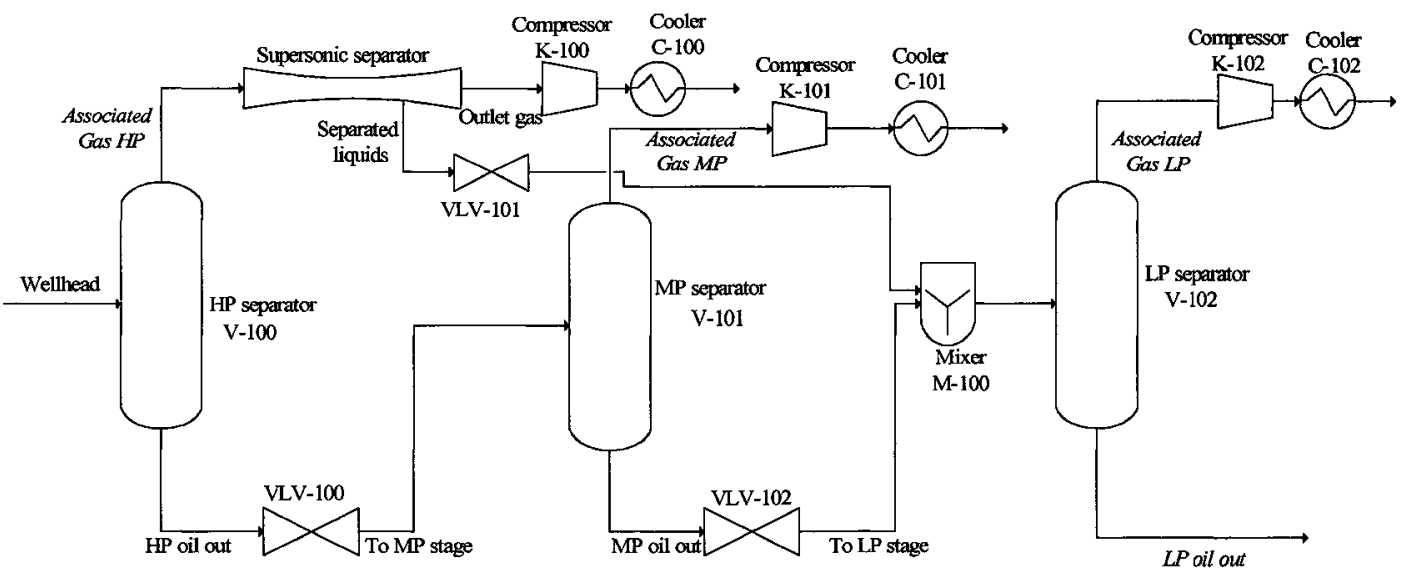

Figure 5.4: Case 1.B: Supersonic nozzle at HP Separator overhead; separated condensates routed to LP Separator

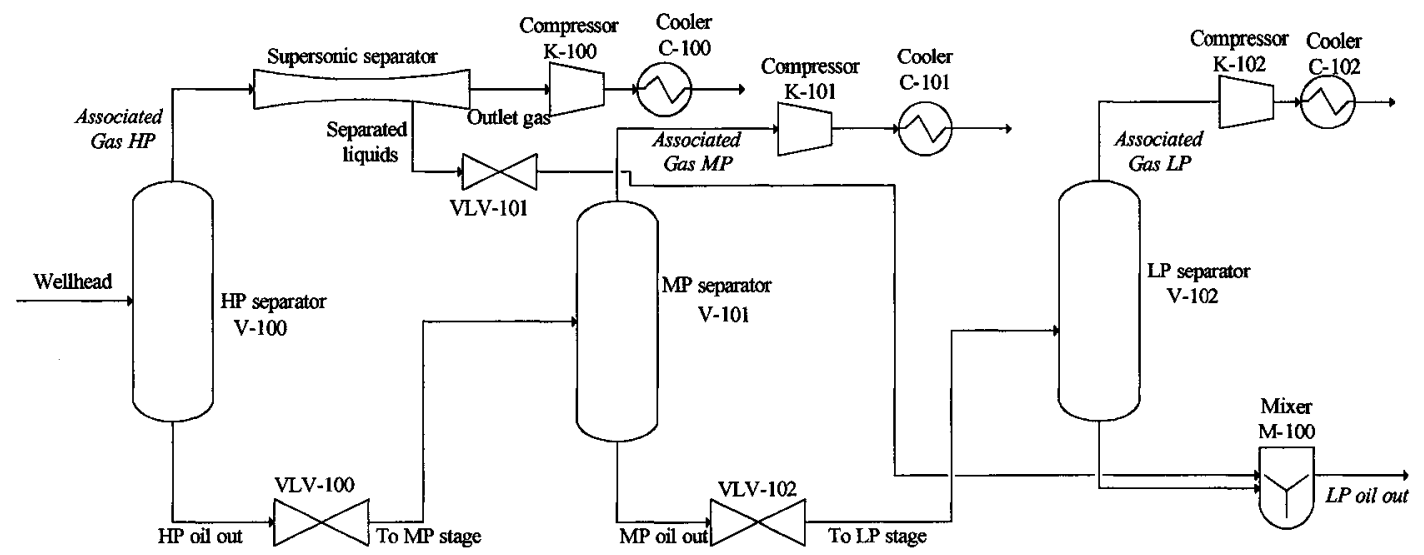

Figure 5.5: Case 1.C- Supersonic nozzle at HP Separator overhead; separated condensates routed to LP Oil Out

The feed stream is the same for these three cases so the same nozzle can be used in all the cases. Table 5.4 shows the designed nozzle geometry for this case. 
Table 5.4: Nozzle geometry for case One

\begin{tabular}{|l|c|}
\hline Inlet diameter(m) & 0.1000 \\
\hline Throat diameter(m) & 0.0718 \\
\hline Outlet diameter(m) & 0.0910 \\
\hline Converging length(m) & 0.1172 \\
\hline Diverging length $(\mathbf{m})$ & 0.1828 \\
\hline Total length (m) & 0.3000 \\
\hline Length upper bound (m) & 0.3000 \\
\hline
\end{tabular}

Figure 5.6 shows the pressure distribution in this nozzle with 70 and $80 \%$ of the inlet pressure recovery.

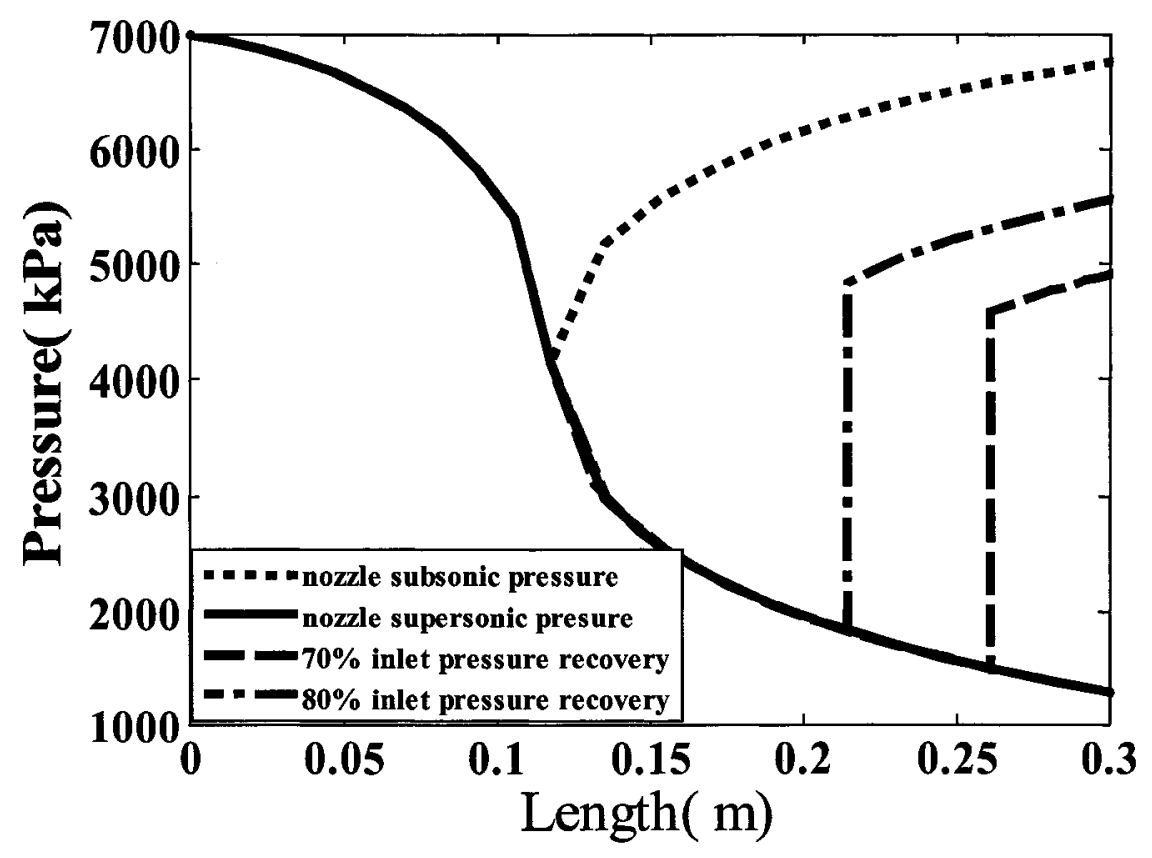

Figure 5.6: Pressure distribution along the nozzle located at HP separator overhead 
In Case 1.A, the separated liquids stream enters the MP Separator. Therefore, the nozzle pressure before the shockwave should be higher than the operating pressure of the MP Separator $(1,724 \mathrm{kPa})$. However, the flow has to expand to $1,409 \mathrm{kPa}$ before the shockwave to recover $70 \%$ of the inlet pressure $(6,998 \mathrm{kPa})$ at the nozzle exit. This problem does not exist for Cases 1.B and 1.C as the operating pressure is $413.7 \mathrm{kPa}$. So a nozzle with the backpressure such that $70 \%$ of the inlet pressure is recovered can not be used in Case 1.A. But the results of NGL recovery for Cases 1.B and 1.C are compared for the $70 \%$ inlet pressure recovery in the nozzle. Table 5.5 indicates the composition, molar flow rate and recovery for "LP Oil Out" and Table 5.6 indicates the crude oil production stream and RVP in both processes. 
Table 5.5: Mole fractions and molar flow rates for"LP Oil Out" stream for Cases 1.B and 1.C

\begin{tabular}{|c|c|c|c|c|c|c|}
\hline & \multicolumn{3}{|c|}{ Case 1.B } & \multicolumn{3}{|c|}{ Case 1.C } \\
\hline & $\begin{array}{c}\text { Mole } \\
\text { Fraction }\end{array}$ & $\begin{array}{c}\text { Molar } \\
\text { Flow } \\
\text { (kgmole/h) }\end{array}$ & $\begin{array}{c}\text { Recovery } \\
\text { (\% of wellhead) }\end{array}$ & $\begin{array}{c}\text { Mole } \\
\text { Fraction }\end{array}$ & $\begin{array}{c}\text { Molar } \\
\text { Flow } \\
\text { (kgmole/h) }\end{array}$ & $\begin{array}{c}\text { Recovery } \\
\text { (\% of wellhead ) }\end{array}$ \\
\hline Total & 1.000 & $6,585.810$ & 32.970 & 1.000 & $6,673.420$ & 33.410 \\
\hline Methane & 0.007 & 44.521 & 0.390 & 0.011 & 73.210 & 0.640 \\
\hline Ethane & 0.020 & 131.370 & 10.320 & 0.023 & 153.680 & 12.071 \\
\hline Propane & 0.065 & 425.490 & 40.920 & 0.068 & 454.170 & 43.680 \\
\hline i-Butane & 0.013 & 82.560 & 67.350 & 0.013 & 85.010 & 69.350 \\
\hline n-Butane & 0.034 & 223.640 & 76.020 & 0.034 & 228.080 & 77.530 \\
\hline i-Pentane & 0.007 & 47.540 & 89.100 & 0.007 & 47.870 & 89.720 \\
\hline n-Pentane & 0.008 & 52.920 & 91.750 & 0.008 & 53.170 & 92.190 \\
\hline Hexane & 0.003 & 20.980 & 96.990 & 0.003 & 21.010 & 97.120 \\
\hline $\mathrm{C} 7+$ & 0.844 & $5,555.180$ & 99.990 & 0.832 & $5,555.180$ & 99.990 \\
\hline C2 Plus & 0.993 & $6,539.690$ & 77.690 & 0.989 & $6,598.190$ & 78.380 \\
\hline C3 Plus & 0.973 & $6,408.317$ & 89.690 & 0.966 & $6,444.510$ & 90.200 \\
\hline N2 & 0.000 & 0.041 & 0.024 & 0.000 & 0.132 & 0.076 \\
\hline $\mathrm{CO} 2$ & 0.000 & 1.558 & 4.002 & 0.000 & 1.885 & 4.840 \\
\hline
\end{tabular}

Table 5.7: Crude oil production of the Cases 1.B, 1.C for 70\% inlet pressure recovery

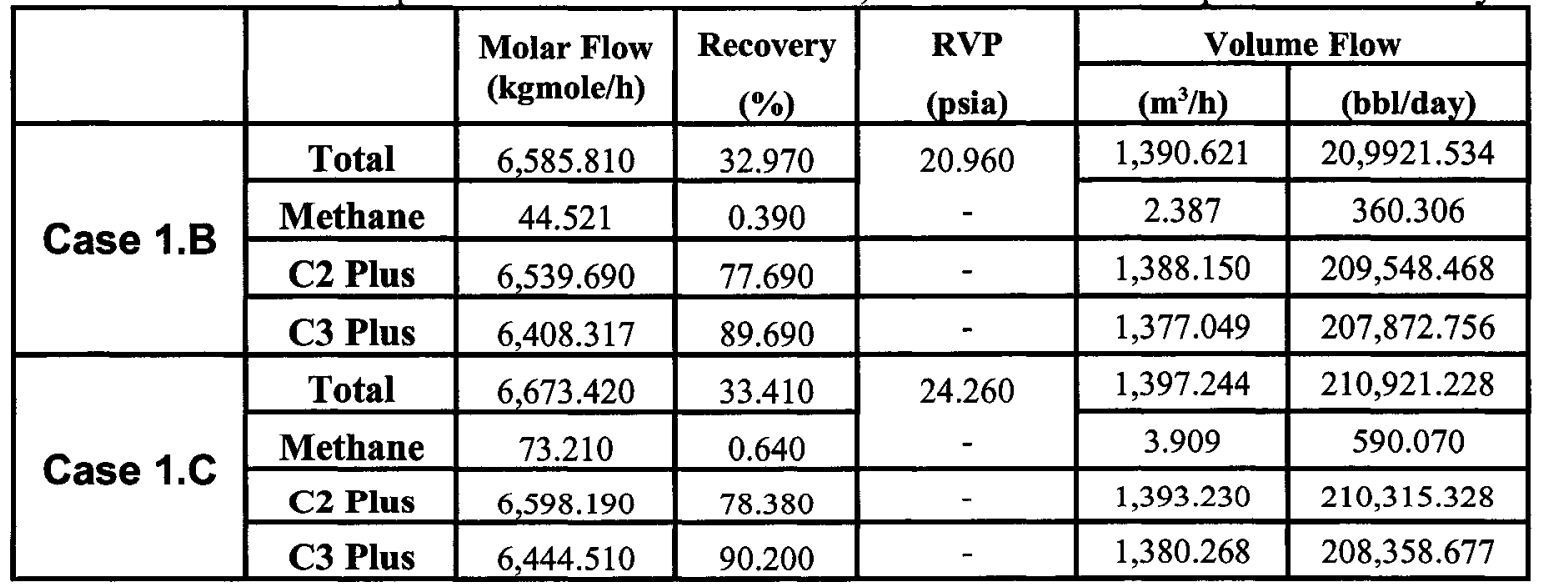

The "LP Oil Out"in the"Base Process" before and after the nozzle is placed, are 
compared. This comparison shows that in Case 1.B, methane concentration is lower than "Base Process" but the concentrations of all other components are higher.

Figure 5.7 reflects the comparison between the phase envelope of the "Base Process" and Cases 1.B and 1.C for the "LP Oil Out" stream. As the stream becomes richer in lighter hydrocarbons, the bubble point curve expands toward the lower bubble point temperatures.

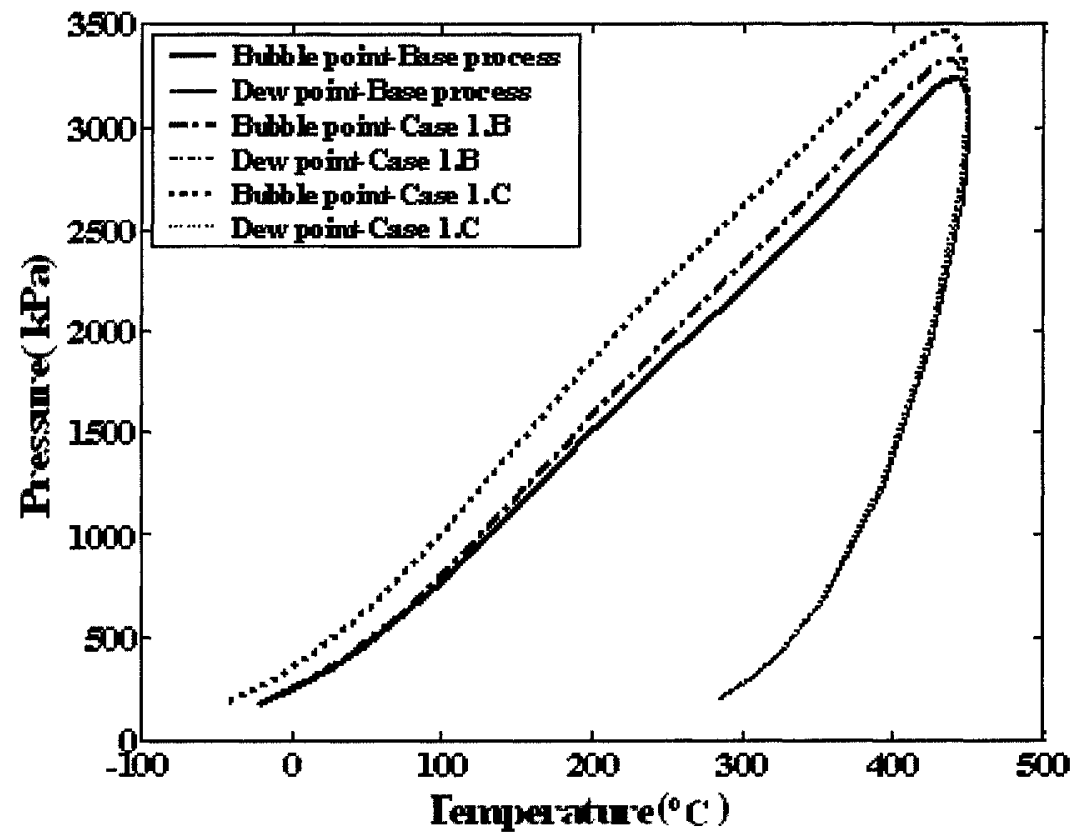

Figure 5.7: Phase envelopes for the stream "LP Oil Out" for "Base Process", Cases 1.B and $1 . C$ with $70 \%$ inlet pressure recovery in the nozzle

As mentioned earlier, the nozzle pressure before shockwave should be kept higher than the previous case $(70 \%)$ if it is desirable to locate any nozzles in case 1 .A. Therefore, the a nozzle with same geometry is used in this case. The operation conditions are adjusted such that the back pressure of the nozzle is equal to $80 \%$ of the inlet pressure. 
The mole fractions and the molar flow rates for "LP Oil Out "for three processes of case one are shown in Table 5.7. Comparison of the cases with the "Base Process" indicates that the lighter hydrocarbons concentration as well as the heavier components concentration is higher when a nozzle is placed in the process. Table 5.6 indicates the crude oil production stream and RVP in three processes in case one.

Table 5.7: Mole fractions and molar flow rates for"LP Oil Out" stream for three processes in case one for $80 \%$ pressure recovery

\begin{tabular}{|c|c|c|c|c|c|c|c|c|c|}
\hline & \multicolumn{3}{|c|}{ Case 1.A } & \multicolumn{3}{|c|}{ Case 1.B } & \multicolumn{3}{|c|}{ Case 1.C } \\
\hline & $\begin{array}{c}\text { Mole } \\
\text { Fraction }\end{array}$ & $\begin{array}{c}\text { Molar } \\
\text { Flow } \\
\text { (kgmole/h) }\end{array}$ & $\begin{array}{c}\text { Recovery } \\
(\% \text { of } \\
\text { wellhead ) }\end{array}$ & $\begin{array}{c}\text { Mole } \\
\text { Fraction }\end{array}$ & $\begin{array}{c}\text { Molar } \\
\text { Flow } \\
\text { (kgmole/h) }\end{array}$ & $\begin{array}{c}\text { Recovery } \\
(\% \text { of } \\
\text { wellhead) }\end{array}$ & $\begin{array}{c}\text { Mole } \\
\text { Fraction }\end{array}$ & $\begin{array}{c}\text { Molar } \\
\text { Flow } \\
\text { (kgmole/h) }\end{array}$ & $\begin{array}{c}\text { Recovery } \\
\text { (\% of } \\
\text { wellhead) }\end{array}$ \\
\hline Total & 1.000 & $\begin{array}{c}6,553.15 \\
0\end{array}$ & 32.810 & 1.000 & $\begin{array}{c}6,553.25 \\
0 \\
\end{array}$ & 32.810 & 1.000 & $\begin{array}{c}6,605.19 \\
0\end{array}$ & 33.070 \\
\hline Methane & 0.007 & 44.910 & 0.400 & 0.007 & 45.020 & 0.400 & 0.010 & 63.360 & 0.560 \\
\hline Ethane & 0.020 & 129.480 & 10.170 & 0.020 & 129.030 & 10.130 & 0.021 & 141.670 & 11.130 \\
\hline Propane & 0.062 & 406.310 & 39.080 & 0.062 & 406.570 & 39.110 & 0.064 & 422.540 & 40.640 \\
\hline i-Butane & 0.012 & 79.000 & 64.450 & 0.012 & 79.100 & 64.540 & 0.012 & 80.580 & 65.740 \\
\hline n-Butane & 0.033 & 216.080 & 73.460 & 0.033 & 216.270 & 73.520 & 0.033 & 219.100 & 74.480 \\
\hline i-Pentane & 0.007 & 46.960 & 88.030 & 0.007 & 46.960 & 88.030 & 0.007 & 47.200 & 88.460 \\
\hline nPentane & 0.008 & 52.550 & 91.110 & 0.008 & 52.540 & 91.090 & 0.008 & 52.720 & 91.400 \\
\hline Hexane & 0.003 & 20.970 & 96.960 & 0.003 & 20.970 & 96.930 & 0.003 & 20.980 & 97.010 \\
\hline $\mathrm{C} 7+$ & 0.848 & $\begin{array}{c}5,555.19 \\
0\end{array}$ & 100.000 & 0.848 & $\begin{array}{c}5,555.19 \\
0\end{array}$ & 100.000 & 0.841 & $\begin{array}{c}5,555.19 \\
0 \\
\end{array}$ & 100.000 \\
\hline C2 Plus & 0.993 & $\begin{array}{c}6,506.54 \\
0 \\
\end{array}$ & 77.300 & 0.990 & $\begin{array}{c}6,506.62 \\
0 \\
\end{array}$ & 77.300 & 0.990 & $\begin{array}{c}6,539.97 \\
0 \\
\end{array}$ & 77.690 \\
\hline C3 Plus & 0.973 & $\begin{array}{c}6,377.06 \\
0 \\
\end{array}$ & 89.260 & 0.970 & $\begin{array}{c}6,377.60 \\
0 \\
\end{array}$ & 89.270 & 0.970 & $\begin{array}{c}6,398.30 \\
0 \\
\end{array}$ & 89.560 \\
\hline $\mathrm{N} 2$ & 0.000 & 0.040 & 0.020 & 0.000 & 0.040 & 0.020 & 0.000 & 0.110 & 0.060 \\
\hline $\mathrm{CO} 2$ & 0.000 & 1.580 & 4.070 & 0.000 & 1.570 & 4.020 & 0.000 & 1.760 & 4.520 \\
\hline
\end{tabular}


Table 5.8: Crude oil production of the three processes in case one for $80 \%$ inlet pressure recovery

\begin{tabular}{|c|c|c|c|c|c|c|}
\hline & & \multirow{2}{*}{$\begin{array}{c}\text { Molar } \\
\text { Flow } \\
\text { (kgmole/h) }\end{array}$} & \multirow{2}{*}{$\begin{array}{c}\text { Recovery } \\
(\%)\end{array}$} & \multirow{2}{*}{$\begin{array}{l}\text { RVP } \\
\text { (psia) }\end{array}$} & \multicolumn{2}{|c|}{ Volume Flow } \\
\hline & & & & & $\left(\mathbf{m}^{3} / \mathbf{h}\right)$ & (bbl/day) \\
\hline \multirow{4}{*}{ Case 1.A } & Total & $6,553.150$ & 32.810 & 20.453 & $1,387.671$ & $209,476.151$ \\
\hline & Methane & 44.910 & 0.400 & - & 2.407 & 363.336 \\
\hline & C2 Plus & $6,506.540$ & 77.300 & - & $1,385.178$ & $209,099.822$ \\
\hline & C3 Plus & $6,377.060$ & 89.260 & - & $1,374.230$ & $207,447.164$ \\
\hline \multirow{4}{*}{ Case 1.B } & Total & $6,553.250$ & 32.810 & 20.446 & $1,387.681$ & $209,477.663$ \\
\hline & Methane & 45.020 & 0.400 & - & 2.412 & 364.104 \\
\hline & C2 Plus & $6,506.620$ & 77.300 & - & $1,385.189$ & $209,101.483$ \\
\hline & C3 Plus & $6,377.600$ & 89.270 & - & $1,374.276$ & $207,454.108$ \\
\hline \multirow{4}{*}{ Case 1.C } & Total & $6,605.190$ & 33.070 & 22.471 & $1,391.626$ & $210,073.181$ \\
\hline & Methane & 63.360 & 0.560 & - & 3.396 & 512.644 \\
\hline & C2 Plus & $6,539.970$ & 77.690 & - & $1,388.133$ & $209,545.895$ \\
\hline & C3 Plus & $6,398.300$ & 89.560 & - & $1,376.155$ & $207,737.753$ \\
\hline
\end{tabular}

The composition differences in Stream "LP Oil Out" are also reflected in the phase envelopes. The envelopes for both processes are shown in Figure 5.8. The dew point curves of these processes are similar; however, the bubble point curve for Case one is above the bubble point of the "Base Process". The reason is that the stream is richer in lighter hydrocarbons, which expands the two-phase region of the envelope towards lower bubble point temperatures. 


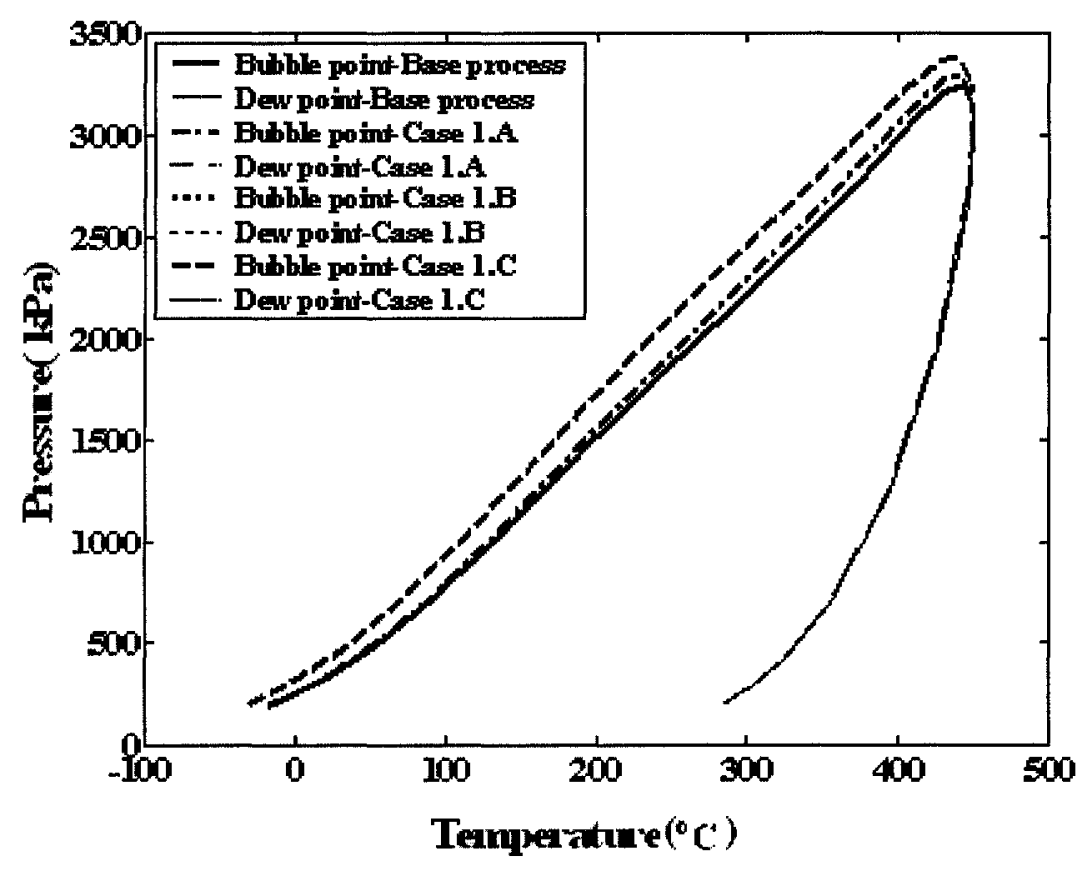

Figure 5.8: Phase envelopes for Stream "LP Oil Out" for "Base Process", Cases 1.A, 1.B and $1 . \mathrm{C}$ with $80 \%$ inlet pressure recovery in the nozzle

For the latter case ( $80 \%$ of inlet pressure recovery), the same results for the NGL recovery can be obtained by designing a shorter nozzle where $70 \%$ of the inlet pressure (exit pressure $=4,898 \mathrm{kPa}$ ) will be recovered. This length will be $0.2203 \mathrm{~m}$.

\subsection{CASE 2: SuPERSONIC NOZZle at MP SEPARATOR OVERHEAD}

In this case the supersonic nozzle is located at overhead of the MP Separator; therefore the nozzle inlet stream is "Associated Gas MP". The pressure of separated liquid stream from the supersonic nozzle is adjusted to meet the operating pressure of the LP Separator and it is mixed with the Stream "To LP Stage" in Case 2.A and the stream 
from bottom of the LP Separator in Case 2.B. The schematic of these two processes are shown in Figures 5.9 and 5.10.

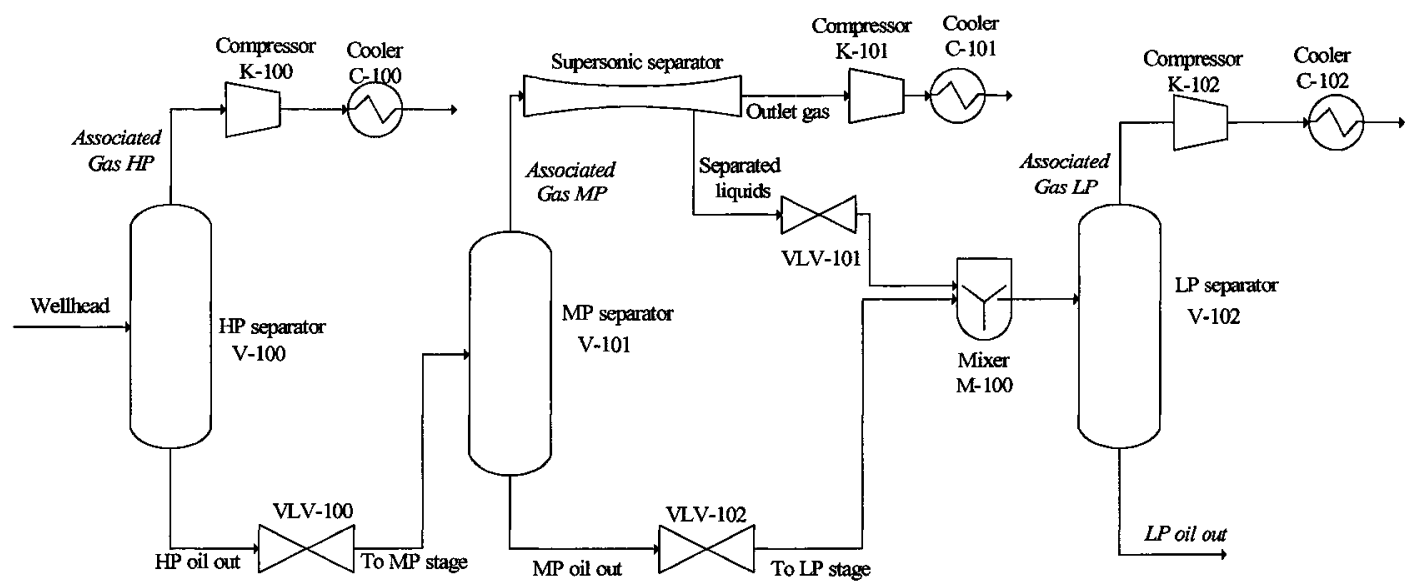

Figure 5.9: Case 2.A: Supersonic nozzle at MP Separator overhead; separated condensates routed to LP Separator

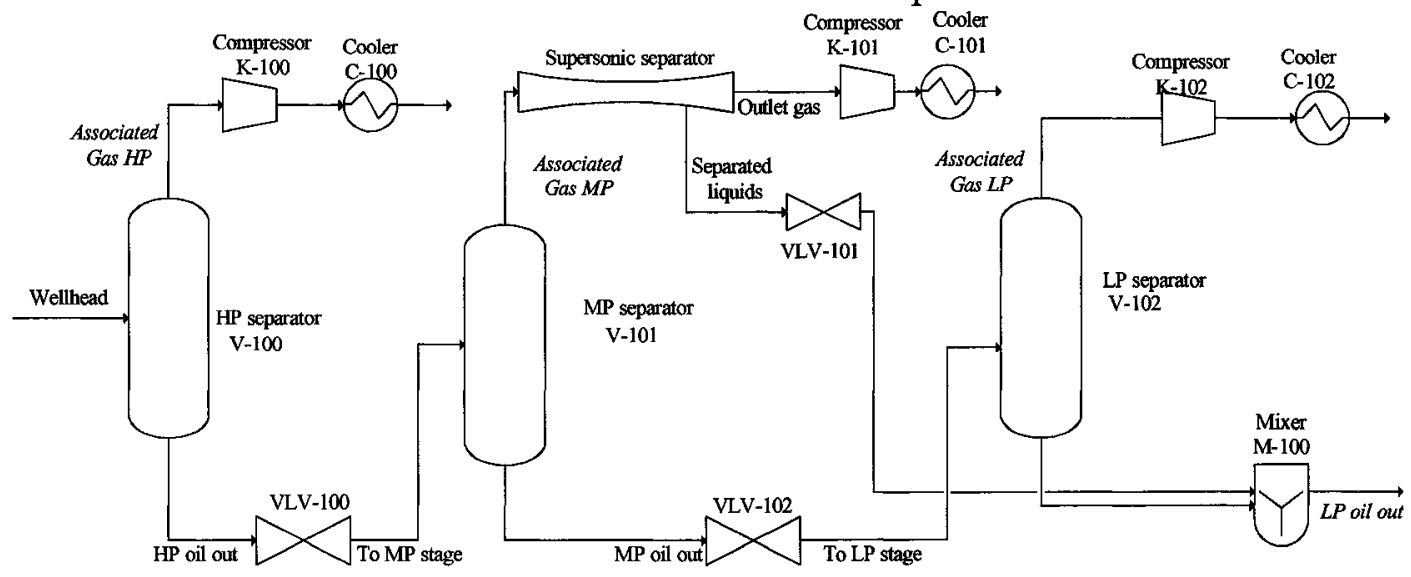

Figure 5.10: Case 2.B: Supersonic nozzle at MP Separator overhead; separated condensates routed to LP Oil Out

A nozzle with the geometry shown in Table 5.9 is designed for this purpose. 
Table 5.9: Nozzle geometry for case two

\begin{tabular}{|l|c|}
\hline Inlet diameter(m) & 0.1000 \\
\hline Throat diameter(m) & 0.0605 \\
\hline Outlet diameter(m) & 0.0747 \\
\hline Converging length(m) & 0.1644 \\
\hline Diverging length (m) & 0.1356 \\
\hline Total length (m) & 0.3000 \\
\hline Length upper bound (m) & 0.4000 \\
\hline
\end{tabular}

As shown in Figure 5.11, if the recovery of $70 \%$ of the inlet pressure is obtained, the nozzle pressure before the shockwave is $(359.64 \mathrm{kPa})$ which is lower than the operating pressure of LP Separator. Therefore, the pressure before shockwave should stay higher. If the backpressure is adjusted at $80 \%$ of the inlet pressure, the pressure in side the nozzle and before the shockwave will be $466.47 \mathrm{kPa}$, which is higher than LP separator operating pressure $(413.7 \mathrm{kPa})$. The supersonic nozzle used in this processes is considered to have a pressure recovery of $80 \%$.

Table 5.10 and Figure 5.12 outline the composition of Stream "LP Oil Out" in Cases 2.A and 2.B. Comparison of these processes with the "Base Process" show that the composition will remain almost the same when a supersonic nozzle is introduced after the MP separator. Plotting the results for the three cases results in almost overlapped lines . Table 5.11 presents the crude oil production and the RVP of the "LP oil out"stream in case 2. 


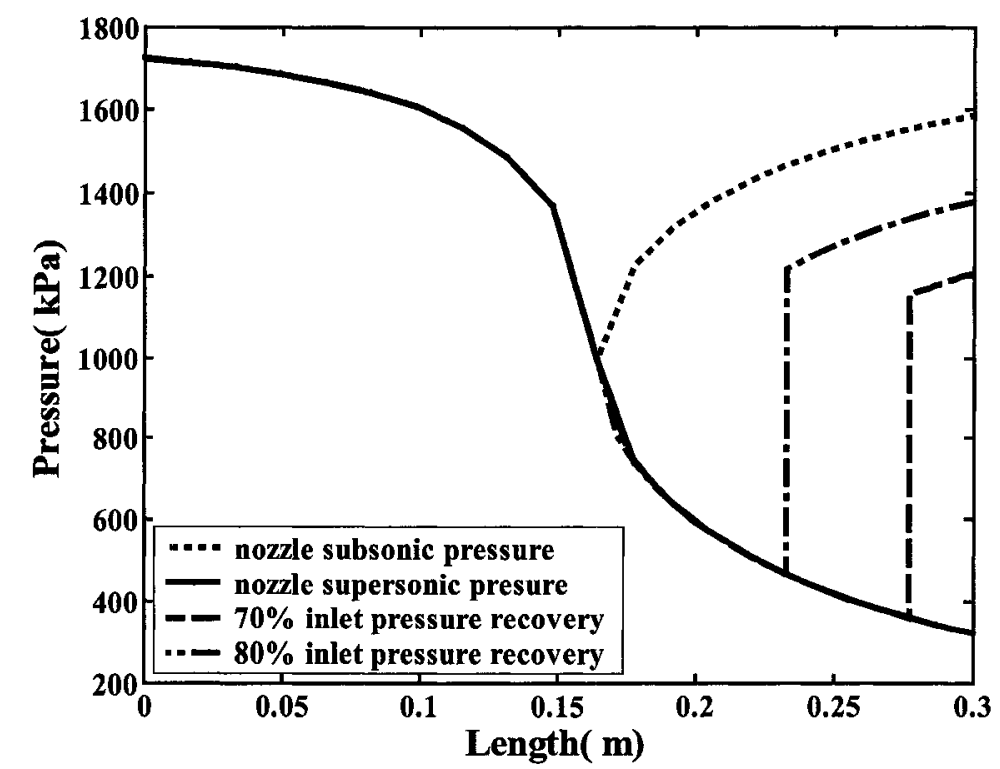

Figure 5.11: Pressure distribution along the nozzle located at MP Separator overhead with $80 \%$ inlet pressure recovery

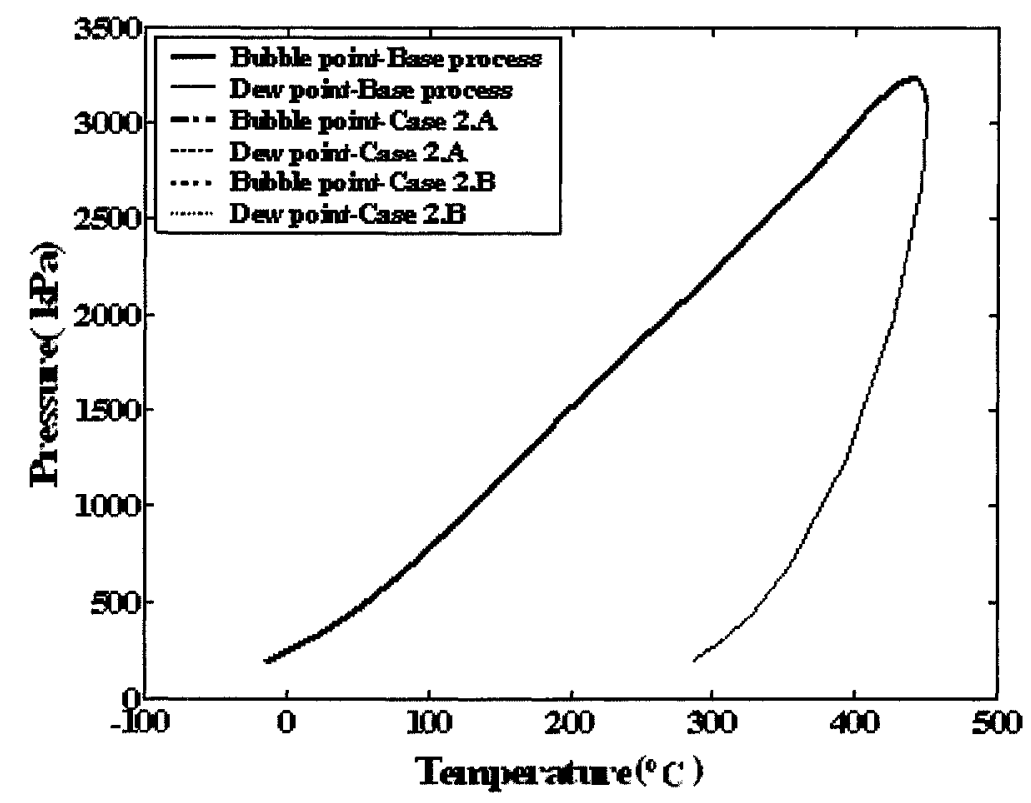

Figure 5.12: Phase envelopes for Stream "LP Oil Out" for "Base Process" and Case 2 with $80 \%$ inlet pressure recovery 
Table 5.10: Mole fractions and molar flow rates of' $L P$ Oil Out" Stream in Case 2 with $80 \%$ inlet pressure recovery

\begin{tabular}{|c|c|c|c|c|c|c|}
\hline & \multicolumn{3}{|c|}{ Case 2.A } & \multicolumn{3}{|c|}{ Case 2.B } \\
\hline & Mole Fraction & $\begin{array}{c}\text { Molar Flow } \\
\text { ( kgmole/h) }\end{array}$ & $\begin{array}{c}\text { Recovery } \\
\text { (\% of } \\
\text { wellhead) }\end{array}$ & Mole Fraction & $\begin{array}{c}\text { Molar Flow } \\
\text { ( kgmole/h) }\end{array}$ & $\begin{array}{c}\text { Recovery } \\
\text { (\% of } \\
\text { wellhead) }\end{array}$ \\
\hline Total & 1.000 & $6,501.550$ & 32.550 & 1.000 & $6,501.430$ & 32.550 \\
\hline Methane & 0.007 & 45.370 & 0.400 & 0.007 & 45.370 & 0.400 \\
\hline Ethane & 0.020 & 126.800 & 9.960 & 0.020 & 126.810 & 9.960 \\
\hline Propane & 0.059 & 384.910 & 37.020 & 0.059 & 384.920 & 37.020 \\
\hline i-Butane & 0.011 & 73.360 & 59.850 & 0.011 & 73.360 & 59.850 \\
\hline n-Butane & 0.031 & 200.410 & 68.130 & 0.031 & 200.410 & 68.130 \\
\hline i-Pentane & 0.007 & 44.000 & 82.480 & 0.007 & 44.000 & 82.480 \\
\hline n-Pentane & 0.008 & 49.630 & 86.040 & 0.008 & 49.630 & 86.040 \\
\hline Hexane & 0.003 & 20.360 & 94.130 & 0.003 & 20.360 & 94.140 \\
\hline $\mathrm{C} 7+$ & 0.854 & $5,554.950$ & 99.990 & 0.854 & $5,554.950$ & 99.990 \\
\hline $\mathrm{C} 2$ Plus & 0.993 & $6,454.440$ & 76.680 & 0.993 & $6,454.440$ & 76.680 \\
\hline C3 Plus & 0.973 & $6,327.640$ & 88.570 & 0.973 & $6,327.640$ & 88.570 \\
\hline $\mathrm{N} 2$ & 0.000 & 0.040 & 0.020 & 0.000 & 0.040 & 0.020 \\
\hline $\mathrm{CO} 2$ & 0.000 & 1.580 & 4.060 & 0.000 & 1.580 & 4.060 \\
\hline
\end{tabular}

Table 5.11: Crude oil production of the three processes in case 2 for $80 \%$ inlet pressure

\begin{tabular}{|c|c|c|c|c|c|c|}
\hline & & \multirow{2}{*}{$\begin{array}{c}\text { Molar } \\
\text { Flow } \\
\text { (kgmole/h) } \\
\end{array}$} & \multirow{2}{*}{$\begin{array}{c}\text { Recovery } \\
(\%) \\
\end{array}$} & \multirow{2}{*}{$\begin{array}{l}\text { RVP } \\
\text { (psia) } \\
\end{array}$} & \multicolumn{2}{|c|}{ Volume Flow } \\
\hline & & & & & $\left(\mathrm{m}^{3} / \mathrm{h}\right)$ & (bbl/day) \\
\hline \multirow{4}{*}{ Case 2.A } & Total & $6,501.550$ & 32.550 & 19.774 & 1382.643 & 208717.151 \\
\hline & Methane & 45.370 & 0.400 & - & 2.431 & 366.972 \\
\hline & C2 Plus & $6,454.440$ & 76.680 & - & 1380.126 & 208337.211 \\
\hline & C3 Plus & 0.993 & 88.570 & - & 1369.406 & 206718.957 \\
\hline \multirow{4}{*}{ Case 2.B } & Total & $6,501.430$ & 32.550 & 19.774 & 1382.643 & 208717.151 \\
\hline & Methane & 45.370 & 0.400 & - & 2.431 & 366.972 \\
\hline & C2 Plus & $6,454.440$ & 76.680 & - & 1380.126 & 208337.196 \\
\hline & C3 Plus & $6,327.640$ & 88.570 & - & 1369.406 & 206718.957 \\
\hline
\end{tabular}


A shorter nozzle with the length of $0.2523 \mathrm{~m}$ can be designed to recover $70 \%$ of the inlet pressure with the same result in the stream composition.

\subsubsection{CASE 3: SuPERSONIC NOZZLE AT LP SEPARATOR OVERHEAD}

Figure 5.13 shows the process that the supersonic nozzle is places at the overhead of LP Separator and the separated liquid stream from the nozzle is mixed with the stream from the bottom of the LP Separator after the pressure reduction. The feed stream of the nozzle is "Associated Gas $L P$ " .This stream has a very low pressure and any small reduction in pressure of the stream can cause it to fall below the LP separator operating pressure, so the supersonic nozzle can not be placed after the LP separator

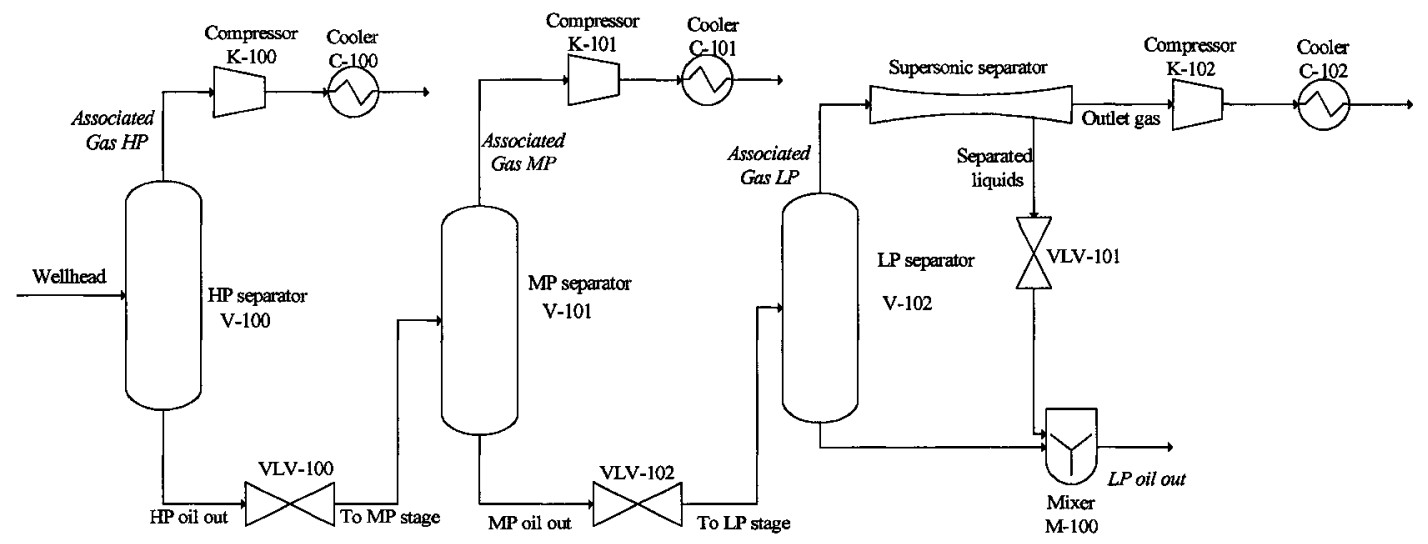

Figure 5.13: Case 3: Supersonic nozzle at LP Separator overhead; separated condensates routed to LP Oil Out

In the following cases, the pressure of the stream separated from the top of the separators is increased; the stream is cooled and entered the supersonic nozzle. 


\subsubsection{CASE 4: SUPERSONIC NOZZLE AT HP COMPRESSOR DISCHARGE}

The pressure of the "Associated Gas HP"stream from the HP separator is 6,998 $\mathrm{kPa}$, this pressure is increased to $10,000 \mathrm{kPa}$ in a compressor and cooled to the stream initial temperature. So the inlet properties are the same as the "Associated Gas HP" except the pressure which is $10,000 \mathrm{kPa}$. This stream is entered the supersonic nozzle. A nozzle with the geometry shown in Table 5.11 is designed for this condition. The nozzle backpressure is adjusted to recover $70 \%$ of the inlet nozzle pressure $(7,000 \mathrm{kPa})$.

Table 5.11: Nozzle geometry for Case 4

\begin{tabular}{|l|c|}
\hline Inlet diameter(m) & 0.0800 \\
\hline Throat diameter(m) & 0.0586 \\
\hline Outlet diameter(m) & 0.0778 \\
\hline Converging length(m) & 0.0891 \\
\hline Diverging length (m) & 0.1829 \\
\hline Total length (m) & 0.2720 \\
\hline Length upper bound (m) & 0.2720 \\
\hline
\end{tabular}

Three processes were considered in this case. In case 4.A the "separated liquids" stream is mixed with "HP Oil Out" and entered MP Separator, in Case 4.B, it is mixed with "MP Oil Out" and enters LP Separator and in the last case (Case 4.C) it is mixed with the stream from the bottom of the LP separator (See Figure 5.14 to 5.16). 


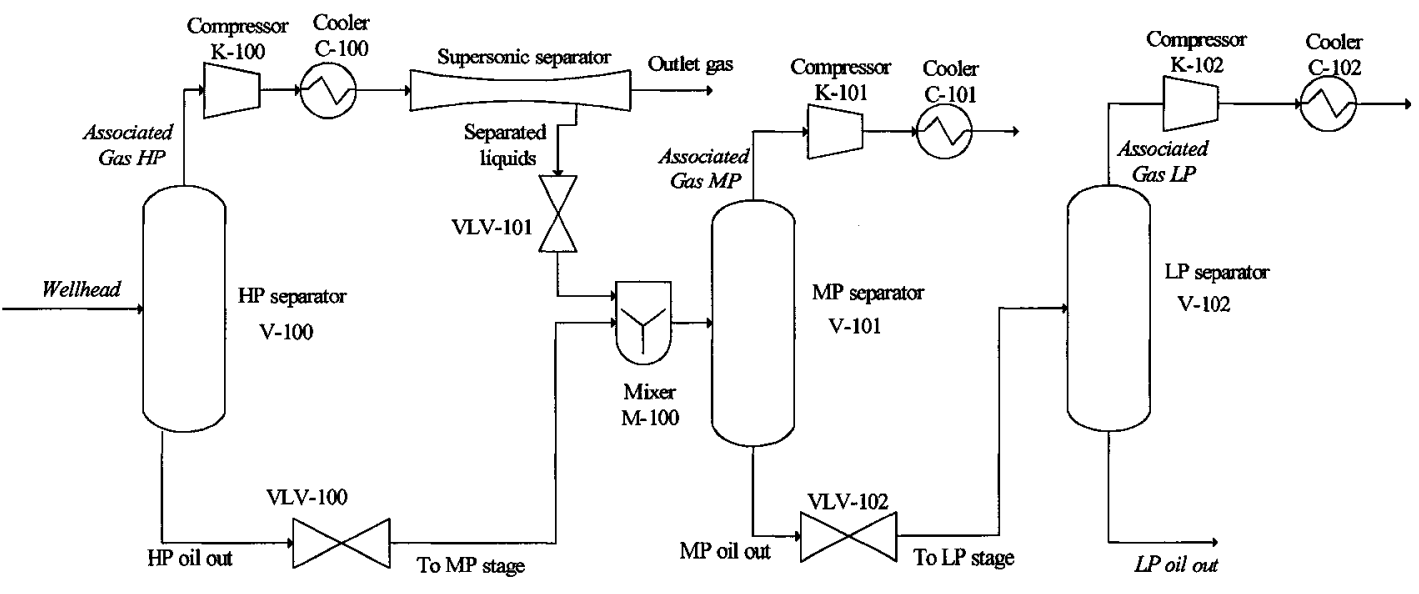

Figure 5.14: Case 4.A: Supersonic separator at HP compressor discharge; separated condensates routed to MP Separator

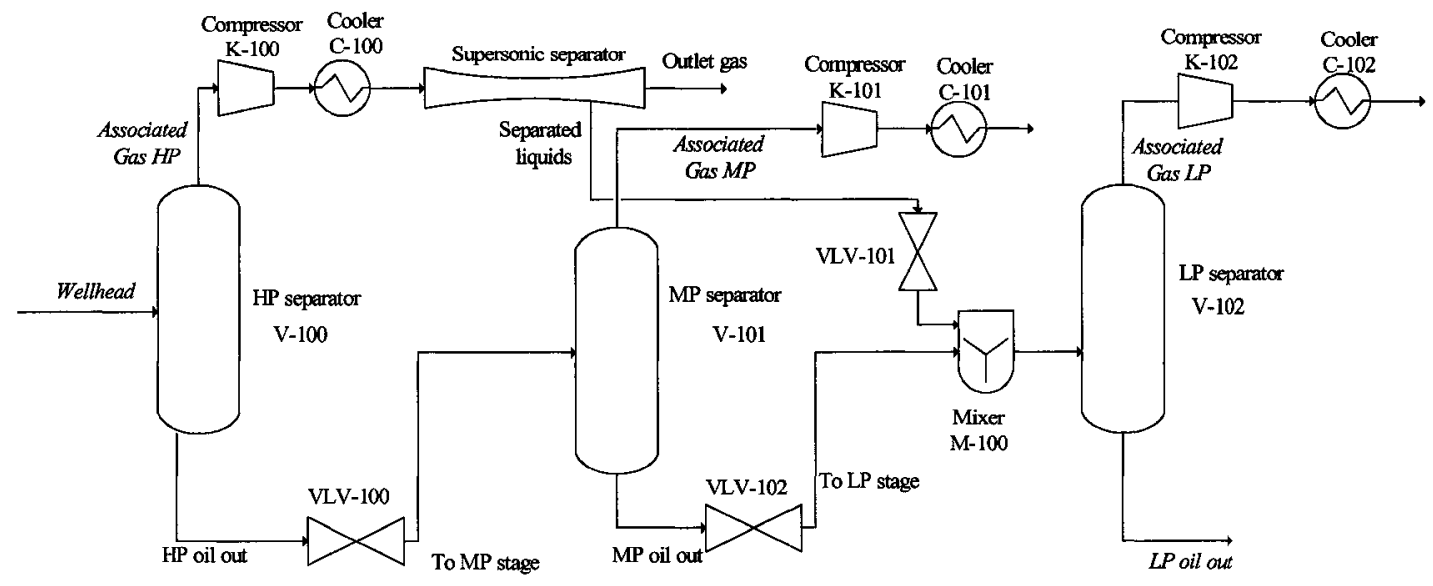

Figure 5.15: Case 4.B: Supersonic separator at HP compressor discharge; separated condensates routed to LP Separator 


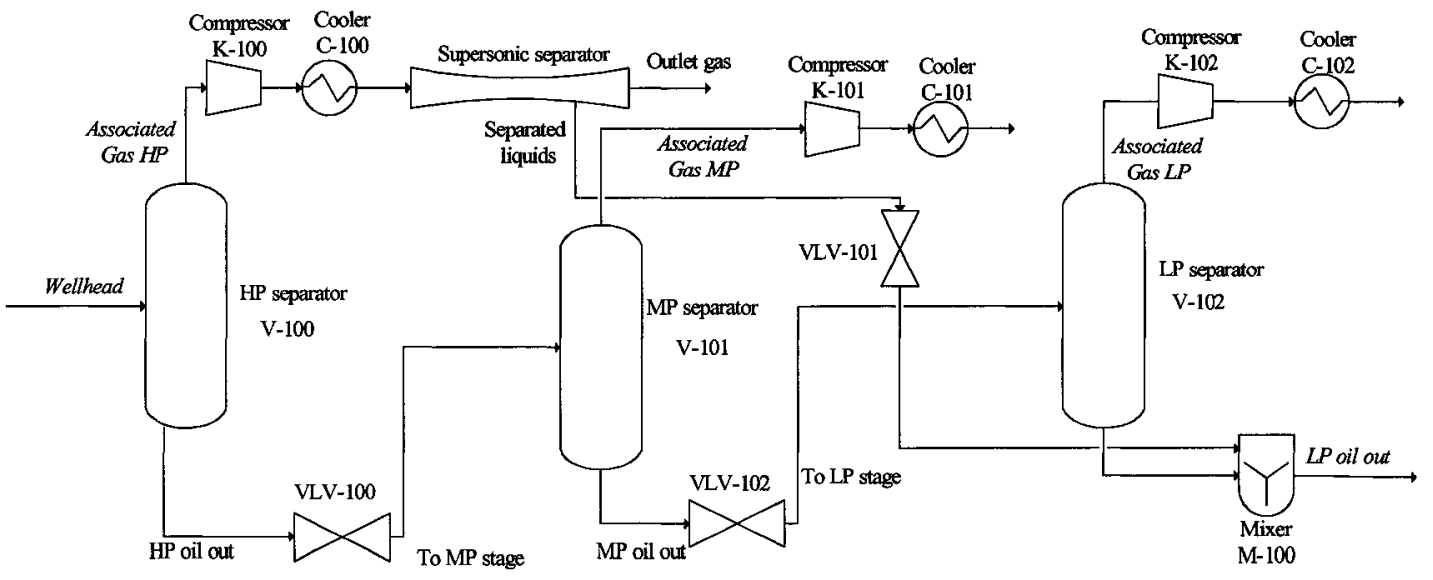

Figure 5.16: Case 4.C: Supersonic separator at HP compressor discharge; separated condensates routed to LP Oil Out

Figure 5.17 indicates the pressure distribution along the nozzle with $70 \%$ recovery of the inlet pressure. As it can be seen the pressure before the shockwave is above the operating pressures of the MP and LP separators. In Table5.12 the mole fractions and mole flows of each component of the "LP Oil Out" stream are shown. This stream is richer in lighter hydrocarbons in this case than the same stream in the "Base Process" which results in the bubble point curve expansion toward the lower bubble point temperatures (see Figure 5.18). Table 5.13 shows the crude oil production and RVP for the "LP oil out" stream in case 4. 
Table 5.12: Mole fractions and molar flow rates for Stream"LP Oil Out" in Case 4 with $70 \%$ inlet pressure recovery

\begin{tabular}{|c|c|c|c|c|c|c|c|c|c|}
\hline & \multicolumn{3}{|c|}{ Case 4.A } & \multicolumn{3}{|c|}{ Case 4.B } & \multicolumn{3}{|c|}{ Case 4.C } \\
\hline & $\begin{array}{c}\text { Mole } \\
\text { Fracti } \\
\text { on }\end{array}$ & $\begin{array}{c}\text { Molar } \\
\text { Flow } \\
\text { ( kgmole/h) }\end{array}$ & $\begin{array}{c}\text { Recovery } \\
\text { (\% of } \\
\text { wellhead) }\end{array}$ & $\begin{array}{c}\text { Mole } \\
\text { Fraction }\end{array}$ & $\begin{array}{c}\text { Molar } \\
\text { Flow } \\
\text { ( kgmole/h) }\end{array}$ & $\begin{array}{c}\text { Recovery } \\
\text { (\% of } \\
\text { wellhead) }\end{array}$ & $\begin{array}{c}\text { Mole } \\
\text { Fraction }\end{array}$ & $\begin{array}{c}\text { Molar } \\
\text { Flow } \\
\text { ( kgmole/h) }\end{array}$ & $\begin{array}{c}\text { Recovery } \\
\text { (\% of } \\
\text { wellhead) }\end{array}$ \\
\hline Total & 1.000 & $6,622.790$ & 33.150 & 1.000 & $6,613.900$ & 33.110 & 1.000 & $6,808.270$ & 34.080 \\
\hline Methane & 0.010 & 43.660 & 0.380 & 0.010 & 44.330 & 0.390 & 0.020 & 116.270 & 1.020 \\
\hline Ethane & 0.020 & 137.030 & 10.760 & 0.020 & 135.150 & 10.610 & 0.030 & 185.810 & 14.590 \\
\hline Propane & 0.070 & 450.050 & 43.290 & 0.070 & 445.510 & 42.850 & 0.070 & 503.050 & 48.380 \\
\hline i-Butane & 0.010 & 85.180 & 69.500 & 0.010 & 84.450 & 68.900 & 0.010 & 88.820 & 72.460 \\
\hline n-Butane & 0.030 & 228.150 & 77.560 & 0.030 & 226.310 & 76.930 & 0.030 & 234.060 & 79.570 \\
\hline i-Pentane & 0.010 & 47.800 & 89.590 & 0.010 & 47.550 & 89.130 & 0.010 & 48.140 & 90.230 \\
\hline n-Pentane & 0.010 & 53.100 & 92.060 & 0.010 & 52.870 & 91.660 & 0.010 & 53.330 & 92.460 \\
\hline Hexane & 0.000 & 21.000 & 97.080 & 0.000 & 20.960 & 96.910 & 0.000 & 21.010 & 97.140 \\
\hline $\mathrm{C} 7+$ & 0.840 & $5,555.190$ & 100.000 & 0.840 & $5,555.190$ & 100.000 & 0.820 & $5,555.190$ & 100.000 \\
\hline C2 Plus & 0.990 & $6,577.490$ & 78.140 & 0.990 & $6,567.990$ & 78.030 & 0.980 & $6,689.410$ & 79.470 \\
\hline C3 Plus & 0.970 & $6,440.460$ & 90.150 & 0.970 & $6,432.840$ & 90.040 & 0.960 & $6,503.600$ & 91.030 \\
\hline $\mathrm{N}_{2}$ & 0.000 & 0.040 & 0.020 & 0.000 & 0.040 & 0.020 & 0.000 & 0.290 & 0.170 \\
\hline $\mathrm{CO}_{2}$ & 0.000 & 1.600 & 4.100 & 0.000 & 1.540 & 3.950 & 0.000 & 2.300 & 5.920 \\
\hline
\end{tabular}

Table 5.13: Crude oil production of the three processes in case 4 for $70 \%$ inlet pressure recovery 


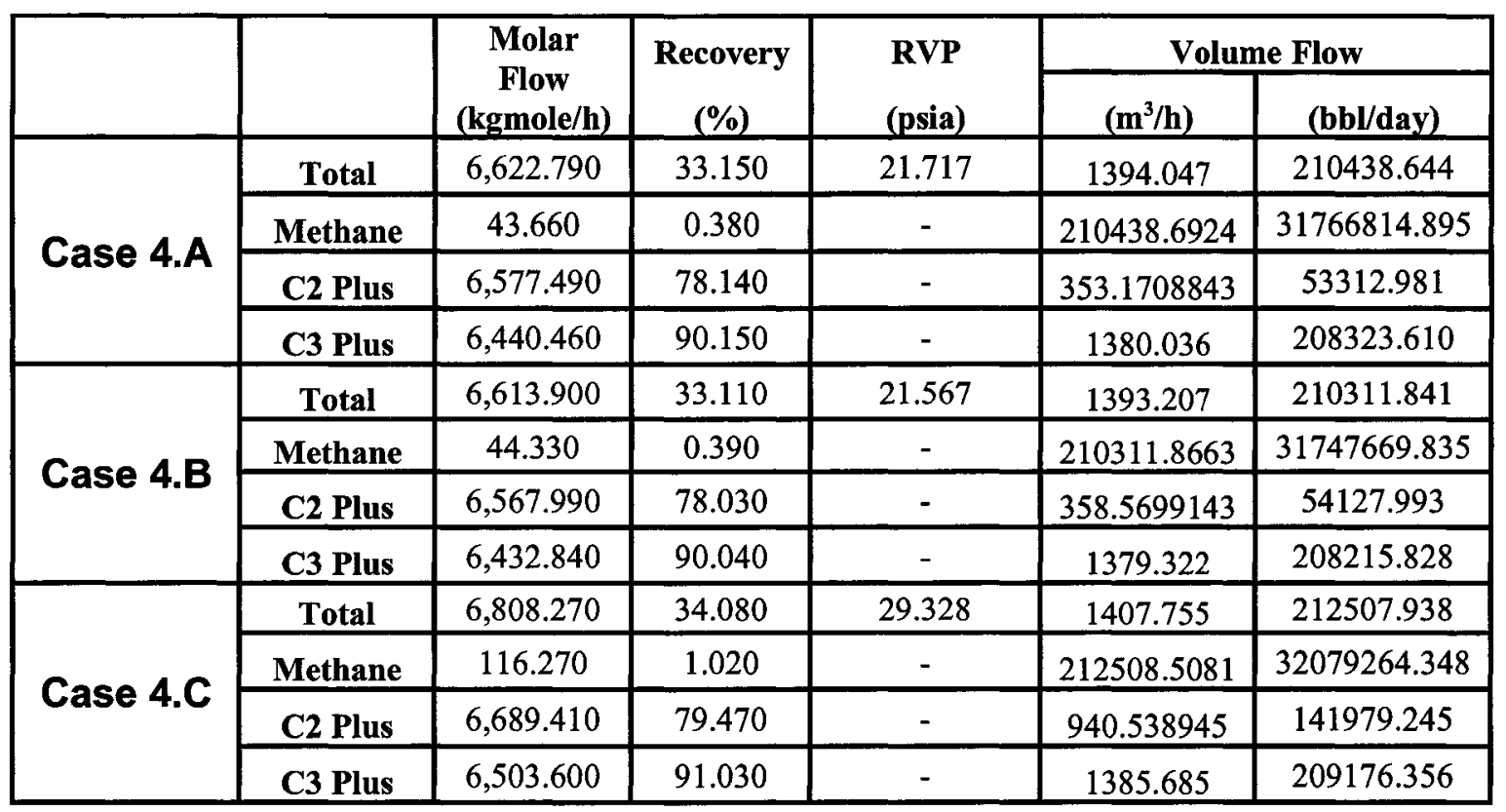

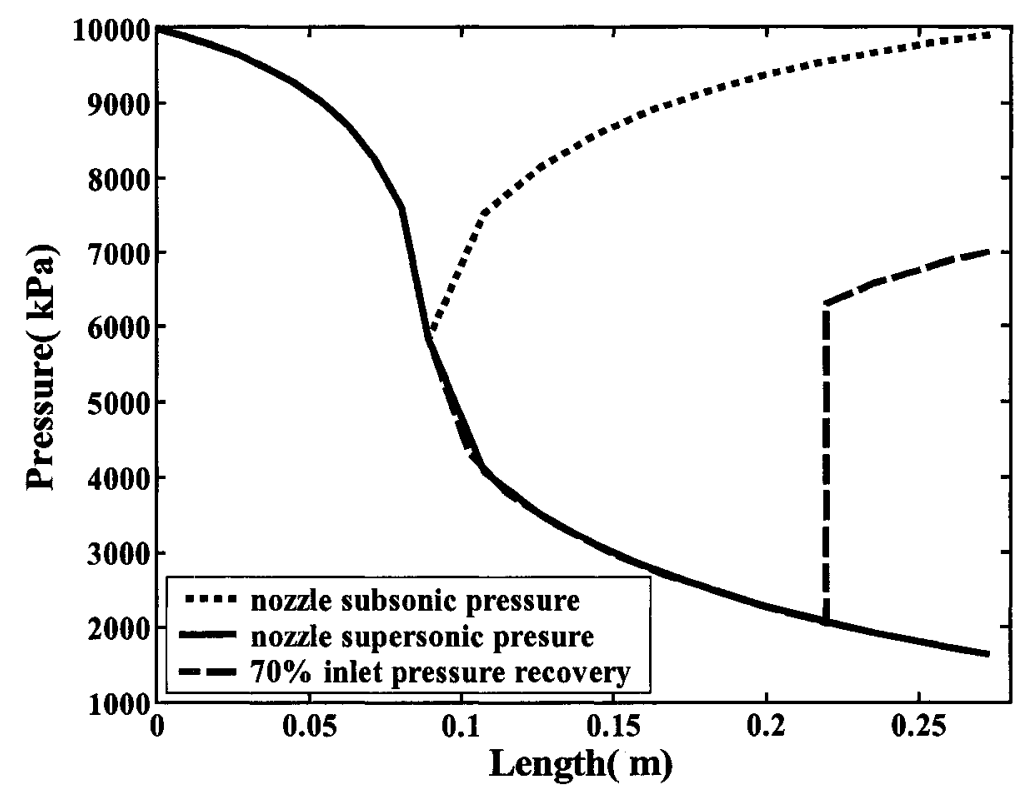

Figure 5.17: Pressure distribution along the nozzle with $70 \%$ pressure recovery in Case 4 


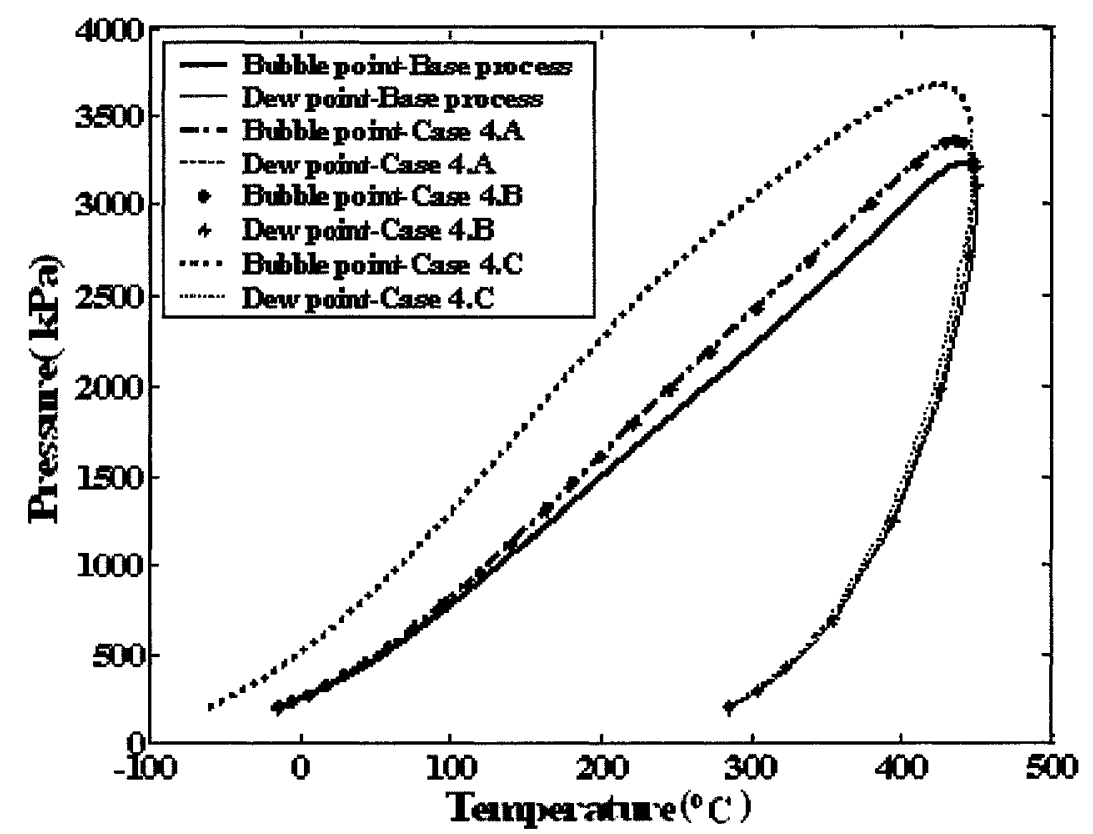

Figure 5.18: Phase envelopes for Stream "LP Oil Out" for "Base Process" and Case 4 with $70 \%$ pressure recovery

\subsubsection{CASE 5: SUPERSONIC SEPARATOR AT MP COMPRESSOR DISCHARGE}

The pressure of "Associated Gas MP“is $1,724 \mathrm{kPa}$, this pressure with the pressure compression ratio of $4(6,896 \mathrm{kPa})$ cooled to the initial stream temperature $\left(40.72{ }^{\circ} \mathrm{C}\right)$. The inlet properties are the same as the "Associated Gas MP" except the pressure which is $6,896 \mathrm{kPa}$. This stream enters the supersonic nozzle. A nozzle with the geometry shown in Table 5.14 is designed for this condition. The nozzle backpressure is adjusted to recover $70 \%$ of the inlet nozzle pressure $(4,827 \mathrm{kPa})$. 
Table 5.14: Nozzle geometry for case 5

\begin{tabular}{|l|c|}
\hline Inlet diameter(m) & 0.0400 \\
\hline Throat diameter(m) & 0.0284 \\
\hline Outlet diameter(m) & 0.0391 \\
\hline Converging length(m) & 0.0481 \\
\hline Diverging length (m) & 0.1019 \\
\hline Total length (m) & 0.1500 \\
\hline Length upper bound (m) & 0.1500 \\
\hline
\end{tabular}

Two different processes are considered in this case, the "separated liquids" stream from the supersonic nozzle is mixed with "MP Oil Out" stream from the bottom of MP Separator and it is entered LP Separator in Case 5.A and mixed with the stream from the bottom of LP Separator in Case 5.B. These two processes are shown in Figures 5.19 and 5.20. As shown in Figure 5.21, the pressure upstream of the shockwave is above the MP and LP separators operating pressures and as a result, this nozzle with $70 \%$ of the inlet pressure recovery can be used in the system.
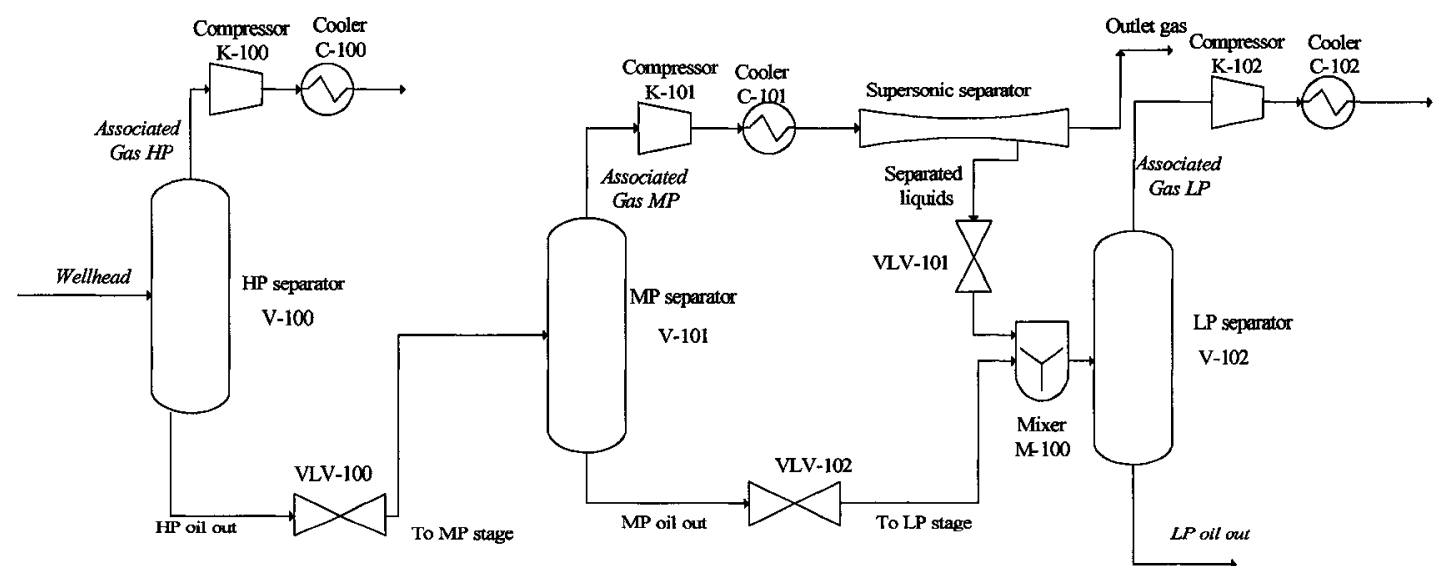

Figure 5.19: Case 5.A: Supersonic separator at MP compressor discharge; separated condensates routed to LP Separator 


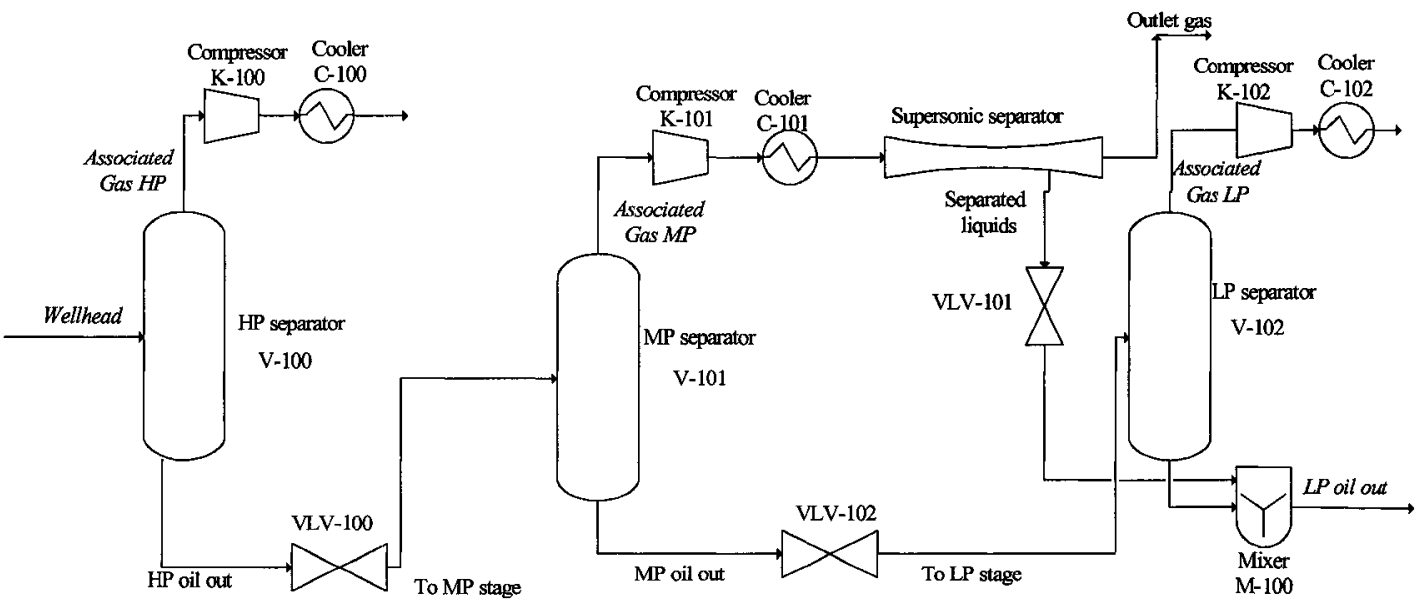

Figure 5.20: Case 5.B: Supersonic separator at MP compressor discharge; separated condensates routed to LP Oil Out

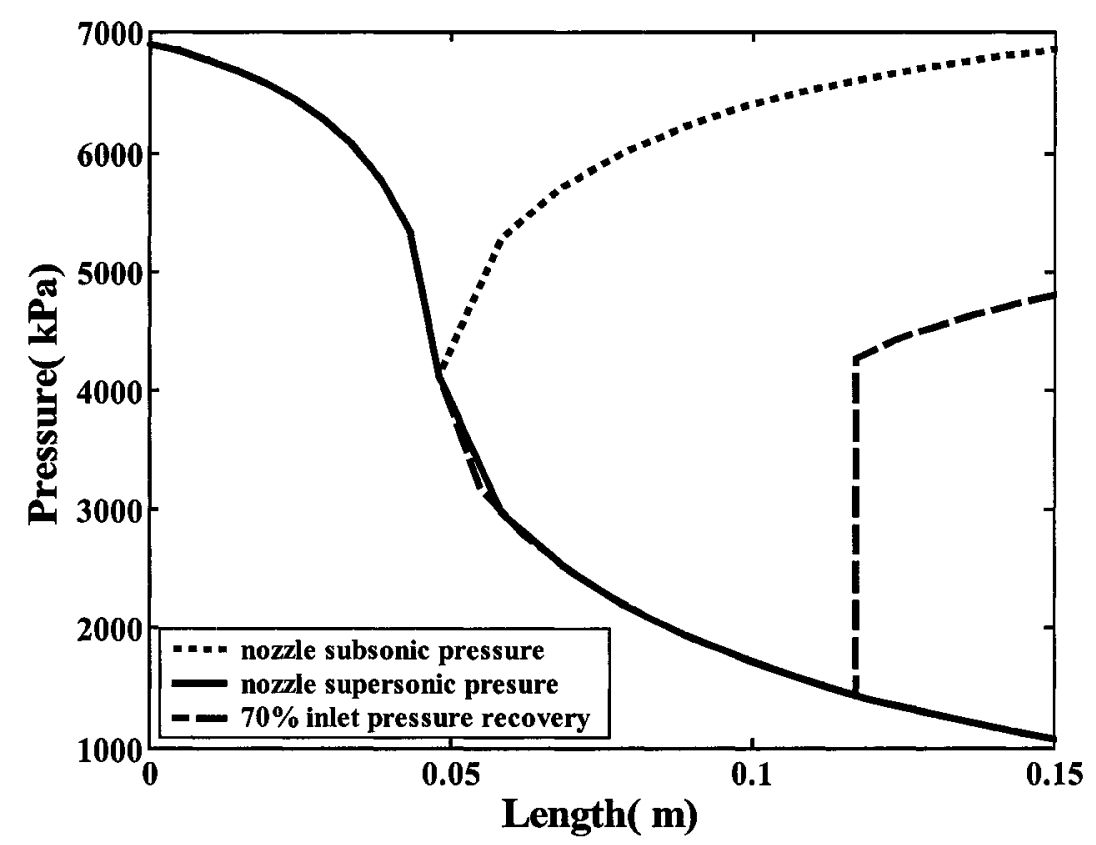

Figure 5.21: Pressure distribution along the nozzle with $70 \%$ pressure recovery in Case 5 


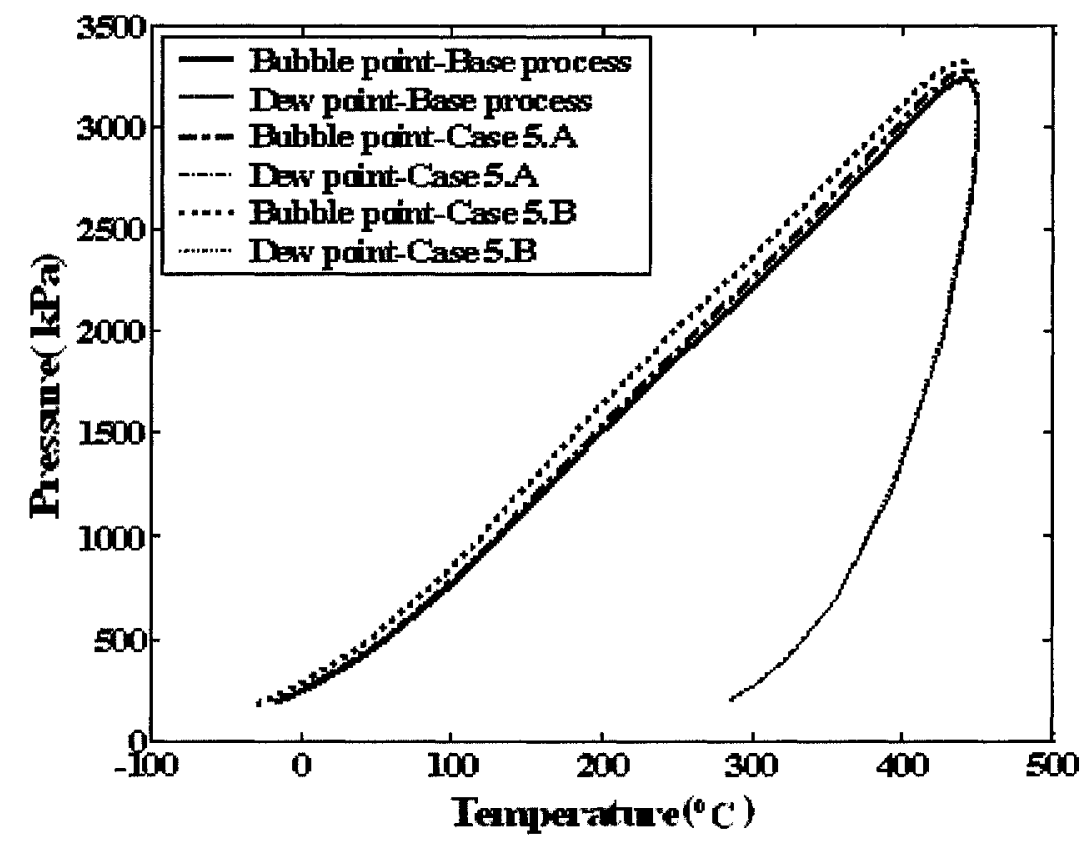

Figure 5.22: Phase envelopes for the stream "LP Oil Out" for "Base Process" and Case 5 with $70 \%$ pressure recovery

In Table5.15, the mole fractions and mole flows of each component of the "LP oil $o u t$ " stream in case Five are shown. This stream is richer in lighter hydrocarbons in this case, especially in case 5.B, than the same stream in the "Base process" which results in the bubble point curve expansion toward the lower bubble point temperatures (see Figure 5.22). Table 5.16 shows the crude oil production and RVP for the "LP oil out" stream for the case 5 . 
Table 5.15:Mole fractions and molar flow rates for Stream "LP Oil Out" for two processes in Case 5

\begin{tabular}{|c|c|c|c|c|c|c|}
\hline & \multicolumn{3}{|c|}{ Case 5.A } & \multicolumn{3}{|c|}{ Case5.B } \\
\hline & $\begin{array}{c}\text { Mole } \\
\text { Fraction }\end{array}$ & $\begin{array}{c}\text { Molar Flow } \\
\text { ( kgmole/h) }\end{array}$ & $\begin{array}{c}\text { Recovery } \\
\text { (\% of } \\
\text { wellhead) }\end{array}$ & Mole Fraction & $\begin{array}{c}\text { Molar Flow } \\
\text { ( kgmole/h) }\end{array}$ & $\begin{array}{c}\text { Recovery } \\
\text { (\% of } \\
\text { wellhead) }\end{array}$ \\
\hline Total & 1.000 & $6,537.920$ & 32.730 & 1.000 & $6,575.860$ & 32.920 \\
\hline Methane & 0.007 & 44.580 & 0.390 & 0.008 & 54.650 & 0.480 \\
\hline Ethane & 0.020 & 130.190 & 10.220 & 0.022 & 141.600 & 11.120 \\
\hline Propane & 0.062 & 405.540 & 39.010 & 0.064 & 418.920 & 40.290 \\
\hline i-Butane & 0.012 & 76.800 & 62.660 & 0.012 & 77.770 & 63.450 \\
\hline n-Butane & 0.032 & 208.320 & 70.820 & 0.032 & 210.020 & 71.400 \\
\hline i-Pentane & 0.007 & 44.960 & 84.270 & 0.007 & 45.080 & 84.500 \\
\hline $\mathrm{n}$-Pentane & 0.008 & 50.470 & 87.510 & 0.008 & 50.570 & 87.670 \\
\hline Hexane & 0.003 & 20.490 & 94.720 & 0.003 & 20.500 & 94.770 \\
\hline $\mathrm{C}_{7}^{+}$ & 0.850 & $5,554.950$ & 99.990 & 0.845 & $5,554.950$ & 99.990 \\
\hline $\mathrm{C}_{2}$ Plus & 0.993 & $6,491.730$ & 77.120 & 0.991 & $6,519.420$ & 77.450 \\
\hline $\mathrm{C}_{3}$ Plus & 0.973 & $6,361.540$ & 89.040 & 0.970 & $6,377.810$ & 89.270 \\
\hline $\mathrm{N}_{2}$ & 0.000 & 0.040 & 0.020 & 0.000 & 0.060 & 0.030 \\
\hline $\mathrm{CO}_{2}$ & 0.000 & 1.580 & 4.050 & 0.000 & 1.740 & 4.470 \\
\hline
\end{tabular}

Table 5.16: Crude oil production of the three processes in case 5 for $70 \%$ inlet pressure

\begin{tabular}{|c|c|c|c|c|c|c|}
\hline \multicolumn{7}{|c|}{ recovery } \\
\hline & & \multirow{2}{*}{$\begin{array}{c}\text { Molar } \\
\text { Flow } \\
\text { (kgmole/h) }\end{array}$} & \multirow{2}{*}{$\begin{array}{c}\text { Recovery } \\
(\%) \\
\end{array}$} & \multirow{2}{*}{$\begin{array}{l}\text { RVP } \\
\text { (psia) } \\
\end{array}$} & \multicolumn{2}{|c|}{ Volume Flow } \\
\hline & & & & & $\left(\mathrm{m}^{3} / \mathrm{h}\right)$ & (bbl/day) \\
\hline \multirow{4}{*}{ Case 5.A } & Total & $6,537.92$ & 32.73 & 20.38 & $1,386.05$ & $209,231.52$ \\
\hline & Methane & 44.58 & 0.39 & - & 2.39 & 360.57 \\
\hline & C2 Plus & $6,491.73$ & 77.12 & - & $1,383.58$ & $208,858.04$ \\
\hline & C3 Plus & 0.991 & 89.04 & - & $1,372.57$ & $207,196.56$ \\
\hline \multirow{4}{*}{ Case 5.B } & Total & $6,575.86$ & 32.92 & 21.78 & $1,389.02$ & $209,680.50$ \\
\hline & Methane & 54.65 & 0.48 & - & 2.93 & 442.09 \\
\hline & C2 Plus & $6,519.42$ & 77.45 & - & $1,386.00$ & $209,224.12$ \\
\hline & C3 Plus & $6,377.81$ & 89.27 & - & $1,374.03$ & $207,417.01$ \\
\hline
\end{tabular}




\subsubsection{CASE 6: SUPERSONIC SEPARATOR AT LP COMPRESOR DISCHARGE}

In Case 6 , the possibility of locating the supersonic nozzle with $70 \%$ of pressure recovery at the discharge of LP compressor is investigated (see Figure 5.23).

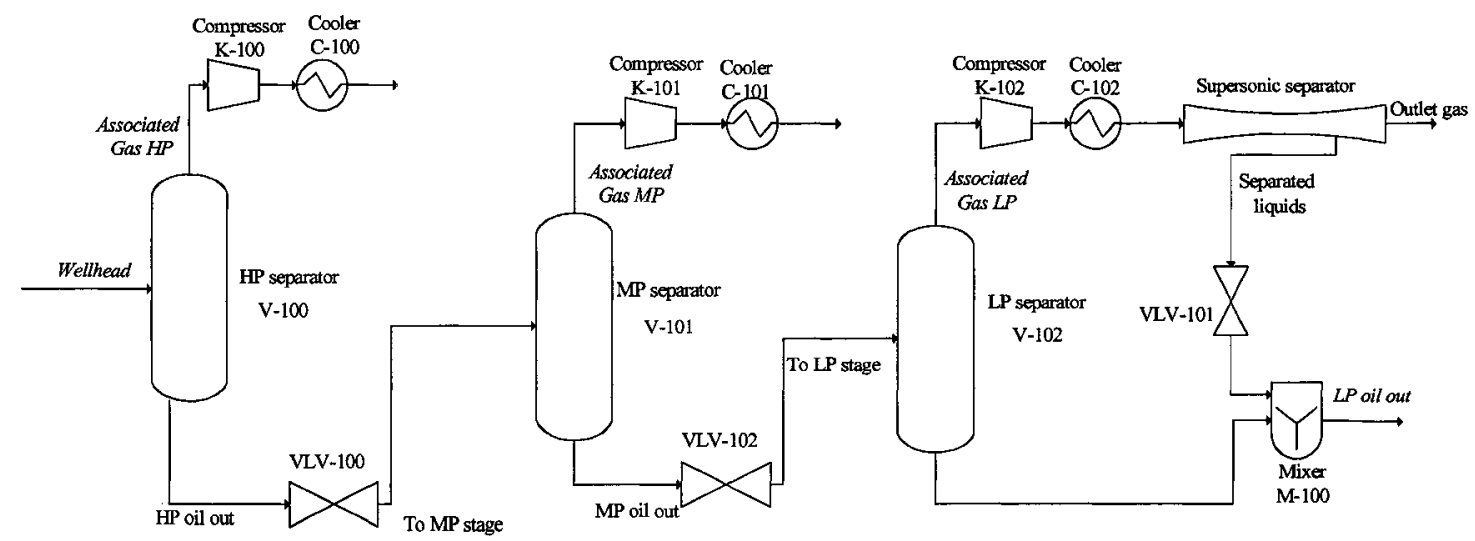

Figure 5.23: Case 6: Supersonic separator at LP compressor discharge; separated condensates routed to LP Oil Out

The pressure of Stream "Associated Gas $L P$ " is increased to $1,655 \mathrm{kPa}$ with the compression ratio of 4 , cooled to the same temperature as the temperature before the compressor and entered the supersonic nozzle. This stream has the same inlet properties as the "Associated Gas $L P$ "with a higher pressure. Table 5.17 shows the geometry of the nozzle designed with this stream as the working fluid. The pressure upstream of the shockwave should be kept above the operating pressure of LP Separator as it is the pressure of the stream exiting the bottom of LP Separator. As shown in Figure 5.24, if backpressure of the nozzle is adjusted to recover $70 \%$ of the inlet pressure, the pressure upstream of the shockwave will fall below the operating pressure of LP Separator (413.7 
$\mathrm{kPa}$ ) and as a result, such a nozzle can not be located in this position.

Table 5.17: Nozzle geometry for Case 6

\begin{tabular}{|l|c|}
\hline Inlet diameter(m) & 0.0520 \\
\hline Throat diameter(m) & 0.0385 \\
\hline Outlet diameter(m) & 0.0484 \\
\hline Converging length(m) & 0.0559 \\
\hline Diverging length (m) & 0.0941 \\
\hline Total length (m) & 0.1500 \\
\hline Length upper bound (m) & 0.1500 \\
\hline
\end{tabular}

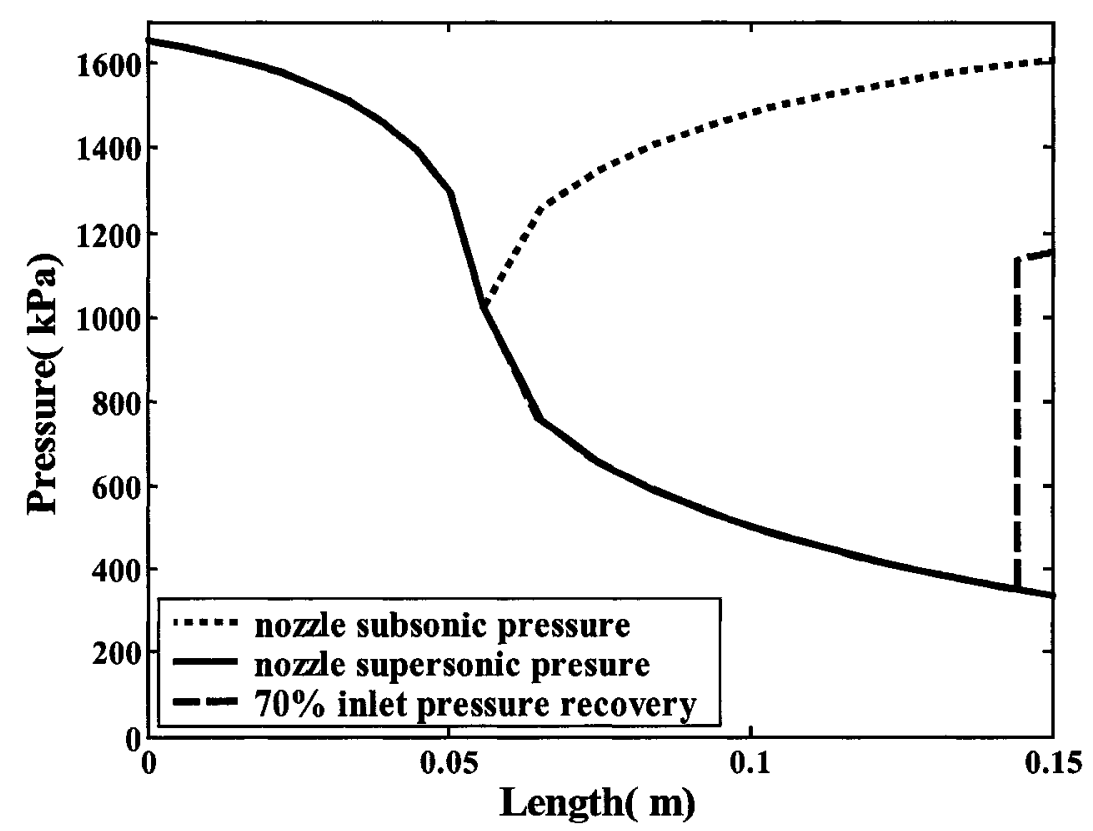

Figure 5.24: Pressure distribution along the nozzle with 70\% pressure recovery in Case 6 
5.2.7 CASE 7: NOZZLES AT OVERHEADS OF HP AND MP COMPRESSORS

As shown in the previous cases, it is more efficient to locate the nozzle after the compressor of each separator. Two processes are considered in this case. In the Case 7.A the stream "separated liquids" from the HP nozzle is mixed with the stream "HP Oil Out" and entered MP Separator after pressure adjustment. The same stream from MP nozzle is mixed with "MP Oil Out" and entered the LP separator. In Case 7.B the stream "separated liquids" from both nozzles are mixed with the "MP Oil Out" and entered LP Separator. These processes are outlined in Figures 5.25 and 5.26.

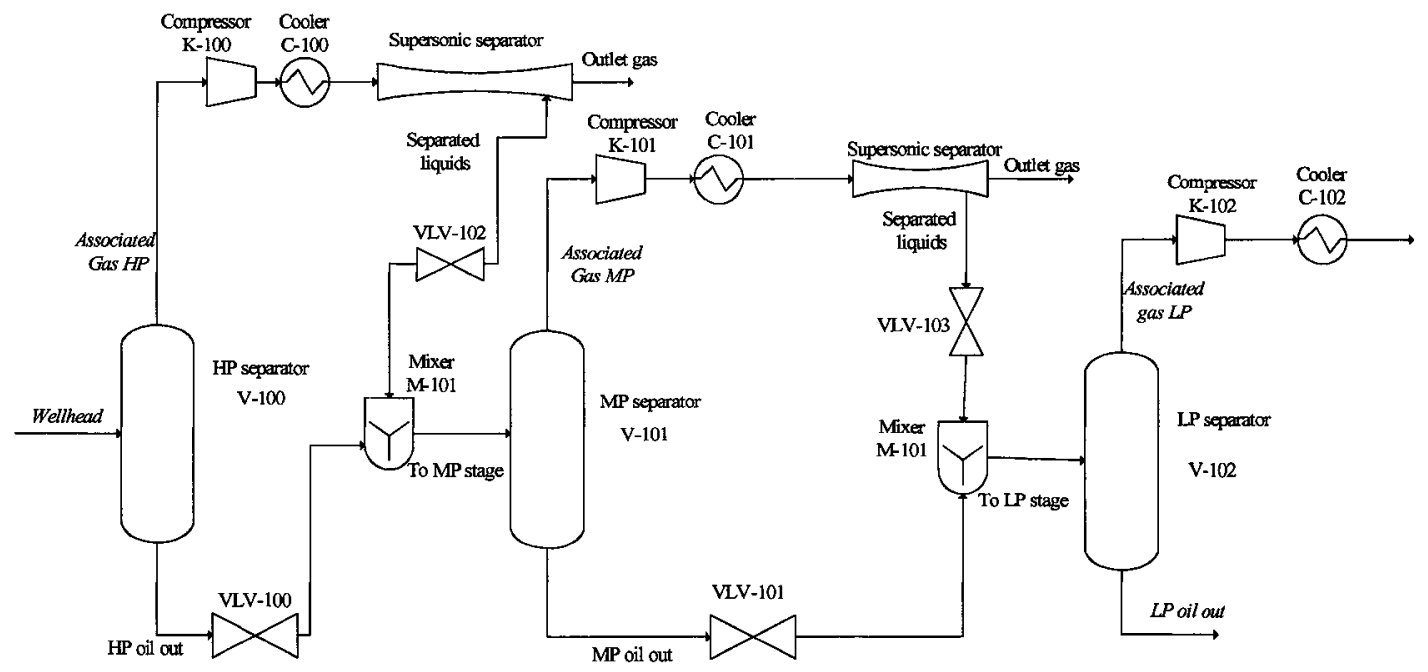

Figure 5.25: Case 7.A: Two supersonic nozzles at discharges of HP and MP compressors; separated liquids to MP and LP separators 


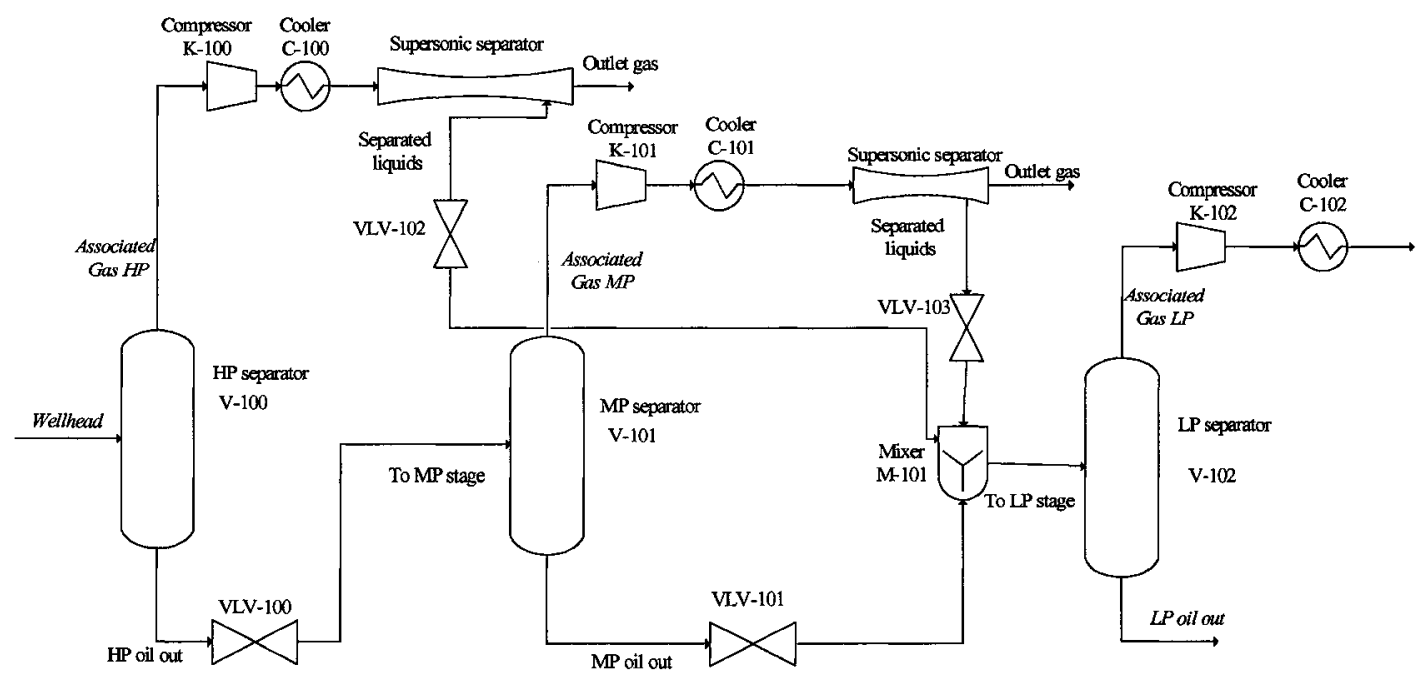

Figure 5.26: Case 7.B: Two supersonic nozzles at discharges of HP and MP compressors; separated liquids to LP Separator

The first nozzle, "HP nozzle", is located after the HP compressor. The inlet properties and therefore the nozzle geometry are the same as Case 4. The other nozzle,"MP nozzle", is located after the MP compressor. The inlet pressure and temperature is the same as Case 5 but the molar flow rate $(1,797 \mathrm{kmole} / \mathrm{h})$ is higher than that of Case 5. The nozzlespecifications designed for this purpose are listed in Table 5.18. The pressure distributions in the "HP and MP nozzles" in Case 7.A, show that the nozzles can be used in the system because the pressure upstream of the shockwave in the nozzle is higher than the operating pressure of the next stage (see Figure 5.17 and Figure 5.27). In Case 7.B, the inlet stream for both nozzles is the "Associated Gas HP" and "Associated Gas MP", respectively as the "separated liquids" from both nozzles are entered the LP Separator. The nozzles designed in Cases 4 and 5 are used as "HP and MP 
nozzles" (see Figures 5.17 and 5.21 for the pressure distributions along the nozzles). In Table 5.14, the mole fractions and molar flows of each component of "LP Oil Out" stream in Case 7 are shown.

Table 5.18: "MP Nozzle" geometry for case 7.A

\begin{tabular}{|l|c|}
\hline Inlet diameter(m) & 0.0400 \\
\hline Throat diameter(m) & 0.0294 \\
\hline Outlet diameter(m) & 0.0395 \\
\hline Converging length(m) & 0.0439 \\
\hline Diverging length (m) & 0.0961 \\
\hline Total length (m) & 0.1400 \\
\hline Length upper bound (m) & 0.1400 \\
\hline
\end{tabular}

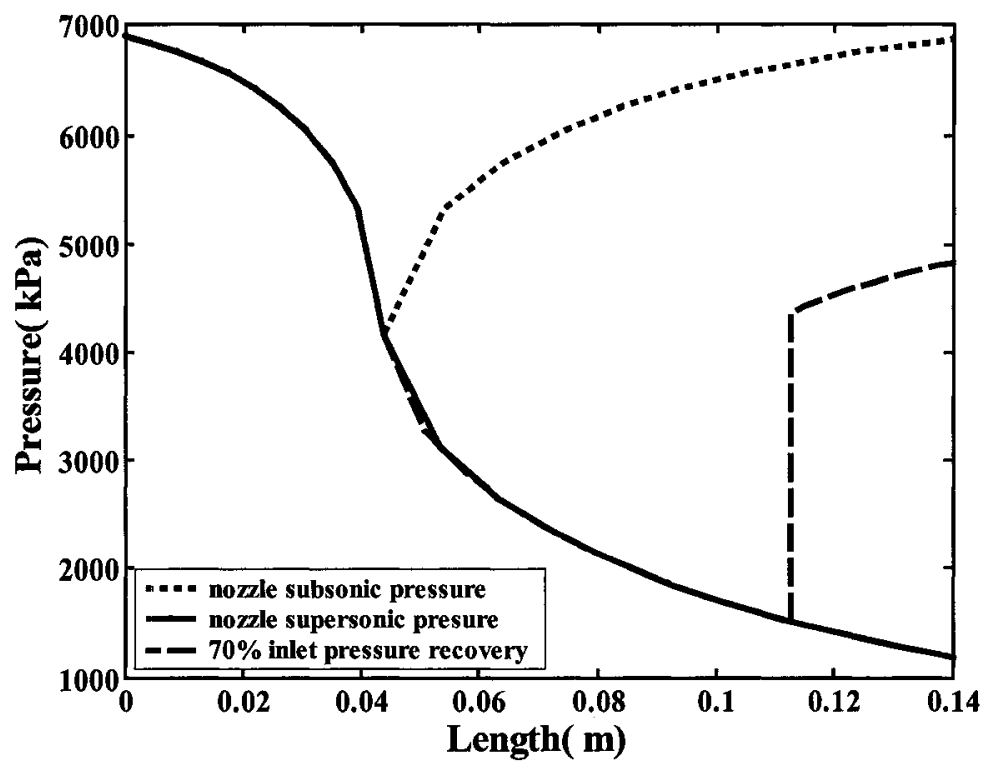

Figure 5.27: Pressure distribution along MP nozzle with 70\% pressure recovery in Case 7 with $70 \%$ inlet pressure recovery 


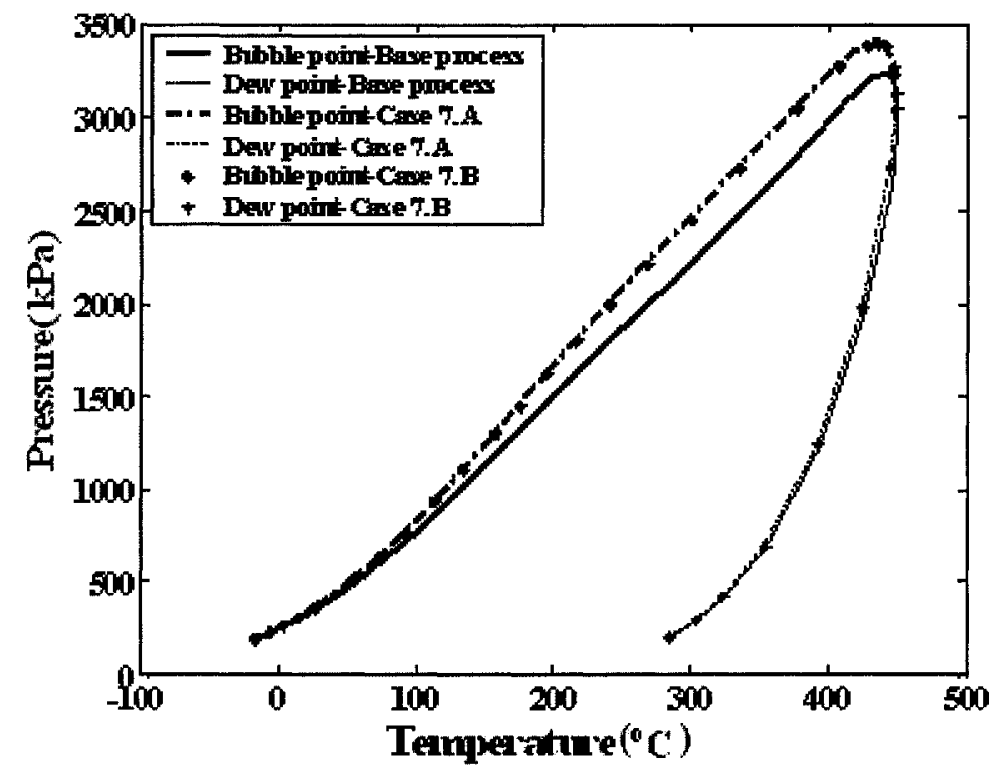

Figure 5.28: Phase envelopes for the stream "LP Oil Out" for "Base Process" and Case 7 with $70 \%$ pressure recovery

Table 5.19: Mole fractions and molar flow rates of' LP Oil Out" for Case 7

\begin{tabular}{|c|c|c|c|c|c|c|}
\hline & \multicolumn{3}{|c|}{ Case 7.A } & \multicolumn{3}{|c|}{ Case 7.B } \\
\hline & Mole Fraction & $\begin{array}{c}\text { Molar Flow } \\
\text { ( kgmole/h) }\end{array}$ & $\begin{array}{c}\text { Recovery } \\
\text { (\% of } \\
\text { wellhead) }\end{array}$ & Mole Fraction & $\begin{array}{c}\text { Molar Flow } \\
\text { ( kgmole/h) }\end{array}$ & $\begin{array}{c}\text { Recovery } \\
\text { (\% of } \\
\text { wellhead) }\end{array}$ \\
\hline Total & 1.000 & $6,663.980$ & 33.360 & 1.000 & $6,648.630$ & 33.280 \\
\hline Methane & 0.006 & 42.910 & 0.380 & 0.007 & 43.760 & 0.390 \\
\hline Ethane & 0.021 & 140.660 & 11.050 & 0.021 & 138.140 & 10.850 \\
\hline Propane & 0.071 & 473.560 & 45.550 & 0.070 & 464.760 & 44.700 \\
\hline i-Butane & 0.013 & 89.090 & 72.680 & 0.013 & 87.790 & 71.630 \\
\hline n-Butane & 0.036 & 236.980 & 80.560 & 0.035 & 234.080 & 79.580 \\
\hline i-Pentane & 0.007 & 48.830 & 91.520 & 0.007 & 48.500 & 90.920 \\
\hline n-Pentane & 0.008 & 54.000 & 93.620 & 0.008 & 53.720 & 93.140 \\
\hline Hexane & 0.003 & 21.130 & 97.690 & 0.003 & 21.090 & 97.510 \\
\hline $\mathrm{C} 7+$ & 0.834 & $5,555.200$ & 100.000 & 0.836 & $5,555.200$ & 100.000 \\
\hline C2 Plus & 0.993 & $6,619.440$ & 78.640 & 0.993 & $6,603.290$ & 78.450 \\
\hline C3 Plus & 0.972 & $6,478.780$ & 90.680 & 0.972 & $6,465.150$ & 90.490 \\
\hline
\end{tabular}




\begin{tabular}{|l|l|l|l|l|l|l|}
$\mathbf{N 2}$ & 0.000 & 0.040 & 0.020 & 0.000 & 0.040 & 0.020 \\
\hline $\mathbf{C O 2}$ & 0.000 & 1.590 & 4.090 & 0.000 & 1.540 & 3.950 \\
\hline
\end{tabular}

Table 5.20: Crude oil production of the three processes in case 7 for $70 \%$ inlet pressure

\begin{tabular}{|c|c|c|c|c|c|c|}
\hline \multicolumn{7}{|c|}{ recovery } \\
\hline & & Molar & Recovery & RVP & Volv & Flow \\
\hline & & (kgmole/h) & & (psia) & $\left(\mathrm{m}^{3} / \mathrm{h}\right)$ & (bbl/day) \\
\hline \multirow{4}{*}{ Case 7.A } & Total & $6,663.980$ & 33.360 & 22.335 & $1,397.633$ & $210,980.017$ \\
\hline & Methane & 42.910 & 0.380 & - & 2.303 & 347.635 \\
\hline & C2 Plus & $6,619.440$ & 78.640 & - & $1,395.244$ & $210,619.371$ \\
\hline & C3 Plus & $6,478.780$ & 90.680 & - & $1,383.379$ & $208,828.227$ \\
\hline \multirow{4}{*}{ Case7.B } & Total & $6,648.630$ & 33.280 & 22.163 & $1,396.690$ & $210,837.618$ \\
\hline & Methane & 43.760 & 0.390 & - & 2.343 & 353.643 \\
\hline & C2 Plus & $6,603.290$ & 78.450 & - & $1,394.262$ & $210,471.165$ \\
\hline & C3 Plus & $6,465.150$ & 90.490 & - & $1,382.574$ & $208,706.775$ \\
\hline
\end{tabular}

In Figure 5.28, the phase envelopes are shown for "Base Process", Cases 7.A, and 7.B. The bubble point curve of the process for Case 7 is shifted slightly to the left indicating a larger amount of heavy hydrocarbons. The small difference between the bubble curve line of Cases 7.A and 7.B, illustrates the higher concentration of heavy hydrocarbons in Case 7.A.

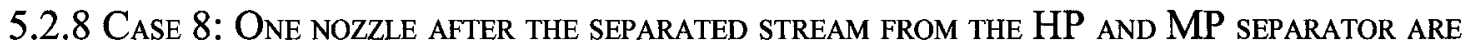
MIXED

In this case the stream "Associated Gas MP "is compressed with the compression ratio of 4 to $6,896 \mathrm{kPa}$ and cooled to the stream temperature, before entering the 
compressor. This stream is mixed with the "Associated Gas HP "and entered a supersonic nozzle. This process is outlined in Figure 5.29.

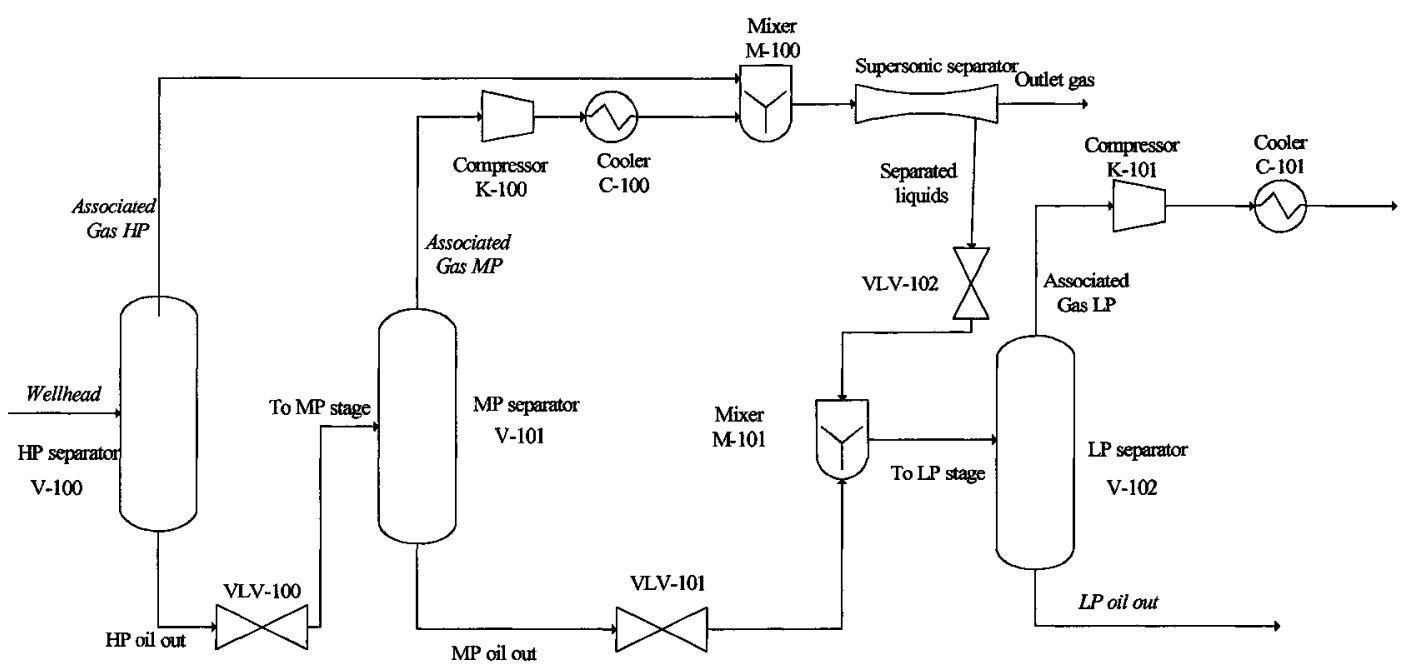

Figure 5.29: Case 8; Supersonic nozzle after the mixed stream from HP and MP separators

In this process, the streams from the high and medium pressure separators are mixed and therefore, the inlet properties of the nozzle are changed. Table 5.21 lists the inlet properties of the fluid entering the nozzle. In Table 5.22 the geometry of the designed nozzle for this case is outlined.

Table 5.21: Properties of nozzle inlet stream in Case 8

\begin{tabular}{|l|c|}
\hline Pressure (kPa) & 6,896 \\
\hline Temperature (C) & 41.6 \\
\hline Molar flow (kmole /h) & $1,2889.67$ \\
\hline
\end{tabular}

Table 5.22: Nozzle geometry for Case 8

\begin{tabular}{l|l}
\hline Inlet diameter(m) & 0.1060 \\
\hline
\end{tabular} 


\begin{tabular}{|c|c|} 
Throat diameter(m) & 0.0774 \\
\hline Outlet diameter(m) & 0.1017 \\
\hline Converging length(m) & 0.1186 \\
\hline Diverging length (m) & 0.2313 \\
\hline Total length (m) & 0.3500 \\
\hline Length upper bound (m) & 0.3500 \\
\hline
\end{tabular}

As the stream from the nozzle is entering the LP separator, the pressure upstream of the shockwave is needed to be kept above the operating pressure of LP Separator (413.7 $\mathrm{kPa})$. The "design pressure" of this nozzle is above the LP separator operating pressure ,so there will not be any limitation in how much the gas is expanded.theerefore the londest possible nozzle in this case $0.35 \mathrm{~m}$ is designed. In Table 5.23, the mole fractions and mole flows for all components in Stream "LP Oil Out" in Case 8 are shown. Higher concentration of heavy hydrocarbons in Stream "LP Oil Out" in Case 8 is also reflected in Figure 5.31. It is clear that the bubble point curve is shifted to the left of the curve for the "Base Process". 


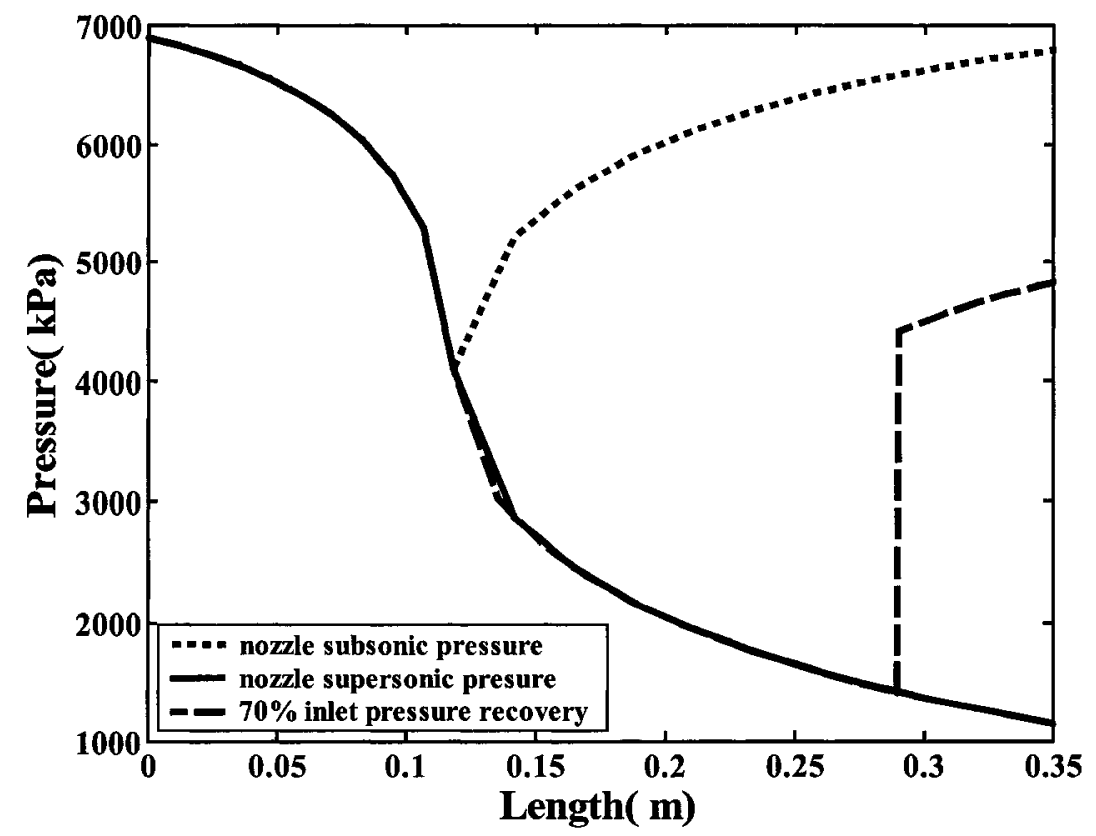

Figure 5.30: Pressure distribution along the nozzle with $70 \%$ pressure recovery in Case 8

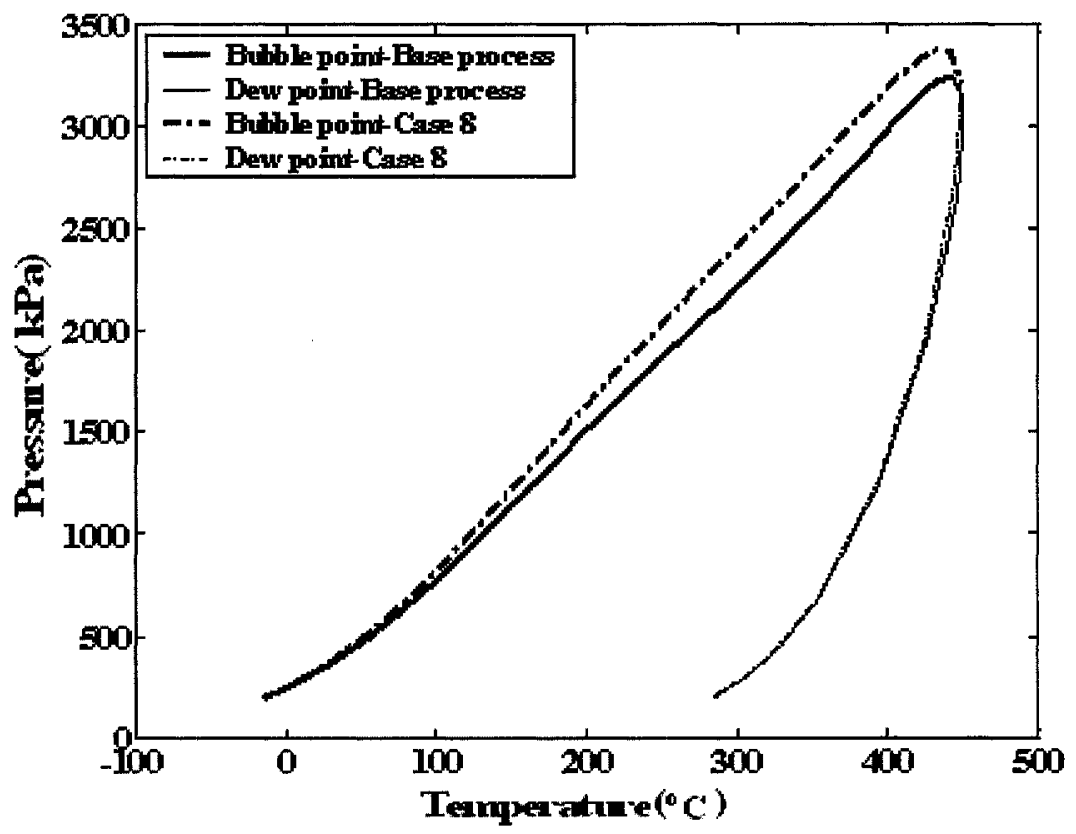

Figure 5.31: Phase envelopes for the stream "LP Oil Out" for "Base process" and Case 8 with $70 \%$ pressure recovery 
Table 5.23: Mole fractions and molar flow rates of the" LP oil out" stream in case eight

\begin{tabular}{|c|c|c|c|}
\hline & & \multicolumn{2}{|c|}{ Case 8 } \\
\cline { 2 - 3 } & Mole Fraction & Molar Flow & Recovery \\
& & (kgmole/h) & (\% of wellhead) \\
\hline Total & 1.000 & $6,663.980$ & 33.360 \\
\hline Methane & 0.007 & 43.810 & 0.390 \\
\hline Ethane & 0.020 & 134.960 & 10.600 \\
\hline Propane & 0.068 & 451.450 & 43.420 \\
\hline i-Butane & 0.013 & 86.940 & 70.930 \\
\hline n-Butane & 0.035 & 233.350 & 79.330 \\
\hline i-Pentane & 0.007 & 48.600 & 91.100 \\
\hline n-Pentane & 0.008 & 53.840 & 93.340 \\
\hline Hexane & 0.003 & 21.110 & 97.610 \\
\hline C7+ & 0.838 & $5,555.200$ & 100.000 \\
\hline C2 Plus & 0.993 & $6,585.450$ & 78.230 \\
\hline C3 Plus & 0.973 & $6,450.490$ & 90.290 \\
\hline N2 & 0.000 & 0.040 & 0.020 \\
\hline CO2 & 0.000 & 1.550 & 3.990 \\
\hline
\end{tabular}

Table 5.24 Crude oil production of the three processes in case 8 for $70 \%$ inlet pressure

\begin{tabular}{|c|c|c|c|c|c|c|}
\hline & & \multirow{2}{*}{$\begin{array}{c}\text { Molar } \\
\text { Flow } \\
\text { (kgmole/h) }\end{array}$} & \multirow{2}{*}{$\begin{array}{c}\text { Recovery } \\
(\%) \\
\end{array}$} & \multirow{2}{*}{$\begin{array}{l}\text { RVP } \\
\text { (psia) } \\
\end{array}$} & \multicolumn{2}{|c|}{ Volume Flow } \\
\hline & & & & & $\left(\mathrm{m}^{3} / \mathrm{h}\right)$ & (bbl/day) \\
\hline \multirow{4}{*}{ Case 8} & Total & $6,663.980$ & 33.360 & 21.713 & 1394.896 & 210566.747 \\
\hline & Methane & 43.810 & 0.390 & - & 2.348 & 354.413 \\
\hline & C2 Plus & $6,585.450$ & 78.230 & - & 1392.464 & 210199.633 \\
\hline & C3 Plus & $6,450.490$ & 90.290 & - & 1381.054 & 208477.225 \\
\hline
\end{tabular}

\subsection{REVIEW OF EIGTH CASES}

Table 5.25 summarizes the results obtained for the "Base Process" and Cases 1 to 
8. In this table the final compositions of each exit stream (LP Oil Out) as well as their exit RVP are shown. The objective is to reach a higher recovery of the heavy hydrocarbons in Stream "LP Oil Out". It is also important that the quality of the final product in terms of vapour pressure be maintained. The preferred processes have a higher recovery of heavy hydrocarbons compared to the "Base Process" while the amount of methane is similar or lower than the "Base process". It is disadvantageous to mix the "separated liquids" with the stream exiting the bottom of LP Separator. The separated liquids are at higher pressure and contined larger amount of higher boiling hydrocarbons (methane and ethane) which increase the vapour pressure of the final crude product. Cases 4.A, 4.B, 7.A, 7.B, and 8 show good performance for increasing the crude oil production efficiency. However, Case 7.A seems to be the most attractive process, although two nozzles have to be used. Case 8 also is a promising option. Althugh the size of the nozzle is bit larger however the recovery is very close to that of Case 7A. 
Table 5.25: Final compositions in the exit streams (LP Oil Out) for Cases 1 to 8

\begin{tabular}{|c|c|c|c|c|}
\hline Case & $\begin{array}{c}\text { Methane } \\
\text { Flow rate } \\
(\mathbf{k m o l e} / \mathbf{h})\end{array}$ & $\begin{array}{c}\mathbf{C}_{2}{ }^{+} \\
\text {Flow rate } \\
(\mathbf{k m o l e} / \mathbf{h})\end{array}$ & $\begin{array}{c}\mathbf{C}_{3}{ }^{+} \\
\text {Flow rate } \\
(\mathbf{k m o l e} / \mathbf{h})\end{array}$ & $\begin{array}{c}\text { RVP } \\
\text { (Psia) }\end{array}$ \\
\hline Base process & 0.40 & 76.68 & 88.57 & 19.773 \\
\hline 1.A & 0.40 & 77.3 & 89.26 & 20.453 \\
\hline 1.B & 0.40 & 77.3 & 89.27 & 20.446 \\
\hline 1.C & 0.56 & 77.69 & 89.56 & 22.471 \\
\hline 2.A & 0.40 & 76.68 & 88.57 & 19.774 \\
\hline 2.B & 0.40 & 76.68 & 88.57 & 19.774 \\
\hline 3 & ---- & ---- & --- & -- \\
\hline 4.A & 0.38 & 78.14 & 90.15 & 21.717 \\
\hline 4.B & 0.39 & 78.03 & 90.04 & 21.567 \\
\hline 4.C & 1.02 & 79.47 & 91.03 & 29.328 \\
\hline 5.A & 0.39 & 77.12 & 89.04 & 20.377 \\
\hline 5.B & 0.48 & 77.45 & 89.27 & 21.778 \\
\hline 6 & ---- & ---- & ---- & -- \\
\hline 7.A & 0.38 & 78.64 & 90.68 & 22.335 \\
\hline 7.B & 0.39 & 78.45 & 90.49 & 22.163 \\
\hline 8 & 0.39 & 78.23 & 90.29 & 21.713 \\
\hline
\end{tabular}




\section{Chapter 6: Conclusions}

\subsection{SUMMARY}

The propose of this thesis was to develop a compact high pressure system which is capable of removing water vapour from natural gas without affecting the heavy hydrocarbons. The proposed system in this work was compared with the traditional dehydration and hydrate inhibition processes such as absorption, adsorption, refrigeration, and membranes. In order to model and simulate the supersonic separators, the continuity and momentum equations, the first and the second laws of thermodynamics, along with a suitable equation of state had to be used to set a set of nonlinear equations. The non-linear equations had to be solved numerically to analyze the performance of the nozzle under various conditions. In order to study the performance of the supersonic separators, two software packages, namely MATLAB and HYSYS were linked. MATLAB was used to numerically solve the governing non-linear equations. The necessary informations were transferred between the two software packages. In this study a specific nozzle could be designed for the desired conditions. The model could also be used to rate a previously designed nozzle. The effect of the feed pressure, temperature, flow rate, backpressure (pressure at the nozzle exit), and friction on the design of the nozzle and the flow behaviour inside the nozzle were evaluated. In order to demonstrate the capability of the developed model, the model was used to simulate the 
production system within a three-stage separation train to examine its ability in recovering the NGLs from the associated gases. The model and simulation runs indicated that the use of a supersonic nozzle can improve the economy of crude production in offshore facilities.

\subsection{CONClusions ANd Future Work}

The following conclusions could be drawn from this work:

1. Dehydration and water removal is an important process in natural gas treatment. Therefore, there is a need to develop a method which:

- works at different pressures

0 is suitable for different applications; compactness is one of the attractive features for offshore applications,

- does not need a large initial investment and operates at low cost,

0 is environmental friendly, and

0 is selective towards water removal

2. Line heating is not an efficient method, as it does not remove the water although it is a simple process and does not need much investment. Hydrate inhibitor injection is costly and is not an environmental friendly process. Absorption using liquid desiccants is a simple process which can be automated for unmanned operations but needs a large footprint and therefore not suitable for offshore production facilities where compactness is of critical 
importance. Adsorption using solid desiccants also requires large facility requiring large amount of energy to regenerate the desiccants. Refrigeration needs a large facility, can be costly to operate. Membranes require lower energy to operate, pose minimal environmental impact over the others, however are not selective for water removal.

3. Supersonic separators have several advantages over the previously mentioned methods and can present attractive features especially for offshore and subsea applications. Such as the compactness, self-induced refrigeration and the high gas velocity in the nozzle.

4. The Newton-Raphson was used as a numerical method to solve the non-linear equation involved in modelling the supersonic nozzle. This technique is an efficient method to simulate the supersonic nozzles. The only pitfall of this method is its sensitivity to the initial guesses. An unsuitable initial guess can result in divergence of the solution from the correct values.

5. The results of modelling also indicated the importance of choosing a suitable equation of state. Ideal gas assumption resulted in inaccurate predictions.

6. When a nozzle is designed, the increase in nozzle inlet pressure, results in an increase in the nozzle length and the converging nozzle length and a decrease in the throat diameter. When the nozzle is rated, the flow capacity increases with inlet pressure. Fixing the backpressure, at a constant percentage of the inlet pressure recovery, the shockwave happens earlier in the nozzle for the 
higher inlet pressures. At both cases the "design pressure" of the nozzle will remain constant with the increase in the inlet pressure but the "recovery pressure" decrease with the increase in inlet pressure.

7. Designing a nozzle for higher inlet temperatures, results in a larger throat diameter in a shorter converging nozzle. The results of nozzle rating show that the flow capacity varies inversely with inlet temperature. For both, designing and rating a nozzle, the "design pressure" of the nozzle remains constant as the inlet pressure varies but the "recovery pressure" increases with the inlet temperature. For the same pressure recovery, the shockwave location shifts towards the nozzle exit as the inlet temperature increases.

8. There is a maximum possible flow rate for each nozzle. For the flow rates lower than this maximum value, the nozzle will not be choked at the throat (Mach number is lower than unity) and therefore flow will be subsonic along the nozzle. If it is desirable to have choked flow at the throat for lower flow rates, the nozzle will have a longer converging length with a smaller throat diameter. For the higher flow rates, a nozzle with shorter converging part and a larger throat should be designed.

9. The nozzle exit pressure (backpressure) affects the shockwave location in the diverging part of the nozzle. The higher the backpressure, the earlier the shockwave happens. The back pressure can be chosen between the "recovery pressure" and the "design pressure". Designers have to compromise between 
higher separation and a better pressure recovery.

10. Presence of friction inside the nozzle does not significantly affect the flow behaviour in the nozzle. It would however affect the location of the shockwave in the diverging aprt of the nozzle. For the chosen flow in this study, the shockwave in frictional flow was predicted later in the nozzle when compared with frictionless flow.

11. The water content of the gas increases with inlet temperature but decreases with increase in inlet pressure. Close to complete water removal may be achieved using the supersonic nozzles. At constant inlet temperature, with increase in pressure, the pressure-temperature of the system is more likely to remain in the dense phase. Therefore selective water removal can be achieved by controlling the design parameters: e.g.,increasing the inlet pressure with constant temperature, increasing the inlet temperature with constant outlet pressure and controlling the backpressure. As mentioned, shockwave happens earlier in the nozzle when the backpressure is higher and in this case the pressure is recovered without any further pressure reduction. This causes the pressure to remain above the cricondenbar.

12. The efficiency of supersonic nozzles in improving the capacity of crude production trains comprising three separation stages was examined. The results with variable nozzle locations were studied. Eight cases were presented. The performance criterion was the highest recovery of heavy 
hydrocarbons with similar or lower amount of methane and lighter hydrocarbons in the crude oil. A case (Case 7.A) where two nozzles were placed in the crude separation system, showed the most attractive performance among all the other studied cases. This study is assumed that two supersonic nozzles can be used in one platform due to their compactness. However, the feasibility study should be done to prove if this case is practical and economical.

Proposed Future Work

The following research activities are recommended as future work:

1. Since the analyses and conclusions in this work are based on the computational simulations, several assumptions were made to perform this study. Therefore, it is recommended to design and construct a pilot plant to confirm the results achieved with the computational simulation. This study is specially recommended for the cases where more than one nozzle is used on the platform.

2. Some of the common equations of state fail to work in all pressure and temperature conditions. Therefore, the tuning the equations of state is recommended. In order to tune equations, PVT tests need to be conducted.

3. The developed program needs a relatively long time to design a nozzle. The program needs to be modified in order to reduce the time of 
computation and it can be improved to become more user-friendly.

4. The design of supersonic nozzles can be combined with the study of separated liquids or solid (ice or hydrate) particles from the nozzle stream.

5. Study of the possibility of using the supersonic nozzles for the other applications such as cryogenic separation, deep cut, ethane recovery and air separation is also recommended.

6. The effect of having multiple nozzles in the crude production or high pressure dehydration processes was not studied in this work. It would add to the work if in the future work the effect of having several nozzles could be studied. 


\section{REFERENCES}

Alfyorov, V., Bagirov, L., Imayev, S., Lacey, J., Dmitriey, L. and Feygin, V.:"supersonic gas conditioning: First Commercial Offshore Experience", Oil and Gas Journal (May 2005).

Arnold, K. and Stewart, M.:, "Surface Production Operations; Volume 2; Design of Gas Handling Facilities”, 2nd Edition, Gulf Professional Publishing, Huston, TX, (1999)46 .

Ballard, D.: "Fundamentals of Gas Dehydration", Proceeding of the Gas Conditioning Conference, Okla, Norman, Mar 5-7, 1979.

Berger, B. D. and Anderson, K. E., "Gas Handling and Field Processing", Pennwell Corp, Tulsa, Ok. (1980)59.

Beronich, E. L., Hawboldt, K., Abdi, M., "Recovering Natural Gas Liquids in Atlantic Canada's Offshore Petroleum Production Projects", paper presented at the 85th Annual Convention of the Gas Processors Association, Grapevine,TX, March 5-8, 2006.

Beronich, E. L.: "Recovery of Natural Gas Liquids with Membranes from Associated Gas on Newfoundland and Labrador Offshore Production Facilities", Masters Thesis, Faculty of Engineering and Applied Science, Memorial University of Newfoundland, 2006.

Beronich, E. L., Hawboldt, K., Abedinzadegan Abdi, M., "Linking a Process Simulator (HYSYS) with MATLAB, a Powerful Modeling Tool for Continuous Process Industry: a Tutorial", paper presented at the annual NECEC conference, Newfoundland, 
Nov. $9^{\text {th }}, 2005$.

Campbell, J.M., "Gas Conditioning and Processing”, Volume 1, Campbell Petroleum Series, Norman, Ok (1992)61.

Covington, K., Collie, T., Behrens, S., "Selection of Hydrate Suppression Methods for Gas Streams", paper presented at the $78^{\text {th }}$ GPA Annual Convention, Nashville, TN, March , 1999

Fox, R. W., McDonald, A. T., "Introduction to Fluid Mechanics", 3rd Edition, John Wiley \& Sons Inc. Hoboken, NJ, (1985)561

Gas Processors Suppliers Association, "GPSA Engineering Data Book”, 12th Edition, Tulsa, OK, ( 2004).

Greitzer, E. M., Tan, C. S., Graf, M. B., "Internal Flow Concepts and Applications" Cambridge, UK, (2004) 40.

Hengwei, L., Zhonggliang, L., Yongxun, F., Keyu, G. and Tingmin, Y., "Characteristic of a Supersonic Swirling Dehydration System of Natural Gas", Chinese Journal of Chemical Eng., (2005)13

Hollis, R. B., "Real-Gas Flow Properties for NASA Langley Research Center Aerothermodynamics Facilities Complex Wind Tunnels", Langley Research Center, Hampton, Virginia, Sep. 1996

Iluhi, M., "Cold Flow Concepts Compared", Masters thesis, Norwegian University of Science and Technology, Dec. 2005

Jacobsen, R. T., Penoncello, S. G., Lemmon, E. W., "Thermodynamic Properties 
of Cryogenic Fluids", Springer, verlag (1997)8

Karimi, A., Abedinzadegan Abdi, M., "Selective Water Removal From Supercritical Natural Gas", paper presented in SPE Gas Technology Symposium, Calgary, Alberta, Canada, 15-18 May, 2006

Khezzar, L, Benayoune, M., “Application of a Design Method of a Supersonic Nozzle", Journal of Engineering and Applied science, (1997) 44

Kidnay, A. J., Paqrrish,W. R., "Fundamentals of Natural Gas Processing”, Taylor and Francis Group,LLC., (2006)9

Man, H. C., Duan, J., Yue, T. M., "Design and characteristic of supersonic nozzle of high pressure laser cutting “, Journal of Materials Processing Technology, (1997)63

Manning, F.S., Thompson, R., “Oilfield Processing of Petroleum, Volume 1: Natural Gas", Pennwell Corp,Tulsa,Ok, (1991) 19

Mohitpour, M., Golshan, H., and Murray, A., "Pipeline Design and Construction, a Practical Approach", 2nd Edition, ASME press, NY, (2003)57

Molleson, G. V., Stasenko, A. L., "An Axsimmetric Flow of a Mixture of Real Gases With a Condensing Component”, High Temperature, (2005)43

Moraitis, C.S, Akritidis, C. B., “Optimization of the Operation of a Drying Heat Pump Using Superheated Steam", Drying Technology,(1997)15

Prast, B., Schinkelshoek, P., Lammers, B., Betting, M., "CFD for Supersonic Gas Processing", paper presented in Multiphase Separation and Multiphase Pumping Technologies Conference, 1-2 September 2005 
Schinkelshoek, P., Epsom, H., "Supersonic Gas Conditioning Introduction of the Lower Pressure Drop Twister" , paper presented in at the GPA $85^{\text {th }}$ Annual Convention, Grapevine, TX, 5-8 March 2006 


\section{Appendix: Matlab Code}

The process showed in Figure A.1 is used to design a nozzle. A gas stream called "strGas" is mixed with the water stream called " strWater" in the mixer to get the water saturated gas stream. The composition properties in the length stream called" strLength" is transferred to inlet stream, "strInlet". To predict the "recovery properties" and "design properties", the properties distribution is extracted from "strInlet" by applying NewtonRaphon method at each cross section. If shockwave happens in the diverging part of the nozzle, the condensed liquids are separated from the main stream of the nozzle and the remained stream will be the dry gas stream, "strDrygas". The composition properties of this stream are transferred to the nat gas stream, "strNatgas" and by applying NewtonRaphson method, the properties in the nozzle after the shockwave will be found.

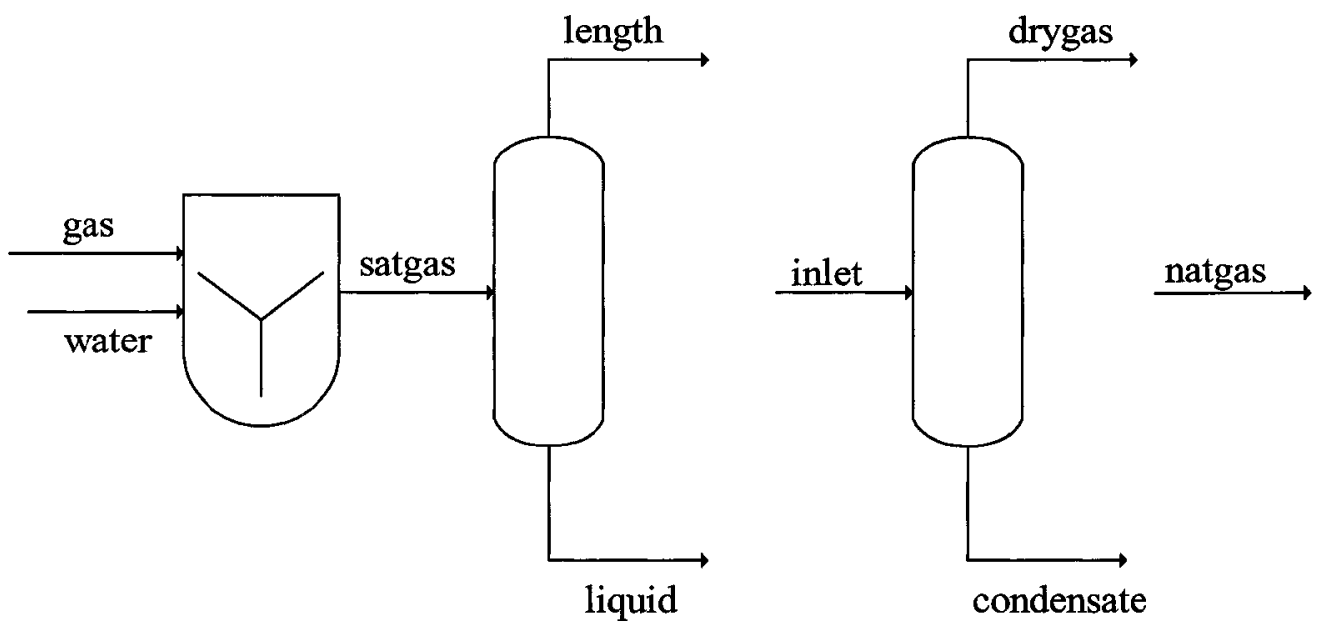

Figure A.1: The process used in HYSYS 
The developed MATLAB program to do this simulation, in both isentropic and non-isentropic cases, is given in the following pages.

\section{A.1 IsENTROPIC FLOW}

\section{A.1.1 FindING NOZZLE THROAT}

clear all;

clc;

$\% \% \% \quad \% \quad \% \quad \% \quad \% \quad \% \quad \% \quad \% \quad \%$

$\%$ Variable name legend

$\%$

$\% \mathrm{~T}$ : temperature (C)

$\% \mathrm{P}$ : pressure $(\mathrm{kPa})$

$\%$ A: $x$-section area $\left(\mathrm{m}^{\wedge} 2\right)$

$\% \mathrm{~L}$ : length (m)

$\%$ mDot: flow rate $(\mathrm{kmole} / \mathrm{hr})$

$\%$ entr: entropy ()

$\%$ enrg: enthalpy ()

$\%$ momt: momentum ()

$\%$ v: velocity $(\mathrm{m} / \mathrm{s})$

$\%$ machNum: mach number

$\%$ ro: density $\left(\mathrm{kg} / \mathrm{m}^{\wedge} 3\right)$

$\%$ seg: segement count

$\%$ shock: shock location measured from inlet (m)

$\%$ alpha: half angle (degrees)

$\%$ vFrac: saturated gas vapour fraction

$\% \% \quad \% \quad \% \quad \% \quad \% \quad \% \quad \% \quad \% \quad \% \%$

$\%$ Postfix legend

$\%$

$\%$ (entr, engr, momt, ro, v)_W: water stream

$\%(\mathrm{~T}, \mathrm{P}$, mach, $\mathrm{v}) 1$ : inlet

$\%$ (L, seg, alpha)_c: converging part

$\%$ (L, seg, alpha)_d: diverging part 
$\%(\mathrm{~L}, \mathrm{mDot})$ as: after shock

$\%$ (L)_bs: before shock

\%Parameters

$\mathrm{T} 1=20$;

$\mathrm{P} 1=30000$

A1 $=0.001257$

$\mathrm{L}=0.12$;

$\mathrm{mDot}=5000$;

\% Linking with hysys

hyApp = feval('actxserver', 'Hysys.Application');

hysolver = hyApp.ActiveDocument.Solver;

solver. CanSolve $=1 ; \%$ Start solver

hysolver.CanSolve $=0$;

strInlet = hyApp.ActiveDocument.Flowsheet.MaterialStreams.Item('inlet');

strLength = hyApp.ActiveDocument.Flowsheet.MaterialStreams.Item('length');

strNatgas $=$ hyApp.ActiveDocument.Flowsheet.MaterialStreams.Item('natgas');

strGas = hyApp.ActiveDocument.Flowsheet.MaterialStreams.Item('gas');

strWater = hyApp.ActiveDocument.Flowsheet.MaterialStreams.Item('water');

strSatgas = hyApp.ActiveDocument.Flowsheet.MaterialStreams.Item('satgas');

strDrygas $=$ hyApp.ActiveDocument.Flowsheet.MaterialStreams.Item('drygas');

hySS = hyApp.ActiveDocument.Flowsheet.Operations.Item('SPRDSHT-1');

$\%$ Gas saturation

vFrac $=1$;

$\mathrm{mDot} \_\mathrm{W}=0$;

[entr1, enrg1, momt1, ro1, v1] = funcs(solver, strGas, T1, P1, A1, mDot);

while vFrac $==1$

mDot_W $=\mathrm{mDot} \mathrm{W}+0.001$;

[entr_W, enrg_W, momt_W, ro_W, v_W] $=$ funcs(hysolver,strWater, T1, P1, A1, mDot_W);

vFrac $=$ hySS.Cell('B6').CellValue;

end

$\%$ Saturated gas properties

T1 = hySS.Cell('B7').CellValue;

P1 = hySS.Cell('B8').CellValue;

$\mathrm{mDot}=$ hySS.Cell('C1').CellValue; 
$\%$ Nozzle design

seg_c $=30$;

alpha_c $=6.85$;

alphaRad_c $=($ alpha_c*pi $) / 180$;

seg $d=300$

alpha_d $=3$;

alphaRad_d $=($ alpha_d*pi) / 180;

$\mathrm{A}(1)=\mathrm{A} 1$

$\mathrm{T}(1)=\mathrm{T} 1$;

$\mathrm{P}(1)=\mathrm{P} 1$;

mDot);

$[\operatorname{entr}(1), \operatorname{enrg}(1), \operatorname{momt}(1), \operatorname{ro}(1), \mathrm{v}(1)]=$ funcs(solver, strInlet, $\mathrm{T}(1), \mathrm{P}(1), \mathrm{A}(1)$,

$[\mathrm{machNum} 1, \mathrm{v} 1]=\operatorname{mach}(\mathrm{T} 1, \mathrm{P} 1, \mathrm{~A} 1, \mathrm{mDot})$;

$\operatorname{machNum}(1)=\operatorname{machNum} 1$;

$\mathrm{v}(1)=\mathrm{v} 1$;

water(1) = hySS.Cell('D1').CellValue;

$\mathrm{r} 1=\operatorname{sqrt}(\mathrm{A} 1 / \mathrm{pi})$

$\mathrm{ID}(1)=2 * \mathrm{r} 1$

$\mathrm{p}(1)=0$;

$\mathrm{i}=1$;

$\mathrm{L}$ segment $=0.0009$;

$\mathrm{x}=\tan (\text { alphaRad_c })^{*} \mathrm{~L}$ ssegment;

hySS.Cell('B1').CellValue = L_segment;

$\%$ Finding the throat

converged(i) = true;

exception $(\mathbf{i})=$ false;

while converged(i) $==$ true $\& \&$ exception(i) $=$ false $\& \&$ abs $(1-\operatorname{machNum}(\mathrm{i}))>0.2$

$\mathrm{i}=\mathrm{i}+1$;

$\operatorname{ID}(\mathrm{i})=\operatorname{ID}(\mathrm{i}-1)-(2 * \mathrm{x})$;

$A(i)=\left(p^{*}(\operatorname{ID}(\mathrm{i}))^{\wedge} 2\right) / 4$;

$\mathrm{p}(\mathrm{i})=\mathrm{p}(\mathrm{i}-1)+\mathrm{L} \_$segment;

[T(i), P(i), machNum(i), v(i), converged(i), exception(i)] = tpDistr(T1, P1, $\mathrm{A} 1, \mathrm{~T} 1, \mathrm{P} 1, \mathrm{~A}(\mathrm{i}), \mathrm{mDot})$;

if converged(i) $=$ true \&\& exception(i) $=$ false

[entr(i), enrg(i), momt(i), ro(i), v(i)] = funcs(hysolver, strInlet, T(i), P(i), A(i), 
mDot);

end

end

L_segment $=0.0000009$;

$\mathrm{x}=\tan (\text { alphaRad_c })^{*} \mathrm{~L}$ segment;

hySS.Cell('B1').CellValue = L_segment;

hysolver.CanSolve $=1 \%$ start solver

hysolver. CanSolve $=0$;

converged $(\mathrm{i})=1$;

converged $(\mathrm{i})==$ true

exception $(\mathrm{i})=0$;

while converged(i) $==$ true $\& \&$ exception(i) $=$ false

$\mathrm{i}=\mathrm{i}+1$;

$\operatorname{ID}(\mathrm{i})=\mathrm{ID}(\mathrm{i}-1)-(2 * \mathrm{x})$;

$\mathrm{A}(\mathrm{i})=\left(\mathrm{pi} *(\mathrm{ID}(\mathrm{i}))^{\wedge} 2\right) / 4$;

$\mathrm{p}(\mathrm{i})=\mathrm{p}(\mathrm{i}-1)+\mathrm{L} \_$segment;

[T(i), P(i), machNum(i), v(i),converged(i), exception(i)] = tpDistr(T(1), $\mathrm{P}(1)$, $\mathrm{A}(1), \mathrm{T}(1), \mathrm{P}(1), \mathrm{A}(\mathrm{i}), \mathrm{mDot})$;

if converged(i) $=$ true $\& \&$ exception $(\mathrm{i})==$ false

mDot);

[entr(i), enrg(i), momt(i), ro(i), v(i)] = funcs(hysolver, strInlet, T(i), P(i), A(i),

end

end

ithroat $=\mathrm{i}-1 ; \%$ throat index

$\%$ saving the throat properties

save nozzlethroat A T P machNum v p ID ithroat entr ro momt enrg mDot

A.1.2 FINDING THE NOZZLE "RECOVERY PROPERTIES"

clear all

clc

load nozzlethroat $\%$ Calling the properties at the converging part $\mathrm{i}=$ ithroat; 


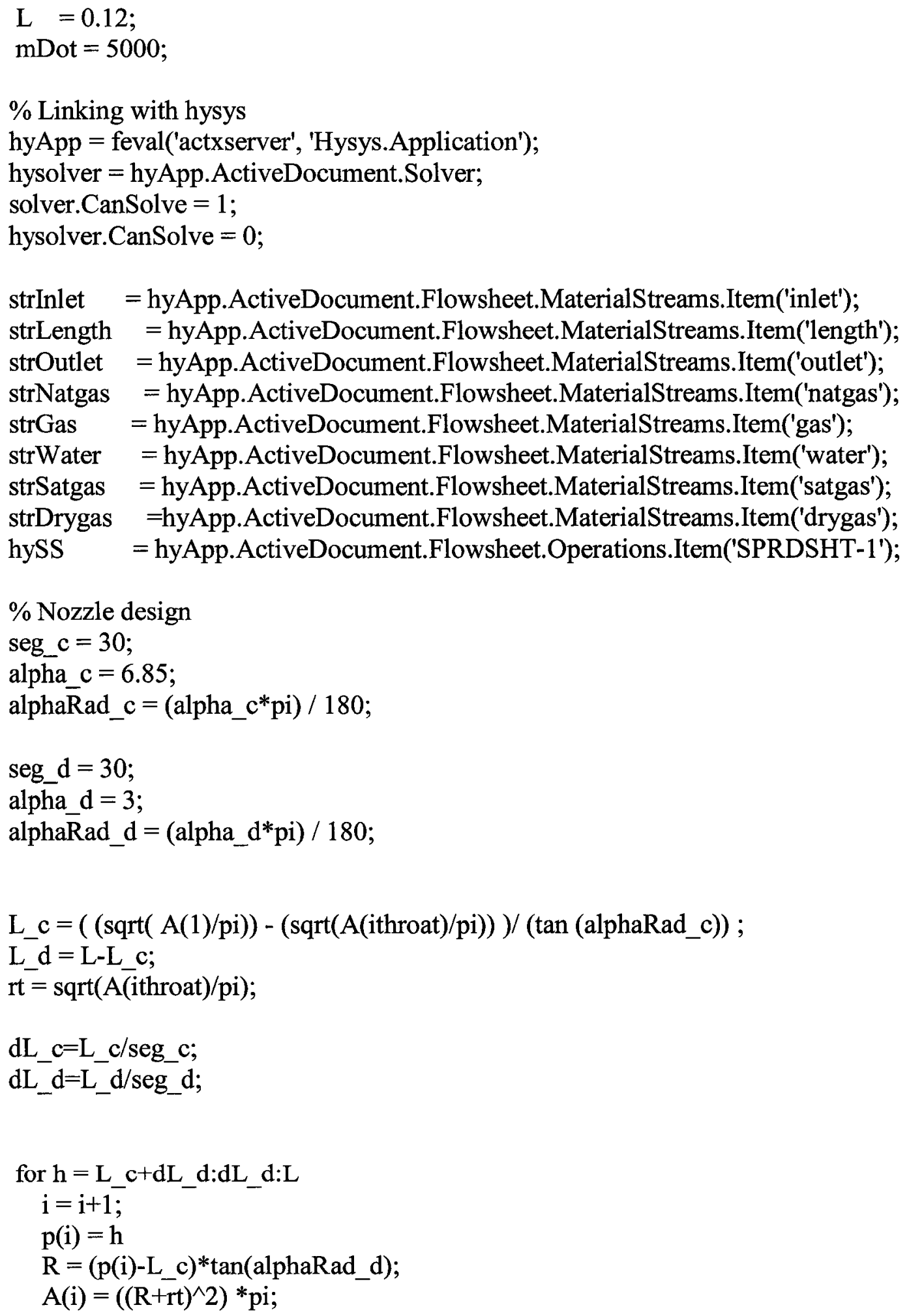


[T(i), $\mathrm{P}(\mathrm{i}), \operatorname{machNum}(\mathrm{i}), \mathrm{v}(\mathrm{i})$, converged, exception] $=\operatorname{tpDistr}(\mathrm{T}(1), \mathrm{P}(1)$, $\mathrm{A}(1), \mathrm{T}(1), \mathrm{P}(1), \mathrm{A}(\mathrm{i}), \mathrm{mDot} 1)$; mDot1); [entr(i), enrg(i), momt(i), ro(i), v(i)] = funcs(hysolver, strInlet, T(i), P(i), A(i), end

\section{A.1.3 FINDING THE DESIGN PROPERTIES}

clear all

clc

load nozzlethroat $\%$ Calling the properties at the converging part $\mathrm{i}=$ ithroat;

$\mathrm{L}=0.12$;

$\mathrm{mDot}=5000$;

\% Linking with hysys

hyApp = feval('actxserver', 'Hysys.Application');

hysolver $=$ hyApp.ActiveDocument.Solver;

solver. CanSolve $=1$;

hysolver.CanSolve $=0$;

strInlet $=$ hyApp.ActiveDocument.Flowsheet.MaterialStreams.Item('inlet');

strLength = hyApp.ActiveDocument.Flowsheet.MaterialStreams.Item('length');

strOutlet $=$ hyApp.ActiveDocument.Flowsheet.MaterialStreams.Item('outlet');

strNatgas = hyApp.ActiveDocument.Flowsheet.MaterialStreams.Item('natgas');

strGas = hyApp.ActiveDocument.Flowsheet.MaterialStreams.Item('gas');

strWater = hyApp.ActiveDocument.Flowsheet.MaterialStreams.Item('water');

strSatgas = hyApp.ActiveDocument.Flowsheet.MaterialStreams.Item('satgas');

strDrygas $=$ hyApp.ActiveDocument.Flowsheet.MaterialStreams.Item('drygas');

hySS = hyApp.ActiveDocument.Flowsheet.Operations.Item('SPRDSHT-1');

$\%$ Nozzle design

seg_c $=30$;

alpha_c $=6.85$;

alphaRad_c $=($ alpha_c*pi) $/ 180$;

seg $d=30$;

alpha_d $=3$;

alphaRad_d $=($ alpha_d*pi) $/ 180$; 
L_c $=((\operatorname{sqrt}(A(1) / p i))-(\operatorname{sqrt}($ A(ithroat $) / p i))) /(\tan ($ alphaRad_c $))$;

L_d $=$ L-L_c;

$\mathrm{rt}=\operatorname{sqrt}(\mathrm{A}(\overline{\mathrm{ithroat}}) / \mathrm{pi})$;

dL_c $=$ L_c $/$ seg_c;

$\mathrm{dL} \_\mathrm{d}=\mathrm{L} \_\mathrm{d} / \mathrm{seg} \mathrm{d}$;

for $h=L \_c+d L \_d: d L \_d: L$

$\mathrm{i}=\overline{\mathrm{i}}+1$;

$\mathrm{p}(\mathrm{i})=\mathrm{h}$

$\mathrm{R}=\left(\mathrm{p}(\mathrm{i})-\mathrm{L} \_\mathrm{c}\right) * \tan ($ alphaRad_d $)$;

$\mathrm{A}(\mathrm{i})=\left((\mathrm{R}+\mathrm{rt})^{\wedge} 2\right) * \mathrm{pi}$;

[T(i), P(i), machNum(i), v(i), converged, exception] = tpDistr(T(1),

$\mathrm{P}(1), \quad \mathrm{A}(1),-120,1000, \mathrm{~A}(\mathrm{i}), \mathrm{mDot} 1)$;

$\mathrm{P}(\mathrm{i}), \mathrm{A}(\mathrm{i}), \mathrm{mDot} 1)$;

[entr(i), enrg(i), momt(i), ro(i), v(i)] = funcs(hysolver, strInlet, T(i),

end

A.1.4 SHOCKWAVE PREDICTION

clear all

clc

load nozzlethroat $\%$ Calling the properties at the converging part $\mathrm{i}=\mathrm{ithroat}$;

$\mathrm{L}=0.12$

$\mathrm{mDot}=5000$;

Pexit $=70 / 100 * \mathrm{P} 1 ; \%$ Desired pressure recovery

Shock $=0.1 ; \%$ first guess for shocklocation, L_c $<$ shock $<\mathrm{L}$

\% Linking with hysys

hyApp = feval('actxserver', 'Hysys.Application');

hysolver = hyApp.ActiveDocument.Solver;

solver. CanSolve $=1$;

hysolver. CanSolve $=0$; 
$\begin{array}{ll}\begin{array}{l}\text { strInlet } \\ \text { strLength }\end{array} & \text { hyApp.ActiveDocument.Flowsheet.MaterialStreams.Item('inlet'); } \\ \text { strOutlet } & =\text { hyApp.ActiveDocument.Flowsheet.MaterialStreams.Item('length'); } \\ \text { strNatgas } & =\text { hyApp.ActiveDocument.Flowsheet.MaterialStreams.Item('natgas'); } \\ \text { strGas } & =\text { hyApp.ActiveDocument.Flowsheet.MaterialStreams.Item('gas'); } \\ \text { strWater } & =\text { hyApp.ActiveDocument.Flowsheet.MaterialStreams.Item('water'); } \\ \text { strSatgas } & =\text { hyApp.ActiveDocument.Flowsheet.MaterialStreams.Item('satgas'); } \\ \text { strDrygas } & =\text { hyApp.ActiveDocument.Flowsheet.MaterialStreams.Item('drygas'); } \\ \text { hySS } & =\text { hyApp.ActiveDocument.Flowsheet.Operations.Item('SPRDSHT-1'); }\end{array}$

$\%$ Nozzle design

seg_c $=30$

alpha_c $=6.85$;

alphaRad_c $=($ alpha_c*pi) $/ 180$;

seg_d $=30$;

alpha_d $=3$;

alphaRad_d=(alpha_d*pi) / 180;

L_c $=((\operatorname{sqrt}(\mathrm{A}(1) / \mathrm{pi}))-(\operatorname{sqrt}(\mathrm{A}(\mathrm{ithroat}) / \mathrm{pi}))) /(\tan ($ alphaRad_c $))$;

L_d = L-L_c;

$\mathrm{rt}=\operatorname{sqrt}(\mathrm{A}(\mathrm{ithroat}) / \mathrm{pi})$;

dL_c $=$ L_c/seg_c;

dL_d $=$ L_d $/$ seg_d;

L_bs=Shock-L_c; ;

$\mathrm{d} \overline{\mathrm{L}} \_\mathrm{bs}=\mathrm{L} \_\mathrm{bs} / \mathrm{seg} \mathrm{d}$;

L_as $=$ L-L_c-L_bs;

$\mathrm{d} \overline{\mathrm{L}}$ as $=\mathrm{L}$ as $/ \mathrm{seg} \mathrm{d}$;

$\left.A \overline{A s}=\left(\left(\left(\bar{L} \_b s *(\tan (\text { alphaRad_d }))\right)+(\operatorname{sqrt}(\text { A(ithroat }) / p i)\right)\right)^{\wedge} 2\right)^{*}$ pi;

Aex $\left.=\left(\left(\left(L_{-} d^{*}(\tan (\text { alphaRad_d }))\right)+(\operatorname{sqrt}(\text { A(ithroat }) / p i)\right)\right)^{\wedge} 2\right)^{*} \mathrm{pi}$;

[Tbs, Pbs, machNumbs, vbs, vFracbs,convergedbs, exceptionbs] = tpDistr(T(ithroat), P(ithroat), A(ithroat),-120,1000, Abs, mDot); $\mathrm{mDot})$;

[entrbs, enrgbs, momtbs, robs, vbs] = funcs(hysolver, strInlet, Tbs, Pbs, Abs,

mDot_as= hySS.Cell('A7').CellValue;

[Tas,,$\overline{P a s}$,machNumas, vas, converged, exception] = tpDistr_as(Tbs, Pbs, Abs, T(1) ,P(1),Abs, mDot,mDot_as); 
[Tex, Pex, machNumex, vex, vFracex,convergedex, exceptionex] = tpDistrdrygas(Tas, Pas, Abs,T1,P1, Aex,mDot_as);

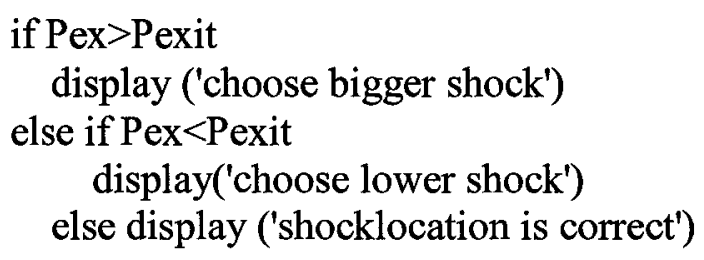

end

end

Aas $=$ Abs;

[entras, enrgas, momtas, roas, vas] = funcs(hysolver, strNatgas, Tas, Pas, Aas, mDot_as);

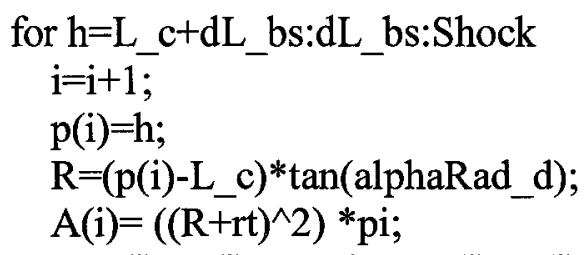

[T(i), P(i), machNum(i), v(i), vFrac, converged, exception] $=\operatorname{tpDistr}(\mathrm{T}(1)$, $\mathrm{P}(1), A(1),-120,1000, A(i), \mathrm{mDot})$;

$\mathrm{mDot})$;

[entr(i), enrg(i), momt(i), ro(i), v(i)] = funcs(hysolver, strInlet, T(i), P(i), A(i),

end

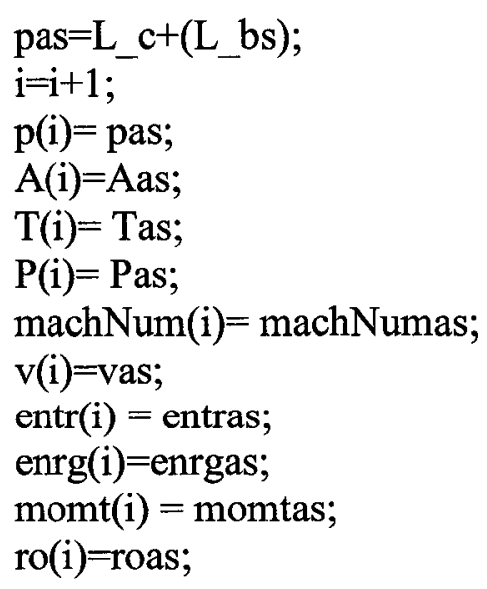




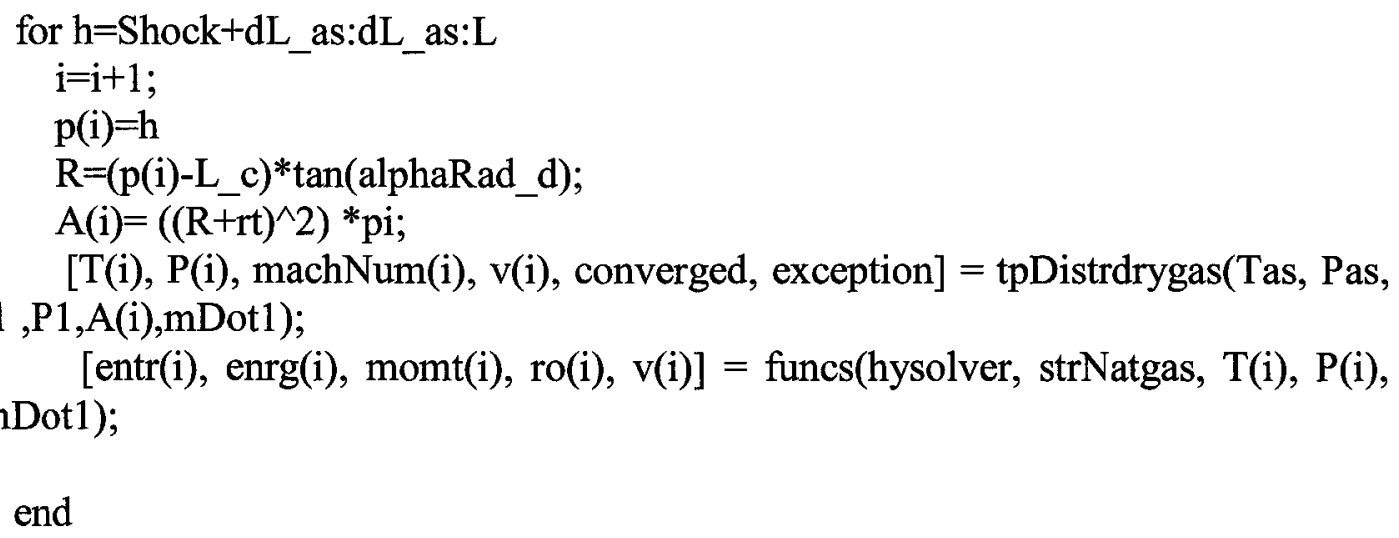

\section{A.1.5 FUNCTIONS}

\section{A.1.5.1 ERROREVAL}

$\% \% \% \% \% \% \% \% \% \%$

$\%$ errorEval - computes error in one iteration of newton raphson

$\%$

$\%$ Input:

$\%$ solver - hysys solver

$\%$ stream - stream name

$\%$ entr 1 - inlet enthalpy

$\%$ enrg1 - inlet energy

$\% \mathrm{~T}$ - temperature guess

$\% \mathrm{P}$ - pressure guess

$\%$ a - xsection

$\%$ mDot - flow rate

$\%$ Output:

$\%$ err - error in current newton raphson iteration

function $[$ err $]=$ errorEval(solver, stream, entr1, enrg1, T, P, a, mDot)

$\mathrm{dT}=0.1 ;$

$\mathrm{dP}=0.1$

[entr, enrg,momt,ro,v] = funcs(solver, stream, T, P, a, mDot);

fl = entr - entr1; 
$\mathrm{f} 2=$ enrg - enrg 1 mDot);

[entr_Tinc, enrg_Tinc,momt_Tinc,ro,v] $=$ funcs(solver, stream, $\mathrm{T}+\mathrm{dT} / 2, \mathrm{P}, \mathrm{a}$, $\mathrm{mDot})$;

[entr_Tdec, enrg_Tdec,momt_Tdec,ro,v] $=$ funcs(solver, stream, T - dT/2, P, a, mDot);

[entr_Pinc, enrg_Pinc,momt_pinc,ro,v] $=$ funcs(solver, stream, $\mathrm{T}, \mathrm{P}+\mathrm{dP} / 2, \mathrm{a}$, $\mathrm{mDot})$;

[entr_Pdec, enrg_Pdec,momt_Pdec,ro,v] = funcs(solver, stream, T, P - dP/2, a,

df1_dT $=($ entr_Tinc - entr_Tdec $) / d T$;

df2_dT $=($ enrg_Tinc - enrg_Tdec $) / d T$;

df1_dP $=($ entr_Pinc - entr_Pdec $) / d P$;

$\mathrm{df} 2 \_\mathrm{dP}=($ enrg_Pinc - enrg_Pdec $) / \mathrm{dP}$;

jacobean $=\left[\mathrm{df1} \_\mathrm{dT}\right.$ df1_dP; df2_dT df2_dP];

err $=-\operatorname{inv}($ jacobean $) *[\mathrm{fl} ; \mathrm{f} 2] ; \% \overline{2} \times 1$ matrix

\section{A.1.5.2 FUNCS}

$\% \quad \% \quad \% \quad \% \quad \% \quad \% \quad \% \quad \% \quad \% \quad \%$

$\%$ funcs - computes stream properties

$\%$

$\%$ Input:

$\%$ solver - hysys solver

$\%$ stream - stream name

$\% \mathrm{~T}$ - temperature

$\% \mathrm{P}$ - pressure

$\%$ a - xsection

$\%$ mDot - flow rate

$\%$ Output:

$\%$ entr - enthalpy

$\%$ enrg - energy

$\%$ momt - momentum

$\%$ ro - density

$\%$ v - velocity

function [entr, enrg, momt, ro, v] = funcs(solver, stream, T, P, a, mDot) 


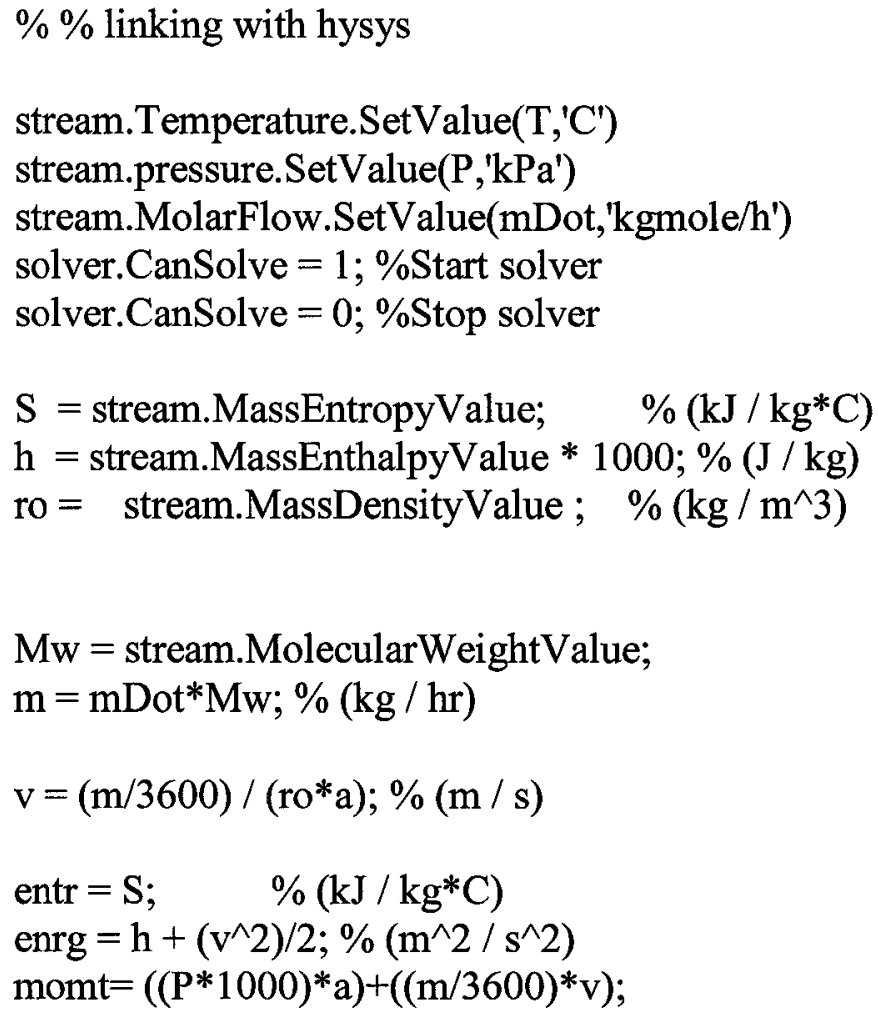

\section{A.1.5.3 TPDISTR}

The function tpDistrdrygas follow the same procedure for "strNatgas"

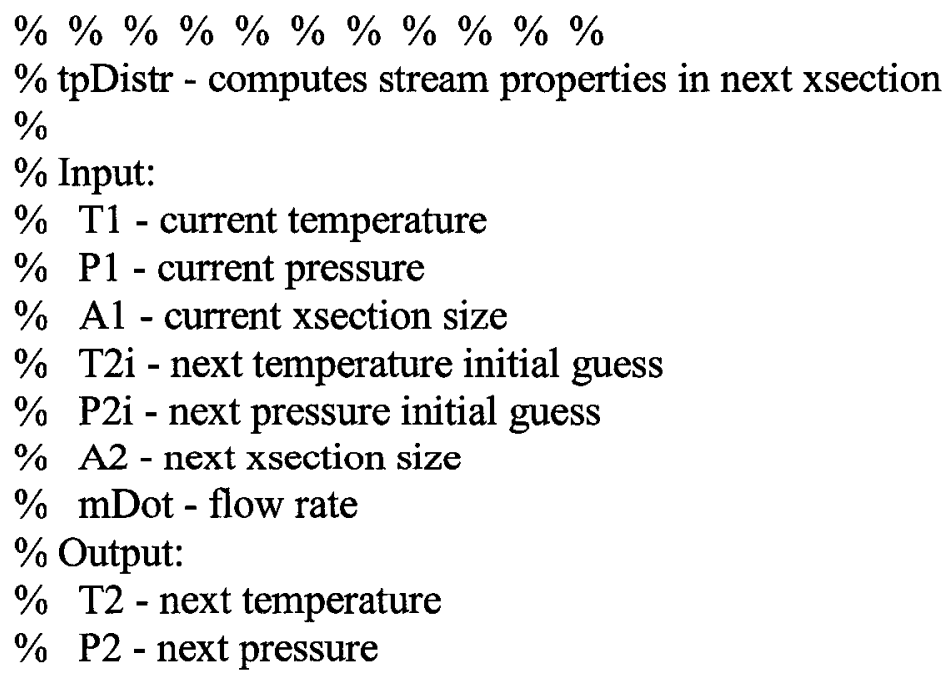


$\% \quad \mathrm{v}-$ next velocity

$\%$ vFrac - next vapour fraction

$\%$ converged - NR convergence flag

$\%$ exception - erroneous parameter flag

function $[\mathrm{T} 2, \mathrm{P} 2$, machNum, $\mathrm{v}, \mathrm{vFrac}$, converged, exception $]=\operatorname{tpDistr}(\mathrm{T} 1, \mathrm{P} 1$, A1, T2i, P2i, A2, mDot)

$\%$ linking with hysys

hyApp = feval('actxserver', 'Hysys.Application');

hysolver = hyApp.ActiveDocument.Solver;

solver.CanSolve $=1 ; \%$ Start solver

hysolver.CanSolve $=0$;

strInlet $=$ hyApp.ActiveDocument.Flowsheet.MaterialStreams.Item('inlet');

$\%$ strLength = hyApp.ActiveDocument.Flowsheet.MaterialStreams.Item('length');

hySS = hyApp.ActiveDocument.Flowsheet.Operations.Item('SPRDSHT-1');

$\%$ Newton-Raphson

[entr1, enrg1, momt1, ro1, v1] = funcs(hysolver, strInlet, T1, P1, A1, mDot);

tol $=0.001 ; \%$ tolerance for error

$\mathrm{kmax}=100 ; \%$ maximum number of iterations

$\%$ set initial guess

$\mathrm{T} 2=\mathrm{T} 2 \mathrm{i} ; \%(\mathrm{C})$

$\mathrm{P} 2=\mathrm{P} 2 \mathrm{i} ; \%(\mathrm{kPa})$

$\mathrm{k}=0$;

pres $=$ tol +1 ;

tres $=$ tol +1 ;

exception $=$ false;

while (exception $=$ false) $\& \&$ (tres $>=$ tol $\|$ pres $>=$ tol) $\& \& \mathrm{k}<=$ kmax

err $=$ errorEval(hysolver, strInlet, entr1, enrg1, T2, P2, A2, mDot);

$\mathrm{T} 2=\mathrm{T} 2+\operatorname{err}(1,1)$

$\mathrm{P} 2=\mathrm{P} 2+\operatorname{err}(2,1)$

if $\mathrm{P} 2<0 \| \mathrm{T} 2<-273$

exception $=$ true;

else

tres $=\operatorname{abs}(\operatorname{err}(1,1))$;

pres $=\operatorname{abs}(\operatorname{err}(2,1))$;

$\mathrm{k}=\mathrm{k}+1$; 


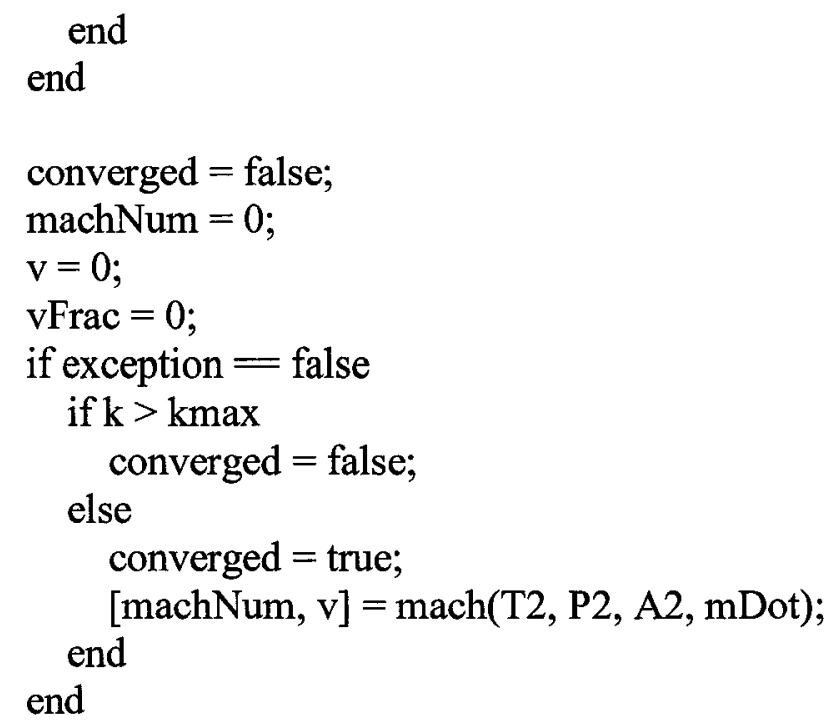

\section{A.1.5.4 MACH}

The function machdrygas follow the same procedure for "strNatgas"

$\% \quad \% \quad \% \quad \% \quad \% \quad \% \quad \% \quad \% \quad \% \quad \% \%$

$\%$ machNum - computes mach number \& velocity

$\%$

$\%$ Input:

$\% \mathrm{~T}$ - temperature

$\% \mathrm{P}$ - pressure

$\%$ A - xsection

$\%$ mDot - flow rate

$\%$ Output:

$\%$ machNum - mach number

$\% \mathrm{v}$ - velocity

function $[\operatorname{machNum}, \mathrm{v}]=\operatorname{mach}(\mathrm{T}, \mathrm{P}, \mathrm{A}, \mathrm{mDot})$

hyApp = feval('actxserver', 'Hysys.Application');

hysolver $=$ hyApp.ActiveDocument.Solver;

solver.CanSolve $=1$;

hysolver. CanSolve $=0$;

strInlet= hyApp.ActiveDocument.Flowsheet.MaterialStreams.Item('inlet');

$\mathrm{dT}=0.1 ;$ 
[entr1, enrg1,momt1,ro1,v1] = funcs(hysolver,strInlet, T, P, A, mDot);

tol $=0.005 ; \%$ tolerance for error

$\mathrm{kmax}=200 ; \%$ maximum number of iterations

$\% \% \% \% \% \% \% \% \% \%$

$\%$ Speed of sound computation

$\%$

$\mathrm{P} 2$ inc $=\mathrm{P}$;

$\mathrm{k}=0$;

pres $=$ tol +1 ;

exception $=$ false;

while (exception $==$ false) $\& \&$ (pres $>=$ tol) $\& \& \mathrm{k}<=\mathrm{kmax}$

err $=$ errorEval_mach(hysolver, strInlet, $\mathrm{T}+\mathrm{dT} / 2, \mathrm{P} 2$ inc, A, mDot,entr1);

$\mathrm{P} 2$ inc $=\mathrm{P} 2$ inc + err;

if $\mathrm{P} 2$ inc $<0$

exception $=$ true;

else

pres $=a b s($ err $)$;

$\mathrm{k}=\mathrm{k}+1$

end

end

[entr, enrg,momt,ro_inc,v_inc] $=$ funcs(hysolver,strInlet, T+dT/2, P2_inc, A, $\mathrm{mDot})$;

$\mathrm{P} 2 \mathrm{dec}=\mathrm{P}$

$\mathrm{k}=0$;

pres $=$ tol +1 ;

exception $=$ false;

while (exception $==$ false) $\& \&$ (pres $>=$ tol) $\& \& \mathrm{k}<=\mathrm{kmax}$

err = errorEval_mach(hysolver, strInlet, T-dT/2, P2_dec, A, mDot,entr1);

P2_dec $=$ P2_dec + err;

if $\mathrm{P} 2 \mathrm{dec}<0$

exception $=$ true;

else

pres $=a b s($ err $)$

$\mathrm{k}=\mathrm{k}+1$

end

end

[entr, enrg,momt,ro_dec,v_dec] $=$ funcs(hysolver,strInlet, T-dT/2, P2_dec, A, $\mathrm{mDot})$; 
$\mathrm{c}=\operatorname{sqrt}(\operatorname{abs}((\mathrm{P} 2$ inc-P2_dec $) * 1000 /($ ro_inc - ro_dec $))) ; \%(\mathrm{~m} / \mathrm{s})$

[entr, enrg,momt, $\overline{r o}, \mathrm{v}]=\overline{\text { funcs}}($ hysolver,strInlet, $\overline{\mathrm{T}}, \mathrm{P}, \mathrm{A}, \mathrm{mDot})$;

machNum $=\mathrm{v} / \mathrm{c}$;

\section{A.1.6 ERROREVALMACH}

$\% \% \% \quad \% \quad \% \quad \% \quad \% \quad \% \quad \% \quad \% \quad \%$

$\%$ errorEval - computes error in one iteration of newton raphson to cpmpute

$\%$ Machnumber

$\%$

$\%$ Input:

$\%$ solver - hysys solver

$\%$ stream - stream name

$\% \mathrm{~T}$ - temperature

$\% \mathrm{P}$ - pressure

$\%$ a - xsection

$\%$ mDot - flow rate

$\%$ entrl- entropy inlet

$\%$ Output:

$\%$ err - error in current newton raphson iteration to compute Mach number

function $[$ err] $=$ errorEval_mach(solver, stream, T, P, A, mDot,entr1)

$\mathrm{dP}=0.1$

[entr, enrg,momt,ro,v] = funcs(solver, stream, T, P, A, mDot);

$\mathrm{fl}=$ entr - entr1;

$\mathrm{mDot}$ );

[entr Pinc, enrg Pinc,momt Pinc,ro,v] $=$ funcs(solver, stream, $\mathrm{T}, \mathrm{P}+\mathrm{dP} / 2, \mathrm{~A}$, $\mathrm{mDot}$;

[entr_Pdec, enrg_Pdec,momt_Pdec,ro,v] = funcs(solver, stream, T, P - dP/2, A,

df1_dP $=($ entr_Pinc - entr_Pdec $) / \mathrm{dP}$;

err $=-\mathrm{fl} / \mathrm{df1} \_\overline{\mathrm{P}} ; \% 2 \times 1$ matrix

A.1.5.7 TPDISTR_AS

$\% \% \% \% \% \% \% \% \%$

$\%$ tpDistr - computes stream properties after downstream the shockwave

$\%$ Input:

$\% \mathrm{~T} 1$ - current temperature

$\% \quad \mathrm{P} 1$ - current pressure 
$\% \quad$ A1 - current xsection size

$\% \quad \mathrm{~T} 2 \mathrm{i}-$ next temperature initial guess

$\% \quad \mathrm{P} 2 \mathrm{i}-$ next pressure initial guess

$\% \quad \mathrm{~A} 2$ - next xsection size

$\%$ mDot - flow rate

$\%$ Output:

$\% \quad \mathrm{~T} 2$ - next temperature

$\% \quad \mathrm{P} 2$ - next pressure

$\% \quad \mathrm{v}-$ next velocity

$\%$ vFrac - next vapour fraction

$\%$ converged - NR convergence flag

$\%$ exception - erroneous parameter flag

function $[\mathrm{T} 2, \mathrm{P} 2$, machNum, $\mathrm{v}$, converged, exception] $=$ tpDistr_as(Tt, Pt, At, T2i,P2i,Aas, mDot)

\% linking with hysys

hyApp = feval('actxserver', 'Hysys.Application');

hysolver = hyApp.ActiveDocument.Solver;

solver. CanSolve $=1 ; \%$ Start solver

hysolver. CanSolve $=0$;

strInlet = hyApp.ActiveDocument.Flowsheet.MaterialStreams.Item('inlet');

strNatgas = hyApp.ActiveDocument.Flowsheet.MaterialStreams.Item('natgas');

hySS = hyApp.ActiveDocument.Flowsheet.Operations.Item('SPRDSHT-1');

$\%$ Newton-Raphson

[entrt, enrgt,momtt,rot,vt] = funcs(solver, strInlet, Tt, Pt, At, mDot);

tol $=0.005 ; \%$ tolerance for error

$\mathrm{kmax}=100 ; \%$ maximum number of iterations

$\%$ set initial guess

Tas $=\mathrm{T} 2 \mathrm{i} ; \%$ (C)

Pas $=\mathrm{P} 2 \mathrm{i}$;

$\mathrm{k}=0$;

tres $=$ tol +1 ;

pres $=$ tol +1 ;

exception $=$ false;

while (exception $==$ false) $\& \&$ (tres $>=$ tol $\|$ pres $>=$ tol) $\& \& \mathrm{k}<=\mathrm{kmax}$ 


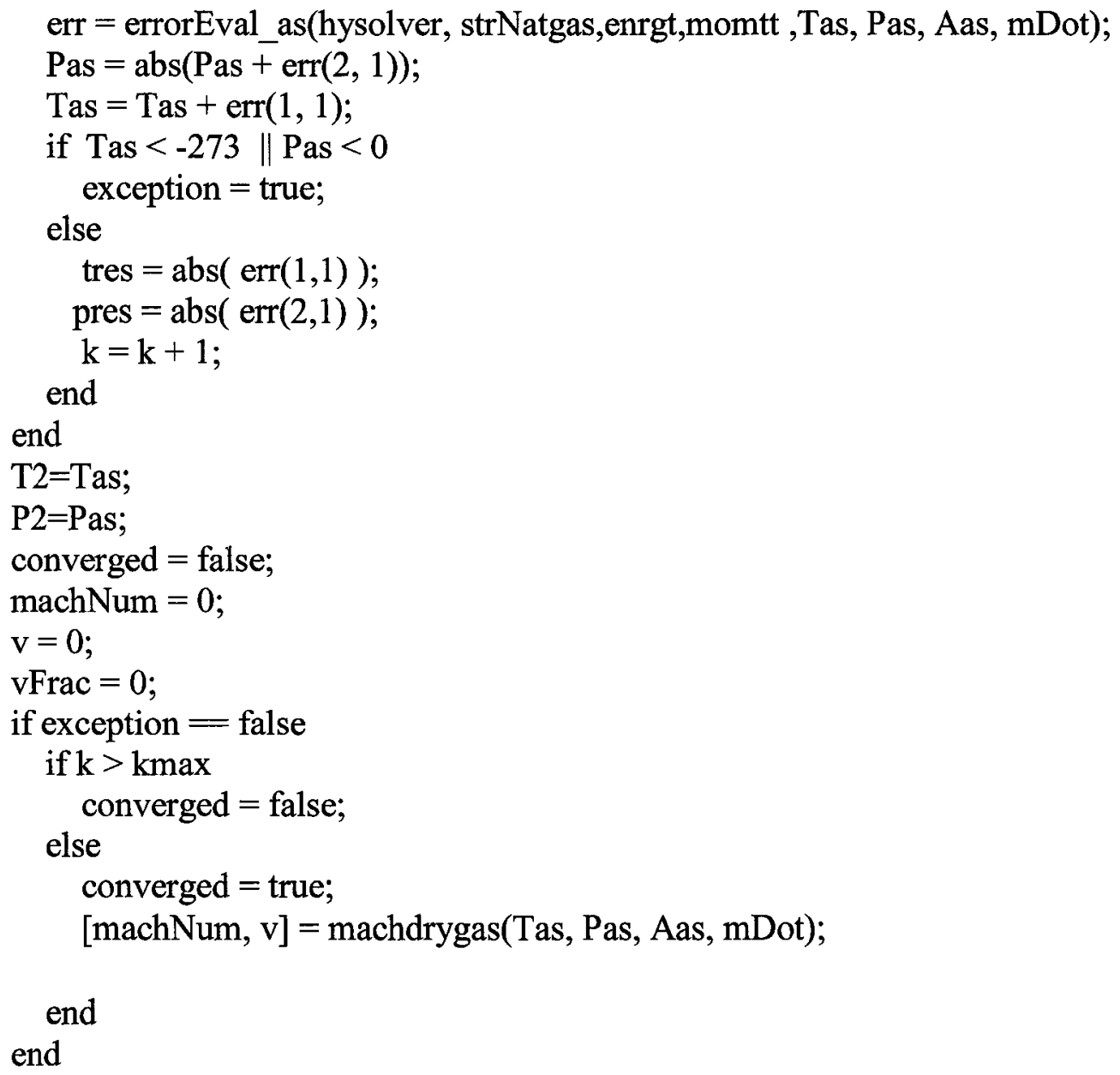

\section{A.1.5.8 ERRORVAL_AS}

$\% \% \% \% \quad \% \quad \% \quad \% \% \% \% \%$

$\%$ errorEval_as - computes error in one iteration of newton raphson to predict $\% \quad$ upstream properties of shockwave

$\%$ Input:

$\%$ solver - hysys solver

$\%$ stream - stream name

$\%$ enrg1 - inlet energy

$\%$ momt1 - inlet momentum

$\% \mathrm{~T}$ - temperature guess

$\% \mathrm{P}$ - pressure guess

$\%$ a - xsection 
$\%$ mDot - flow rate

$\%$ Output:

$\%$ err - error in current newton raphson iteration

function [err] = errorEval_as(solver, stream,enrg1,momt1, T, P, a, mDot)

$\mathrm{dT}=0.1$

$\mathrm{dP}=0.1$

[entr, enrg,momt,ro,v] = funcs(solver, stream, T, P, a, mDot);

f1 = enrg - enrg1;

$\mathrm{f} 2=$ momt - momt 1

[entr_Tinc, enrg_Tinc,momt_Tinc,ro,v] $=$ funcs(solver, stream, $\mathrm{T}+\mathrm{dT} / 2, \mathrm{P}, \mathrm{a}$, mDot);

[entr_Tdec, enrg_Tdec,momt_Tdec,ro,v] $=$ funcs(solver, stream, T $-\mathrm{dT} / 2, \mathrm{P}, \mathrm{a}$, mDot);

[entr_Pinc, enrg_Pinc,momt_Pinc,ro,v] $=$ funcs(solver, stream, T, P+dP/2 , a, $\mathrm{mDot})$;

[entr_Pdec, enrg_Pdec,momt_Pdec,ro,v] $=$ funcs(solver, stream, T, P- dP/2, a, mDot);

df2_dT $=$ (momt Tinc - momt Tdec) $/ \mathrm{dT}$;

$\mathrm{dfl} \_\mathrm{dT}=($ enrg_Tinc - enrg_Tdec $) / \mathrm{dT}$;

$\mathrm{df} 2 \_\mathrm{dP}=$ (momt Pinc - momt_Pdec $) / \mathrm{dP}$;

$\mathrm{df1} \_\mathrm{dP}=($ enrg_Pinc - enrg_Pdec $) / \mathrm{dP}$;

jacobean $=\left[\mathrm{df1} \_\mathrm{dT}\right.$ df1_dP; df2_dT df2_dP];

err $=$-inv(jacobean $) *[\mathrm{f} 1 ; \mathrm{f} 2] ; \% \overline{2} \times 1$ matrix

\section{A.2 NON-ISENTROPIC}

\section{A.2.1 FINDING THE NOZZLE THROAT}

clear all;

clc; 


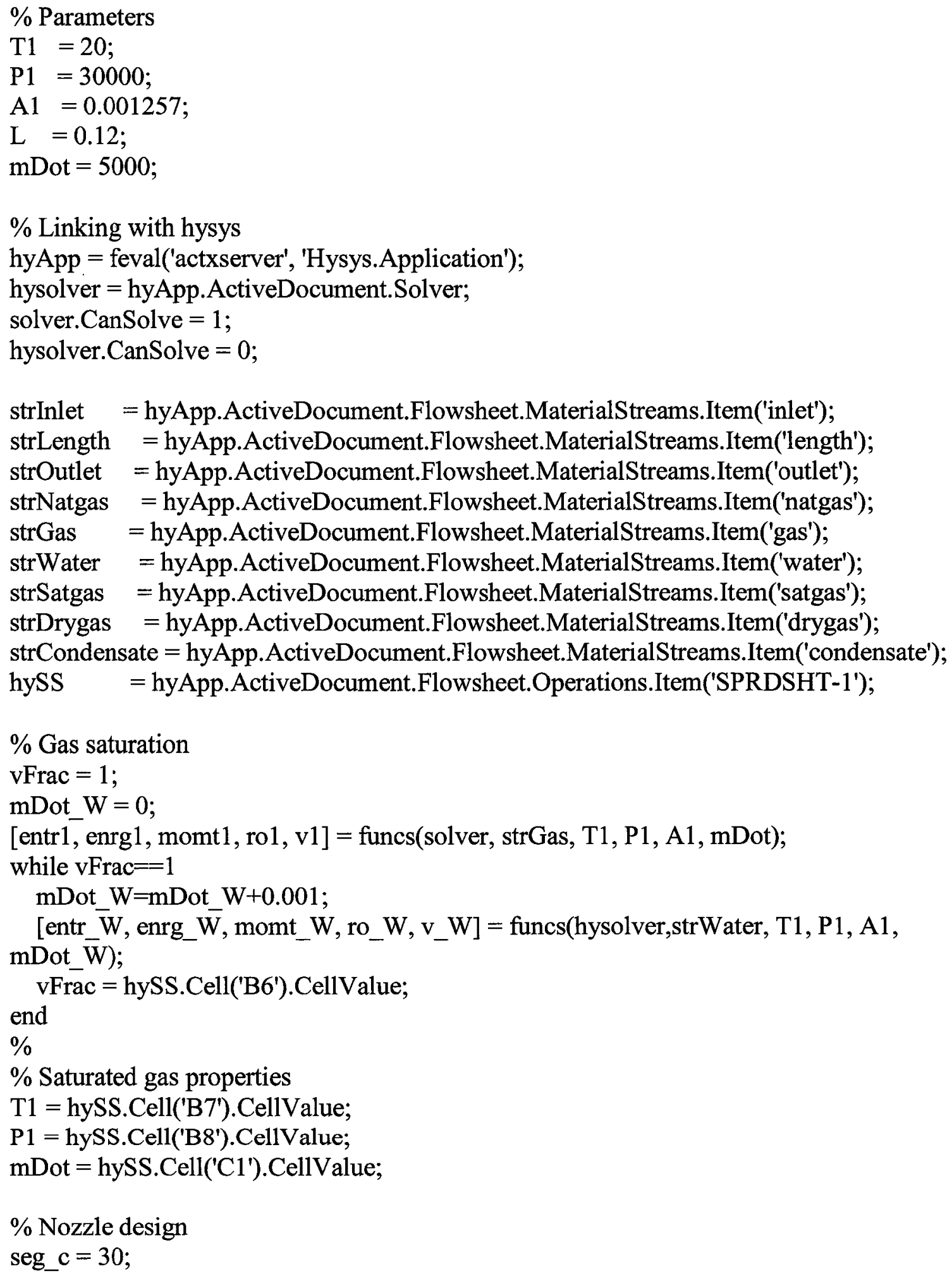


alpha_c $=6.85$;

alphaRad_c $=($ alpha_c*pi $) / 180$;

$\operatorname{seg} \mathrm{d}=300$

alpha_d $=3$;

alphaRad_d $=($ alpha_d*pi) $/ 180$;

$\mathrm{A}(1)=\mathrm{A} 1$

$\mathrm{T}(1)=\mathrm{T} 1$

$\mathrm{P}(1)=\mathrm{P} 1$;

$[\operatorname{entr}(1), \operatorname{enrg}(1), \operatorname{momt}(1), \operatorname{ro}(1), \mathrm{v}(1)]=$ funcs(solver, strInlet, $\mathrm{T}(1), \mathrm{P}(1), \mathrm{A}(1), \mathrm{mDot})$;

$[\mathrm{machNum} 1, \mathrm{v} 1]=\operatorname{mach}(\mathrm{T} 1, \mathrm{P} 1, \mathrm{~A} 1, \mathrm{mDot})$;

$\operatorname{machNum}(1)=\operatorname{machNum} 1$;

$\mathrm{v}(1)=\mathrm{v} 1$;

water(1) = hySS.Cell('D1').CellValue;

$\mathrm{r} 1=\operatorname{sqrt}(\mathrm{A} 1 / \mathrm{pi})$;

$\mathrm{ID}(1)=2 * \mathrm{r} 1$;

$\mathrm{p}(1)=0$;

$\mathrm{i}=1$;

L_segment $=0.0009$;

$\mathrm{x}=\tan \left(\right.$ alphaRad_c) ${ }^{*} \mathrm{~L} \_$segment;

hySS.Cell('B1').CellValue = L_segment;

$\%$ Finding the throat

converged(i) = true;

exception $(\mathbf{i})=$ false;

while converged(i) $==$ true $\& \&$ exception(i) $=$ false $\& \&$ abs $(1-\operatorname{machNum}(\mathrm{i}))>0.2$

$\mathrm{i}=\mathrm{i}+1$;

$\operatorname{ID}(\mathrm{i})=\operatorname{ID}(\mathrm{i}-1)-(2 * \mathrm{x})$

$\mathrm{A}(\mathrm{i})=\left(\mathrm{pi}^{*}(\mathrm{ID}(\mathrm{i}))^{\wedge} 2\right) / 4$;

$\mathrm{p}(\mathrm{i})=\mathrm{p}(\mathrm{i}-1)+\mathrm{L} \_$segment;

[T(i), P(i), machNum(i), v(i), vFrac(i), converged(i), exception(i)] = tpDistr_as(T(i-1), $\mathrm{P}(\mathrm{i}-1), \mathrm{A}(\mathrm{i}-1) 1, \mathrm{~T} 1, \mathrm{P} 1, \mathrm{~A}(\mathrm{i}), \mathrm{mDot})$;

if converged(i) = true \&\& exception(i) $==$ false end

[entr(i), enrg(i), momt(i), ro(i), v(i)] = funcs(hysolver, strInlet, T(i), P(i), A(i), mDot);

end

L_segment $=0.0000009$;

$\mathrm{x}=\tan ($ alphaRad_c $) *$ L_segment; 
hySS.Cell('B1').CellValue = L_segment;

hysolver.CanSolve $=1 \%$ start solver

hysolver. CanSolve $=0$;

converged(i) $=1$;

converged $(\mathrm{i})==$ true

exception $(\mathbf{i})=0$;

while converged $(\mathrm{i})==$ true $\& \&$ exception $(\mathrm{i})=$ false

$\mathrm{i}=\mathrm{i}+1$;

$\mathrm{ID}(\mathrm{i})=\mathrm{ID}(\mathrm{i}-1)-(2 * \mathrm{x})$;

$\mathrm{A}(\mathrm{i})=\left(\mathrm{pi} *(\mathrm{ID}(\mathrm{i}))^{\wedge} 2\right) / 4$;

$\mathrm{p}(\mathrm{i})=\mathrm{p}(\mathrm{i}-1)+\mathrm{L} \_$segment;

[T(i), P(i), machNum(i), v(i), vFrac(i), converged(i), exception(i)] = tpDistr_as(T(i-1), $\mathrm{P}(\mathrm{i}-1), \mathrm{A}(\mathrm{i}-1), \mathrm{T} 1, \mathrm{P} 1, \mathrm{~A}(\mathrm{i}), \mathrm{mDot})$;

if converged(i) $=$ true \&\& exception $(\mathrm{i})==$ false

[entr(i), enrg(i), momt(i), ro(i), v(i)] = funcs(hysolver, strInlet, T(i), P(i), A(i), mDot); end

end

ithroat $=\mathrm{i}-1 ; \%$ throat index

save nozzlethroat A T P machNum v p ID ithroat entr ro momt enrg mDot

\section{A.2.2 NOZZLE RECOVERY PROPERTIES}

clear all

clc

load nozzlethroat $\%$ Calling the properties at the converging part $\mathrm{i}=\mathrm{ithroat}$;

$\mathrm{L}=0.12$

$\mathrm{mDot}=5000$;

$\%$ Linking with hysys

hyApp = feval('actxserver', 'Hysys.Application');

hysolver = hyApp.ActiveDocument.Solver;

solver. CanSolve $=1$;

hysolver.CanSolve $=0$;

strInlet = hyApp.ActiveDocument.Flowsheet.MaterialStreams.Item('inlet');

strLength = hyApp.ActiveDocument.Flowsheet.MaterialStreams.Item('length'); 


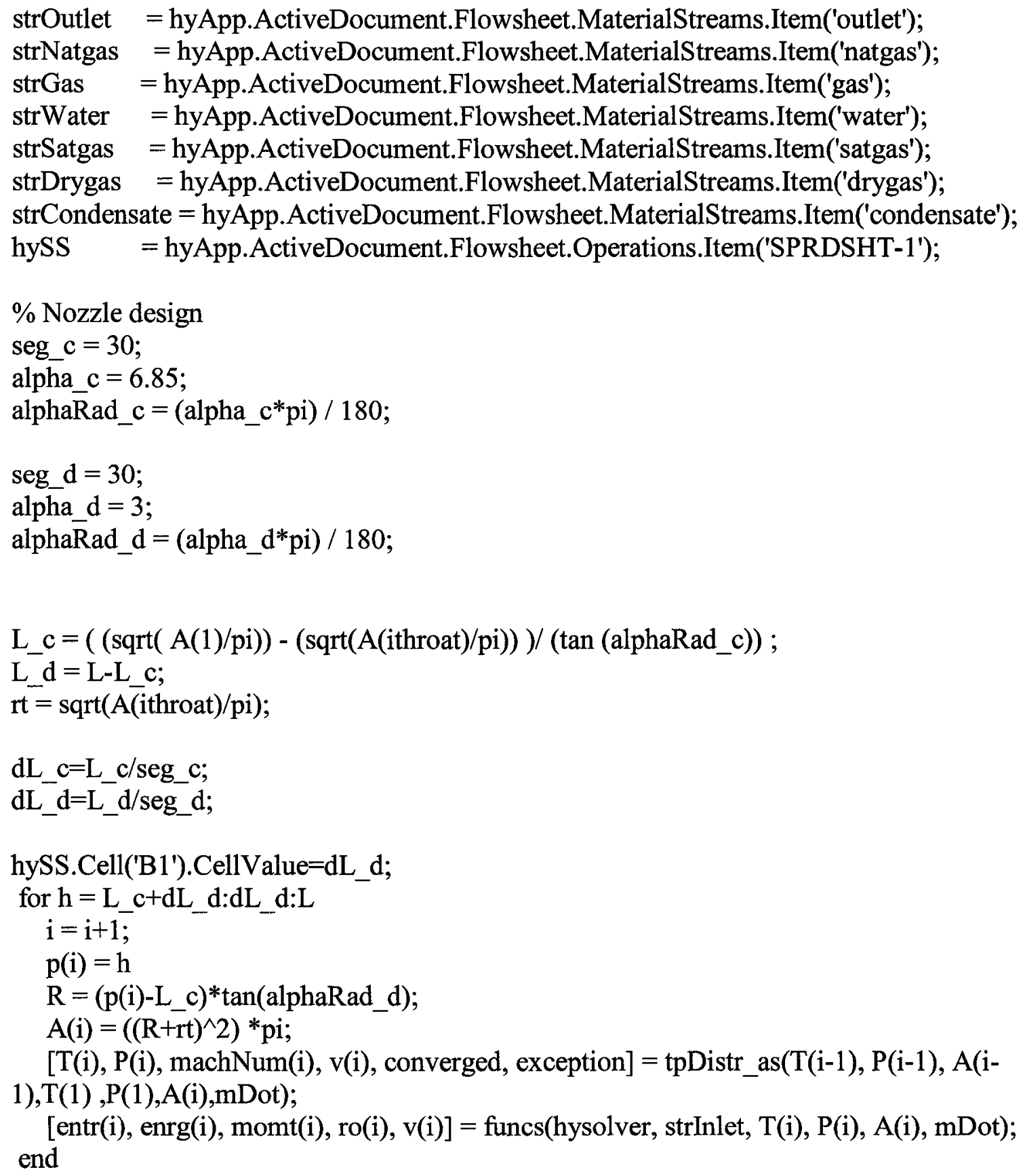

\section{A.2.3 NOZZLE DESIGN PROPERTIES}

clear all

$\mathrm{clc}$ 
load nozzlethroat \% Calling the properties at the converging part

$\mathrm{i}=\mathrm{ithroat}$;

$\mathrm{L}=0.12$;

$\mathrm{mDot}=5000$;

\% Linking with hysys

hyApp = feval('actxserver', 'Hysys.Application');

hysolver = hyApp.ActiveDocument.Solver;

solver. CanSolve $=1$;

hysolver. CanSolve $=0$;

strInlet = hyApp.ActiveDocument.Flowsheet.MaterialStreams.Item('inlet');

strLength = hyApp.ActiveDocument.Flowsheet.MaterialStreams.Item('length');

strOutlet = hyApp.ActiveDocument.Flowsheet.MaterialStreams.Item('outlet');

strNatgas = hyApp.ActiveDocument.Flowsheet.MaterialStreams.Item('natgas');

strGas = hyApp.ActiveDocument.Flowsheet.MaterialStreams.Item('gas');

strWater = hyApp.ActiveDocument.Flowsheet.MaterialStreams.Item('water');

strSatgas = hyApp.ActiveDocument.Flowsheet.MaterialStreams.Item('satgas');

strDrygas = hyApp.ActiveDocument.Flowsheet.MaterialStreams.Item('drygas');

strCondensate $=$ hyApp.ActiveDocument.Flowsheet.MaterialStreams.Item('condensate');

hySS = hyApp.ActiveDocument.Flowsheet.Operations.Item('SPRDSHT-1');

$\%$ Nozzle design

seg_c $=30$;

alpha_c $=6.85$;

alphaRad_c $=($ alpha_c*pi) $/ 180$;

seg_d $=30$

alpha_d $=3$;

alphaR $a d \_d=($ alpha_d*pi $) / 180$;

L_c $=((\operatorname{sqrt}(A(1) / p i))-(\operatorname{sqrt}($ A(ithroat $) / p i))) /(\tan ($ alphaRad_c $))$;

L_d $=$ L-L c;

$\mathrm{rt}=\operatorname{sqrt}(\mathrm{A}(\mathrm{ithroat}) / \mathrm{pi})$;

$\mathrm{dL} \_\mathrm{c}=\mathrm{L} \_\mathrm{c} / \mathrm{seg} \mathrm{c}$;

$\mathrm{dL}_{-} \mathrm{d}=\mathrm{L}_{-} \mathrm{d} / \mathrm{seg}$ _d;

hySS.Cell('B1').CellValue=dL_d; 
for $h=L \_c+d L \_d: d L \_d: L$

$\mathrm{i}=\mathrm{i}+1$;

$\mathrm{p}(\mathrm{i})=\mathrm{h}$

$\mathrm{R}=\left(\mathrm{p}(\mathrm{i})-\mathrm{L} \_\mathrm{c}\right) * \tan \left(\operatorname{alphaRad} \_\mathrm{d}\right)$;

$\mathrm{A}(\mathrm{i})=\left((\mathrm{R}+\mathrm{rt})^{\wedge} 2\right) * \mathrm{pi}$;

[T(i), P(i), machNum(i), v(i), converged, exception] = tpDistr_as(T(i-1), P(i1), $\mathrm{A}(\mathrm{i}-1),-120,1000, \mathrm{~A}(\mathrm{i}), \mathrm{mDot})$;

[entr(i), enrg(i), momt(i), ro(i), v(i)] = funcs(hysolver, strInlet, T(i), P(i),

A(i), mDot);

end

\subsubsection{SHOCKWAVE PREDICTION}

clear all

clc

load nozzlethroat $\%$ Calling the properties at the converging part

$i=$ ithroat;

$\mathrm{L}=0.12$;

$\mathrm{mDot}=5000$;

Pexit $=70 / 100 * \mathrm{P}(1) ; \%$ Desired pressure recovery

Shock $=0.1 ; \%$ first guess for shocklocation, $L_{-} \mathrm{c}<$ shock $<\mathrm{L}$

\% Linking with hysys

hyApp = feval('actxserver', 'Hysys.Application');

hysolver = hyApp.ActiveDocument.Solver;

solver. CanSolve = 1;

hysolver.CanSolve $=0$;

strInlet = hyApp.ActiveDocument.Flowsheet.MaterialStreams.Item('inlet');

strLength = hyApp.ActiveDocument.Flowsheet.MaterialStreams.Item('length');

strOutlet = hyApp.ActiveDocument.Flowsheet.MaterialStreams.Item('outlet');

strNatgas =hyApp.ActiveDocument.Flowsheet.MaterialStreams.Item('natgas');

strGas = hyApp.ActiveDocument.Flowsheet.MaterialStreams.Item('gas');

strWater = hyApp.ActiveDocument.Flowsheet.MaterialStreams.Item('water');

strSatgas = hyApp.ActiveDocument.Flowsheet.MaterialStreams.Item('satgas');

strDrygas $=$ hyApp.ActiveDocument.Flowsheet.MaterialStreams.Item('drygas');

strCondensate = hyApp.ActiveDocument.Flowsheet.MaterialStreams.Item('condensate');

hySS = hyApp.ActiveDocument.Flowsheet.Operations.Item('SPRDSHT-1'); 


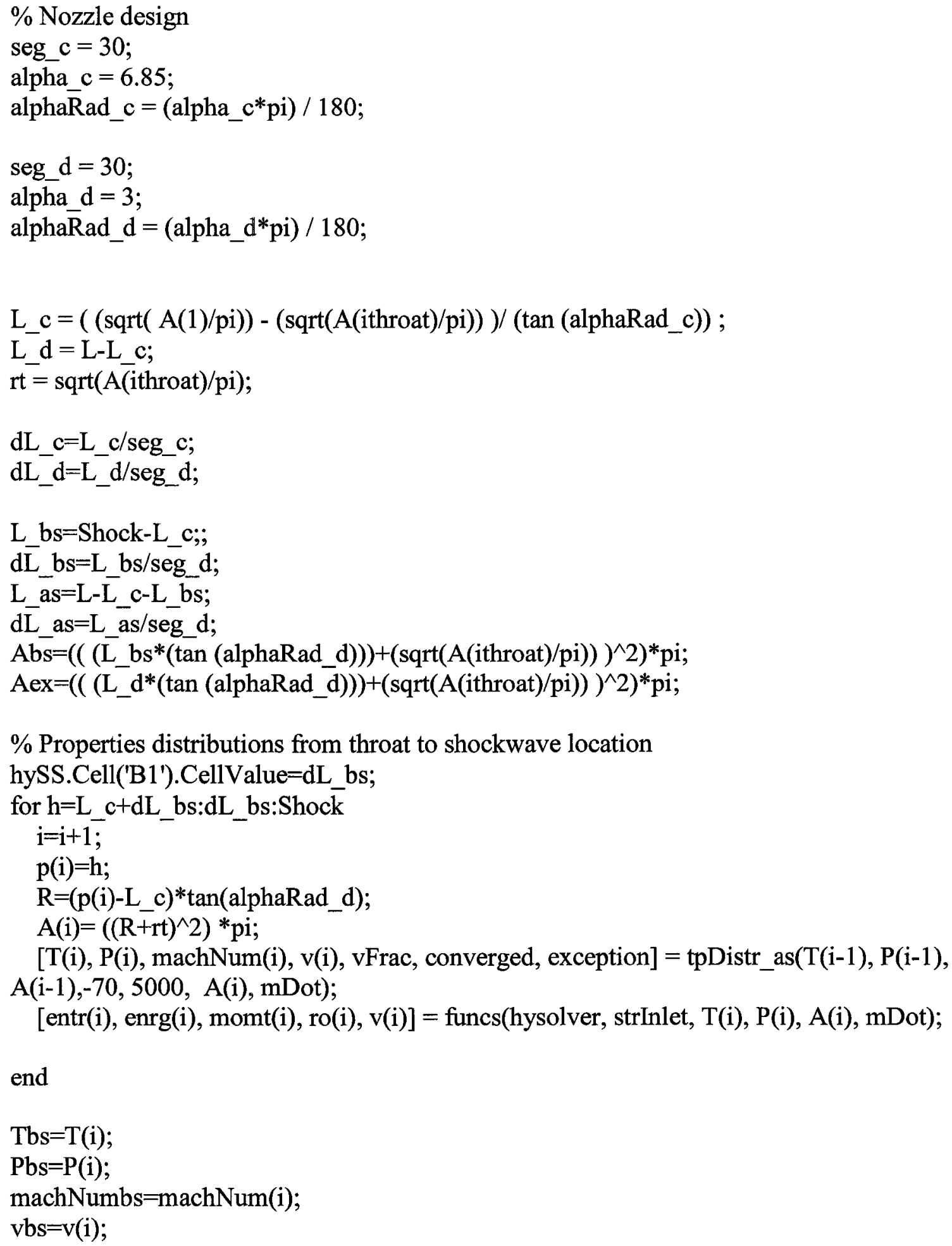


$\mathrm{Abs}=\mathrm{A}(\mathrm{i})$;

[entrbs, enrgbs, momtbs, robs, vbs] = funcs(hysolver, strInlet, Tbs, Pbs, Abs, mDot); mDot_as= hySS.Cell('A7').CellValue;

Aas $=\overline{\mathrm{A}} \mathrm{bs}$;

$\%$ Properties ownstream of the shockwave

[Tas,Pas ,machNumas, vas, converged, exception] = tpDistr(Tbs, Pbs, Abs, T(1)

,P(1),Abs,mDot_as);

[entras, enrgas, momtas, roas, vas] = funcs(hysolver, strNatgas, Tas, Pas, Aas, mDot_as);

pas $=$ L_c $+($ L_bs $)$;

$\mathrm{i}=\mathrm{i}+1$;

$\mathrm{p}(\mathrm{i})=$ pas;

$\mathrm{A}(\mathrm{i})=$ Aas;

$\mathrm{T}(\mathrm{i})=$ Tas;

$\mathrm{P}(\mathrm{i})=$ Pas;

machNum(i) = machNumas;

$\mathrm{v}(\mathrm{i})=\mathrm{vas}$;

entr(i) = entras;

enrg(i)=enrgas;

$\operatorname{momt}(\mathrm{i})=$ momtas;

ro(i)=roas;

\%Properties distribution after the shockwave location

hySS.Cell('B1').CellValue $=\mathrm{dL} \_$as;

for $\mathrm{h}=\mathrm{Shock}+\mathrm{dL}$ as: $\mathrm{dL}$ as: $\mathrm{L}$

$\mathrm{i}=\mathrm{i}+1$;

$\mathrm{p}(\mathrm{i})=\mathrm{h}$

$\mathrm{R}=\left(\mathrm{p}(\mathrm{i})-\mathrm{L} \_\mathrm{c}\right) * \tan ($ alphaRad_d $)$;

$A(i)=\left((R+r t)^{\wedge} 2\right) * p i$

[T(i), P(i), machNum(i), v(i), converged, exception] = tpDistr(T(i-1), P(i-1), A(i-

1),T(1),P(1),A(i),mDot_as);

[entr(i), enrg(i), momt(i), ro(i), v(i)] = funcs(hysolver, strNatgas, T(i), P(i), A(i),

mDot_as);

end

$\mathrm{Pex}=\mathrm{P}(\mathrm{i})$;

if Pex>Pexit

display ('choose bigger shock')

else if Pex $<$ Pexit 
display('choose lower shock')

else display ('shocklocation is right');

end

end

A.2.5 FUNCTIONS

A.2.5.1 TPDISTR_AS

$\% \% \% \% \% \% \% \% \% \%$

$\%$ tpDistr_as - computes stream properties along the nozzle

$\%$

$\%$ Input:

$\% \mathrm{~T} 1$ - current temperature

$\%$ P1 - current pressure

$\%$ A1 - current size

$\% \mathrm{~T} 2 \mathrm{i}$ - next xsection temperature initial guess

$\% \quad \mathrm{P} 2 \mathrm{i}-$ next xsection pressure initial guess

$\% \quad \mathrm{~A} 2$ - next xsection size

$\%$ mDot - flow rate

$\%$ Output:

$\% \quad \mathrm{~T} 2$ - next xsection temperature

$\%$ P2 - next xsection pressure

$\% \mathrm{v}$ - next xsection velocity

$\%$ vFrac - next xsection vapour fraction

$\%$ converged - NR convergence flag

$\%$ exception - erroneous parameter flag

function $\left[\mathrm{T} 2, \mathrm{P} 2\right.$, machNum, v, vFrac, converged, exception] $=\operatorname{tpDistr} \_a s(\mathrm{~T} 1, \mathrm{P} 1$, $\mathrm{A} 1, \mathrm{~T} 2 \mathrm{i}, \mathrm{P} 2 \mathrm{i}, \mathrm{A} 2, \mathrm{mDot})$

\% linking with hysys

hyApp = feval('actxserver', 'Hysys.Application');

hysolver = hyApp.ActiveDocument.Solver;

solver.CanSolve $=1 ; \%$ Start solver

hysolver.CanSolve $=0$; 
strInlet $=$ hyApp.ActiveDocument.Flowsheet.MaterialStreams.Item('inlet');

hySS = hyApp.ActiveDocument.Flowsheet.Operations.Item('SPRDSHT-1');

$\%$ Newton-Raphson

[entr1, enrg1,momt1,ro1,v1] = funcs(hysolver, strInlet, T1, P1, A1, mDot);

tol $=0.005 ; \%$ tolerance for error

$\mathrm{kmax}=100 ; \%$ maximum number of iterations

$\%$ set initial guess

$\mathrm{T} 2=\mathrm{T} 2 \mathrm{i} ; \%(\mathrm{C})$

$\mathrm{P} 2=\mathrm{P} 2 \mathrm{i}$

$\mathrm{k}=0$;

tres $=$ tol +1

pres $=$ tol +1 ;

entr $2=$ entr $1-20$;

exception $=$ false;

while $($ exception $=$ false) $\& \&$ (tres $>=$ tol $\|$ pres $>=$ tol $) \& \& \mathrm{k}<=\mathrm{kmax}$

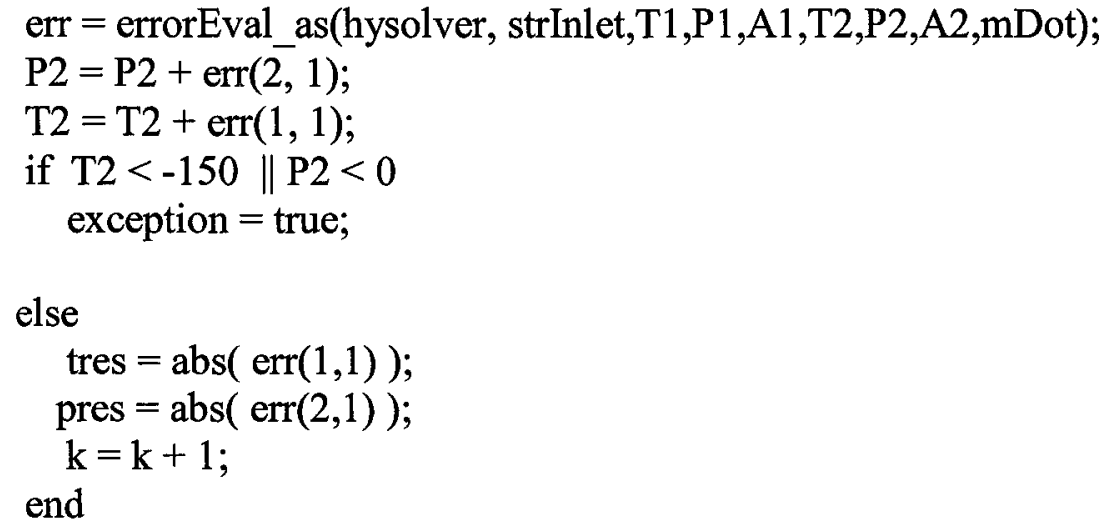

end $\mathrm{mDot})$;

[entr2, enrg2, momt2, ro2, v2,nu2,D2,Mw] = funcs(hysolver, strInlet, T2, P2, A2,

converged $=$ false;

$\operatorname{machNum}=0$

$\mathrm{v}=0$

$\mathrm{vFrac}=0$;

if exception $=$ false

if $\mathrm{k}>\mathrm{kmax}$ 


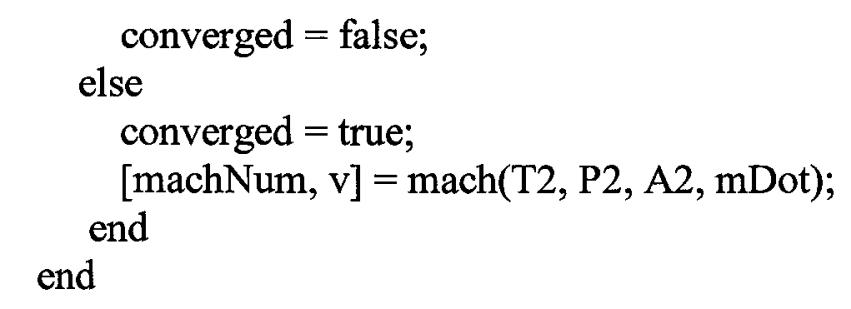

\subsubsection{ERRORVAL_AS}

$\% \quad \% \quad \% \quad \% \quad \% \quad \% \quad \% \quad \% \quad \% \quad \% \quad \%$

$\%$ errorEval_as - computes stream properties in next xsection

$\%$

$\%$ Input:

$\% \quad \mathrm{~T} 1$ - current temperature

$\% \mathrm{P} 1$ - current pressure

$\%$ A1 - current xsection size

$\%$ T2 - next temperature initial guess

$\%$ P2 - next pressure initial guess

$\%$ A2 - next xsection size

$\%$ mDot - flow rate

$\%$ Output:

$\%$ err-error in current neton-Raphson iteration

function [err] = errorEval_as(solver, stream,T1,P1,A1,T2,P2,A2,mDot)

$\mathrm{dT}=0.1$;

$\mathrm{dP}=0.1$;

hyApp = feval('actxserver', 'Hysys.Application');

hysolver $=$ hyApp.ActiveDocument.Solver;

solver. CanSolve $=1 ; \%$ Start solver

hysolver.CanSolve $=0$;

strInlet $=$ hyApp.ActiveDocument.Flowsheet.MaterialStreams.Item('inlet');

strNatgas = hyApp.ActiveDocument.Flowsheet.MaterialStreams.Item('natgas');

hySS = hyApp.ActiveDocument.Flowsheet.Operations.Item('SPRDSHT-1'); $\mathrm{mDot}$;

[entr1, enrg1, momt1, ro1, v1, nu1,D1,Mw,h1] = funcs(solver, stream, T1, P1, A1, $\mathrm{mDot})$;

[entr2, enrg2, momt2, ro2, v2,nu2,D2,Mw,h2] = funcs(solver, stream, T2, P2, A2, 


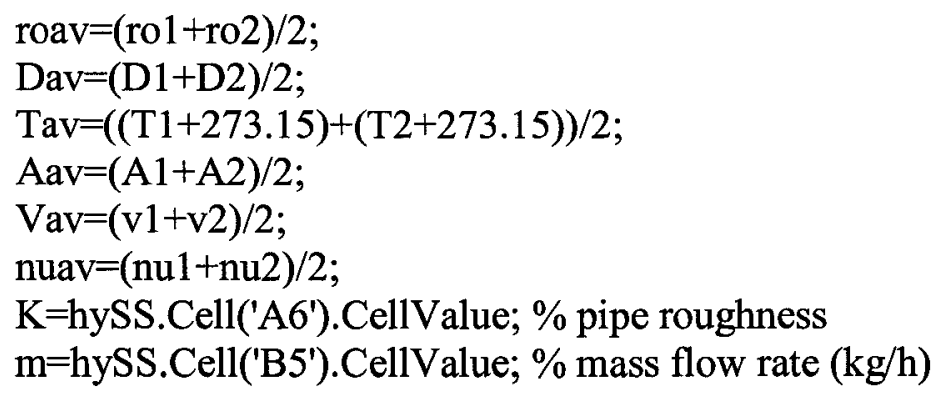

$[\mathrm{Rx}, \mathrm{PHi}, \mathrm{f}]=$ frictionfactor(hysolver,stream,ro1,nu1,D1,T1,v1,P1,A1,ro2,nu2,D2, T $2, \mathrm{v} 2, \mathrm{P} 2, \mathrm{~A} 2, \mathrm{mDot}) ; \%$ finding the frictionfactor,energy loss term and thrust

L_segment=hySS.Cell('B1').CellValue;

$$
\begin{aligned}
& \mathrm{f} 1=\text { enrg } 2-\text { enrg } 1+\mathrm{PHi} \\
& \mathrm{f} 2=\text { momt } 2-\mathrm{momt} 1+\mathrm{Rx}-((\mathrm{P} 1+\mathrm{P} 2) * 500 *(\mathrm{~A} 2-\mathrm{A} 1))
\end{aligned}
$$

[entr_Tinc,

enrg_Tinc,momt_Tinc,ro_Tinc,v_Tinc,nu_Tinc,D_Tinc,Mw_Tinc,h_Tinc] = funcs(solver,stream, T2 + dT/2, $\overrightarrow{\mathrm{P}} 2, \mathrm{~A} 2, \overline{\mathrm{mD}} \mathbf{\mathrm { Dt }})$;

[Rx_Tinc,PHi_Tinc,f_Tinc] $=$ frictionfactor(hysolver,stream,ro1,nu1,D1,T1,v1,P1, A1,ro_Tinc,nu_Tinc, $\bar{D} \_$Tinc, $\left.\bar{T} 2+d T / 2, v \_T i n c, P 2, A 2, m D o t\right)$;

[entr_Tdec, enrg_Tdec,momt_Tdec,ro_Tdec,v_Tdec,nu_Tdec,D_Tdec,Mw_Tdec,h_Tdec] = funcs(solver, stream, T2 - dT/2, P $2, \mathrm{~A} 2, \mathrm{mDot}$ );

[Rx_Tdec,PHi_Tdec,f_Tdec]=frictionfactor(hysolver,stream,ro1,nu1,D1,T1,v1,P1 ,A1,ro_Tdec,nu_Tdec,D_Tdec,T2-dT/2,v_Tdec,P2,A2,mDot);

[entr_Pinc, enrg_Pinc,momt_Pinc,ro_Pinc,v_Pinc,nu_Pinc,D_Pinc,Mw_Pinc,h_Pinc] = funcs(solver,stream, T2, $\mathrm{P} 2+\mathrm{dP} / 2, \mathrm{~A} 2, \mathrm{mDot}$ );

[Rx_Pinc,PHi_Pinc,f_Pinc] $=$ frictionfactor(hysolver,stream,ro1,nu1,D1,T1,v1,P1, A1,ro_Pinc,nu_Pinc,D_Pinc,T2,v_Pinc,P2+dP/2,A2,mDot);

[entr_Pdec, 
enrg_Pdec,momt_Pdec,ro_Pdec,v_Pdec,nu_Pdec,D_Pdec,Mw_P2dec,h_Pdec] = funcs(solver, stream, T2, $\mathrm{P} 2-\mathrm{dP} / \overline{2}, \mathrm{~A} 2, \mathrm{mD}$ ot);

[Rx_Pdec,PHi_Pdec,f_Pdec]=frictionfactor(hysolver,stream,ro1,nu1,D1,T1,v1,P1 ,A1,ro_Pdec,nu_Pdec,D_Pdec,T2,v_Pdec,P2-dP/2,A2,mDot);

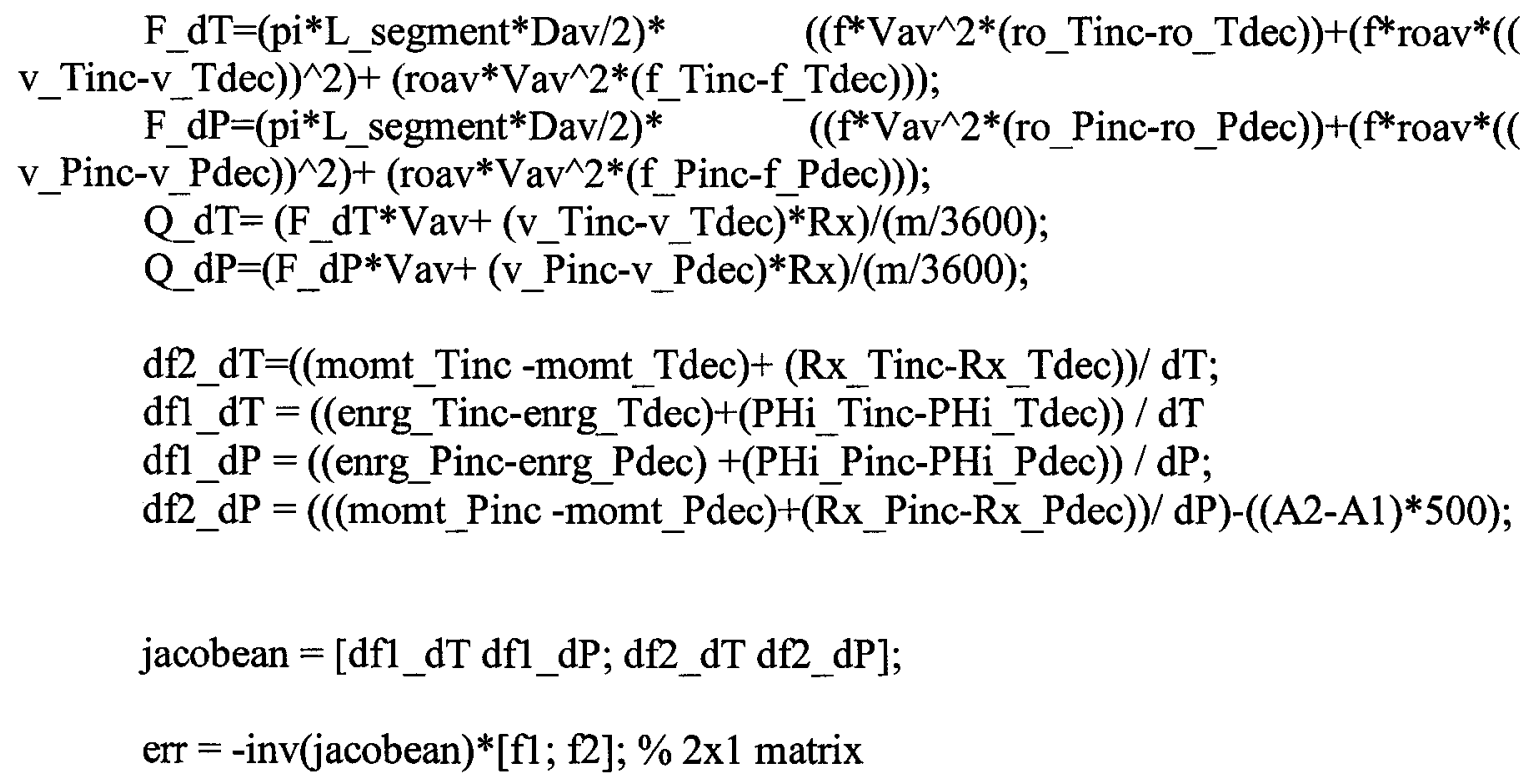

\subsubsection{FRCITIONFACTOR}

$\% \% \% \% \% \% \% \% \% \% \%$

$\%$ frictionfactor - computes the frictionfactor,energy loss term and thrust

$\%$

$\%$ Input:

$\%$ rol - current density $\left(\mathrm{kg} / \mathrm{m}^{\wedge} 3\right)$

$\%$ nu1- currnet kinematic viscosity (cSt)

$\%$ D1- current xsection diameter(m)

$\%$ T1- current temperature (C)

$\%$ v1- current velocity $(\mathrm{m} / \mathrm{s})$

$\% \quad \mathrm{P} 1$ - current pressure $(\mathrm{kPa})$

$\%$ A1 - current xsection size $\left(\mathrm{m}^{\wedge} 2\right)$

$\%$ ro2 - next density $\left(\mathrm{kg} / \mathrm{m}^{\wedge} 3\right)$

$\%$ nu2- next kinematic viscosity (cSt)

$\%$ D2- next xsection diameter(m) 
$\% \quad$ T2- next temperature (C)

$\%$ v2- next velocity $(\mathrm{m} / \mathrm{s})$

$\% \quad \mathrm{P} 2$ - current pressure $(\mathrm{kPa})$

$\%$ A2 - current xsection size $\left(\mathrm{m}^{\wedge} 2\right)$

$\%$ mDot - flow rate

$\%$ Output:

$\%$ Rx-Thrust

$\%$ PHi- energy loss term

$\%$ f- friction factor

function[Rx,PHi,f]=frictionfactor(solver,stream,ro1,nu1,D1,T1,v1,P1,A1,ro2,nu2, $\mathrm{D} 2, \mathrm{~T} 2, \mathrm{v} 2, \mathrm{P} 2, \mathrm{~A} 2, \mathrm{mDot})$

hyApp = feval('actxserver', 'Hysys.Application');

hysolver = hyApp.ActiveDocument.Solver;

solver. CanSolve $=1 ; \%$ Start solver

hysolver. CanSolve $=0$;

strInlet $=$ hyApp.ActiveDocument.Flowsheet.MaterialStreams.Item('inlet');

hySS = hyApp.ActiveDocument.Flowsheet.Operations.Item('SPRDSHT-1');

$\%$ computing average properties

roav $=(\mathrm{ro} 1+\mathrm{ro} 2) / 2$;

$\mathrm{Dav}=(\mathrm{D} 1+\mathrm{D} 2) / 2$;

$\mathrm{Tav}=((\mathrm{T} 1+273.15)+(\mathrm{T} 2+273.15)) / 2$;

$\mathrm{Aav}=(\mathrm{A} 1+\mathrm{A} 2) / 2$;

$\mathrm{Vav}=(\mathrm{v} 1+\mathrm{v} 2) / 2$;

nuav $=($ nu1+nu2)/2;

$\mathrm{K}=$ hySS.Cell('A6').CellValue; \% kinematic viscosity (cSt)

$\mathrm{m}=$ hySS.Cell('B5').CellValue; \%mass flow rate (kg'h)

$\mathrm{Re}=\mathrm{Vav}^{*} \mathrm{Dav} /$ nuav; $\quad \%$ caculating Reynolds number

$\mathrm{f}=\left(1 /\left(\left(-3.6^{*} \log \left(\left(\mathrm{K} /\left(3.7^{*} \mathrm{Dav}\right)\right)^{\wedge} 1.11\right)+(6.9 /(\mathrm{Re}))\right)\right)\right)^{\wedge} 2 ; \quad \%$ calculating friction

factor

L_segment=hySS.Cell('B1').CellValue;

$\overline{\mathrm{Rx}}=\mathrm{f}^{*} \operatorname{roav}^{*}\left(\left(\operatorname{Vav}^{\wedge} 2\right) / 2\right) * \mathrm{pi}^{*} \mathrm{~L} \_$segment $*(\operatorname{Dav}) ; \quad \%$ calculating thrust term

$\mathrm{PHi}=\mathrm{Rx} * \operatorname{Vav} /(\mathrm{m} / 3600) ; \quad \%$ calculating energy loss term 


\subsubsection{MACH}

Machdrygas has the same procedure to calculate the Mach number for the nozzle after the shockwave.

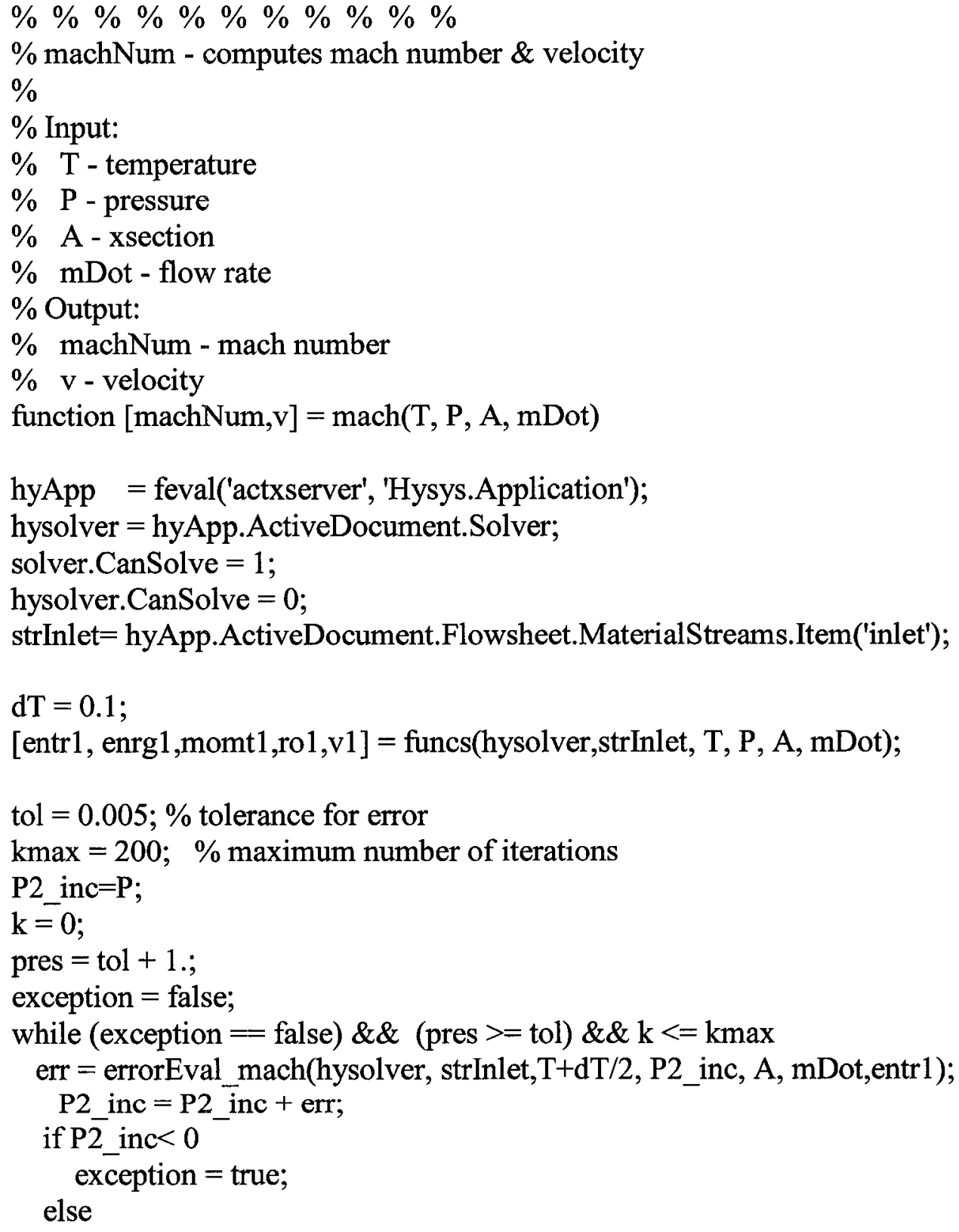




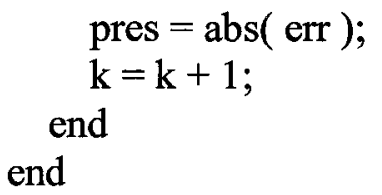

$\mathrm{mDot})$;

[entr, enrg,momt,ro_inc, v_inc] $=$ funcs(hysolver,strInlet, $\mathrm{T}+\mathrm{dT} / 2, \mathrm{P} 2$ _inc, A,

$\mathrm{P} 2$ dec $=\mathrm{P}$;

$\mathrm{k}=0$;

pres $=$ tol +1 ;

exception $=$ false;

while (exception $==$ false) $\& \&$ (pres $>=$ tol) $\& \& \mathrm{k}<=$ kmax

err = errorEval_mach(hysolver, strInlet, T-dT/2, P2_dec, A, mDot,entr1);

P2_dec $=$ P2_dec + err;

if $\overline{\mathrm{P}} 2$ dec $<\overline{0}$

exception $=$ true;

else

pres $=\operatorname{abs}($ err $)$

$\mathrm{k}=\mathrm{k}+1$;

end

end

[entr, enrg,momt,ro_dec,v_dec] $=$ funcs(hysolver,strInlet, T-dT/2, P2_dec, A, $\mathrm{mDot})$;

$(\mathrm{m} / \mathrm{s})$

$\mathrm{c}=\operatorname{sqrt}(\operatorname{abs}((\mathrm{P} 2$ inc-P2_dec $) * 1000 /($ ro_inc - ro_dec $))) ; \%$ sepeed of sound

[entr, enrg,momt,ro,v] = funcs(hysolver,strInlet, T, P, A, mDot);

$\operatorname{machNum}=\mathrm{v} / \mathrm{c}$

\subsubsection{FUNCS}

$\% \% \% \% \% \% \% \% \% \%$

$\%$ funcs - computes stream properties

$\%$

$\%$ Input:

$\%$ solver - hysys solver 


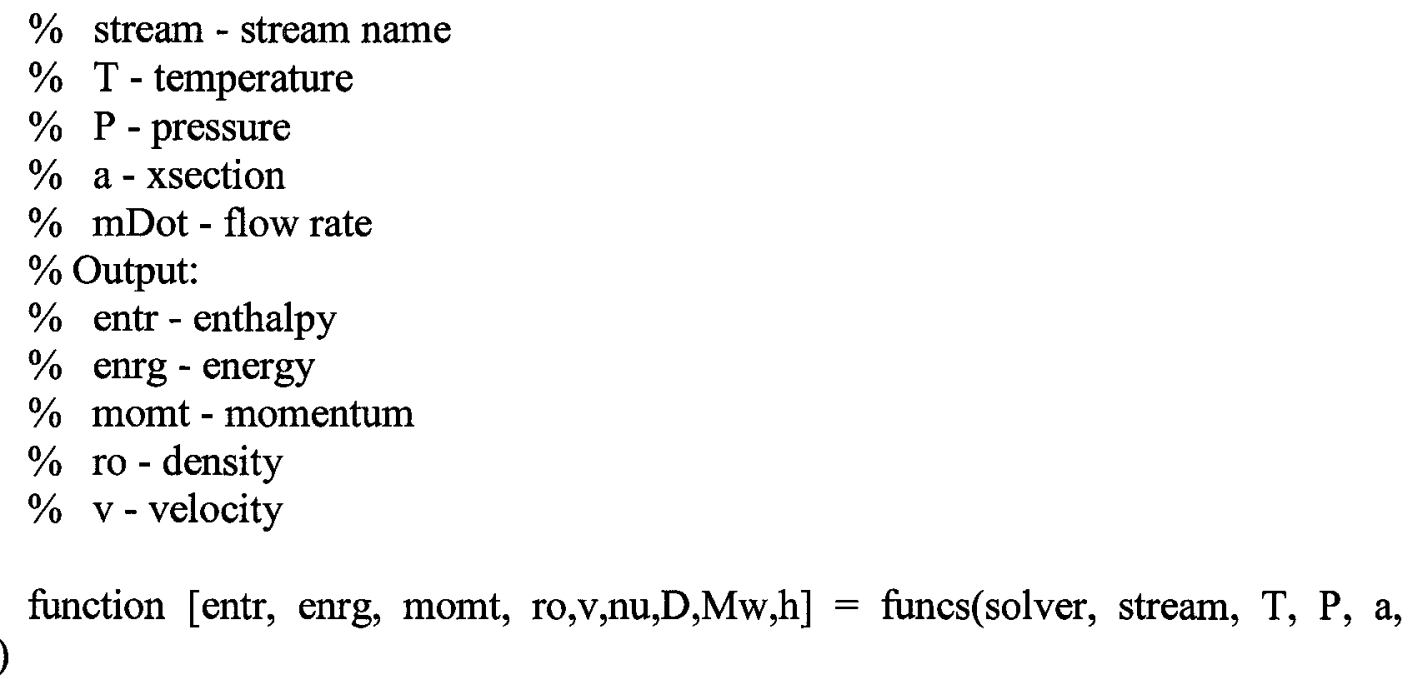

hyApp = feval('actxserver', 'Hysys.Application');

hysolver = hyApp.ActiveDocument.Solver;

solver.CanSolve $=1 ; \%$ Start solver

hysolver. CanSolve $=0$;

hySS = hyApp.ActiveDocument.Flowsheet.Operations.Item('SPRDSHT-1');

stream.Temperature.SetValue( $\left.T,{ }^{\prime} C^{\prime}\right)$

stream.pressure.SetValue( $\left.\mathrm{P}, \mathrm{KPa}^{\prime}\right)$

stream.MolarFlow.SetValue(mDot,'kgmole/h')

solver. CanSolve $=1 ; \%$ Start solver

solver.CanSolve $=0 ; \%$ Stop solver

$\mathrm{S}=$ stream.MassEntropyValue; $\quad \%\left(\mathrm{~kJ} / \mathrm{kg}^{*} \mathrm{C}\right)$

$\mathrm{h}=$ stream.MassEnthalpyValue * 1000; \% (J/ kg)

ro $=$ stream.MassDensityValue; $\quad \%\left(\mathrm{~kg} / \mathrm{m}^{\wedge} 3\right)$

$\mathrm{nu}=$ hySS.Cell('A5').CellValue;

$\mathrm{D}=\operatorname{sqrt}(4 * \mathrm{a} / \mathrm{pi})$;

$\% \mathrm{Z}=$ hySS.Cell('A7').CellValue;

$\mathrm{Mw}=$ stream.MolecularWeightValue;

$\mathrm{m}=\mathrm{mDot} * \mathrm{Mw} ; \%(\mathrm{~kg} / \mathrm{hr})$

$\mathrm{v}=(\mathrm{m} / 3600) /($ ro*a $) ; \%(\mathrm{~m} / \mathrm{s})$

entr $=\mathrm{S} ; \quad \%\left(\mathrm{~kJ} / \mathrm{kg}^{*} \mathrm{C}\right)$

enrg $=h+\left(v^{\wedge} 2\right) / 2 ; \%\left(\mathrm{~m}^{\wedge} 2 / \mathrm{s}^{\wedge} 2\right)$

$\mathrm{momt}=((\mathrm{P} * 1000) * \mathrm{a})+((\mathrm{m} / 3600) * \mathrm{v})$; 


\title{
4.2.5.6 ERROREVAL_MACH
}

\author{
$\% \quad \% \quad \% \quad \% \quad \% \quad \% \quad \% \quad \% \quad \% \quad \% \quad \%$ \\ $\%$ errorEval_mach - computes error in one iteration of newton raphson to \\ cpmpute \\ $\%$ Machnumber \\ $\%$ \\ $\%$ Input: \\ $\%$ solver - hysys solver \\ $\%$ stream - stream name \\ $\% \mathrm{~T}$ - temperature \\ $\% \mathrm{P}$ - pressure \\ $\%$ a - xsection \\ $\%$ mDot - flow rate \\ $\%$ entr1 - entropy inlet \\ $\%$ Output: \\ $\%$ err - error in current newton raphson iteration to compute Mach number \\ function $[\mathrm{err}]=$ errorEval_mach(solver, stream, T, P, A, mDot,entr1) \\ $\mathrm{dP}=0.1$ \\ [entr, enrg,momt,ro,v] = funcs(solver, stream, T, P, A, mDot); \\ $\mathrm{fl}=$ entr - entr1; \\ $\mathrm{mDot})$; \\ [entr_Pinc, enrg_Pinc,momt_Pinc,ro,v] $=$ funcs(solver, stream, $\mathrm{T}, \mathrm{P}+\mathrm{dP} / 2, \mathrm{~A}$, \\ [entr_Pdec, enrg_Pdec,momt_Pdec,ro,v] = funcs(solver, stream, T, P - dP/2, A, \\ mDot); \\ df1_dP $=($ entr_Pinc - entr_Pdec $) / \mathrm{dP}$; \\ err $=-f 1 / d f 1 \_d P ; \% 2 x 1$ matrix
}

\subsubsection{ERROREVAL}

$\% \quad \% \quad \% \quad \% \quad \% \quad \% \quad \% \quad \% \quad \% \quad \% \quad \%$

$\%$ errorEval_as - computes stream properties downstream the shockwave

$\%$

$\%$ Input:

$\% \mathrm{~T} 1$ - current temperature

$\% \quad \mathrm{P} 1$ - current pressure 
$\%$ A1 - current xsection size

$\% \mathrm{~T} 2$ - next temperature initial guess

$\%$ P2 - next pressure initial guess

$\% \mathrm{~A} 2$ - next xsection size

$\%$ mDot - flow rate

$\%$ Output:

$\%$ err-error in current neton-Raphson iteration

function [err] = errorEval(solver, stream, momt1, enrg1, T, P, a, mDot)

$\mathrm{dT}=0.1$

$\mathrm{dP}=0.1$;

[entr, enrg,momt,ro,v] = funcs(solver, stream, T, P, a, mDot);

$\mathrm{fl}=$ momt - momt 1

$\mathrm{f} 2=$ enrg - enrg1; $\mathrm{mDot})$;

[entr_Tinc, enrg_Tinc,momt_Tinc,ro,v] $=$ funcs(solver, stream, $\mathrm{T}+\mathrm{dT} / 2, \mathrm{P}, \mathrm{a}$, $\mathrm{mDot})$;

[entr_Tdec, enrg_Tdec,momt_Tdec,ro,v] $=$ funcs(solver, stream, T - dT/2, P, a,

[entr_Pinc, enrg_Pinc,momt_Pinc,ro,v] $=$ funcs(solver, stream, $T, P+\mathrm{dP} / 2$, a, $\mathrm{mDot}$ ); $\mathrm{mDot})$;

[entr_Pdec, enrg_Pdec,momt_Pdec,ro,v] $=$ funcs(solver, stream, T, P - dP/2, a,

dfl $\mathrm{dT}=($ momt Tinc - momt $\mathrm{Tdec}) / \mathrm{dT}$;

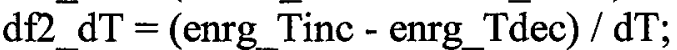

dfl_dP $=$ (momt Pinc-momt_Pdec) $/ \mathrm{dP}$;

$\mathrm{df} 2$ _ $\mathrm{P}=($ enrg_Pinc - enrg_Pdec $) / \mathrm{dP}$;

jacobean = [df1_dT df1_dP; df2_dT df2_dP];

err $=-$ inv $($ jacobean $) *[f 1 ; f 2] ; \% \overline{2} \times 1$ matrix

\subsubsection{TPDISTR}

$\% \% \% \quad \% \quad \% \quad \% \quad \% \quad \% \quad \% \quad \% \%$

$\%$ tpDistr - computes stream properties in shockwave downstream

$\%$

$\%$ Input:

$\% \mathrm{~T} 1$ - current $\mathrm{xsection}$ temperature

$\% \quad \mathrm{P} 1$ - current xsection pressure 
$\%$ A1 - current xsection size

$\%$ T2i - next xsection temperature initial guess

$\% \mathrm{P} 2 \mathrm{i}-$ next $\mathrm{xsection}$ pressure initial guess

$\% \quad \mathrm{~A} 2$ - next xsection size

$\% \mathrm{mDot}$ - flow rate

$\%$ Output:

$\% \mathrm{~T} 2$ - next xsection temperature

$\% \mathrm{P} 2$ - next xsection pressure

$\% \mathrm{v}-$ next xsection velocity

$\%$ vFrac - next xsection vapour fraction

$\%$ converged - NR convergence flag

$\%$ exception - erroneous parameter flag

function $[\mathrm{T} 2, \mathrm{P} 2$, machNum, v, vFrac, converged, exception $]=\operatorname{tpDistr}(\mathrm{T} 1, \mathrm{P} 1$, A1, T2i, P2i, A2, mDot)

$\%$ linking with hysys

hyApp = feval('actxserver', 'Hysys.Application');

hysolver = hyApp.ActiveDocument.Solver;

solver.CanSolve $=1 ; \%$ Start solver

hysolver.CanSolve $=0$;

strInlet = hyApp.ActiveDocument.Flowsheet.MaterialStreams.Item('inlet');

strNatgas = hyApp.ActiveDocument.Flowsheet.MaterialStreams.Item('natgas');

hySS = hyApp.ActiveDocument.Flowsheet.Operations.Item('SPRDSHT-1');

$\%$ Newton-Raphson

[entr1, enrg1, momt1, ro1, v1] = funcs(hysolver, strInlet, T1, P1, A1, mDot);

tol $=0.005 ; \%$ tolerance for error

$\mathrm{kmax}=200 ; \%$ maximum number of iterations

$\%$ set initial guess

$\mathrm{T} 2=\mathrm{T} 2 \mathrm{i} ; \%(\mathrm{C})$

$\mathrm{P} 2=\mathrm{P} 2 \mathrm{i} ; \%(\mathrm{kPa})$

$\mathbf{k}=0$;

pres $=$ tol +1 ;

tres $=$ tol +1 ;

exception $=$ false;

while (exception $=$ false) $\& \&$ (tres $>=$ tol $\|$ pres $>=$ tol $) \& \& \mathrm{k}<=$ kmax 


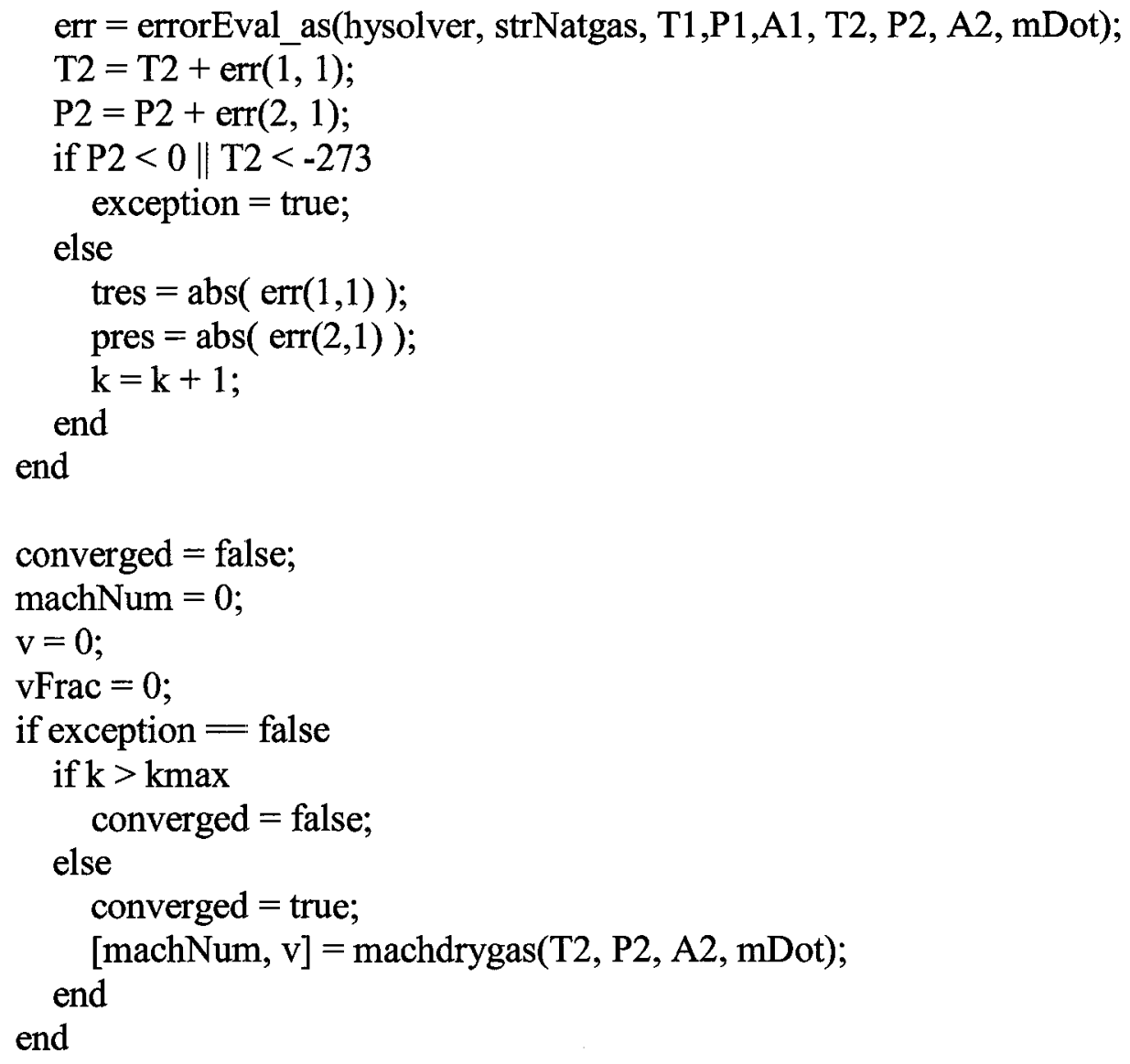




